\title{
The citizenship premium
}

Citation for published version (APA):

Peters, F. W. C. (2018). The citizenship premium: immigrant naturalisation and socio-economic integration in the Netherlands. [Doctoral Thesis, Maastricht University]. Datawyse / Universitaire Pers Maastricht. https://doi.org/10.26481/dis.20180328fp

Document status and date:

Published: 01/01/2018

DOI:

10.26481/dis.20180328fp

Document Version:

Publisher's PDF, also known as Version of record

\section{Please check the document version of this publication:}

- A submitted manuscript is the version of the article upon submission and before peer-review. There can be important differences between the submitted version and the official published version of record.

People interested in the research are advised to contact the author for the final version of the publication, or visit the DOI to the publisher's website.

- The final author version and the galley proof are versions of the publication after peer review.

- The final published version features the final layout of the paper including the volume, issue and page numbers.

Link to publication

\footnotetext{
General rights rights.

- You may freely distribute the URL identifying the publication in the public portal. please follow below link for the End User Agreement:

www.umlib.nl/taverne-license

Take down policy

If you believe that this document breaches copyright please contact us at:

repository@maastrichtuniversity.nl

providing details and we will investigate your claim.
}

Copyright and moral rights for the publications made accessible in the public portal are retained by the authors and/or other copyright owners and it is a condition of accessing publications that users recognise and abide by the legal requirements associated with these

- Users may download and print one copy of any publication from the public portal for the purpose of private study or research.

- You may not further distribute the material or use it for any profit-making activity or commercial gain

If the publication is distributed under the terms of Article $25 \mathrm{fa}$ of the Dutch Copyright Act, indicated by the "Taverne" license above, 


\title{
The Citizenship Premium
}

\author{
Immigrant naturalisation and \\ socio-economic integration \\ in the Netherlands
}

Floris Peters 
(C) copyright Floris Peters, Maastricht 2018

Printing: Datawyse | Universitaire Pers Maastricht

ISBN 9789461598172

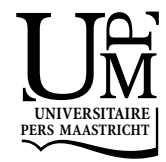




\title{
The Citizenship Premium
}

\section{Immigrant Naturalisation and Socio-Economic Integration in the Netherlands}

\author{
Dissertation \\ To obtain the degree of Doctor at Maastricht University \\ on the authority of the Rector Magnificus, \\ Prof. dr. Rianne M. Letschert \\ in accordance with the decision of the Board of Deans, \\ to be defended in public \\ on Wednesday, 28 March 2018 at 14:00
}

by

Floris Peters 


\section{Supervisors:}

Prof. dr. M.P. Vink

Prof. dr. J.J.G. Schmeets

\section{Assessment Committee:}

Prof. dr. V. Mazzucato (chair), Maastricht University

Prof. dr. P. Bevelander, Malmö Högskola

Prof. dr. G. Engbersen, Erasmus University Rotterdam

Prof. dr. G.-R. de Groot, Maastricht University

Prof. dr. M. Siegel, Maastricht University 
Voor Jozef 



\section{Acknowledgements}

I distinctly remember saying (in a colourful turn of phrase ill-suited to these pages) that I would never, ever do a PhD. Indeed, on reflection, the chain of events that led to this monolithic project feels worryingly accidental. The successful completion of the project on the other hand has been anything but random, and instead was made possible by the tireless efforts and support of family, friends and colleagues. In these acknowledgments, I will try to do them justice.

First and foremost, heartfelt gratitude goes to my supervisors, Maarten Vink and Hans Schmeets. This book owes its existence to their extraordinary academic insight, palpable enthusiasm for the job, and deep sense of care and commitment. Maarten and Hans: you are a truly inspirational team, and your attention for detail and ability to provide instant, high-quality feedback are legendary. As Bismarck apparently never said: "(...) the less you know about the process, the more you respect the result". He was talking about sausages and law-making, but it applies to PhD's as well. As supervisors, you were privy to all the bumpy ins and outs along the way, but I could always rely on your enduring patience and understanding when it occasionally all went pear-shaped. I am honoured to have been under your supervision, and I am very glad that I have been given the opportunity to continue working with you both in the coming years. I also want to take this opportunity to express my gratitude to the assessment committee, with special mention to Pieter Bevelander, who generously agreed to host me in Malmö for research as I am writing this.

A substantial part of my PhD was spent at CBS, trying to get all my proverbial dataducks in a line, and grappling with unfamiliar analytical software. Without the monumental support, patience and understanding of my colleagues there, none of the analyses would have been possible. Special thanks goes to Koos Arts, Clemens Siermann and Henk Florie (and any other data-specialists working on my applications behind the scenes), who graciously and repeatedly took the time to provide me with the vast and complex data that I needed. I am also grateful to Marly Odekerken and the SocSamteam for hosting me (and those who followed in my footsteps), and generally making me feel very welcome. It has been a pleasure, and I am happy that I can stay a while longer in my capacity as postdoctoral researcher.

My time as a PhD has been highly enjoyable, in no small part because of my colleagues at Maastricht University. First, sincere gratitude goes to Marloes de Hoon, whose arrival at the faculty heralded a number of uncoincidental breakthroughs in my PhD. Marloes: your kindness, insight and openness have been instrumental in my ability to navigate the project into the smooth sailing waters they have generally been in. Your mark is indelibly etched on many aspects of the dissertation. Support was further cemented by the new MiLifeStatus arrivals: Swantje Falcke, Marie Labussière and 
Christophe Leclerc. Already, I am much indebted to Swantje for invaluable support in coordinating and managing data, and I am happy that I get to work with you all on a daily basis in the MiLifeStatus team. Further appreciation goes to migration-colleagues Karlijn Haagsman and Joan van Geel for making me feel at home in the faculty, and Anna-Lena Hoh for tolerating my frequent, unannounced visits to her office to talk about nothing in particular. Finally, special mention goes to the many office-mates I have had over the years, in particular Valentina Carraro, Ester Serra Mingot and Linnea Semmerling, with whom I have shared most of my desk time. You have played a central role in my pleasant time at the University. And on a side-note: Linnea, thank you for injecting some much needed sanity into the "Duvel-project".

I also enjoyed indispensable and heart-warming support outside of academic circles. Special thanks goes to my paranymphs Zoë Peters and Thijs van den Enden, for graciously agreeing to help organise the defence, but more importantly for your continued, genuine interest in my work, and countless instances of spoken and unspoken encouragement that kept me going to the finish line and beyond. The creative wheels were further greased by Friday nights at 'de Paula' with the usual suspects, and all the other get-togethers with the group of friends that goes way back. It means a lot to me that we continue to see each other on such a regular basis. The same goes for my friends in Utrecht, among others Jacqueline Sips (who was there with Thijs to witness my first steps in academia with the crazy yet memorable choice of adjective), Meron Vermaas \& Charlie van Genuchten, and all those from the Utrecht Wind Ensemble, who ignited my acquired taste for contemporary classical 'music'. Also, a promised and much deserved thank you to Roel "krullie" van Engelen, who had the unenviable task of turning my incoherent musings about the cover art into something workable. And finally, a major, heartfelt word of appreciation and gratitude for my parents, whose love and support have brought me to where I am today. 


\section{Contents}

Acknowledgements

List of tables

List of Figures

Chapter 1 Introduction

Chapter 2 Naturalisation and the Socio-Economic Integration of Immigrants

Introduction

Literature on naturalisation

Naturalisation and socio-economic integration

The sociological life course paradigm

A life course perspective on naturalisation and socio-economic integration

Conclusion

Chapter 3 The Ecology of Immigrant Naturalisation: A Life course Approach in the Context of Institutional Conditions 47

Introduction

Theoretical framework and hypotheses

Context

Data and operationalization

Analysis 56

Robustness analyses

Conclusion

Chapter 4 Anticipating the Citizenship Premium: Before and After Effects of Immigrant Naturalisation on Employment

Introduction

Context: immigration and citizenship policy in the Netherlands

Theoretical framework

Data and methods

Analysis

Robustness analyses

87

Conclusion and discussion

89 
Chapter 5 Naturalisation and Immigrant Earnings: Why and To Whom Citizenship Matters

Introduction

Context: citizenship policy and labour market access in the Netherlands

Theoretical framework

Data and methodology

Analysis

100

Robustness analyses

Conclusion

Chapter 6 Naturalisation and the Transition to Homeownership: An Analysis of Signalling and Legal Status Discrimination in the Dutch Housing Market 113 Introduction

Context

Theoretical framework

Data and methodology

Analysis 125

Robustness analyses

Conclusion

Chapter 7 Conclusion

References

Appendix A: Additional Tables

Appendix B: Additional Figures

Nederlandse Samenvatting

Valorisation Addendum

About the author 


\section{List of tables}

Table 1. Cox proportional hazards regression on the risk of naturalisation, cohorts 1995-2002.

Table 2. Logistic individual fixed effects regression on the probability of having employment of male and female immigrants, cohorts 1999-2002.

Table 3. Logistic individual fixed effects regression on the probability of having employment of male and female immigrants by development origin countries, cohorts 1999-2002. $\dagger$

Table 4. Logistic individual fixed effects regression on the probability of having employment of male and female immigrants by EU-membership origin countries, cohorts 1999-2002. ${ }^{\dagger}$

Table 5. Individual fixed effects regression on Log labour income of male and female immigrants with and without employment, cohorts 1999$2002+$.

Table 6. Distributed individual fixed effects regression on Log labour income of male and female immigrants with employment who naturalise during the observation period, cohorts 1999-2002.

Table 7a. Individual fixed effects regression on Log labour income of male immigrants with employment by origin regions, cohorts 1999-2002. ${ }^{\dagger}$

Table 7b. Individual fixed effects regression on Log labour income of female immigrants with employment by origin regions, cohorts 1999-2002. ${ }^{\dagger}$

Table 8. Individual fixed effects regression on Log labour income and Log labour income when controlling for working hours of male and female immigrants with employment, cohorts 2001-2002.

Table 9a. Individual fixed-effects regression on Log labour income and Log labour income when controlling for labour market sectors of male immigrants with employment, cohorts 1999-2002. ${ }^{\dagger}$

Table 9b. Individual fixed-effects regression on Log labour income and Log labour income when controlling for labour market sectors of female immigrants with employment, cohorts 1999-2002. ${ }^{\dagger}$

Table 10. Cox proportional hazard regression on the risk of homeownership of immigrants, cohorts 1999-2002.

Table 11. Cox proportional hazard regression on the risk of homeownership of employed immigrants, cohorts 1999-2002. ${ }^{\dagger}$

Table A1. Naturalisation by personal- and contextual characteristics, cohorts 1995-2002.

Table A2. Cox proportional hazards regression on the risk of naturalisation of migrants, from low developed countries, cohorts 1995-2002. 
Table A3. Cox proportional hazards regression on the risk of naturalisation of migrants, from high developed countries, cohorts 1995-2002.

Table A4. Descriptive statistics total sample (cohorts 1995-2002) and education sample, cohorts 2000-2002.

Table A5. Cox proportional hazards regression on the risk of naturalisation including education cohorts 2000-2002.

Table A6. Cox proportional hazards regression on the risk of naturalisation including rush into naturalisation dummy, cohorts 1995-2002.

Table A7. Descriptive statistics on employment of male and female immigrants in percentages, cohorts 1999-2002.

Table A8. Distributed logistic individual fixed effects regression on the probability of having employment of male and female immigrants who naturalise during the observation period, cohorts 1999-2002.

Table A9a. Distributed logistic individual fixed effects regression on the probability of having employment, male immigrants who naturalise during the observation period from low/high developed countries, cohorts 1999-2002+.

Table A9b. Distributed logistic individual fixed effects regression on the probability of having employment, female immigrants who naturalise during the observation period from low/high developed countries, cohorts 1999-2002†.

Table A10a. Distributed logistic individual fixed effects regression on the probability of having employment, male immigrants who naturalise during the observation period from EU/non-EU countries, cohorts 1999-2002†.

Table A10b. Distributed logistic individual fixed effects regression on the probability of having employment, female immigrants who naturalise during the observation period from EU/non-EU countries, cohorts 1999-2002†.

Table A11. Logistic regression on the probability of having employment, male and female immigrants, cohorts 1999-2002. ${ }^{\dagger}$

Table A12. Logistic individual fixed effects regression on the probability of having paid employment of male and female immigrants under differing institutional conditions, cohorts 1996-1997 and 2001-2002. ${ }^{\dagger}$

Table A13. Distributed logistic regression on the probability of having employment, male and female immigrants with and without variance on the dependent variable who naturalise during the observation period, cohorts 1999-2002. + 
Table A14. Distributed logistic individual fixed effects regression on the probability of having employment, male and female immigrants without right-truncation who naturalise during the observation period, cohorts 1999-2002.

Table A15. Logistic individual fixed effects regression on the probability of having employment of male and female immigrants, cohorts 1999-2002. ${ }^{\dagger}$

Table A16. Descriptive statistics on mean Log labour income of male and female immigrants with employment in percentages, cohorts 1999-2002.

Table A17. Individual fixed effects regression on Log labour income of male and female immigrants with employment by development origin countries, cohorts 1999-2002.†

Table A18. Percentages labour market sector by naturalisation of male and female immigrants with employment, cohorts 1999-2002.

Table A19. Percentages labour market sector by naturalisation of male and female immigrants with employment, cohorts 1999-2002.

Table A20. Distributed individual fixed effects regression on Log labour income of male and female immigrants with employment. No right truncation. Cohorts 1999-2002.

Table A21. Individual fixed-effects regression on Log labour income of male and female immigrants with employment, cohorts 1999-2002. ${ }^{\dagger}$

Table A22. Individual fixed-effects regression on Log labour income of male and female immigrants, cohorts 1999-2002. ${ }^{\dagger}$

Table A23. Individual fixed-effects regression on Log labour income of male and female immigrants from countries that joined the EU in 2004, cohorts 1999-2002. $\dagger$

Table A24. Individual fixed-effects regression on Log labour income of male and female immigrants with employment, cohorts 1996-1997 and 20012002. ${ }^{\dagger}$

Table A25. Individual fixed-effects regression on Log labour income of male and female immigrants with employment, cohorts 1996-1997 and 20012002.†

Table A26. Descriptive statistics on homeownership of immigrants in percentages, last observation, cohorts 1999-2002.

Table A27. Cox proportional hazard regression on the risk of homeownership of unemployed immigrants, cohorts 1999-2002. ${ }^{\dagger}$

Table A28. Cox proportional hazard regression on the risk of homeownership of employed immigrants, cohorts 1999-2002.

Table A29. Cox proportional hazard regression on the risk of homeownership of employed immigrants, cohorts 1999-2002.

Table A30. Cox proportional hazard regression on the risk of homeownership of employed immigrants without right-truncation, cohorts 1999-2002. 


\section{List of Figures}

Figure 1. Independent naturalisations in the Netherlands.

Figure 2a. Cumulative naturalisation migrant cohort 1995-1997 by level of development origin country.

Figure 2b. Cumulative naturalisation migrant cohort 2000-2002 by level of development origin country.

Figure 3. Cumulative naturalisation by migrant cohorts.

Figure 4. Schematic illustration citizenship premium.

74

Figure 5. Distributed logistic individual fixed-effects regression on the probability of having paid employment of male of female immigrants, cohorts 1999-2002. ${ }^{\dagger}$

Figure 6. Distributed logistic individual fixed-effects regression on the probability of having employment of male and female immigrants from low/high developed countries who naturalise during the observation period, cohorts 1999-2002. ${ }^{\dagger}$

Figure 7. Distributed logistic individual fixed-effects regression on the probability of having employment of male and female immigrants from non-EU/EU countries who naturalise during the observation period, cohorts 19992002. ${ }^{\dagger}$

Figure 8a. Cumulative homeownership of immigrants who do not naturalise during the observation period by age at migration.

Figure $8 \mathrm{~b}$. Cumulative homeownership of immigrants who naturalise during the observation period by age at migration.

Figure A1a. Cumulative naturalisation migrant cohorts 1995-1997 by level of stability origin country.

Figure A1b. Cumulative naturalisation migrant cohorts 2000-2002 by level of stability origin country. 
Chapter

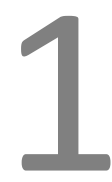

Introduction 

Citizenship, understood as the legal relationship between a person and a state, is a key concept in contemporary political theory. Over the last two decades, there has been a resurgence of scholarship on citizenship. A substantial part of this re-emerged body of literature is dedicated to the role of citizenship in a globalised and privatised world (Dauvergne, 2007, pp. 490-491). Scholarly debates on transnational and participatory citizenship and post-national forms of membership have triggered a theoretical and empirical discussion on the extent to which traditional conceptions and practices of citizenship remain relevant (Jacobsen, 1996; Sassen, 1996). The process of citizenship becoming 'denationalised' or 'deterritorialised' is often portrayed as part of a growing tension between globalisation and the nation-state, where the latter is losing ground to the former (Bosniak, 2000; Soysal, 1994; Tan, 2017). Examples include the partial denationalisation of territory, the transfer of some components of state-sovereignty to supranational institutions and entities, the extension of traditional citizenship rights to resident non-citizens, cross-border flows and regulation of capital and goods, modern telecommunications, and transnational communities. However, an examination of political debates and citizenship law suggests that state-centric citizenship, and the rights and duties it entails, continues to be highly relevant. Politicians and legislators emphasize the importance of citizenship for identity, loyalty and security, for instance by problematizing dual citizenship in the context of war and holding public office. States increasingly attempt to retain or re-establish ties with emigrants by granting them various socio-economic and socio-cultural benefits, and providing facilitated pathways to naturalisation (Joppke, 2003). Citizenship policies continue to transform, as policy makers put in place a variety of civic and linguistic integration requirements to reinvigorate the meaning of citizenship, and ensure commitment to common values and practices (Goodman, 2014). These examples serve to illustrate that while relationships and communities may supersede national boundaries, citizenship is still the subject of contention. If anything, processes of globalisation have reinvigorated the discussion on the scope, meaning, and criteria of membership to the nation (Orgad, 2017). This raises the question whether access to and holding citizenship still matters.

Formally speaking, the answer is convincingly illustrated by considering those without citizenship. Lack of any citizenship status, or statelessness, is a very practical obstacle to international mobility, access to public services and labour market opportunities in countries around the world (Blitz \& Lynch, 2011; Bosniak, 2017). Without trivializing the problem of statelessness, a second dichotomy exists between individuals who possess the citizenship of the country in which they reside, and those who only hold another nationality. Being a citizen theoretically implies full equality of rights and standing in a particular political community. Conversely, individuals who do not possess the host country citizenship are not full members of the polity, and thus do not enjoy the rights and entitlements that are associated exclusively with citizenship. While formal benefits differ between citizenship regimes, non-citizens generally require permission to enter and reside on state territory, and have conditioned access to labour 
markets and social systems. ${ }^{1}$ In spite of anti-discrimination law harbouring rights for citizens and non-citizens alike, employers, mortgage officers, public servants and residents may in practice still treat fellow citizens favourably, with more respect, or more seriously. Furthermore, the limited electoral power of non-citizens disincentives political parties, unions and other advocacy groups to invest in their plight. Moreover, limited means for mobilisation and political change may hamper the development of a sense of identification and solidarity with the political community. Lack of selfempowerment and the means to enact change may also factor into non-citizens' social and psychological well-being. For all of the above reasons, naturalisation carries the promise of a better life that is more equal, free, just and prosperous. However, from an empirical perspective, citizenship does not deliver on its promise. Migrants ${ }^{2}$ as such suffer from taste-based and statistical discrimination by employers and lenders (Aalbers, 2007; Blommaert, Coenders, \& van Tubergen, 2014; Ross \& Tootell, 2004; Zschirnt \& Ruedin, 2016), but naturalised migrants still perform worse than natives in the labour and housing market (Enchautegui \& Giannarelli, 2015; OECD, 2011), and are more likely to be socially excluded (Hutcheson \& Jeffers, 2013). Even though naturalised migrants are constituents of the political community, individuals with a migrant background are underrepresented in legislatures of established electoral democracies (Bird, 2005; Ruedin, 2009). Furthermore, ethnic minorities continue to have a higher probability of incarceration, regardless of citizenship status (Light, Massoglia, \& King, 2014). In that context, citizenship is a hollow promise; a theoretical notion that has no substantive weight in practice.

From such a pessimistic perspective, the valorisation of citizenship based on its theoretical ideal may be construed as a veiled attempt by states to ignore socially generated inequality, by presenting vulnerable migrant groups with an explanation for their disadvantaged position, and the false hope of a better tomorrow. However, the important observation that substantively citizenship does not meet its theoretical ideal does not necessarily imply that it does nothing. While inequalities based on origin, religion, education and class are not washed away by naturalisation, citizenship may have the potential to mitigate them, and function as a tool for upward mobility of immigrants (Bloemraad, 2017, p. 546). Acquisition of the host country citizenship may improve labour market access and stimulate wage growth (Bratsberg, Ragan, and Nasir, 2002; Helgertz, Bevelander, \& Tegunimitaka, 2014; Steinhardt, 2012), increase political participation and civic engagement (Hainmueller, Hangartner, \& Pietrantuono, 2015) and foster social integration (Bloemraad \& Wright, 2014; Hainmueller, Hangertner, \&

\footnotetext{
${ }^{1}$ Note that membership of political communities is in practice more complex, as membership boundaries are blurred by quasi-citizens, understood as individuals who possess some rights and duties associated with full membership while not being recognised as citizens, and semi-citizens, who possess formal citizenship but lack particular rights and duties that are typically associated with the status (Bauböck, 2017; Cohen, 2009; Smith, 2017). This thesis does not distinguish between these intermediate forms of membership.

${ }^{2}$ In this thesis, 'migrant', 'immigrant' and 'individual with a migrant background' are used interchangeably. Emigrants are always referred to as such.
} 
Pietrantuono, 2016; Manning \& Roy, 2010; Maxwell \& Bleich, 2014). Yet research on the outcomes of naturalisation - also known as the citizenship premium - is far from conclusive on whether citizenship matters for the integration of immigrants.

\section{Aim of the thesis: the central research question}

In this dissertation, I attempt to shed light on the question of the relevance of citizenship by analysing legal status transitions and related socio-economic outcomes among first generation immigrants. ${ }^{3}$ । start with the question of immigrant naturalisation, and which personal and contextual characteristics factor into this decision. In contrast to most of the literature, I simultaneously analyse the relevance of citizenship policies, and how the institutional context conditions the propensity and ability to naturalise of different migrant groups. Subsequently, the importance of access to and holding citizenship is addressed by analysing socio-economic outcomes of naturalisation. First, I explore the relevance of citizenship for labour market access of immigrants by analysing whether naturalisation improves the probability of employment. Furthermore, I focus not only on whether citizenship matters, but particularly to whom and under which conditions this is the case by performing separate analyses for different migrant groups, and through a detailed comparison of the labour market performance of immigrants before and after naturalisation. Next, the socio-economic outcomes of naturalisation are examined in greater detail by analysing income from labour, and the extent to which citizenship acquisition provides access to better (i.e. higher paying) jobs, increases working hours, and facilitates mobility between labour market sectors. Finally, I go beyond the exclusive focus in the literature on labour market indicators of socio-economic integration by analysing the relevance of citizenship in the housing market. More specifically, I investigate whether naturalisation improves the probability of homeownership, and which migrant groups benefit from citizenship most. To answer these questions, I focus on the Dutch context, and make use of individual-level administrative data from Statistics Netherlands. Immigrant integration and naturalisation has been the subject of fierce political debate in the Netherlands over the last decades (Entzinger, 2003). This is reflected in substantial variation in citizenship policies and naturalisation rates over time (van Oers, 2014). As such, the case of the Netherlands allows for a comparative analysis of the relevance of transforming institutional conditions for immigrants' propensity and ability to naturalise. Furthermore, the use of register data offers important advantages in terms of population coverage and data validity, as well as methodological opportunities to address omitted variable bias and causality issues. Details regarding the specific

\footnotetext{
${ }^{3}$ In this thesis, I focus on first generation immigrants, understood as foreign-born individuals of whom both parents are born abroad, because second and later generations can attain citizenship by descent or through facilitated procedures. Indeed, literature suggests that the decision to naturalise fundamentally differs between immigrant generations (Bauböck et al., 2013; Dronkers \& Vink, 2012).
} 
advantages of the Dutch case and the use of administrative data in the context of this dissertation are discussed below. More generally, the aim of the thesis is to answer the following central research question: what are the determinants of citizenship acquisition, and what is the relevance of naturalisation for the socio-economic integration of first generation immigrants in the Netherlands?

From a societal perspective, this thesis aims to contribute to effective, targeted policy making in the field of naturalisation and socio-economic integration of immigrants. Although there is a large field of literature that has analysed the effects of citizenship in the labour market (e.g. OECD, 2011), these studies focus almost exclusively on the question whether citizenship matters or not. Such research is of limited use for policy makers, because there is substantial heterogeneity in citizenship regimes and pathways to citizenship. For example, migrants may acquire citizenship early or late in the settlement process, and at different stages of their life course. Citizenship policies differ between countries and over time, and may not matter equally to all migrant groups. This thesis specifically analyses to whom and under which conditions citizenship matters, providing policy makers with a more detailed understanding of the outcomes of citizenship policies for particular migrant groups, and offering evidence-based suggestions on how to facilitate settlement success of immigrants.

\section{A life course approach to naturalisation and socio-economic integration of immigrants}

Research on the labour market outcomes of naturalisation is an established field of literature that dates back to the late seventies, and originated in the United States (Chiswick, 1978). In light of the structural disadvantages of immigrants in the labour market (Algan, Dustmann, Glitz, \& Manning, 2010), scholars have theorized that citizenship may facilitate integration by removing legal obstacles to labour market access and reducing administrative costs in the hiring process (Bauböck et al., 2013; OECD, 2011). Furthermore, employers may assume that possession of the host country citizenship reflects positive characteristics such as commitment and motivation. Citizenship may thus function as a signalling device that placates feelings of risk associated with hiring a foreign-born individual. More recently, North-American studies have been replicated in the European context (e.g. Bevelander \& Veenman, 2008; Bratsberg \& Raaum, 2011; Fougère \& Safi, 2009; Helgertz et al., 2014; Steinhardt, 2012). Although the analytical models have developed over time, almost all of these studies share the same underlying goal: to identify whether a citizenship premium exists or not. Yet after numerous studies across a range of countries, this remains an open question. Citizenship acquisition confers individual rights and lifts legal obstacles to participation, but it is not so clear whether naturalisation also stimulates socioeconomic integration. Empirical findings paint an ambiguous picture that frequently, yet 
inconsistently, reveals a citizenship premium (Helgertz et al., 2014, p. 343). Most of the literature has explored methodological explanations for this empirical ambiguity. Citizenship acquisition is an inherently selective process, and recent studies increasingly make use of individual-level panel data to disentangle the direction of the association between citizenship and integration. Empirical findings clearly show that this is important, as the relevance of citizenship acquisition reduces substantially when controlling for selection into naturalisation (Bratsberg \& Raaum, 2011, p. 197; Engdahl, 2014, p. 23; Steinhardt, 2012, p. 818). However, self-selection does not explain the inconsistent findings between studies. Remarkably, this persistent ambiguity is often taken as a challenge to the overall relevance of citizenship for the integration of immigrants. The result is a polarised field of literature, featuring scholars who theoretically and empirically argue either for or against the existence of a citizenship premium.

I approach this puzzle by developing a more complex understanding of the theoretical mechanisms underlying naturalisation and its associated outcomes. The literature predominantly attempts to identify whether a citizenship premium exists or not, but this implies a universal effect. Instead, I argue that the more important question is to whom and under which conditions citizenship matters (Bloemraad, 2017, p. 544). Migrants have different motivations to naturalise, and the legal and financial obstacles to naturalisation differ between host countries, change over time, and may not be equally relevant to all migrant groups. This raises the question whether variation in the pathways to citizenship - fast or slow, under liberal or restrictive conditions, the list goes on matters for related outcomes. Furthermore, how do naturalisation decisions take shape in the broader social context of family, friends and communities (Helgertz \& Bevelander, 2016; Street, 2014)? Since the established mechanisms in the literature provide limited guidance to answer these questions, I introduce new theoretical concepts to the stateof-the-art, drawing on the sociological life course paradigm (Elder, 1974). This approach is increasingly used in migration studies (Wingens, Valk, Windzio, \& Aybek, 2011) but so far not in the field of citizenship. Life course research puts emphasis on the way in which human lives are embedded in the social and institutional context in which they take place, and conceptualises human development through strings of life events. The underlying notion is that there is a temporal dynamic to these events, where the interaction between skills and resources on the one hand, and opportunities and ambitions on the other hand, promote or stifle subsequent events. Most of the literature on the citizenship premium focusses either on the contextual level, by comparatively analysing destination countries in terms of citizenship policies and migration history, or the individual level, by focusing on personal incentives for naturalisation and associated outcomes. However, one of the central ideas of the life course paradigm is that contextual structures shape biographical plans and developments. As such, a complex understanding of immigrant naturalisation and socio-economic integration should be based on the interrelatedness of societal structures and institutions on the one hand, 
and the micro-foundations of naturalisation decisions on the other hand. In other words, immigrants' plans and ambitions for the future are evaluated in light of transforming institutional opportunity structures. Since the value and meaning of citizenship differs between migrant groups, and restrictive citizenship policies likely constitute a bigger hurdle for some migrants than for others, the interrelated nature of membership regulations and individual incentives for naturalisation may explain why some migrants acquire the host country citizenship and benefit from naturalisation, while others do not. This thesis poses the central idea that the decision to naturalise and related outcomes need to be understood from the perspective of interrelated immigrant biographies embedded in transforming institutional structures. In Chapter 2, the application of this life course approach to immigrant naturalisation and the citizenship premium is outlined and discussed in detail.

\section{Context: the Netherlands}

In this dissertation, I focus on the case of the Netherlands. On January 1, 2011, the Netherlands numbered 16.7 million registered residents, of which 3.4 million had a migrant background. While mostly a country of net-immigration, the number of immigrants arriving in the Netherlands has fluctuated over the last decades. Between 1999 and 2011, immigration to the Netherlands shows a curvilinear pattern, varying between more than 92,000 individuals in 1999, less than 71,000 in 2005, and around 132,000 in 2011. The gradual drop in the number of immigrants from 2001 onwards is likely the result of policy changes regarding the (economic) requirements for family reunification (Jennissen, pp. 38-39). The subsequent rise in migration figures is mostly due to economic migrants from Romania and Bulgaria (which became part of the EU in 2007), as well as an increase in economic migration from Southern European countries - most notably Spain - which suffered particularly high unemployment rates during the financial crisis. On average, around 99,000 first generation immigrants migrated to the Netherlands per year between 1999 and 2011. As a result, the percentage of first generation immigrants residing in the Netherlands has increased, from 8.8 percent of the Dutch population in 1999, to 10.4 percent in 2011. Moreover, while the migrant population of the Netherlands has grown in volume, it has particularly increased in diversity. Whereas the Netherlands only numbered 110 nationalities in 1998, this has increased to more than 200 in 2015. This reflects a broader trend of migration flows from an increasingly diverse array of non-European countries concentrating on a shrinking pool of destination countries (Czaika \& de Haas, 2014). As immigration has played a prominent role in the Netherlands over the last decades, so too has the political debate regarding the integration and naturalisation of immigrants.

Since 1985, when the first Dutch Nationality Act was introduced, the role of citizenship for the integration of immigrants has been the subject of contention in Dutch politics (Entzinger, 2003). This is apparent in the gradual shift from a 'thin' 
minorities policy, aimed at preserving immigrants' identities, to a full-fledged integration policy with formally tested civic and linguistic integration requirements. Under the former ideology, access to citizenship was relatively liberal, reflecting the notion of naturalisation as a stepping stone for integration (van Oers, 2014, p. 36-38). This perspective to immigrant integration was heavily influenced by the advice of the Scientific Council for Governmental Policy, urging the Dutch government not to make naturalisation more difficult than necessary (Heijs, 1995). The underlying notion was to reinforce the legal position of immigrants through naturalisation, thereby facilitating their participation and integration. To that end, the Council recommended allowing dual citizenship, which would be particularly interesting to the substantial number of Turkish migrants in the Netherlands, who could only give up their Turkish citizenship after completing their military service (Groenendijk \& Heijs, 2001). In 1991, the Dutch government, consisting of the Christian Democratic CDA and the Social Democratic PVDA, decided on a compromise. The CDA withdrew their objections to dual citizenship, and the PVDA gave up their plans to extend voting rights at the national level to nonDutch residents of the Netherlands. Consequently, in the memorandum 'Multiple citizenship and voting rights for aliens', the government proposed to abolish the renunciation requirement, a decision which was implemented by statuary discretion and with consent of the Second Chamber in November 1991. Although dual citizenship was tolerated from that moment onwards, the bill was never formalised due to a shift in the integration debate in the early nineties. Around 1994, some political parties developed a more restrictive assimilationist view on naturalisation as the legal and emotional completion of the integration process (de Hart, 2004). Steps were taken towards more demanding criteria with the re-instalment of the renunciation requirement in 1997, and the introduction of a formal naturalisation test in 2003 . This restrictive development of citizenship policies in the Netherlands is mirrored in the number of naturalisations during this period of time. Figure 1 reveals substantial variation in naturalisation rates, with a large decrease in 1997 and 2003. Researchers have theorized that the former drop may be explained by migrants anticipating the reintroduction of the renunciation requirement, and the latter by the introduction of the naturalisation test (van Oers, de Hart, \& Groenendijk, 2013). However, these aggregate data do not allow for controls on compositional factors. As such, the extent to which the policy restrictions caused the number of naturalisations to decline remains unclear. More generally, we know very little about the role of citizenship policies for immigrants' propensity to naturalise, ${ }^{4}$ and how policy variation conditions the relevance of citizenship. In other words, does citizenship policy matter, and if so, to whom does it matter? In light of substantial variation in Dutch citizenship policy over time, the context of the Netherlands presents unique opportunities to explore these questions.

\footnotetext{
${ }^{4}$ See Vink, Prokic-Breuer, and Dronkers (2013) for a cross-national analysis, and Helgertz et al. (2014) for a binational comparison between Sweden and Denmark.
} 


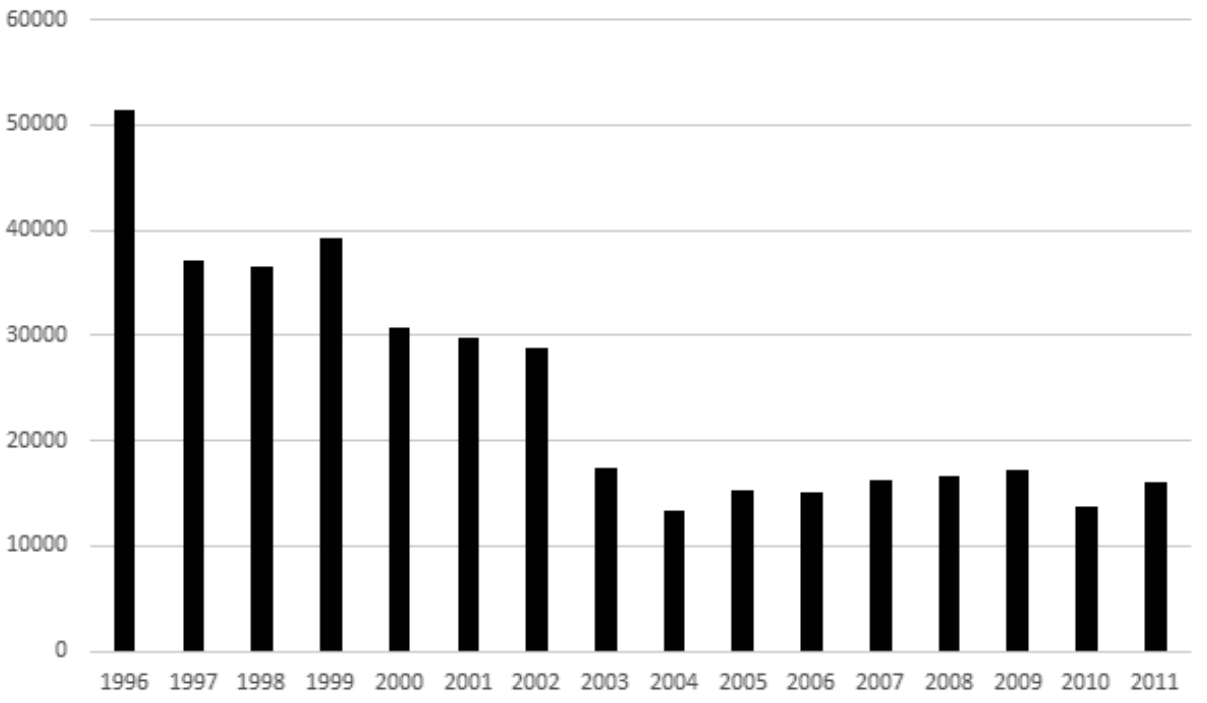

Figure 1. Independent naturalisations in the Netherlands.

Source: Statistics Netherlands.

\section{Data: the System of Social Statistical Datasets}

To analyse immigrant naturalisation and integration, I make use of register data from Statistics Netherlands. The use of administrative data is increasingly popular in social sciences. Traditionally, information on individuals and households is principally collected through surveys. But non-response rates (de Leeuw \& de Heer, 2002) ( $^{5}$ and the relatively high cost of surveys have animated some statistical offices to develop alternative forms of data collection. ${ }^{6}$ In the Netherlands, this resulted in the System of Social Statistical Datasets (SSD). The SSD is a linked system of centrally stored and standardized registers, covering a wide range of socio-economic and demographic characteristics (Bakker, van Rooijen, \& van Toor, 2014). Using unique identification keys, these data can easily be linked to different units of observation, including individuals. To ensure the quality of the data and facilitate efficient use and secure storage, the SSD is embedded in an elaborate support system of organised processes, software tools and coordination principles.

In the context of this thesis, register data have important advantages. First, while the development, collection and analysis of survey data presents multiple challenges (see Couper [2017] and Biemer et al. [2017] for a recent discussion), these issues are often amplified when researching ethnic minorities (Kappelhof, 2014, 2017). Lack of

\footnotetext{
${ }^{5}$ Note that more recent analyses, which are yet to be published, suggest that the trends reported by de Leeuw and de Heer (2002) have continued over the years.

${ }^{6}$ For instance, the 2001 census in the Netherlands was produced on the basis of register data for the first time. While the costs of the traditional census were estimated around 300 million euros, the 2001 census cost approximately 3 million euros (Schulte Nordholt, Hartgers, \& Gircour, 2004).
} 
mastery of the native language among foreign-born individuals increases the chance of non-response and measurement errors (Font \& Mendez, 2014, p. 16). Potential feelings of distrust and suspicion towards interviewers are likely stronger for those who have experienced racist attitudes, do not speak or understand the native language well, or originate from countries where talking to and confiding in researchers carries risk. Moreover, cultural differences and a potentially insecure legal status may make it hard to assess up front which topics will be sensitive or controversial for immigrants, and thus how valid the collected data will be. Furthermore, residential patterns of immigrants are less stable than natives, presenting researchers with a more limited window of opportunity for interviews at home. All these issues complicate the collection and analysis of survey data on immigrants, but are circumvented by the use register data. Almost all registered foreign-born individuals are represented in these data, which is particularly relevant in light of the increasingly diverse nature of the migrant population (Czaika \& de Haas, 2014). Furthermore, the administrative character of these data solves some of the problems associated with non-response and social desirability. Second, to analyse naturalisation decisions and outcomes, panel data is crucial. Methodologically, a panel data structure provides opportunities to isolate selection bias resulting from endogenous characteristics that are difficult to measure and control for. Moreover, in terms of research design, the focus on one host-country (in this case, the Netherlands) implies that the relevance of the policy context can only be analysed longitudinally, by comparing time periods where different institutional conditions applied. Furthermore, to develop a complex understanding of the social context in which naturalisation decisions take place, it is important to be able to not only track individuals, but also their partners, over time. The Dutch register data in the SSD offer these opportunities.

There are of course limitations to these data as well. For instance, in spite of its increasing popularity, little is known about the quality of administrative data. Some research has analysed this by linking survey data to register data, and using structural equation modelling to determine the indicator validity (Bakker, 2012). Although results suggest that the accuracy of administrative data is not substantially lower than survey data (and in some cases even better), there is not enough research to provide definitive conclusions on this matter (see Oberski, Kirchner, Eckman, and Kreuter [2017] for a recent discussion). Critical reflection on the plausibility of empirical findings in light of previous research based on non-register data is thus of key importance. Administrative data also raise questions regarding representation. Although the inclusive nature of register data is generally portrayed as one of its strongpoints, these data per definition do not include the non-registered or 'illegal' population. For target populations with substantial variation in legal status, such as immigrants, this can lead to selection bias. However, since legal residence is a formal requirement for naturalisation, undocumented migrants would have to be excluded even if the information was available. As such, the problem in the context of this thesis is not so much selection 
bias, but rather that the relevance of the empirical findings does not extend to those who are not registered in the host country. Furthermore, administrative delays, both at the moment of arrival (migration) and permanent departure (emigration), can result in under-coverage and over-coverage respectively. In many cases however, administrative delays can be corrected over time (Bakker, 2011). Furthermore, the probability of administrative delays is lower if the accuracy of the variable in question matters to the reporter. As such, it is important to critically assess the quality of the data in light of its source, and repeatedly check the plausibility of the data by comparing the information to other registers. If one administrative source for instance suggests that a migrant has left the country, while another does not, this should prompt further scrutiny of both registers. Finally, the conceptual scope of administrative data is inherently limited, as there is typically no information on opinions, motivations or experiences. One solution would be to link register data to surveys with more specific information, but doing so will always constitute a trade-off between quantitative mass and conceptual reach. However, the literature on the citizenship premium predominantly focuses on basic administrative information such as legal status, employment, income, gender, age and marital status. These data are all available in register format. Notwithstanding its limitations, the SSD is therefore ideally suited for an analysis of the citizenship premium, and this thesis is the first to exploit it to that end.

\section{Empirical strategy}

Both naturalisation rates and associated integration outcomes are characterised by substantial heterogeneity. Some migrant groups have a higher propensity to naturalise than others, and not all migrants benefit equally (or at all) from citizenship acquisition in the labour market. However, unravelling the ambiguity regarding the relevance of citizenship for the socio-economic integration of immigrants presents methodological challenges (OECD, 2011). Studies in this field of literature typically focus on identifying the direction of the association between citizenship and labour market outcomes. Legal status transitions are not random, and migrants who naturalise may thus be positively selected with regard to their labour market performance already prior to naturalisation, as a result of endogenous characteristics such as motivation, skill and ability, which are associated with both the propensity (and ability) to naturalise and labour market outcomes. These characteristics are difficult to measure and control for, but failing to do so will result in an overestimation of the unique relevance of citizenship acquisition. In that context, the state-of-the-art methodology in this field of literature (developed by Bratsberg et al. [2002]) makes use of longitudinal data to disentangle selection effects from citizenship effects. Yet in spite of the methodological focus in the literature on the causal relationship between citizenship and integration outcomes, empirical heterogeneity between studies persists. The core question whether a citizenship premium exists or not thus remains unresolved. 
While the importance of the development of the analytical models cannot be overstated, the theoretical foundation underlying these models has not received similar attention. More specifically, the literature has analysed the relevance of citizenship for integration outcomes largely in isolation of the pathway to citizenship. The effects of naturalisation are typically modelled as a binary before-after phenomenon. In other words, citizenship is expected to matter in the labour market after it is acquired. The assumption is that employers associate less risk with hiring a naturalised migrant compared to a non-naturalised counterpart. However, the focus on the acquisition of citizenship itself neglects the role of access to the status, and the way in which it is acquired. Citizenship acquisition is not merely a legal status transition, but also involves a preparatory process leading up to naturalisation. Migrants will have to invest in meeting the formal linguistic and civic requirements for naturalisation. Furthermore, the decision to naturalise often implies the intention to stay and build a life in the host country. As such, investing in host-country specific knowledge and skills is likely to pay off for these migrants. I therefore expect to observe positive outcomes of naturalisation already prior to citizenship acquisition (Bratsberg et al., 2002, p. 590). These effects are not the result of the legal status transition itself, but rather stem from the explicit life course decision to naturalise in the future, and the investments that are associated with that decision. Since any positive outcomes prior to naturalisation are typically considered inconsistent with the notion of a citizenship premium (Helgertz et al., 2014, p. 351), the analytical models in the literature are often not designed to analyse the years preceding naturalisation in detail. In other words, the citizenship premium is generally modelled and analysed as a transition (from non-citizen to citizen), while ignoring the process (where migrants prepare and invest in themselves leading up to naturalisation). The existence of an anticipation effect may thus explain the limited empirical support for a citizenship premium in the literature, as positive outcomes associated with the decision to naturalise in the future already manifest prior to naturalisation. Furthermore, institutional conditions likely play an important role in this anticipatory mechanism. In countries with liberal citizenship policies, where few demonstrable skills are a requirement for naturalisation (such as Sweden), we may not expect an anticipation effect, since migrants are not obliged to invest in their labour market potential in order to naturalise. But in countries with very restrictive requirements (for instance Denmark), we may similarly not expect an effect, as vulnerable migrant groups - who are highly interested in naturalisation and stand to benefit from citizenship most (Fougère \& Safi, 2009; Vink et al., 2013) - do not have the resources to meet the formal requirements, and are demotivated to invest in its acquisition. In other words, the institutional context in which immigrants are embedded, and which stipulates the relative accessibility of citizenship, may matter for the socio-economic outcomes of naturalisation. In this thesis, I employ a more complex distributed fixed-effects model that goes beyond the dichotomous comparison before and after naturalisation. More specifically, this empirical strategy provides detailed 
information about the years surrounding naturalisation, thus capturing potential positive integration outcomes leading up to citizenship acquisition, as migrants prepare for the formal requirements, and anticipate future benefits and rights associated with the status.

It is well established that a cost-benefit framework is a good predictor of the propensity to naturalise (Yang, 1994). The motivation and ability to naturalise differs between migrant groups, depending on the origin context and personal characteristics (Chiswick \& Miller, 2009). However, individual life courses are interconnected through a continuously transforming network of social relationships (Elder, 1994). From that perspective, I argue that the value and meaning of citizenship is also determined by the social context of the family, which has so far have received limited systematic attention. $^{7}$ The decision to naturalise suggests the intention to stay and invest in building a life in the host country. This implies that naturalisation decisions are at least partly made at the family level. Yet the relevance of the family - for instance the spouse - is traditionally considered from a utilitarian rather than a social perspective, and analysed as an individual-level characteristic (e.g. married versus not married). Instead, I argue for a more dynamic understanding of the relevance of the family, for instance by analysing the timing of naturalisation relative to the spouse, and by accounting for the legal status of the partner. Since these characteristics change over the course of immigrant lives, it is crucial to employ a longitudinal empirical strategy that captures these temporal dynamics. For this reason, I analyse immigrant naturalisation using Cox Proportional Hazards regression with time dependent covariates. This methodology examines the relationship between the survival distribution and explanatory variables. In other words, it estimates the relevance of personal and contextual characteristics for the probability that a specific event (such as naturalisation) occurs. The benefit of this approach is twofold. First, Cox regression accounts for changes in characteristics within individuals over time, including partners and their legal status. Second, this strategy specifically addresses the causal nature of determinants of immigrant naturalisation, thus accounting for potential bias resulting from reverse causation. For the same reasons, this methodology is used to analyse the impact of legal status transitions on the probability of homeownership of immigrants.

\section{Outline of the dissertation}

The thesis is structured along five substantive chapters based on a combination of published and submitted research articles. Chapter 2 introduces the theoretical innovation of the thesis. First, I outline the state-of-the-art literature on the citizenship premium, and identify the need for a more developed theoretical framework that may

\footnotetext{
7 See Bevelander and Helgertz (2016) and Street (2014) for a quantitative and qualitative exception respectively.
} 
account for varying outcomes of naturalisation across countries and time. To that end, concepts and guiding principles of the sociological life course paradigm are introduced, which may provide a useful starting point. I then offer concrete suggestions on what an application of this life course approach to the literature on the citizenship premium would look like. In the subsequent chapters, this is put into practice by analysing immigrant naturalisation and related outcomes using Dutch register data from Statistics Netherlands. In Chapter 3, I analyse determinants of citizenship acquisition, with a specific focus on how naturalisation decisions are shaped by the social context of the family, and the institutional context of citizenship policies. Results confirm that a cost-benefit framework is a good predictor of citizenship acquisition. The propensity to naturalise is high among migrants with a native-born or naturalised partner, particularly during the year in which the partner acquires Dutch citizenship, suggesting that the decision to naturalise is at least partly made at the family level. Furthermore, the analyses show that the institutional context matters: restrictive citizenship policies decrease the propensity to naturalise, particularly among disadvantaged migrants from economically less developed and politically unstable countries of origin, who are interested in and stand to benefit from citizenship most. In the subsequent chapters, I focus on the importance of access to and holding citizenship. Chapter 4 analyses the relevance of citizenship for acquiring employment, and employs a distributed individual fixed-effects regression to not only analyse legal status transitions, but also the trajectory to citizenship. Empirical findings show that citizenship acquisition increases the probability of employment of immigrants. However, the positive labour market outcomes particularly manifest leading up to naturalisation, suggesting that migrants invest in their human capital development to meet the requirements for naturalisation, and in anticipation of the rewards and opportunities that citizenship will offer. The labour market outcomes observed in Chapter 4 are explored in greater detail in Chapter 5, where the role of citizenship for immigrant earnings is addressed. While some migrants benefit from naturalisation in terms of income from labour, the positive effects are comparatively small, and generally limited to vulnerable migrant groups from less developed countries of origin, who face structural obstacles in the labour market. In so far as citizenship matters, it provides access to higher paying jobs and more working hours, but does not facilitate mobility between labour market sectors. Chapter 6 broadens the substantive scope of the thesis by investigating a citizenship premium in the housing market, specifically in terms of homeownership. Results show that naturalisation increases the probability of homeownership, but only for employed migrants, who likely meet the basic economic requirements for a credit in the housing market. Moreover, possession of the host country citizenship does not matter for migrants with a native-born partner. More generally, empirical findings suggest that legal status discrimination may be one of the underlying mechanisms behind the positive effects of naturalisation in the housing market. Finally, Chapter 7 concludes with a discussion of the main findings and their implications, and suggestions for future research. 



\section{Chapter}

\section{Naturalisation and the Socio-Economic Integration of Immigrants ${ }^{8}$}

\footnotetext{
${ }^{8}$ This chapter has been published as: Peters, F., \& Vink, M. (2016). Naturalization and the Socio-Economic Integration of Immigrants. In G. P. Freeman \& N. Mirilovic (Eds.), Handbook on migration and social policy (362-376). Northampton: Edward Elgar Publishing. In 2017, the chapter received the Best Chapter Award by the Migration and Citizenship Section of the American Political Science Association.
} 



\section{INTRODUCTION}

Is citizenship an important instrument for the socio-economic integration of immigrants into the host society, and if so, why do some immigrants naturalise while others do not? Although research on these questions dates back decades, the literature provides no straightforward answer. While most empirical evidence indeed suggests a positive relationship between citizenship and labour market integration, not all studies support these findings. For example, Bratsberg et al. (2002), Steinhardt (2012), and Helgertz et al. (2014) found evidence of a positive association between citizenship acquisition and labour market outcomes in the North American and European context. However, Chiswick (1978), Scott (2008) and Bevelander and Veenman (2008) found no such effect, or even a negative relationship. While this empirical incongruence hardly comes as a surprise, given the wide variation in empirical contexts, types of data and methodological designs that characterise studies in this area, much of the literature is preoccupied more with the question of whether there is ' $a$ ' citizenship premium, instead of the question to whom, and especially under which conditions citizenship matters for immigrants.

In this chapter, we argue that the literature would benefit from a more comprehensive theoretical model that accounts for how immigrant naturalisation and socio-economic outcomes can be understood in light of variation in destination countries' demographic composition and institutional setting (e.g. Bauböck et al., 2013; OECD, 2011). We draw especially on the sociological life course paradigm (Elder, 1974), where life course development is analysed as the product of personal characteristics and individual action as well as cultural frames and institutional conditions (Mayer, 2009). A life course perspectives has been increasingly popular within migration studies (Wingens et al., 2011), yet so far under-utilized in naturalisation research. In our view of the state-of-the-art of the field, a life course perspective chimes well with research that demonstrates that the decision to naturalise is not solely the result of an individual deliberation, but rather made in the context of the family situation and broader social network in which immigrant lives are embedded (Helgertz \& Bevelander, 2016; Street, 2014). Comparative research has demonstrated that the decision to naturalise is contextualized by the institutional setting, especially the relative restrictiveness of the host country citizenship policy and origin/destination country dual citizenship policies (Vink et al., 2013). A more developed theoretical framework that accounts for these institutional and social aspects of naturalisation may reveal why certain immigrants naturalise and benefit from citizenship acquisition while others do not, thus providing potential to go beyond merely observing empirical ambiguity in the literature.

Methodologically, a life course perspective also fits with the increasing use of longitudinal rather than cross-sectional data in order to deal with the frequently observed problem of self-selection in naturalisation research. More specifically, it could be argued that migrants who are better equipped to perform well in the labour market, 
regardless of their legal status, are also more likely to naturalise. Research by for instance Scott (2008) and Engdahl (2011) shows that the positive association between naturalisation and labour market outcomes is largely attributable to endogeneity in Sweden. However, analyses by Steinhardt (2012) contradict these findings for Germany, revealing a substantial wage growth for male immigrants after naturalisation, even when controlling for self-selection. By emphasizing the way in which early life events promote or stifle subsequent events, and by acknowledging how biographical actions and plans are embedded in the social and institutional context in which these take place, a life course perspective may aid the development of a theoretical model that can account for both the institutional and social context of naturalisation and labour market outcomes.

This chapter is structured in three parts. First, we review the state-of-the-art, both on immigrant naturalisation and the relationship between citizenship and labour market outcomes. The second part then introduces the sociological life course paradigm, outlining its key concepts and methodological principles. Third, we return to the stateof-the-art to illustrate how a life course approach has the potential to go beyond the empirical ambiguity in the literature, differentiating between biographical and ecological aspects of immigrant naturalisation and labour market outcomes. Finally, we discuss the implications of this approach to future research on citizenship, and reflect on its limitations.

\section{LITERATURE ON NATURALISATION}

Traditionally, research on immigrant naturalisation has been strongly embedded in a broader literature on integration and adaptation processes of immigrants in the host society, both on a socio-economic and socio-cultural level (e.g. Barkan \& Khokhlov, 1980; Bernard, 1936; Beijbohm, 1971; Chiswick, 1978). In his seminal work, Yang (1994) introduces a cost-benefit model of subjective utility maximization, which constitutes the basis of the dominant theoretical framework on citizenship acquisition. In this utility model, benefits comprise political and socio-economic rights and privileges, while costs include the effort spent in an application process, the potential loss of the former nationality and the rights it offered, increased citizen obligations in the host country and potential financial expenses (Bevelander \& Veenman, 2008; Yang, 1994).

The continued development of the literature has centred on identifying which elements play a role in this deliberation. One strand of research puts emphasis on the origin context and personal characteristics and the way in which these properties condition the perceived utility of citizenship acquisition. A lack of economic freedom, political security and low standards of living in the country of origin may discourage migrants to return. In these cases, citizenship of the host country offers security by providing unrestricted access to its territory. Research shows that these migrants 
naturalise quickly and in large numbers (Bueker, 2005; Chiswick \& Miller, 2009; Dronkers \& Vink, 2012; Jasso \& Rosenzweig, 1986; Vink et al., 2013). By contrast, for immigrants from high developed countries, the perceived benefits are typically lower given the value of the original citizenship in the country of origin. For such immigrants, if they choose to naturalise at all, years of residence plays a crucial role (Vink et al., 2013).

Furthermore, the origin context not only conditions the relative value of the citizenship of the destination country, but also plays a role in determining whether people are required to renounce their original citizenship upon acquiring another. Losing the original citizenship can have important implications, for example with regard to ability to work, hold property or invest in the origin country, as well as the loss of rights to its public services and social benefits (Bloemraad, 2004; Jones-Correa, 2001; Mazzolari, 2009). Furthermore, the loss of mobility rights may imply a more permanent disconnection from relatives and friends in the origin country. A cost-benefit framework counts the automatic loss of the original citizenship as an important deterrent to naturalisation. Empirical findings in the literature, however, produce an ambiguous picture and do not universally support the hypothesis that being able to retain the citizenship of the origin country increases the propensity to naturalise in the destination country (Dronkers \& Vink, 2010; Jones-Correa, 2001; Logan, Oh, \& Darrah, 2012; Mazzolari, 2009; Scott, 2008; Yang, 1994).

Besides the origin context, the value and meaning of citizenship depends on one's current life situation. In this regard, one of the most important personal characteristics that is consistently found to be positively related to citizenship acquisition is length of residence (e.g. Bueker, 2005; Dronkers \& Vink, 2012). Prolonged residence is not only in most cases a requirement for naturalisation, but also increases commitment to the host society through the gradual accumulation of socio-economic, political and cultural resources specific to the host country. The literature is less conclusive about the relevance of other personal characteristics, such as age. Jasso and Rosenzweig (1986) find a negative association between age and citizenship acquisition. They argue that, as age increases, the period of time in which one may enjoy the benefits associated with the destination countries' citizenship reaches a point where it no longer justifies the effort to acquire it. In contrast, Yang (1994) finds a curvilinear relationship and Chiswick and Miller (2009) a positive association. Another example of contradictory findings concerns the role of children. While Yang (1994) finds that having young children increases the odds of naturalisation, these results are often contradicted in subsequent contributions (e.g. Chiswick \& Miller, 2009; Vink et al., 2013).

The relevance of marital status is relatively undisputed. Yang (1994) argues that marriage provides stability and societal integration, which may facilitate naturalisation. Furthermore, marriage with a native born not only increases commitment to the host society, but may also lower potential legal obstacles to naturalisation such as the residence requirement. Most empirical findings indeed support the notion that 
marriage is positively associated with citizenship acquisition (e.g. Bueker, 2003; Liang, 1994; Vink et al., 2013). Recently, Helgertz and Bevelander (2016) analysed this relationship in further detail using longitudinal data, finding that marriage with a foreign-born citizen subsequently increases the propensity to naturalise, particularly during the year in which the spouse attains citizenship. Notwithstanding the dominant view of naturalisation as a product of an individual utility-maximizing calculation, these results indicate that the decision to naturalise is a joint resolution between partners based on a shared ambition to invest in a long-term settlement in the host country. These social aspects of naturalisation are also emphasized by Street (2014), whose work reveals the intergenerational motivation for citizenship acquisition by immigrants in Germany in order to guarantee citizenship status for their children.

A recurrent trait of many contributions that analyse individual incentives for naturalisation based on the origin context and personal characteristics is their focus on a specific point in time and a single destination context (e.g. Chiswick \& Miller, 2009; Yang, 1994). The lack of both a cross-national and longitudinal design leaves little room to address the relevance of the destination context, for instance in terms of citizenship policies. However, citizenship law constitutes a legal framework that determines the conditions for citizenship eligibility, and is thus of crucial importance. This is particularly the case in Europe, where citizenship policies vary significantly (Vink \& de Groot, 2010). Consequently, a separate strand of literature specifically investigates the relevance of the destination context in terms of migration history, citizenship policies and the political landscape across countries and time (e.g. Aleksynska \& Algan, 2010; GonzalezFerrer \& Cortina-Trilla, 2011; Janoski, 2010; Reichel, 2011). This research clearly illustrates the relevance of the destination context by revealing large discrepancies in naturalisation rates between countries. However, as most of these macro-level studies employ aggregate data, they employ limited controls for the demographic composition of migrant populations, for example with regard to levels of education, wealth, or migration background. Such studies may thus compare countries that are in compositional terms highly dissimilar, and run the risk of drawing inferences about individuals based on aggregate data (better known as the ecological fallacy). In other words, there is literature focussing on variation at the individual-level of immigrants, and the macro-level of institutional contexts. But while these lines of research have the potential to complement each other, they mostly exist in isolation.

\section{NATURALISATION AND SOCIO-ECONOMIC INTEGRATION}

It is widely accepted that the labour market performance of immigrants regarding employment and earnings is worse when compared to natives (e.g. Algan et al., 2010; Fleischmann \& Dronkers, 2010; Schmidt, 1997; van Tubergen, 2006; van Tubergen, Maas, \& Flap, 2004). Research has identified five major reasons for this discrepancy. 
Social capital theory states that social networks, and the resources they entail, can promote labour market opportunities (de Graaf \& Flap, 1988; Drever \& Hoffmeister, 2008; Franzen \& Hangartner, 2006; Lancee, 2012; Lancee \& Hartung, 2012). Since immigrants are relatively new to the host society, they can be expected to have less social capital than natives (e.g. Nee \& Sanders, 2001; Schmeets \& te Riele, 2010), and as such are less able to employ their social network to attain employment. Social capital provides access to host-country specific human capital, which brings us to the second argument. Migrants are often less empowered by human capital, or possess human capital that is less relevant in the host society, than natives, to the detriment of their labour market performance in Western societies (Becker, 1962; Heath \& Cheung, 2007; Schultz, 1961). Education and labour market experience in the country of origin is not simply transferable to the country of destination, since employers cannot always readily interpret the relevance of said qualifications. Also, due to restrictive regulations, immigrants may not have access to specific segments of the labour market, such as public sector jobs. Furthermore, most immigrants are at a disadvantage with regard to mastery of the native language when compared to natives, which hampers their employability (Hayfron, 2001).

Citizenship has the potential to mitigate some of these disadvantages (Bauböck et al., 2013; OECD, 2011). The main mechanism through which citizenship contributes to the socio-economic integration of immigrants is threefold. First, citizenship removes restrictions on public sector jobs, increasing employment opportunities. Second, the administrative costs of hiring and retaining a naturalised migrant are lower compared to a migrant who has not attained citizenship. Third, citizenship acquisition placates employers' uncertainties about the educational qualifications, work experience and general work ethos of a migrant by signalling 'good' integration. Therefore naturalised migrants have more job opportunities, are less expensive and pose less of a risk to hire compared to those who have not naturalised.

While these mechanisms may explain how citizenship can be beneficial to the socioeconomic integration of immigrants, findings in the literature on this core question of the impact of citizenship are ambiguous (e.g. Engdahl, 2011; Scott, 2008; Steinhardt, 2012). For instance, longitudinal studies in North America or Germany reveal increased wage growth after naturalisation (Bratsberg et al., 2002; Steinhardt, 2012). By contrast, a similar study performed by Engdahl (2011) and Scott (2008) in Sweden suggests that the relationship between citizenship and socio-economic integration is largely due to self-selection. In other words, immigrants who perform well in the labour market in the first place may be the ones who are also more likely to naturalise, and might consequently be positively selected before the act of naturalisation. Each set of contributions tells a different story, but neither reflects on the mechanisms that might explain these results. In our view, this is surprising, given the differences in empirical contexts, types of data and methodological designs among these various studies. In other words, it may be possible that acquiring destination-country citizenship matters 
for some immigrants, but not for others. As such, what the literature needs is a more developed theoretical framework that may account for varying outcomes of naturalisation across countries and time. To that end, we introduce the sociological life course paradigm, whose concepts and principles may provide a useful starting point for such a framework. Subsequently, we apply this perspective to the field of naturalisation and integration.

\section{THE SOCIOLOGICAL LIFE COURSE PARADIGM}

The sociological life course paradigm (Elder, 1974) can be characterised by the search for regularities in socially interrelated human lives, where life course development is analysed as the product of personal characteristics and individual action, as well as cultural frames and institutional conditions (Mayer, 2009). Broadly speaking, life course research concerns itself with the concepts of time, context and processes by analysing the interrelated development of human biographies in transforming societal conditions (Diewald \& Mayer, 2009). As such, it represents a distinct way of thinking about and studying human lives that combines two conceptual models. On the one hand, it is essentially a multilevel approach that analyses pathways of human life as the product of the interplay between micro- (individuals), meso- (societal structures and institutions) and macro- (historical time) level dynamics. In this manner, life course research explicitly positions biographical actions and plans in the formal and social context of structures and institutions in which these take place, and which are similarly susceptible to changes through time. On the other hand, it is also a strongly longitudinal approach that attempts to go beyond the investigation of point-like states of being by analysing human development through strings of life events. The key assumption here is that there is a temporal dynamic to these events, where past experiences and resources, as well as opportunities and ambitions for the future, promote or stifle subsequent choices and developments.

To translate these conceptions into models for empirical research, the life course is perceived in terms of trajectories and transitions. Transitions are changes in state that are more or less abrupt (Elder, 1985), for example from having employment to being unemployed. While the perpetuation of a status is informative in its own right, it is arguably the life events that mark transitions between states that most research questions are focused on. Trajectories are periods of time in life domains or institutions, such as education, work or health, in which transitions are embedded (Elder, 1985). In this sense, a trajectory is the conceptual glue that ties various life events together in a meaningful way. Through trajectories, changes in state have cumulative effects that produce long-term advantageous or disadvantageous developments in the life course. Rather than a random sequence of idiosyncratic life events, the life course is at least partly a conglomerated structure of social pathways that follow a certain temporal, 
institutionalized sequencing (Mayer, 2004). Societal institutions, such as educational and occupational systems, provide a framework of rules and regulations, as well as ageand time-scheduled sequences of classes that shape life course trajectories. These models of standardized life courses are culturally endowed, and often dissimilar between groups, such as men and women. For instance, the transition to a shared household or starting a family may signify a less active role in the labour market in the life course of women, in contrast to men (Fortin, 2005; Vella, 1994). Furthermore, the life course is not simply the product of societal and institutional conditions at a given time, but is actively constructed within these contextual circumstances. Individuals are agentic actors who evaluate formal and social opportunities and constraints in light of past biographical events and outcomes, as well as ambitions and plans for the future. Thus trajectories represent the longitudinal way of thinking about actors in changing societies, by capturing the causal connections between transitions (Elder, 1994, p. 4).

As the name implies, trajectories are characterised by a sense of direction. When a certain life event causes a fundamental shift in the direction of a trajectory, it is marked as a turning point. Since all transitions are thought to have long-term effects, a turning point is essentially a transition that has a discontinuous effect on its trajectory, relative to its predecessors. By their very nature, these transitions can only be dubbed as such with hindsight, since their defining features only become apparent in retrospect (Abbott, 1997). Nevertheless, turning points can be an important concept to make sense of biographical development.

Life course research has introduced a number of guiding principles that help us link trajectories and transitions to substantive theory that explains these lines of development (Shanahan \& Macmillan, 2008; Wingens et al., 2011). Here we discuss those that will prove most relevant to theory on citizenship, namely linked lives, life stage, accentuation and agency.

'Linked lives' refer to the fact that life courses do not exist independently but are interconnected through a network of social dependencies and relationships (Elder, 1994). These lines of association range from family and friends to colleagues and communities, and provide resources and opportunities that mutually affect people's lives. The 'life-stage' principle emphasizes the way in which the impact and meaning of life events changes throughout the life course (Shanahan \& Macmillan, 2008). In other words, to understand the impact of life events, one needs to take into account the phase of life in which the event occurs (Wingens et al., 2011). 'Accentuation' is the process when existing values, beliefs and practices become more pronounced when environmental structures and conditions rapidly change (Wingens et al., 2011). For example, a migrant residing in a foreign country may feel strongly connected to another individual solely on the basis of a shared cultural background, even though these qualities would not have been as relevant prior to migrating. The principle of 'agency' refers to the ability of individuals to actively plan and construct their life course within the boundaries of societal and institutional opportunity structures. As such, individuals 
evaluate their options in light of available resources, ambitions and situational constraints, and actively react to changes in these conditions (Heinz, 1996). An example of this would be individuals anticipating and acting on a pending policy change.

The central ideas of the life course paradigm relate naturally to processes of migration and integration. As Wingens et al. (2011, p. 2) point out: 'Understanding migrants' behaviour and explaining the cumulative effects resulting from their actions which, in turn, are embedded in societal structures and framed by institutions, requires just the kind of dynamic research approach the sociological life course perspective suggests.' However, so far the life course approach is rarely used explicitly in migration and integration research, let alone in the literature on citizenship acquisition and socioeconomic integration. However, we will show that these life course concepts and principles neatly fit and complement the existing theoretical framework, while simultaneously highlighting the very elements that may prove crucial in explaining the current empirical ambiguity in the literature.

\section{A LIFE COURSE PERSPECTIVE ON NATURALISATION AND SOCIO- ECONOMIC INTEGRATION}

How are the theoretical concepts and principles of the sociological life course paradigm relevant to research on citizenship? Since migration and integration are life course processes, the act of citizenship acquisition can be perceived as an important transition - from non-citizen to citizen - within this trajectory. To understand the underlying motivations that underpin this transition (why do immigrants naturalise?) and its implications (what is the impact of citizenship on socio-economic integration?), the dynamic research perspective of the life course is needed to grasp both the social and institutional context in which immigrant decision-making is embedded.

\section{The biography of immigrant naturalisation}

The literature on citizenship acquisition has developed considerably since the introduction of a cost-benefit model by Yang (1994), both in conceptual and methodological terms. However, throughout this period of development, the underlying theoretical model has remained largely unchanged, and at its heart still focuses on individual utility as the key motivation for citizenship acquisition. As such, it provides limited guidelines regarding the role of social relations. Yet recent findings in the literature clearly show that the decision to naturalise is not an individual deliberation, but rather made in close consultation with the spouse, or for the future benefit of children (Helgertz \& Bevelander, 2016; Street, 2014). Therefore citizenship acquisition has to be understood in a biographical sense, where the utility of citizenship depends largely on the point in one's life course at a given time. For instance, the value and 
meaning of citizenship will differ between migrants who may want to start a family, compared to those who are either younger and whose plans and ambitions for the future are not as intertwined with others, or who are older and for whom naturalisation no longer carries the potential of a life-changing turning point. In other words, linked lives and life stage are crucial concepts to accurately portray the complex dynamic of human lives in which the decision to naturalise is embedded. This not only relates to the propensity to naturalise, but also to its subsequent socio-economic impact. For instance, Street (2014) demonstrates that a key motivation for naturalisation of migrants in Germany was in fact not focused on personal gain, but rather on securing citizenship status for their children to promote their opportunities for upward mobility. Clearly, if the propensity to naturalise is not necessarily based on personal benefit, an individualistic model of subjective utility maximization is too limited. In other words, concluding that citizenship does not matter if it has no positive effect for the naturalising individual is presumptuous. Hence we need a biographical understanding of the decision-making process, not as a substitute, but in addition to existing calculating explanations of immigrant decision-making; however, our understanding of an immigrant's motivation to naturalise should refer not only to purely individual considerations, but also to those made at the family level.

A biographical perspective is not only a valuable addition to the model, but also provides an important starting point to address empirical findings which seem puzzling in the context of the current theoretical framework. For example, Steinhardt (2012) finds that naturalisation offers no wage benefit for women; from a life course perspective, this may partly be due to dissimilar models of standardized life courses per gender (Fortin, 2005; Vella, 1994). As mentioned earlier, certain life events such as marriage or having children may have distinct implications for men and women. Since Steinhardt focuses on migrants who are full-time employed, it is perhaps unsurprising that the women included in his analysis are very motivated and skilled, since these women have chosen to remain highly active in the labour market in spite of the prevailing life course pattern where women predominantly start working part time or leave the labour market after having children (Fortin, 2005; Wingens et al., 2011). For this reason, we emphasize that it is important to reflect on the implications of the selected research population.

Furthermore, the temporal dynamic inherent to a biographical perspective also builds on an ongoing methodological discussion in the literature that emphasizes the importance of using longitudinal data. Since citizenship acquisition is a selective process, this entails the methodological risk that those migrants who choose to naturalise do so partly because of endogenous qualities related to their labour market outcomes. Immigrants who perform well in the labour market may also have a high propensity to naturalise, and might consequently be positively selected even before the act of naturalisation (Helgertz et al., 2014; Steinhardt, 2012). By employing a life course approach, the assumption of causality - where citizenship acquisition precedes socio- 
economic integration - is directly addressed through the longitudinal analysis of life events in the human biography. In that sense, a biographical approach that emphasizes both the temporal and social aspects of immigrant naturalisation and labour market outcomes synchronizes well with current methodological developments in the literature regarding the increased usage of longitudinal data. In other words, longitudinal data offer more than just methodological opportunities, and should invite us to develop and test more complex theoretical models.

\section{The ecology of immigrant naturalisation}

A central idea of the sociological life course paradigm is that individual lives are embedded in societal structures and institutions that shape biographical plans (Wingens et al., 2011). As such, institutional transformations at the meso/macro-level are consequential to life courses at the micro-level, as redefined opportunity structures open new pathways or close existing ones. Yet the literature on citizenship and labour market integration largely focuses on either the macro- (in terms of for instance citizenship law or the migration history of destination countries) or micro-level (in terms of individual incentives for naturalisation). However, individuals evaluate societal and institutional opportunity structures against their aspirations and plans, and act accordingly (Heinz, 1996). As Street points out: 'Research on citizenship laws should be based on an understanding of the micro-foundations of naturalisation behaviour' (Street, 2014, p. 265). Similarly, an analysis of the individual's decision to naturalise has to account for the societal and institutional context in which this deliberation takes place. However, the development of such a theoretical model is hampered by the fact that most contributions in the literature focus on a single destination country, and, when employing longitudinal data, choose not to analyse the impact of changes in the destination context through time (e.g. Bevelander \& Pendakur, 2012; Bevelander \& Veenman, 2008; Bratsberg et al., 2002; Mazzolari, 2009; Scott, 2008; Steinhardt, 2012). Indeed, Steinhardt makes an empirical caveat on this point: 'Given that (...) the effect [of citizenship] depends strongly on the legal requirements and consequences of naturalisation within a country, the following discussion refers explicitly to the situation in Germany' (Steinhardt, 2012, p. 815).

While it is true that destination contexts often cannot be readily compared, given the limits of available datasets, we should at least theorize on their impact and strive towards a model that accounts for its relevance. For instance, with regard to personal characteristics, Yang (1994) finds a curvilinear relationship between age and citizenship acquisition, arguing that the utility of citizenship is particularly relevant during the period of time in which an immigrant is active in the labour market. By contrast, Chiswick and Miller (2009) find a positive relationship and Jasso and Rosenzweig (1986) a negative association. Chiswick and Miller argue that the absence of a curvilinear relationship may be linked to policy changes that have limited non-citizens' access to 
social services, particularly increasing the benefit of citizenship for those of higher age (Chiswick \& Miller, 2009, p. 32). As such, individual incentives for naturalisation based on age are conditioned by the institutional context at a given time and place.

Similarly, Yang (1994) finds that having young children increases the odds of naturalisation, but these results are often contradicted in subsequent contributions (e.g. Chiswick \& Miller, 2009; Vink et al., 2013). However, citizenship policies may play an important role in the relevance of children by conditioning whether naturalisation can be employed as a strategy for intergenerational upward mobility (Street, 2014). When Germany changed its citizenship policy in 2000 to include ius soli citizenship provisions, extending citizenship to immigrants' children born in Germany, citizenship rates actually lowered in contrast to political expectations. Even though the policy reform made citizenship acquisition easier for most migrants, a key naturalisation motive for foreign parents, namely upward mobility for their children, was removed. In other words, opportunity structures defined at the macro-level condition the impact of personal characteristics at the micro-level.

Just as the impact of the institutional context depends on individual incentives to naturalise, so too is the relevance of personal characteristics conditioned by the destination context. Although restrictive citizenship policies are negatively associated with naturalisation rates (Bauböck et al., 2013; Dronkers \& Vink, 2012), recent findings show that this is particularly true for migrants from less developed countries (Vink et al., 2013). Although further research on the underlying mechanisms is required, one could argue that, as citizenship policies become more demanding in terms of financial costs, as well as the required level of knowledge and skills, this will particularly present an obstacle to migrants from less developed countries. Thus, to understand the relevance of citizenship policies of the destination context, it is important to account for demographic properties of its immigrant population. For example, in countries with a large number of refugees, who predominantly originate from less developed countries, a restrictive citizenship policy might have a relatively strong impact.

Furthermore, the institutional context may not only reflect on naturalisation rates, but also on the subsequent outcomes of naturalisation. Since German citizenship law was based almost exclusively on the ius sanguinis principle until 2000, it is possible that many migrants in the analysis of Steinhardt (2012) chose to naturalise to guarantee citizenship status for their children, rather than the core aim of improving one's employability. If the motivation for naturalisation of immigrants is not so much motivated by these personal utility payoffs, but rather by those of others, then this may also be reflected in the relation between naturalisation and labour market outcomes. Similarly, the particularities of labour market regulation should also be expected to matter; in highly regulated systems, the 'citizenship premium' may be expected to be larger than in those systems where access to the labour market generally is less restricted. For example, whereas it is common to state your citizenship status in job applications in some countries, such as Germany or Austria, in other countries, like 
Norway or Sweden, this is not the case (OECD, 2011). In other words, citizenship acquisition is far less relevant for successful socio-economic integration in the latter countries. This may explain why the literature finds empirical evidence for a citizenship premium in Germany, and not in Sweden (Engdahl, 2011; Scott, 2008; Steinhardt, 2012). Similarly, the de facto opportunities that naturalisation provides, in terms of access to restricted jobs, the housing market or credit, which may increase immigrant mobility and thus improve labour market opportunities, differ between countries. Again, in the Swedish context, naturalisation has a very limited impact on these benefits (Scott, 2008).

The relevance of citizenship acquisition for labour market outcomes is not only conditioned by the institutional setting of the destination context, but also by the demographic composition of its migrant population. Sweden houses a relatively large number of refugees, who may be highly motivated to naturalise in order to reinforce their legal status in the host country. However, refugees are also particularly disadvantaged in the labour market (e.g. Krahn, Derwing, Mulder, \& Wilkinson, 2000; Wooden, 1991), which may go some way to explaining why Scott (2008) finds a negative relationship between citizenship and labour market integration in Sweden, while studies in some other countries do not (e.g. Bratsberg et al., 2002; Steinhardt, 2012). Another example is the relevance of co-ethnic communities. Just as there are initially fewer obstacles to establishing social ties with co-ethnics compared to natives, so too is it easier to find and attain employment under an employer who shares your language and cultural background (Bevelander \& Pendakur, 2012; Edin, Fredriksson, \& Åslund, 2003). The benefit of the host country citizenship to demonstrate the possession of some country-specific human capital, cultural knowledge and basic language mastery (as required in many naturalisation procedures) is in that case much less valuable. In other words, there are fewer incentives for migrants to invest in their labour market opportunities through naturalisation when residing in communities with a high coethnic population, since their disadvantages are mitigated through opportunities offered by co-ethnic workplaces. Moreover, processes of accentuation, resulting from the societal change inherent in the act of migration, may motivate migrants to actively seek these work environments with shared values, cultural codes and habits from the country of origin (Shanahan \& Macmillan, 2008). The impact of ethnic communities on immigrants' propensity to naturalise has so far only been analysed by Yang (1994), who found a positive association between the ethnic composition of a community and citizenship acquisition. Yang argues that a large immigrant community facilitates naturalisation by providing its members with information concerning benefits, procedures and experiences of naturalisation (Yang, 1994, p. 457). Whether communities also condition the relative impact of naturalisation remains an open question however.

What is clear from all of this is that the theoretical lacunae lie not so much in omitted variables, but rather in a theoretical framework that ties the separate strands 
of literature focusing either on characteristics of individuals or countries together in a systematic fashion. In this regard, the sociological life course paradigm provides the conceptual tools to simultaneously grasp the biographical and ecological aspects of citizenship, while a model of subjective utility maximization allows us to utilize these tools to systematically formulate hypotheses for analysis.

\section{CONCLUSION}

Findings from the literature on the core question of the effect of citizenship for immigrants' socio-economic integration are ambiguous. Instead of arguing for or against the existence of a so-called citizenship premium, this chapter explores the potential of the sociological life course paradigm to strengthen the theoretical foundation of research on citizenship and socio-economic integration. We argue that the development of a more comprehensive theoretical model may aid the identification of the conditions under which citizenship is effective. A review of the state-of-the-art reveals two strands of literature. A first, longstanding strand focuses on individual incentives for naturalisation based on the origin context and personal characteristics, but fails to account for the societal and institutional conditions of the destination country in which these individuals are embedded. A second, more recent strand of literature focuses on properties of the destination context in terms of citizenship policies, migration history, the political landscape, and changes in these characteristics over time, but ignores differences in the demographic composition of the migrant populations in these countries. When combining these micro and meso/macro approaches to citizenship acquisition and labour market integration though life course concepts and principles, a comprehensive theoretical framework appears that allows for the formulation of hypotheses that explain why some immigrants naturalise and benefit from citizenship, while others do not. More specifically, a life course perspective emphasizes the biographical and ecological aspects of naturalisation, where variation in citizenship acquisition rates and labour market outcomes can be explained by the social, institutional and demographic context in which immigrant lives are embedded. The added benefit of such an approach is that it provides potential to go beyond merely observing empirical ambiguity in the literature, thus increasing the comparative scope of research on naturalisation and socio-economic integration.

Methodologically, a life course approach to immigrant naturalisation calls for longitudinal individual-level data and dynamic microanalyses embedded in multilevel models of social processes (Wingens et al., 2011, p. 6). This notion builds well on the recent emphasis in the literature on the importance of longitudinal data to account for self-selection concerning unobservable characteristics (e.g. Helgertz et al., 2014; Steinhardt, 2012). As such, a life course approach to citizenship is highly compatible with contemporary methodological considerations in the state-of-the-art. However, 
these high demands on the required quality of data also pose potential challenges, given that suitable longitudinal dataset are only available in a limited set of countries. As a result, much of the literature focuses on specific countries, such as Sweden, Norway, Germany or the USA, for which these particular types of data are relatively accessible (Bratsberg \& Raaum, 2011; Bratsberg et al., 2002; Engdahl, 2011; Helgertz \& Bevelander, 2016; Scott, 2008; Steinhardt, 2012). Furthermore, the comparability of the findings from these studies is limited given that these datasets are structured according to national specificities and do not facilitate cross-national comparisons. In other words, opportunities to analyse the biographical and ecological aspects of naturalisation and labour market outcomes are constrained by the limits of available datasets. While these constraints may be addressed through the use of 'big data' approaches, combining register data with available surveys, access to these types of data is limited so far to only a small set of European countries, such as the Netherlands and Scandinavian countries.

Finally, we reiterate our initial question: is citizenship an important instrument for the socio-economic integration of immigrants into the host society? We would argue that there is no definitive answer, and indeed, that it is the wrong question. Instead, the literature would benefit by focusing more on identifying to whom and under which conditions citizenship matters. Doing so requires the development of a more comprehensive theoretical framework and, in this regard, we see a life course approach to immigrant naturalisation and socio-economic integration as the most promising step. 


\section{Chapter}

\section{The Ecology of Immigrant Naturalisation: A Life course Approach in the Context of Institutional Conditions ${ }^{9}$}

\footnotetext{
${ }^{9}$ This chapter has been published as: Peters, F., Vink, M., \& Schmeets, H. (2016). The Ecology of Immigrant Naturalisation: A Life Course Approach in the Context of Institutional Conditions. Journal of Ethnic and Migration Studies, 42(3), 359-381. In 2017, this paper received an Honourable Mention for the Best Paper Award by the migration and citizenship section of the American Political Science Association.
} 



\section{INTRODUCTION}

Citizenship acquisition has been the subject of growing political and academic interest. Given concerns of some countries regarding levels of integration of immigrants, naturalisation is considered a potential vehicle that may mitigate these issues by facilitating and expediting the process of socio-economic and socio-cultural integration. As such, the question of immigrant naturalisation is well established in the field of migration. Most research focuses on personal and contextual determinants of naturalisation (Bevelander \& Veenman, 2008; Bloemraad, 2002; Chiswick, 1978; Chiswick \& Miller, 2009; Mazzolari, 2009; OECD, 2008; Portes \& Curtis, 1987; Street, 2014; Yang, 1994). Personal characteristics include years of residence, age, marital status and education, while contextual characteristics focus on socio-economic and political properties of the country of origin, and the ability to hold dual citizenship.

However, there is surprisingly limited attention in the literature to the relevance of the destination context, and more specifically on citizenship policies which determine the institutional opportunity structure in which naturalisation takes place. This notable caveat may be linked to the predominant use of cross-sectional data focusing on a single host country, constraining opportunities for the analysis of the destination context. Furthermore, studies that perform a cross-national comparison are typically based on aggregate data, and as a result, compositional differences between countries - in terms of for instance education or wealth - are not taken into account (Aleksynska \& Algan, 2010; Janoski, 2010; Reichel, 2011). Limited individual-level research on the impact of institutional conditions shows that policy indeed matters in the European context, as more restrictive citizenship policies deter citizenship acquisition (Dronkers \& Vink, 2012; Vink et al., 2013; Reichel \& Perchinig, 2015). However, these studies are based on cross-sectional data, and a deeper understanding of the relevance of policy requires a longitudinal analysis of citizenship acquisition under transforming institutional conditions.

In this chapter we look at the case of the Netherlands, where the introduction of a naturalisation test in 2003 significantly restricted the conditions under which immigrants could naturalise. We use longitudinal, individual-level data from Statistics Netherlands to analyse determinants of citizenship acquisition of almost all registered first generation immigrants in the Netherlands. These high-quality population register data offer unique opportunities for a dynamic analysis of naturalisation rates of different migration cohorts under varying institutional conditions. The chapter is structured as follows: first, we present an overview of the literature on citizenship acquisition, and introduce the theoretical framework and hypotheses. We then provide a description of the Dutch context in terms of citizenship legislation, and more specifically the amendment of the Dutch Nationality Act on April 1, 2003. Next, we detail the dataset and operationalisation of our theoretical concepts. Subsequently, results from the analyses are presented, starting with personal and contextual 
determinants of naturalisation, before addressing the impact of citizenship policy. We conclude by considering the implications and limitations of this contribution.

\section{THEORETICAL FRAMEWORK AND HYPOTHESES}

Traditionally, research on citizenship acquisition has predominantly focused on immigrants' demographic characteristics and socio-economic achievement in the destination country, both as indicators of socio-cultural integration and as predictors of naturalisation (e.g. Portes \& Curtis, 1987). However, following the line of argument that naturalisation is the result of successful integration implies a process of inevitability that defeats any notion of choice on the part of immigrants, and cannot explain why highly integrated immigrants would not naturalise. Indeed, in his seminal work on citizenship acquisition, Yang (1994) argues for the importance of rational calculation in the consideration to naturalise. His suggestion is the introduction of a cost-benefit model of subjective utility maximisation, which forms the basis of the contemporary theoretical framework on citizenship acquisition. Benefits comprise political and socio-economic rights and privileges, while costs include the effort spent in an application process that can prove quite long and strenuous, the potential loss of the former nationality and the rights it offered, and increased citizen obligations in the host country.

The literature has identified a number of determinants that condition these perceptions of utility, chief among them the economic and political situation in the country of origin (e.g. Bueker, 2005; Chiswick \& Miller, 2009; Jasso \& Rosenzweig, 1986; Logan et al., 2012). A lack of economic freedom, political security and low standards of living in the country of origin may discourage migrants to return. In this regard, citizenship of the host country offers security by providing unrestricted access to its territory. In other words, the potential benefits of citizenship are much greater for migrants from less developed or politically unstable countries because the rights and privileges associated with citizenship acquisition are particularly relevant to their situation. In contrast, migrants from the European Union (EU) will be less inclined to acquire citizenship of another EU country, since the added benefit is comparatively small. Indeed, a large portion of the variation in naturalisation rates between migrant groups is explained by origin characteristics (Chiswick \& Miller, 2009; Devoretz \& Pivnenko, 2008; Dronkers \& Vink, 2012; Helgertz \& Bevelander, 2016; Logan et al., 2012; Vink et al., 2013).

Additionally, the relevance of immigrants' country of origin also relates to the ability to maintain one's original citizenship upon acquiring another (Bloemraad, 2004; JonesCorrea, 2001; Mazzolari, 2009). In many countries, citizenship policies dictate that the voluntary acquisition of a new citizenship automatically results in the loss of the former. Furthermore, citizenship policies in the country of destination may require immigrants to renounce their original citizenship to be eligible for naturalisation. In these cases, 
naturalisation has relatively severe implications, such as a more permanent disconnection from one's relatives or origin country. A cost-benefit model would thus predict the toleration of dual citizenship to increase the propensity to naturalise, although empirical findings regarding the impact of dual citizenship toleration are ambiguous (Dronkers \& Vink, 2012; Logan et al., 2012; Mazzolari, 2009; Scott, 2008; Yang, 1994).

Although the origin context is an important determinant of citizenship acquisition, there still exist substantial differences in naturalisation rates within groups of migrants from similar countries. In the context of a cost-benefit model, the utility of citizenship depends partly on one's personal life situation. In this regard, age, years of residence, marital status, having children and education have all been shown to influence the propensity to naturalise in various national contexts, by conditioning the perceived value and meaning of citizenship (Bevelander \& Veenman, 2008; Chiswick \& Miller, 2009; Devoretz \& Pivnenko, 2008; Dronkers \& Vink, 2012). Furthermore, when assessing the potential utility of citizenship, it is important to consider the broader social context in which immigrant lives are embedded. From a life course perspective, individuals do not exist independently but are interconnected through a network of social relations (Elder, 1994). In this context of linked lives, the relevance and potential impact of citizenship is bound in a mutually shared context with others, such as one's partner (Wingens et al., 2011). Therefore, if a migrant has a native or naturalised partner, who already has a substantial interest in staying in the destination country, either by being born there, or by having invested in meeting the requirements for naturalisation, this will likely play an important part in the consideration to invest in a long-term settlement in the destination country through naturalisation (Helgertz \& Bevelander, 2016). As such, motives for naturalisation can also be intergenerational in nature. Migrants with young children may want to maintain a stable life situation for their children to grow up in, and are thus less likely to emigrate in the foreseeable future (Portes \& Curtis, 1987; Yang, 1994). Furthermore, naturalisation can promote opportunities for upward social mobility in countries where children naturalise in conjunction with their parents (Saurer \& Felfe, 2014; Street, 2014). Yet, there is still limited systematic attention in the literature for this social aspect of the decision-making process. Most research assumes that individuals arrive at conclusions independently, a shortcoming coined 'methodological individualism' by Joseph Schumpeter (see von Hayek [1943] for an elaborate discussion). However, given the fact that citizenship acquisition implies costs and effort and can be a life changing event, it can be argued that third parties who play a major role in an individuals' life factor into the decision-making process.

Until recently, the relevance of the destination context has enjoyed limited systematic attention beyond the toleration of dual citizenship. Citizenship policies in the destination country provide a legal framework conditioning who is de facto eligible for naturalisation. These conditions usually refer to a minimal period of uninterrupted legal residence, but may also include the successful completion of a language- or integration requirement, as well as financial costs. The exact requirements depend on the destination country in 
question, and can vary significantly, especially across European countries (Vink \& de Groot, 2010). In the context of a cost-benefit model, one can expect that in countries where citizenship policy is more restrictive, migrants will be less likely to naturalise. In this regard, individual-level research on citizenship policies shows that liberal policies increase the odds of naturalisation, while restrictive policies indeed produce the opposite effect (Bauböck et al., 2013; Bloemraad, 2002; Dronkers \& Vink, 2012; Reichel \& Perchinig, 2015; Vink et al., 2013). Our hypothesis reads: after a restriction of the citizenship law, immigrants are less likely to acquire destination country citizenship.

However, the impact of citizenship policies depends on the extent in which these institutional conditions are relevant and influential obstacles to naturalisation in the first place, which will not be equal among immigrants. As mentioned, the underlying motivation to naturalise is quite different among immigrants depending on for instance their country of origin. To reiterate: migrants from less developed or politically unstable countries naturalise quickly and often because citizenship acquisition provides crucial political and socio-economic privileges that are particularly relevant to their situation (Bevelander \& Veenman, 2008; Chiswick \& Miller, 2009; Vink et al., 2013). Therefore, it is likely that constraints to citizenship acquisition for these migrants will be predominantly institutional in nature, and that transforming opportunity structures due to changes in citizenship law will particularly affect their decision to naturalise. In other words, migrants for whom citizenship acquisition is an important step in their life course, and who are thus highly motivated to naturalise, are principally affected by the institutional conditions that stipulate its availability, since these represent the most significant - if not only - obstacle to naturalisation. In contrast, migrants from more developed countries have many reasons not to naturalise - only one of which are restrictive policies - and enjoy more liberty to simply be indifferent about naturalisation. Also, migrants from less developed countries may, due to a lack of resources in terms of education or wealth, find it increasingly difficult to successfully complete all the necessary requirements for eligibility as citizenship policies become more complex and demanding. Thus, these migrants are particularly dependent on policies that make naturalisation a realistic proposition or not. This implies the following interaction hypothesis: the negative effect of a restriction of the citizenship law is stronger for immigrants from less developed countries of origin.

\section{CONTEXT}

The first citizenship policy in the Netherlands - the Dutch Nationality Act - came into force on January 1, 1985, and was implemented with the aim of improving the legal position of immigrants through naturalisation, thus facilitating their societal integration (van Oers, 2014). Under this legislation, immigrants were eligible for citizenship acquisition when at least 18 years of age, residing legally in the Netherlands for an 
uninterrupted period of 5 years (three if married to a Dutch national), and having made an attempt at renouncing his or her original citizenship. Also migrants should not pose a threat to national security (i.e. have no criminal record), have a basic knowledge of the Dutch language and generally be accepted into Dutch society. The final two requirements would be demonstrated through a short interview, in which a municipal official appraised the abilities of the applicant by way of a short conversation. Although there were general guidelines, the integration interview was not standardised, and therefore subject to the interpretation of the municipal official in question. As a result, the examination was in practice lenient on certain groups, such as women or the elderly, and only a small number of applicants were refused on the basis of insufficient capabilities demonstrated during the interview. Furthermore, the interview was not meant to test the successful completion of the integration process, but rather to assess a general progression towards that goal. Migrants who were able to have a simple conversation in Dutch about everyday life, and had some social contact with natives, would fulfil the language and integration requirement. In general, the requirements for naturalisation under the Dutch Nationality Act of 1985 reflect the notion that citizenship acquisition was an important part of the integration process.

This policy appeared to be successful in the sense that the number of naturalisations rose considerably after its implementation (van Oers, 2014; van Oers et al., 2013). Nevertheless, in 1997 and 1998, steps were taken towards a more restrictive citizenship policy, with the re-instalment of the renunciation requirement in 1997 (since dual citizenship had been tolerated from 1991 onwards), and the call for a more demanding examination of language capabilities and levels of integration. This resulted in the revised Dutch Nationality Act, which was implemented on April 1, 2003. The most notable difference between the Dutch Nationality Act of 1985 and 2003 was the formalisation of the integration interview into a so-called 'naturalisation test'. As part of the naturalisation test, knowledge about Dutch society and writing skills were required as well as oral capabilities. Training courses are rather expensive, varying from a few hundred to over 2,000 euro. Furthermore, whereas the integration interview was free of charge, the naturalisation test would cost 260 euros (more if re-examination was required). As such, it can be stated that Dutch citizenship policy became more restrictive after April 1, 2003. However, it should be noted that this policy change was implemented under the notion that the former, relatively liberal approach to immigrant integration had failed. The stricter requirements for naturalisation were thus meant to eventually improve immigrants' integration into Dutch society, not exclude particular migrant groups from the opportunity to become Dutch citizens. Nevertheless, official figures from Statistics Netherlands show that the number of naturalisations decreased substantially after the introduction of the revised Dutch Nationality Act in 2003, from 42,000 in 2002, to 25,000 in 2003 and 21,000 in 2004. However, no systematic research has been done to assess the extent in which this policy amendment actually caused the number of naturalisations to decline, and if so, which migrant groups were principally affected. 


\section{DATA AND OPERATIONALIZATION}

We analyse citizenship acquisition in the Netherlands using register data on first generation immigrants between 1995 and 2011. Specifically constituted by Statistics Netherlands for this research, this dataset is based on municipal population registers, and complemented by data from the Dutch System of Social Statistical Datasets. Conjointly, it contains information on immigration, citizenship, demography, and other relevant personal and contextual characteristics of almost all registered first generation immigrants in the Netherlands over time. We keep track of individuals per day from the moment they become eligible for citizenship acquisition until their potential moment of naturalisation, emigration, or the final point in the dataset (January 1, 2012). Since, as mentioned above, eligibility differs between migrants (normally after 5 years of residence, but 3 years for migrants with a Dutch partner), the moment at which an individual enters the dataset is subject to this criteria.

The analysis focusses on immigrants who migrated to the Netherlands between 1995 and 2002. In light of the residence requirement, the vast majority of these migrants were not eligible for citizenship acquisition prior to the first year of observation (1998). In order to follow migrants for a substantial period of time, and given the fact that the dataset only provides information until 2012, we decided to exclude migrant cohorts after 2002. To ensure that later cohorts do not suffer disproportionately from right-truncation due to a shorter tracking period, we fix the period of observation to a maximum of 10 years for all cohorts.

We define an individuals' country of origin by birth. Only immigrants of whom both parents were born abroad are included, since immigrants of whom one parent was born in the Netherlands are expected to be similar to natives. Consequently, they could be positively selected in terms of skills and resources relevant to citizenship acquisition. Furthermore, we exclude all migrants born in Suriname before 1975 or in the Netherlands Antilles, since they are often Dutch citizens by birth. To prevent any further cases of potential citizenship acquisition by different means than the explicit decision to naturalise, we exclude all immigrants who naturalise before the age of 18 .

We focus on first generation immigrants for two reasons: second and further generation immigrants can attain citizenship by descent. However, this study is interested in the explicit decision to naturalise. Also, this decision is thought to be fundamentally different for second or further generation immigrants, since citizenship acquisition indicators differ between generations (Bauböck et al., 2013; Dronkers \& Vink, 2012).

The dependent variable in this research is citizenship of the destination country, which is a dichotomous variable that measures whether a migrant has acquired Dutch citizenship. The independent variables can be classified as either personal or contextual characteristics. Personal variables include gender, age, the citizenship status of the partner, having young children and the level of education. The age of migrants is determined at the moment of migration. With regard to the partner, we distinguish 
between migrants with no partner, a native partner, a foreign-born Dutch partner (a naturalised migrant), and a foreign-born foreign partner (a non-naturalised migrant). We measure the impact of the naturalisation of the partner over time by including a specific category for the year in which the partner acquires Dutch citizenship, the subsequent 3 years, and a final category for all the following years.

We define children as young until the age of 18 , because until then, they can acquire citizenship through their parents. Furthermore, we only classify migrants as having young children when these children are actually part of the household, in which case they are presumed to be an important and influential part of their parents' lives.

Unfortunately, information on the educational level of immigrants, especially of the first generation, is limited mostly to survey data in the Netherlands. Using information from various surveys, as well as the incomplete educational register, we were able to ascertain the educational level of about 44,000 individuals from migrant cohort 2000 onwards.

Contextual variables relate to characteristics of the country of origin. We include measurements for the countries' level of development, political stability, toleration of dual citizenship and membership of the EU, and keep track of changes in these characteristics per year. Given that for a number of smaller origin countries, the dataset only includes a very limited number of migrants, we aim to capture variation at the origin country level by including general characteristics of these countries. While we do not exclude that there may be additional variation at the level of individual origin countries, on the basis of the literature we assume that these characteristics capture most of the relevant origin country variation (Chiswick \& Miller, 2009; Helgertz \& Bevelander, 2016; Jasso \& Rosenzweig, 1986; Logan et al., 2012; Vink et al., 2013; Yang, 1994). The level of development of a country is measured using the Human Development Index (HDI), which is based on gross domestic product, as well as indicators for life expectancy and educational levels. The index provides a scale ranging from 0 to 1 , where a higher score indicates a higher level of development. Although gross domestic product is often used to measure a country's economic condition, we argue that the HDI draws a more comprehensive, multidimensional picture. Political stability is measured using the Kaufmann Index (Kaufmann, Kraay, \& Mastruzzi, 2011), indicating the probability that a government will be overthrown in the foreseeable future by unconstitutional or violent means. Similar to the HDI, the Kaufmann index is a continuous scale, ranging from approximately -2.5 to 2.5 , where a higher score equals more stability. We also use the Global Dual Citizenship database (Vink, de Groot, \& Luk, 2015), which provides information on the possibility of holding dual citizenship for nearly all origin countries between 1960 and 2015. It should be noted that migrants from countries that tolerate dual citizenship are normally required in the Netherlands to renounce their original citizenship when naturalising. However, Dutch citizenship law includes a large number of exceptions to this rule and as such, dual citizenship is still possible for many migrants who wish to attain Dutch citizenship. Hence this variable distinguishes between migrants whose origin country citizenship policy either allows for dual citizenship, or not, but does not determine whether individuals will hold dual citizenship after naturalisation, 
given that this depends on a complex set of rules and the specific situation of immigrants. All of the above variables have been included in the analysis after checking for potential multicollinearity, which is well within acceptable parameters (VIF < 2.0) (O'brien, 2007).

Table A1 contains descriptive statistics for migrants who naturalise and those who do not, revealing a familiar and expected pattern. Values are shown for the final measurement of each individual (i.e. at the moment of naturalisation, when emigrating from the Netherlands, or at the end of 2011). 33\% of female migrants are naturalised, which is more often than male immigrants, of which $29 \%$ is naturalised. Furthermore, naturalised migrants are generally younger. Migrants with a native Dutch partner are naturalised about twice as often as migrants with a foreign partner or no partner. However, during the year in which the foreign partner naturalises, 91\% acquires Dutch citizenship as well. In the following years, this gradually declines to slightly above the level of migrants with a native Dutch partner. Furthermore, having children matters; $36 \%$ of migrants with young children are naturalised, compared to $26 \%$ amongst those with no children. The country of origin of naturalised migrants is characterised by a low level of development and stability, and a tolerance for dual citizenship. Also, migrants originating from outside the EU are naturalised considerably more often than their counterparts ( $40 \%$ compared to $5 \%$ ). Note that the number of individuals per quartile is not exactly equal, since migrants with the same country of origin share equal values on the HDI and Kaufmann index, and thus produce a slight overflow across the quartile points. Finally, migrants from later cohorts naturalise less often, ranging from $34 \%$ for migrant cohort 1995 to $28 \%$ for migrant cohort 2002. These findings generally correspond to our theoretical expectations, where migrants make a rational decision to naturalise based on perceived utility in light of personal and contextual conditions. To analyse these data in further detail, we use Cox proportional hazards regression with time dependent covariates (Cox, 1972).

\section{ANALYSIS}

\section{Origin and personal characteristics}

Table 1 shows the results of the regression analysis, providing hazard ratios associated with the covariates on the risk of naturalisation. Note that the size of the effect should always be interpreted in light of the measurement of the covariate in question. Starting with personal characteristics in Model 1, the analysis shows that migrants who immigrate at an older age are less likely to naturalise (a decrease of about $2 \%$ per year of age). This corresponds to the notion that the period of time in which one may enjoy the benefits associated with citizenship acquisition becomes shorter when one migrates at a later stage in the life course, up to a point where migrants may feel it no longer weighs up to the necessary effort to acquire it. 
Table 1. Cox proportional hazards regression on the risk of naturalisation, cohorts 1995-2002.

\begin{tabular}{|c|c|c|c|c|c|c|}
\hline & \multicolumn{3}{|c|}{ Model 1} & \multicolumn{3}{|c|}{ Model 2} \\
\hline & Coef. & Exp. coef. & Std. error & Coef. & Exp. coef. & Std. error \\
\hline \multicolumn{7}{|l|}{ Gender } \\
\hline Male & 0.016 & 1.016 & 0.008 & 0.013 & 1.014 & 0.008 \\
\hline Female & ref. & ref. & ref. & ref. & ref. & ref. \\
\hline Age at migration & -0.016 & $0.984^{* * *}$ & 0.001 & -0.016 & $0.984^{* * *}$ & 0.001 \\
\hline \multicolumn{7}{|l|}{ Partner } \\
\hline No partner & ref. & ref. & ref. & ref. & ref. & ref. \\
\hline Native Dutch partner & 0.526 & $1.692 * * *$ & 0.013 & 0.504 & $1.656 * * *$ & 0.013 \\
\hline Foreign born foreign partner & -0.272 & $0.762 * * *$ & 0.013 & -0.288 & $0.750 * * *$ & 0.013 \\
\hline Year naturalisation partner & 2.200 & $9.024^{* * *}$ & 0.015 & 2.175 & $8.803^{* * *}$ & 0.015 \\
\hline 1 year after naturalisation partner & 0.878 & $2.407 * * *$ & 0.030 & 0.862 & $2.368 * * *$ & 0.030 \\
\hline 2 years after naturalisation partner & 0.620 & $1.858^{* * *}$ & 0.035 & 0.592 & $1.807 * * *$ & 0.035 \\
\hline 3 years after naturalisation partner & 0.359 & $1.432 * * *$ & 0.035 & 0.311 & $1.365^{* * *}$ & 0.036 \\
\hline$>3$ years after naturalisation partner & -0.161 & $0.852^{* * *}$ & 0.014 & -0.132 & $0.876 * * *$ & 0.014 \\
\hline \multicolumn{7}{|l|}{ Children $<18$ in household } \\
\hline Yes & ref. & ref. & ref. & ref. & ref. & ref. \\
\hline No & 0.002 & 1.002 & 0.009 & 0.013 & 1.013 & 0.009 \\
\hline \multicolumn{7}{|l|}{ Dual nationality } \\
\hline No automatic loss & ref. & ref. & ref. & ref. & ref. & ref. \\
\hline Automatic loss & -0.020 & $0.980^{*}$ & 0.009 & -0.032 & $0.968 * * *$ & 0.009 \\
\hline Development country of origin & -1.525 & $0.218 * * *$ & 0.032 & -1.438 & $0.237 * * *$ & 0.032 \\
\hline Stability country of origin & -0.205 & $0.814^{* * *}$ & 0.005 & -0.232 & $0.793 * * *$ & 0.005 \\
\hline \multicolumn{7}{|l|}{ EU } \\
\hline Yes & -1.632 & $0.196 * * *$ & 0.021 & -1.639 & $0.194 * * *$ & 0.021 \\
\hline No & ref. & ref. & ref. & ref. & ref. & ref. \\
\hline \multicolumn{7}{|l|}{ Migrant cohort } \\
\hline Cohort 1995 & & & & ref. & ref. & ref. \\
\hline Cohort 1996 & & & & -0.001 & 0.999 & 0.016 \\
\hline Cohort 1997 & & & & -0.065 & $0.937 * * *$ & 0.016 \\
\hline Cohort 1998 & & & & -0.301 & $0.740 * * *$ & 0.016 \\
\hline Cohort 1999 & & & & -0.297 & $0.743 * * *$ & 0.016 \\
\hline Cohort 2000 & & & & -0.403 & $0.668 * * *$ & 0.016 \\
\hline Cohort 2001 & & & & -0.451 & $0.637 * * *$ & 0.016 \\
\hline Cohort 2002 & & & & -0.429 & $0.651^{* * *}$ & 0.016 \\
\hline$* * *: p<0.001$ & \multicolumn{3}{|c|}{$N=231,122$} & \multicolumn{3}{|c|}{$N=231,122$} \\
\hline \multirow[t]{2}{*}{$*: p<0.05$} & \multicolumn{3}{|c|}{ Events $=72,098$} & \multicolumn{3}{|c|}{ Events $=72,098$} \\
\hline & \multicolumn{3}{|c|}{ Observations $=1,152,036$} & \multicolumn{3}{|c|}{ Observations $=1,152,036$} \\
\hline Source: Statistics Netherlands. & \multicolumn{3}{|c|}{ Logrank = 99,559 $(p<0.00001)$} & \multicolumn{3}{|c|}{ Logrank = 101,743 $(p<0.00001)$} \\
\hline
\end{tabular}

The results also show that migrants with a native or foreign-born Dutch partner are more likely to naturalise themselves compared to migrants with no partner. Most interesting is the temporal dynamic for migrants with a foreign-born Dutch partner. In the year in which the partner acquires Dutch citizenship, migrants are more than nine times as likely to naturalise as well compared to those with no partner, all else constant. 
In subsequent years, this effect gradually declines, but remains significant for at least three more years. These results support the notion that the decision to naturalise is not just made individually, but at least partly at the family level. Since a Dutch partner already has a strong interest in staying in the country of destination, emigrating from the Netherlands is not done as lightly. If a migrant is likely to remain in the Netherlands for an extended period of time, then acquiring Dutch citizenship to enjoy similar rights to natives becomes interesting and lucrative.

Migrants with a foreign-born foreign partner are about $24 \%$ less likely to naturalise compared to migrants with no partner. If the decision to naturalise is partly made at the family level, one can assume that this can have both a positive or negative impact. Whilst in families in which the partner naturalises there apparently exists the (shared) notion that citizenship acquisition is valuable, in families where the partner does not naturalise, this is for some reason not the case. In that sense, migrants with no partner have more options, since their propensity to naturalise is influenced neither positively nor negatively by a partner's life situation and ambitions for the future. Generally, these results support findings in the Swedish context on the relevance of the partner (Helgertz \& Bevelander, 2016).

Contrary to our expectation, having young children is not significantly associated with the propensity to naturalise, even though the bivariate analysis showed that migrants with young children are naturalised more often. Further analyses show that migrants with children are overrepresented in all categories of the other personal and contextual characteristics that are positively associated with citizenship acquisition. In general, migrants with children are younger at the moment of migration and often have a Dutch partner. Also, they generally originate from less developed, politically less stable and non-EU countries of origin, and policies in their origin countries often allow them to retain their original citizenship when acquiring another. As such, having children has no additive effect on the propensity to naturalise.

Turning from personal to contextual characteristics in Model 1, we observe a significant impact of both the level of development and political stability of the country of origin. As expected, the relationship is negative, where a higher level of development or stability decreases the chance of naturalisation. Migrants from less developed or politically unstable countries will be more inclined to naturalise in order to secure their legal right to stay in the country of destination, and obtain a formal guarantee not to be sent back to their country of origin in the future. In contrast, migrants from more developed countries might consider eventually returning to their origin country. Furthermore, migrants from countries that do not allow for dual citizenship status are $2 \%$ less likely to acquire citizenship of the destination country, indicating that the renunciation requirement is considered an obstacle to naturalisation. Finally, migrants from the EU are more than $80 \%$ less likely to naturalise, all else constant. 
The impact of citizenship policy

Some of the above characteristics have so far received limited systematic attention most notably the relevance of the partner - but the majority of the personal and contextual characteristics are widely accepted in the literature. However, where most research stops here, we argue that it is crucial to go one step further and address the relevance of the destination context. To that end, we investigate the impact of citizenship policy in the Netherlands, and more specifically the impact of the revision of the Dutch Nationality Act on April 1, 2003, which introduced a formal naturalisation test as a requirement for citizenship acquisition. To analyse the relationship between citizenship policy and naturalisation, we divide the population of our dataset into three groups, namely migrant cohorts 1995-1997, cohorts 1998-1999 and cohorts 20002002. Given the fact that migrants are eligible for naturalisation after 5 years of uninterrupted residence, and 3 years for migrants with a Dutch partner, the first cohort group (1995-1997) would have been able to naturalise prior to the policy change in 2003. However, for cohort group 1998-1999, only migrants who immigrated early in 1998, or those with a Dutch partner would have been eligible for naturalisation under the more liberal Dutch Nationality Act of 1985. Migrants who came to the Netherlands after April 1, 1998 and who had no Dutch partner would have been forced to successfully complete the naturalisation test (and pay the associated financial costs) in order to acquire Dutch citizenship. Finally, almost all migrants from the final cohort group (2000-2002) became eligible for naturalisation after the policy change in 2003. As such, these three cohort groups represent the transition from the relatively liberal to the more restrictive citizenship legislation.

Naturalisation among these cohort groups is compared using Kaplan Meier analyses. The associated survival curves, which indicate the cumulative naturalisation over time, are illustrated in Figure 3. The proportion of non-naturalised immigrants after 10 years of residence (520 weeks) is lowest for migrants from cohort group 1995-1997 (42\%), who were able to naturalise under the old citizenship policy, and highest for migrants from cohort group 2000-2002 (58\%), who were almost exclusively forced to naturalise under the more restrictive legislation. As expected, cohort group 1998-1999 occupies a position between the other groups. Interestingly the survival curves for cohort group 1995-1997 and 1998-1999 are almost identical during the first 5 years of residence (260 weeks), and subsequently diverge. This coincides with the moment in which the policy change was implemented for migrant cohort 1998-1999. These findings provide general support for the notion that citizenship policy indeed matters, and that migrants were less likely to naturalise under the more restrictive institutional conditions stipulated by the revised Dutch Nationality Act of 2003. 


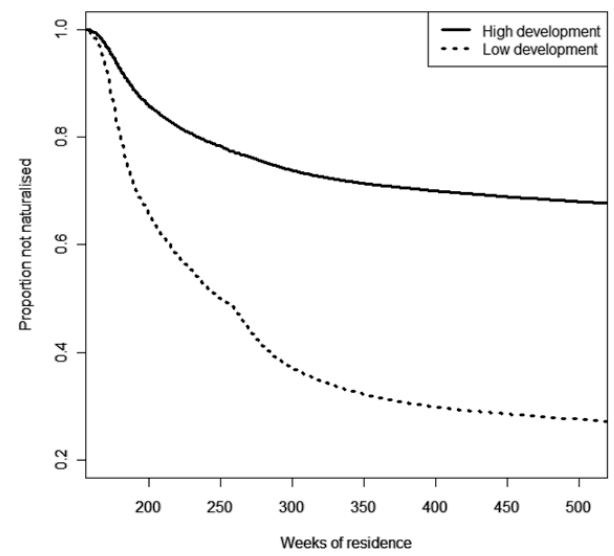

Figure 2a. Cumulative naturalisation migrant cohort 1995-1997 by level of development origin country.

Source: Statistics Netherlands.

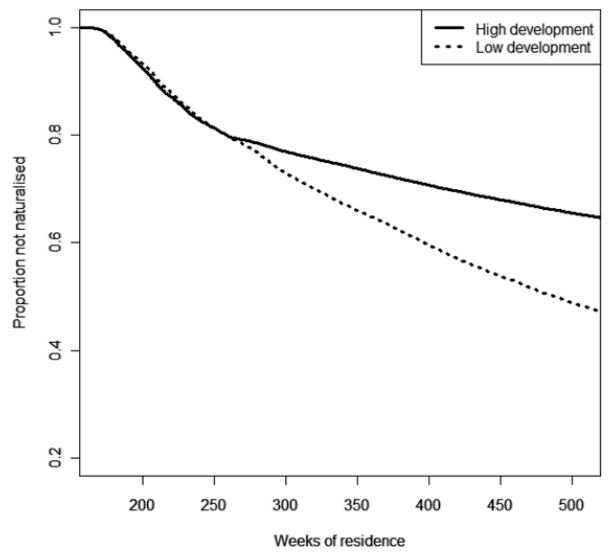

Figure 2b. Cumulative naturalisation migrant cohort 2000-2002 by level of development origin country.

Source: Statistics Netherlands.

Although the survival curves illustrate the cumulative naturalisation of the cohort groups in general, they do not account for potential differences in composition between migrants from these cohort groups. As such, the differences between the survival curves in Figure 3 may be due to variation in terms of personal and contextual characteristics, rather than differences in the institutional context. To account for this potential ecological fallacy, we incorporate the separate migrant cohorts into the regression model. The results are shown in Table 1, Model 2, and confirm the findings from the Kaplan Meier analyses. There is no statistical difference between migrants who came to the Netherlands in 1995, and those who immigrated in 1996. Although migrants from cohort 1997 are about 6\% less likely to naturalise, they are comparatively similar to the cohorts 1995 and 1996. These are migrants who were able to naturalise before the policy change in 2003. The subsequent cohort groups are less likely to naturalise than cohorts 1995-1997, all else constant, where the impact is stronger for cohorts 2000-2002, who are about 35\% less likely to naturalise, than for cohorts 19981999 , for whom the propensity to naturalise is approximately $26 \%$ lower. These findings are robust when controlling for right-truncation, which is slightly more prevalent among migrants from high developed and stable countries of origin. This confirms that the effect shown in Figure 3 is not solely due to compositional differences between the cohort groups, at least as far as our covariates are concerned. 


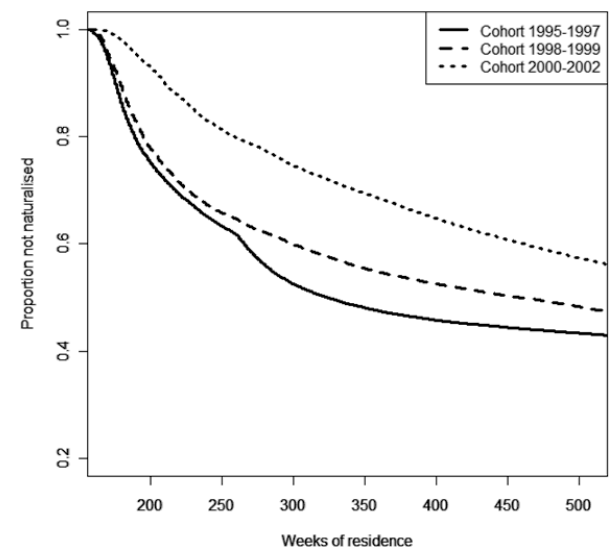

Figure 3. Cumulative naturalisation by migrant cohorts. Source: Statistics Netherlands.

However, the question is not just if policy matters, but crucially to whom it matters? We hypothesise that the transition towards a more restrictive citizenship policy particularly affects migrants from less developed countries, who are highly motivated to naturalise because the benefits associated with citizenship acquisition are particularly relevant to their situation. This hypothesis is confirmed cross-nationally in the European context (Vink et al., 2013), but has so far not been analysed longitudinally. To that end, we split the outer cohort groups (1995-1997 and 2000-2002) by level of development. Migrants are categorised along the mean of development per cohort group. We expect that, although the later cohort group is in general less likely to naturalise compared to the earlier cohort group, this effect is largely driven by migrants from less developed countries.

Figure $2 \mathrm{a}$ and Figure $2 \mathrm{~b}$ show the survival curves of both cohort groups by level of development. In Figure 2a, we see that migrants from cohort group 1995-1997, and who originate from less developed countries, naturalise much more quickly than their counterparts from high developed countries. Whereas almost $70 \%$ of migrants from high developed countries is not naturalised after 10 years of residence, this is $30 \%$ for migrants from less developed countries after the same period of time. However, when comparing the survival curves of migrants from high and low developed countries for the cohort group 2000-2002 (Figure 2b) the difference is much smaller. Especially during the first 5 years of residence, the curves are almost identical. After 10 years of residence, about $50 \%$ of migrants from less developed countries are not naturalised. In contrast, there is hardly any difference for migrants from high developed countries between the cohort groups. As such, these findings confirm the notion that the policy change primarily affected migrants from less developed countries. Naturalisation was principally delayed for these migrants, which is apparent in the continuous decline of the survival curve in Figure $2 \mathrm{~b}$. It is likely that additional time was needed to accumulate 
the necessary skills, knowledge and financial means for naturalisation, which increased compared to the more liberal institutional context before 2003. However, to a certain extent, migrants were demotivated to naturalise altogether, as Figure $2 \mathrm{a}$ and Figure $2 \mathrm{~b}$ show that the survival curves for the cohort groups differ for migrants from low developed countries, even after 10 years of residence.

In general, three main conclusions can be derived from this analysis of the impact of citizenship policy. First, citizenship policy matters; migrants are less likely to naturalise under a more restrictive citizenship policy. These findings remain robust when keeping personal and contextual characteristics constant. Second, the impact of citizenship policy is not equal among immigrant groups. The difference between migrants who could naturalise under relatively liberal conditions and those who could not is exclusively driven by migrants from less developed countries. Third, the transition towards a more restrictive citizenship policy drives migrants to postpone, and in some cases put off naturalisation altogether.

\section{ROBUSTNESS ANALYSES}

In this final paragraph, we perform a number of robustness analyses to assess the stability of our findings. First, Figure $2 a$ and Figure $2 b$ reveal that the impact of citizenship policy is conditioned by the level of development of the origin country. However, the Kaplan Meier analyses do not control for compositional differences between these migrant groups and as such, the findings from Figure $2 a$ and Figure $2 b$ are not necessarily the product of differences in the institutional context. Therefore, we perform a separate regression analysis for migrants from low and high developed countries to control for personal and contextual characteristics. This has the added benefit that it provides insight into potential variation in the relevance of these characteristics between the migrant groups. Table A2 reveals a familiar pattern for migrants from less developed countries; migrants from cohorts 1998-1999 are about 20\% less likely to naturalise compared to migrants from cohorts 1995-1997, all else constant. This discrepancy is increased to about 35\% for cohorts 2000-2002. Note that migrants from cohorts 1995 and 1996 no longer statistically differ from those who immigrated in 1997. However, the pattern is strongly reversed for migrants from high developed countries, as shown in Table A3. Migrant cohorts 1996-1999 are approximately $15 \%$ less likely to naturalise compared to cohort 1995, all else constant, while cohorts 2000-2002 are about 10\% more likely to naturalise. These findings strongly relate to the survival curves from Figure $2 a$ and Figure $2 b$, where migrants from less developed countries are less likely to naturalise under the more restrictive citizenship policy, while migrants from high developed countries are hardly affected in their propensity to naturalise under the same conditions. Overall, it can be concluded that the findings from Figure $2 a$ and Figure $2 b$ cannot be solely attributed to 
compositional differences between these migrant groups in terms of included personal and contextual characteristics.

Furthermore, the separate regression analyses reveal that for migrants from less developed countries, male immigrants are almost $20 \%$ more likely to naturalise than female immigrants. This effect is reversed for migrants from high developed countries, where males are 37\% less likely to naturalise. Also, whereas having children has no additive effect on the propensity to naturalise of migrants from less developed countries, migrants from high developed countries without children are about $7 \%$ less likely to naturalise. The impact of dual citizenship also differs between these migrant groups: whereas automatic loss of the original nationality results in a decreased propensity to naturalise of about $6 \%$ for migrants from less developed countries, the same condition increases the propensity to naturalise for migrants from high developed countries by $15 \%$. Subsequent bivariate analyses reveal that migrants from high developed countries who automatically lose their original citizenship when acquiring another, indeed naturalise more often than their counterparts, while this pattern is reversed for migrants from less developed countries. In general, these findings emphasise that both the relevance of personal and contextual characteristics need to be understood in the context of immigrant life courses - which are markedly different for migrants from high and low developed countries.

Second, we know from the literature that the educational level of immigrants is an important determinant of naturalisation, where low educated migrants are less likely to naturalise. Unfortunately, information on the level of education is only available for a subsample of migrants from cohorts 2000 onwards. Table A4 shows that the education subsample is compositionally similar to the main sample; migrants for whom the level of education is known are on average slightly younger when migrating to the Netherlands, and more often originate from outside the EU. Table A5 shows that the educational level of immigrants matters; middle and high educated migrants are $75 \%$ and $46 \%$ more likely to naturalise than those with low levels of education, all else constant. Crucially, controlling for education does not cancel the relevance of all other personal and contextual characteristics. As such, it seems that the level of education is indeed an important predictor of citizenship acquisition, but there is no reason to assume that the absence of education to the main analyses results in misleading or incomplete findings with regard to the characteristics included in this model.

Third, our results show a difference in the propensity to naturalise between migrants under the more liberal and restrictive institutional conditions. However, in light of the pending policy change, migrants may have decided to naturalise quickly prior to April 1, 2003, while the more liberal citizenship policy was still in effect. As such, differences in the propensity to naturalise between the migrant cohorts may be largely due to this 'rush into naturalisation', instead of the more restrictive institutional context after the policy change. Figure 3 seems to confirm this notion, given the slight offset in the survival curve of migrants from cohort group 1995-1997 after 5 years of residence. 
To account for this, we added a dummy for the year prior to the policy change (from April 1, 2002 until April 1, 2003) to the main model. Table A6 shows that migrants were about $37 \%$ more likely to naturalise in the year prior to the policy change, all else constant, suggesting that some migrants indeed anticipated the policy change, and decided to quickly naturalise under the more liberal conditions. However, the differences between the migrant cohorts remain, where the later cohorts are less likely to naturalise.

Finally, although our analysis reveals that migrants from less developed countries are particularly affected by a restrictive change in citizenship policy, we hypothesise that the reason for this is that these migrants are, for various reasons, particularly motivated to naturalise. As such, an increased residence requirement, the introduction of a naturalisation test, or an increase in financial costs will be principally considered an obstacle to citizenship acquisition for these migrant groups. Following this line of reasoning, the selective impact of citizenship policy should not just apply to migrants from less developed countries, but also to other migrant groups who are highly motivated to naturalise, such as migrants from politically unstable countries. Figure A1a and Figure A1b illustrate the survival curves for migrant cohorts 1995-1997 and 20002002, split by the level of political stability of the origin country. Migrants are aggregated into low and high stability countries along the mean per cohort group. Results reveal a pattern that is similar to the analysis by level of development; migrants from cohorts 1995-1997 are more likely to naturalise than those from cohorts 20002002. However, crucially, migrants from politically less stable countries are more affected by the policy change than those from stable countries of origin, as is apparent from the limited difference between the survival curves in the latter cohort group compared to the former. After 300 weeks (approximately 6 years) of residence, less than $40 \%$ of migrants from cohort group 1995-1997, who originate from less stable countries are not naturalised, compared to $70 \%$ after the same period for cohorts 2000-2002. Of migrants from cohort group 1995-1997, who originate from politically stable countries of origin, $65 \%$ is not naturalised after 300 weeks of residence, compared to about $80 \%$ for cohorts 2000-2002. Even after 10 years of residence (520 weeks), the difference between the survival curves of the cohort groups is twice as large for migrants from less stable countries, compared to those from more stable countries of origin. These findings confirm the notion that restrictive citizenship policies particularly affect migrants who are strongly motivated to naturalise. More generally, these results emphasise that not only economic, but also political characteristics of the country of origin are an important aspect in the decision to naturalise or not. 


\section{CONCLUSION}

In this chapter, we analysed determinants of citizenship acquisition in the Netherlands using register data from Statistics Netherlands. Neither a longitudinal research design, nor these unique register data, has so far been used in the Dutch context for naturalisation research. The analysis was divided into two parts: first we analysed the relevance of personal and contextual characteristics to the propensity to naturalise. Besides traditional characteristics, we put specific emphasis on social relations as a key element in the decision-making process. Results confirm earlier findings on prevalent characteristics in the literature, where the decision to naturalise is largely based on the perceived utility of citizenship acquisition in light of the country of origin and one's personal life situation. Migrants from less developed or politically unstable countries are more likely to naturalise, as are migrants who do not lose their original citizenship upon acquiring another, and those originating from outside the EU. Furthermore, migrants who are younger when immigrating to the Netherlands are more likely to naturalise. Our analysis also points towards the relevance of one's partner. Migrants with a Dutch partner (either native or naturalised) are more likely to naturalise than those with no partner. However, for migrants with a foreign-born foreign partner this relationship is reversed. Furthermore, migrants with a foreign-born Dutch partner particularly naturalise during the year in which the partner acquires Dutch citizenship. In subsequent years, the effect gradually declines, but remains positive for at least 3 years. These results point towards the risk of assuming that the utility of citizenship is evaluated in a social vacuum. Our analysis suggests that migrants who live together, and are an important part of each other's lives, also make important decisions together. Studies that ignore this social aspect of the decision-making process fail to do justice to the complexity of immigrant lives. Furthermore, marital status is not a viable substitute to measure this social dynamic, since the effect of the partner on the propensity to naturalise is not uniformly positive.

However, our most important findings refer to the second part of the analysis: the relevance of citizenship policy. More specifically, we focus on the revised Dutch Nationality Act of April 1, 2003, which introduced a naturalisation test and generally stipulated more restrictive conditions for citizenship acquisition. We compared migrant cohorts who were eligible for naturalisation prior to this policy amendment, and those who were forced to acquire Dutch citizenship under the more restrictive regulations. The conclusions of this analysis are twofold: first, we show that policy matters. Migrant cohorts who became eligible after the policy change, and thus faced more restrictive institutional conditions, naturalised less quickly and less often than those under the more liberal policy. In other words, it is important to account for the institutional context of the destination country, which provides a framework of rules and regulations determining who is able to naturalise under particular conditions. Clearly these requirements factor into the decision - or even the ability - to naturalise or not. 
Second, and most importantly, the impact of policy is not equal across migrant groups. Due to large differences in the underlying motivation to naturalise, migrants from less developed countries benefit from citizenship acquisition most, and are highly motivated to naturalise. As such, their ability to quickly naturalise depends strongly on the conditions set by citizenship policies, which make this a realistic proposition or not. Indeed, our analysis shows that migrants naturalise later and less often under more restrictive institutional conditions, especially those migrants from less developed and politically unstable countries of origin. These findings are consistent with earlier crossnational findings in the European context (Vink et al., 2015), but this is the first longitudinal analysis to confirm this relationship. Furthermore, the results are highly robust.

As such, citizenship policies of the destination context play an important role in immigrant naturalisation, yet few micro-level studies specifically address their respective contexts. More explicit theorisation and analyses on the relevance of the destination context may help explain empirical variation between countries that cannot be explained by personal and origin characteristics. Furthermore, our analysis of the relevance of education has, due to data-limitations, been addressed less than ideally. Further research is needed to assess the robustness of our findings in light of a better measurement of education, as well as other socio-economic characteristics (Reichel \& Perchinig, 2015).

Finally, these findings also raise important new questions for policy-makers. If indeed citizenship acquisition has the potential to facilitate and expedite the integration process, and citizenship policies stipulate the conditions under which citizenship acquisition is de facto possible, then restrictive citizenship policies may potentially hamper opportunities for full participation and integration of immigrants. Our analysis indeed shows that more restrictive citizenship policies demotivate migrants to naturalise. This is particularly the case for migrants who may find it difficult to meet the requirements for naturalisation due to a lack of resources and skills, namely those from less developed or politically unstable countries. These are also the very migrants who are in need of citizenship the most. The revision of the Dutch Nationality Act in 2003 was a direct response to the perceived failure of previous integration policies, and the implementation of civic integration requirements was part of a political agenda to improve immigrant integration. Yet, given our findings, one could question the success of these measures. After all, we find that migrants for whom citizenship acquisition is a potentially valuable asset to their integration were particularly deterred by the more restrictive citizenship policy. As such, it would seem that the consequence of the policy reform was not so much that integration of immigrants was facilitated or improved, but rather that Dutch citizenship became more exclusive. 


\section{Chapter}

\section{Anticipating the Citizenship Premium: Before and After Effects of Immigrant Naturalisation on Employment ${ }^{10}$}

${ }^{10}$ This chapter is published as: Peters, F., Vink, M., \& Schmeets, H. (2017). Anticipating the Citizenship Premium: Before and After Effects of Immigrant Naturalisation on Employment. Journal of Ethnic and Migration Studies. DOI: 10.1080/1369183X.2017.1367650. 



\section{INTRODUCTION}

Research consistently shows that migrants are at a disadvantage compared to natives in the labour market when it comes to return rates on their level of education and labour market experience (Heath \& Cheung, 2007; Lancee, 2012; van Tubergen et al., 2004). Policy-makers of receiving countries have a strong incentive to facilitate the quick and successful incorporation of immigrants into the labour market, both to ensure migrants' self-sufficiency and independence from welfare benefits, and to promote their opportunities for full participation and integration. In this regard, acquiring citizenship of the destination country can potentially facilitate the process of economic integration (OECD, 2011). This chapter analyses how and to what extent citizenship is relevant for the labour market integration of immigrants in terms of employment.

Many studies have found that there is a positive association between citizenship acquisition and labour market integration (e.g. Bakker, Dagevos, \& Engbersen, 2016; Fougère \& Safi, 2009; Helgertz et al., 2014; Steinhardt, 2012), yet the mechanisms through which citizenship affects economic integration remain unclear. The established theoretical framework focusses on how citizenship acquisition facilitates access to the labour market, reduces administrative costs in the hiring process and functions as a positive signalling device, but these mechanisms fail to explain substantial empirical ambiguity. Indeed, an examination of the literature reveals that (a) the positive economic impact of citizenship is not observed for all migrant groups or (b) in all countries and (c) the extent to which naturalisation has an effect differs per migrant group and national context, and in some cases is even observed to be negative (Bratsberg \& Raaum, 2011; Engdahl, 2011; Helgertz et al., 2014; Scott, 2008). This ambiguous picture has so far been predominantly attributed to the methodological challenge of an analysis of the economic consequences of naturalisation. Individuals who naturalise may differ from those who do not in terms of non-trivial characteristics such as motivation or ability, which are hard to measure and control for, thus introducing the risk of overestimating the relevance of citizenship (Bratsberg et al., 2002, pp. 581-582). However, even when accounting for this 'self-selection' bias using panel data, the contradictory findings persist, as some migrants enjoy a so-called citizenship premium, whereas others do not. As such, a substantial amount of literature suggests at least some effect of naturalisation, but there is still limited understanding in the literature as to why, when and for whom citizenship matters or not.

In this chapter, we go beyond the signalling argument, and argue that better labour market outcomes prior to the moment of naturalisation are not solely due to selfselection, but also reflect a human capital investment by immigrants in order to meet the requirements of naturalisation. Moreover, immigrants anticipate the rewards and opportunities that citizenship will offer in the future. As such, we expect the probability of employment to increase before, and not only after naturalisation, even when controlling for endogeneity in the naturalisation process. This 'anticipation effect' 
manifests prior to the moment of naturalisation because it reflects the outcome of the decision to naturalise rather than citizenship acquisition itself. To test this new theoretical approach, we initially follow the state-of-the-art empirical strategy as developed by Bratsberg et al. (2002), and subsequently adjust this strategy to analyse a potential anticipation effect in greater detail.

We use data from Dutch population registers and the Dutch System of Social Statistical Datasets, containing almost all registered first-generation immigrants in the Netherlands ( $N=94,320)$, which allows us to track and compare the citizenship status and labour market performance of these immigrants over time. The chapter is structured as follows: first, we briefly outline the Dutch context, followed by the theoretical framework and hypothesis. We continue by detailing the dataset, operationalisation and methodology. Subsequently, results from the analyses are presented, and finally we discuss the conclusions and implications of our findings.

\section{CONTEXT: IMMIGRATION AND CITIZENSHIP POLICY IN THE NETHERLANDS}

The number of foreign-born individuals migrating to the Netherlands has fluctuated over the last decades, from roughly 95,000 in 1998 and 71,000 in 2005 to 132,000 in 2011. Figures from Statistics Netherlands show that on January 2011, roughly $1,735,000$ foreignborn individuals resided in the Netherlands, constituting $10.4 \%$ of the entire population.

Under the conditions of the revised Dutch Nationality Act of April 2003, migrants are eligible for citizenship acquisition when at least 18 years of age, having a residence permit for an undefined period of time and residing legally in the Netherlands for an uninterrupted period of 5 years. If an individual is the registered partner of a Dutch national for three consecutive years, only a non-temporary residence permit and principal residence in the Netherlands is required. Furthermore, migrants should renounce their original citizenship (although numerous exceptions to the renunciation requirement exist) and not constitute a danger to public order (i.e. have no criminal record). Being employed before or at the moment of naturalisation is not a requirement for citizenship acquisition. Migrants do have to pass a language and integration requirement by successfully completing a formalised naturalisation test. To pass this test, migrants have to be able to read, write and speak Dutch at level A2 of the Common European Framework of Reference for Languages, and possess sufficient knowledge of the Dutch society. These requirements constitute a significant hurdle to naturalisation, particularly for migrants who are most interested to naturalise (see Chapter 3 for details). As such, citizenship acquisition is not simply an isolated and abrupt legal status transition, but rather a process that requires careful planning and preparation, starting the moment a migrant decides to naturalise in the future. In terms of formal benefits, Dutch citizenship provides a secure legal status and full voting rights, 
as well as access to a small number of professions that are restricted to non-citizens, namely jobs in the army and high-ranking positions in law and the public sector, such as judges and members of parliament.

\section{THEORETICAL FRAMEWORK}

\section{Citizenship in the context of immigrant employment}

Immigrants generally perform worse in the labour market than natives. These disadvantages are often explained in the framework of human capital theory (Becker, 1964). Human capital, understood as an individuals' endowment of intrinsic ability in terms of capacities and skills, as well as educational qualifications and work experience, is generally poorer for migrants compared to natives for various reasons. Skills concerning the successful navigation of the labour market, as well as formal and informal credentials, are not equally relevant or valued across national contexts (Friedberg, 2000). Migrants are also generally at a disadvantage with regard to mastery of the native language (van Tubergen \& Kalmijn, 2005). Furthermore, employers may be less inclined to hire a foreign-born job candidate due to the perceived risk of short-term emigration, or in the context of statistical discrimination (Arrow, 1972).

Within this framework of labour market disadvantages of immigrants, citizenship acquisition is perceived by policy-makers as a potentially promising vehicle to mitigate at least some of these issues, and promote immigrant integration (OECD, 2011). The literature has identified three mechanisms by which citizenship of the host country contributes to the labour market opportunities of immigrants (Liebig \& von Haaren, 2011). First, naturalised migrants gain access to jobs that require citizenship of the host country, such as professions in the police force, the army or the public sector. Second, employers face administrative costs when hiring a foreigner, such as the verification of worker rights, which are not relevant to naturalised migrants. Third, citizenship may play an important role in the hiring process within the framework of statistical discrimination by functioning as a positive signalling device. Employers may assume naturalised migrants are positively selected, placating feelings of uncertainty with regard to hiring the foreign-born individual.

\section{The ambiguous economic impact of citizenship}

The above arguments constitute a common theoretical framework in the literature on citizenship and labour market integration. However, empirical findings do not universally support the notion of a citizenship premium. For instance, most longitudinal studies reveal some positive effects of naturalisation, but also show that the relationship is to a varying degree (and in some cases entirely) attributable to self- 
selection (Bratsberg et al., 2002; Engdahl, 2014; Scott, 2008; Steinhardt, 2012). Moreover, the citizenship premium is sometimes only observed for particular migrant groups, such as those from economically less developed countries of origin (Fougère \& Safi, 2009). It is hard to compare these studies in the literature given notable differences in the types of data, methods and controls, but it is clear that there is substantial empirical heterogeneity between contributions, even when accounting for endogeneity in the naturalisation process (see Helgertz et al. [2014, p. 343] for an overview). Surprisingly, there is almost no theorising in the literature on potential explanations for these contradictory findings, which might answer why and for whom citizenship matters. Whereas most of the literature focusses on the relationship between naturalisation and wages, the main underlying mechanism - namely positive signalling - seems particularly relevant in the context of having employment or not. Hiring an immigrant implies risk due to potentially unfamiliar qualifications and possible short-term emigration. Employers thus look at indicators for motivation, commitment and the intention to stay. The naturalised status is an example of such an indicator, but so is being employed. Citizenship of the host country is therefore particularly relevant to non-employed migrants, since the current occupation of employed individuals has a positive signalling effect in its own right. Moreover, positive signalling matters most when employers have limited information on the basis of which they can assess the suitability of a migrant for a job. This will particularly be the case for immigrants who are still trying to secure their first job after migration, for whom no record of their occupational performance in the host country exists. In other words, signalling will particularly facilitate access to the labour market rather than occupational mobility. As such, there seems to be a mismatch between the prevalent object of study, namely earnings, and the main theoretical mechanism that explains the relationship between citizenship acquisition and labour market integration, which is particularly relevant in the context of acquiring employment.

Furthermore, the traditional mechanisms in the literature imply a causal relationship, where citizenship acquisition precedes positive labour market outcomes. However, many studies suggest an increase in economic integration already prior to naturalisation, even when controlling for endogeneity (Bratsberg \& Raaum, 2011, p. 198; Engdahl, 2014, p. 20; Helgertz et al., 2014, p. 353). In that context, we argue for a more complex understanding of the mechanisms underlying the citizenship premium.

\section{Anticipating naturalisation}

The main mechanism through which citizenship is commonly expected to affect the economic integration of immigrants is positive signalling. As such, the literature considers the citizenship premium to be predominantly the product of employers' perception of immigrants, which is assumed to be more positive when citizenship is acquired. From this notion generally follows the assumption that citizenship should have a positive impact on 
the chances of employment of immigrants after naturalisation (Helgertz et al., 2014, p. 344). Indeed, it is argued that the moment of naturalisation marks the threshold where employers are able to identify that a particular migrant is committed to stay and integrate into the host society. Given the inherently selective process of naturalisation, studies in this field of literature typically account for so-called self-selection. The assumption here is that migrants who naturalise perform better in the labour market even before naturalisation due to characteristics that are associated with both an increased propensity to naturalise and better labour market outcomes, but which are not explicitly linked to the moment of naturalisation itself. Figure 4 schematically illustrates this point, where migrants who naturalise already exhibit an advantage in the labour market (line d) compared to migrants who never naturalise (line e), even before the moment of naturalisation. This advantage remains equal over time, and is the result of endogenous characteristics such as motivation or ability (Bratsberg et al., 2002, pp. 572573). These characteristics are unrelated to the moment of naturalisation, even though they are related to the propensity to naturalise. The notion of the citizenship premium as traditionally understood in the literature then assumes that - besides the positive selection into naturalisation - the employability of immigrants increases after citizenship acquisition due to more positive outcomes of statistical discrimination.

However, citizenship acquisition is not an abrupt legal status transition, but rather a process that requires careful planning and preparation leading up to naturalisation. The decision to naturalise is typically understood as the result of a cost-benefit consideration. But qualitative research on motivations for naturalisation shows that what appears to be instrumental reasons for naturalisation can actually signal attachment and interest in full membership, and is conceptualised by immigrants as a logical step on the road towards building a life in the host country (Aptekar, 2015, p. 65). Furthermore, immigrant lives do not exist in a vacuum. Plans and ambitions for the future are made in the context of the life course (Wingens et al., 2011). Important choices in the lives of immigrants, including the decision to permanently settle and naturalise, are embedded in a broader social and institutional framework. Countries can channel political incorporation through policies of diversity and newcomer settlement, facilitating structured mobilisation by friends, family, communities and local leaders (Bloemraad, 2006). As such, citizenship acquisition takes place in a broader social and societal context in which the decision to naturalise in the future is not trivial. Furthermore, citizenship policies provide the opportunity structure under which citizenship acquisition is de facto possible. Most European countries have formalised the conditions for eligibility into not only a minimum period of (legal) residence, but also obligatory language and civic integration requirements. These conditions imply that migrants need to invest in themselves, most notably in linguistic terms, if they wish to naturalise in the future. Moreover, migrants who have decided to naturalise in the future are likely to invest in host-country specific human capital to make use of the opportunities that citizenship acquisition will offer, such as unrestricted access to the labour market. Indeed, multiple studies show that migrants have an economic 
incentive to acquire citizenship of the host country, as naturalisation has the potential to increase earnings for some migrant groups (Helgertz et al., 2014, p. 353; Bratsberg et al., 2002, p. 582; Steinhardt, 2012, p. 819). This human capital development in anticipation of acquiring citizenship will increase the probability of employment leading up to the moment of naturalisation. For instance, investment in mastery of the native language which is a prevalent requirement for naturalisation in European countries - has often been shown to yield positive labour market outcomes (e.g. Kee \& von Ophem, 1996). This effect is illustrated in line $c$ of Figure 4. What fundamentally separates this anticipation effect from what is traditionally perceived as self-selection (represented by line d) is timing. Migrants who naturalise differ from those who do not in terms of unmeasured capacities and skills that positively affect their probability of employment (line $d$ and e). But these effects are not part of the naturalisation process. In other words, self-selection is related to the propensity to naturalise but not the act of naturalisation itself. In contrast, the anticipation effect reflects the consequences of the decision to naturalise, and is therefore intimately linked to the process of naturalisation. Finally, lines $a$ and $b$ of Figure 4 illustrate the traditional notion that the citizenship premium not only manifests as an anticipation effect, but also as a one-time upward shift (line a) or gradual increase (line b) in the probability of employment following naturalisation. Our expectation is thus that under conditions where naturalisation requires demonstrable integration skills, citizenship acquisition has a positive effect on the probability of having employment of immigrants during the period leading up to the moment of naturalisation, even when controlling for endogeneity in the naturalisation process.

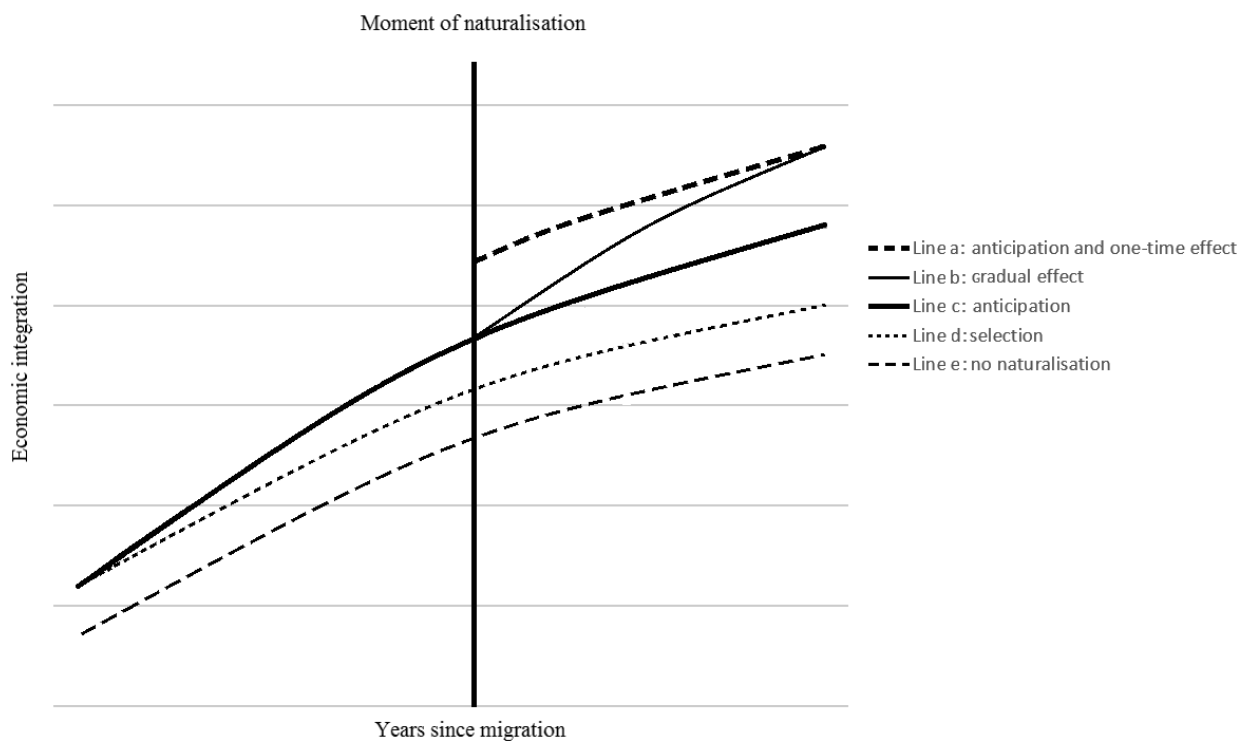

Figure 4. Schematic illustration citizenship premium. 


\section{DATA AND METHODS}

We use register data from Statistics Netherlands to analyse the relevance of citizenship for the probability of employment of immigrants in the Netherlands. These data provide information on almost all registered foreign-born residents of the Netherlands from 1999 until 2011, and is based on municipal population registers, complemented by information from The System of Social Statistical Datasets. We keep track of individuals per 6 months, starting from the moment of arrival in the Netherlands, and until they either emigrate or reach the end of the observation period (January 2012).

We focus on migrants who arrived in the Netherlands between 1999 and 2002 for two reasons. First, almost all migrants from these cohorts are eligible for citizenship under the same conditions. Second, we are interested in the labour market performance of immigrants before and after naturalisation. Given the fact that we only have employment data from 1999 onwards, we are unable to analyse the period before naturalisation in its entirety for migrants arriving before this point in time. We analyse cohorts no later than 2002 to be able to track immigrants of all cohorts for more than 9 years. The maximum period of observation is fixed at 10 years for all cohorts. The analysis focusses on foreign-born immigrants who have not yet acquired Dutch citizenship before the observation period ( $N=94,320)$. Hence, migrants born in Suriname before 1975, and those born in the Netherlands Antilles are excluded from the analysis, since these migrants are often Dutch citizens by birth. We perform separate analyses for men and women to account for differing labour market orientations between genders, as well as potential gender discrimination in the labour market.

The dependent variable in the analysis is employment. The focus on employment as opposed to other forms of economic integration (such as earnings) is an explicit decision made for two reasons: first, the potential relationship between citizenship and wages is a fundamentally different research question, focusing on a different research population (namely migrants with employment). Second, the main mechanism explaining the relationship between citizenship and economic integration in the literature is predominantly relevant in the context of acquiring employment rather than wages. Indeed, the few studies focusing on both employment and income show that citizenship matters in terms of employment, but less so for annual earnings conditional on being employed (Engdahl, 2011, 2014). We dichotomise between having employment in contrast to not being employed. Employed individuals are employees and the self-employed, whereas the non-employed are those who seek work and individuals who are inactive in the labour market by choice. Hence, the analysis focusses on the active labour force, complemented by those who are not active by choice, such as domestic workers or individuals who have become demotivated due to negative experiences in the labour market. While the latter, inactive group may not be seeking employment, we include them for two reasons. First, we have no definitive way to 
distinguish between those who seek employment, and those who could, but choose not to. Second, we are interested in the role of citizenship to the probability of being employed, including for those migrants who are less active in the labour market, for instance due to demotivating experiences (Lancee, 2012, pp. 58-59). We exclude migrants who are inactive and clearly identifiable as such, namely students, retirees and individuals with health problems or disabilities that impede their participation in the labour market. In accordance with the literature (e.g. Helgertz et al., 2014, p. 347), we also exclude migrants younger than 20 and older than 50 years at the moment of arrival in the Netherlands. These boundaries were chosen to further focus the selection on those who could be active in the labour market, and who likely have similar incentives to integrate into the labour market (Engdahl, 2014, p. 11).

The independent variables can be categorised as either individual or contextual characteristics. Individual characteristics include citizenship, age at the moment of migration, years since migration, the citizenship status of the potential partner and having young children in the household, while contextual characteristics include the level of economic development and EU-membership of the origin country. We keep track of changes in individual characteristics per 6 months, and in contextual characteristics per year. ${ }^{11}$

Our empirical strategy follows the state-of-the-art method developed by Bratsberg et al. (2002). In line with earlier research in this field of literature (Helgertz et al., 2014; Steinhardt, 2012), we use (distributed) logistic individual fixed-effects regression, and distinguish between three parameters of interest that measure the relevance of citizenship. The first parameter $\left(a_{1}\right)$ is an interaction between a time-invariant dummy $\left(D_{i}\right)$ set to unity if a migrant naturalises within the observation period, and years since migration $\left(X_{i t}\right)$. As such, this parameter provides an indication of a potentially steeper slope of years since migration for migrants who naturalise (line c of Figure 4). Note that this effect is already present prior to naturalisation. The second parameter $\left(a_{2}\right)$ captures any additional growth in the probability of employment surrounding the moment of naturalisation. This is an interaction between a dummy set to unity in the year that a migrant acquires citizenship and all subsequent years $\left(N_{i t}\right)$, and a variable for years since naturalisation $\left(X_{i t}-X_{i N}\right)$. The latter is a continuous variable that is negative prior to naturalisation, positive after naturalisation, and 0 in the year of citizenship acquisition. A positive coefficient thus indicates a steeper increase in the probability of employment after naturalisation (line b), whereas a negative coefficient is indicative of the slope after naturalisation being less steep compared to migrants who are not naturalised. Finally, the third parameter $\left(a_{0}\right)$ is a dummy set to unity in the year a migrant is naturalised and all subsequent years $\left(N_{i t}\right)$, thus capturing a potential one-

\footnotetext{
${ }^{11}$ Due to the relatively small cohort selection, there is a strong relationship between years since migration and the observation years. Detailed analyses confirm multicollinearity when the observation years are added to the models (VIF > 7) (O'brien, 2007). For this reason, we refrain from including dummies for the observation years in our analyses.
} 
time shift in the probability of employment after naturalisation (line a). We include individual fixed-effects $\left(u_{i}\right)$ in all our models to control for unmeasured time-invariant heterogeneity between individuals (the difference between line $d$ and line e). Furthermore, we control for variables which feature substantial change over time, and thus are not captured by the individual fixed-effects $\left(Z_{i t}\right)$. First, we include the partner status, distinguishing between having no partner, a foreign-born foreign partner (a nonnaturalised partner), a foreign-born Dutch partner (a naturalised partner) and a native partner. When a migrant has one or more children below the age of 18 in the household, we classify them as having children. Furthermore, given substantial differences in the propensity to naturalise between migrant groups (Vink et al., 2013), we perform separate analyses for migrants from different origin contexts, focusing on the level of economic development and EU-membership of origin countries. Although most studies in the literature focus on origin regions (e.g. Bratsberg \& Raaum, 2011; Engdahl, 2014; Helgertz et al., 2014), we argue that these predominantly measure different levels of development. The level of development of the origin country is measured through the Human Development Index (UNDP, 2014). The HDI combines information on gross domestic product, indicators for life expectancy and general education levels, providing a scale between 0 and 1 , where a higher score equals a higher level of development. We keep track of changes in EU-membership of origin countries over time. The main econometric equation is as follows:

$$
Y_{i t}=a_{0} N_{i t}+a_{1} D_{i} X_{i t}+a_{2} N_{i t}\left(X_{i t}-X_{i N}\right)+\gamma X_{i t}+\delta Z_{i t}+u_{i}+\varepsilon_{t}
$$

Table A7 in the annex contains descriptive statistics for male and female immigrants, respectively. We observe a higher proportion of employed individuals among male immigrants. As expected, migrants who naturalise eventually perform better in the labour market, although this is not yet the case many years prior to the actual moment of naturalisation. Furthermore, the relevance of the additional individual and contextual characteristics corresponds to findings in the literature (Kogan, 2011; van Tubergen et al., 2004).

To analyse these data in further detail, we use logistic individual fixed-effects regression, which is the method used in the state-of-the-art literature (Bratsberg \& Raaum, 2011; Bratsberg et al., 2002; Engdahl, 2014; Helgertz et al., 2014; Steinhardt, 2012). This method allows us to control for unobserved time-invariant heterogeneity between individuals. This includes characteristics of the country of origin and the migration motive, but also concepts that are difficult to measure, such as motivation or ability. Since the fixed-effects regression focusses on differences within individuals over time, this implies that individuals who do not vary on the dependent variable are excluded from the model. Hence, migrants who always or never have employment during the observation period cannot be taken into account in the fixed-effects analysis. To increase transparency regarding potential selection bias resulting from omitted individuals due to non-variance, we perform a detailed comparison between the group 
with and without variance on the dependent variable. We discuss those analyses in the paragraph 'robustness analyses'.

\section{ANALYSIS}

Table 2 contains the results of the logistic individual fixed-effects regression, providing estimates for the three parameters on citizenship outlined in the 'data and methods' section, as well as a number of control variables. Results show that immigrants who naturalise enjoy a one-time boost in the probability of employment after citizenship acquisition, constituting an increase of $12 \%$ and $13 \%$ for men and women, respectively, all else constant. This effect is consistent with the notion that naturalised migrants are attractive to employers due to reduced administrative costs and positive signalling, and in line with some earlier longitudinal research (Helgertz et al., 2014, p. 352). Furthermore, the interaction between years since migration and whether a migrant naturalises during the observation period indicates that migrants who naturalise integrate substantially faster in the labour market than their counterparts even before the moment of naturalisation, which is a common observation in the literature (e.g. Bratsberg \& Raaum, 2011, p. 196; Engdahl, 2014, p. 18; Helgertz et al., 2014, p. 352). Finally, the coefficient of the interaction between years since naturalisation and whether a migrant is naturalised or not is negative for both men and women, indicating that the probability of employment develops faster for migrants who are not (yet) naturalised. This goes contrary to the traditional interpretation of the citizenship premium, although this pattern is frequently observed in the literature (e.g. Bratsberg \& Raaum, 2011, p. 196; Helgertz et al., 2014, p. 852; Scott, 2008, p. 118). We hypothesise that the positive effects prior to naturalisation are due to the investment that migrants make in anticipation of acquiring citizenship. Citizenship acquisition is not an abrupt legal status transition, but a process that starts the moment migrants decide to naturalise. The formal linguistic and civic requirements for citizenship acquisition imply that migrants need to invest in themselves leading up to naturalisation. Moreover, migrants who have decided to naturalise may invest in host-country specific human capital to enjoy the economic benefits associated with naturalisation (Helgertz et al., 2014, p. 353; Bratsberg et al., 2002, p. 582; Steinhardt, 2012, p. 819). The steeper slope prior to naturalisation provides empirical support for these assumptions. Furthermore, the diminishing returns after citizenship acquisition may be due to the fact that naturalised migrants have undergone an accelerated integration trajectory leading up to naturalisation, and that migrants who do not naturalise thus catch up afterwards. As mentioned, the hypothesised anticipation effect is fundamentally different from selfselection. The generally high levels of motivation and commitment of migrants who naturalise results in a stronger baseline position for these migrants, but this endogeneity effect is unrelated to the act of naturalisation. The anticipation effect, 
however, is an integral part of the naturalisation process, reflecting the consequences of the decision to acquire citizenship of the host country.

The relevance of the other time-varying characteristics corresponds to the patterns from the descriptive statistics, as well as previous findings in the literature (Kogan, 2011; van Tubergen et al., 2004). The longer migrants reside in the host country, the higher their probability of having employment. Having a partner is positively associated with the probability of having employment for both men and women. This is particularly true if the partner is native-born, in which case migrants are more than twice as likely to be employed compared to migrants with no partner. In accordance with earlier findings in the literature, the relevance of having a partner is more pronounced for men than for women (Kogan, 2011). Having children in the household has a positive, but limited effect on the employment probability of male immigrants (an increase of 3\%). As expected, this effect is strongly reversed for female immigrants, who are almost 54\% less likely to be employed when having young children (Kogan, 2011). Clearly, having children has dissimilar employment implications in the life course of men and women.

Table 2. Logistic individual fixed effects regression on the probability of having employment of male and female immigrants, cohorts 1999-2002.

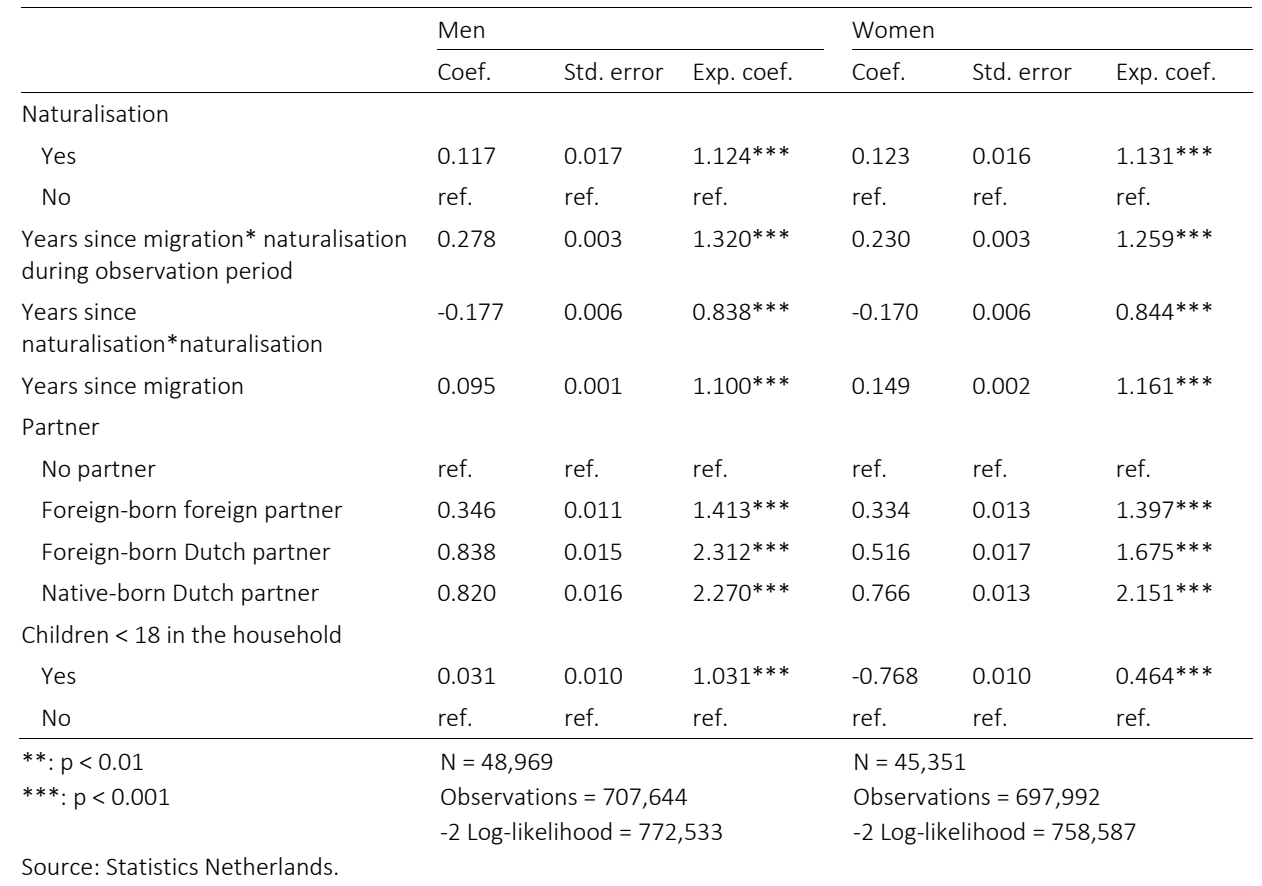

On the basis of these findings, we can conclude that citizenship matters. But are these findings driven by migrants from a particular origin context? In other words, to whom does citizenship matter? To answer this question, we perform separate analyses for 
migrants from more/less developed (Table 3) and EU/non-EU (Table 4) countries of origin. In terms of development, migrants have been categorised along the median of male and female immigrants respectively. ${ }^{12}$

We find some evidence of heterogeneity in naturalisation effects by descent. More specifically, the coefficient of the one-time effect of citizenship acquisition is higher for male immigrants from more developed countries, and female immigrant from EU countries of origin. However, the discrepancy with the reference category is almost equal for female immigrants from more and less developed countries, and smaller for male immigrants from the EU. The slope for migrants who have not (yet) naturalised is steeper for those from less developed and non-EU countries of origin compared to their naturalised counterparts, with the exception of women from high developed countries. Migrants from all origin contexts enjoy an accelerated integration trajectory already prior to naturalisation. A comparison between groups on the basis of these coefficients should be considered with care, since the baselines are not necessarily comparable across the origin groups. The results, therefore, do not allow for conclusions whether citizenship has a stronger effect for migrants from one origin context compared to the other. These findings do show that the results from Table 2 are not exclusively driven by migrants from a particular origin context.

Although these findings provide a first indication of an anticipation effect, the interaction between years since migration and whether a migrant naturalises during the observation period does not reveal the exact shape of the pattern before and after naturalisation. To analyse this in detail, we perform a distributed logistic individual fixed-effects regression in which we measure citizenship categorically, based on the amount of time between a given observation point and the moment of naturalisation. Since this analysis is specifically designed to illuminate how citizenship matters rather than whether it matters or not (which is the main focus of Tables 2-4), we focus on migrants who naturalise during the observation period. The reference group are migrants in the period more than 3 years prior to naturalisation.

\footnotetext{
${ }^{12}$ Note that the sum of individuals of the separate groups does not exactly equal the aggregate number of individuals, whereas the number of observations does. The reason for this is that both the level of development and EU-membership of origin countries exhibit minor changes over time. As a result, some individuals have observations in both groups.
} 


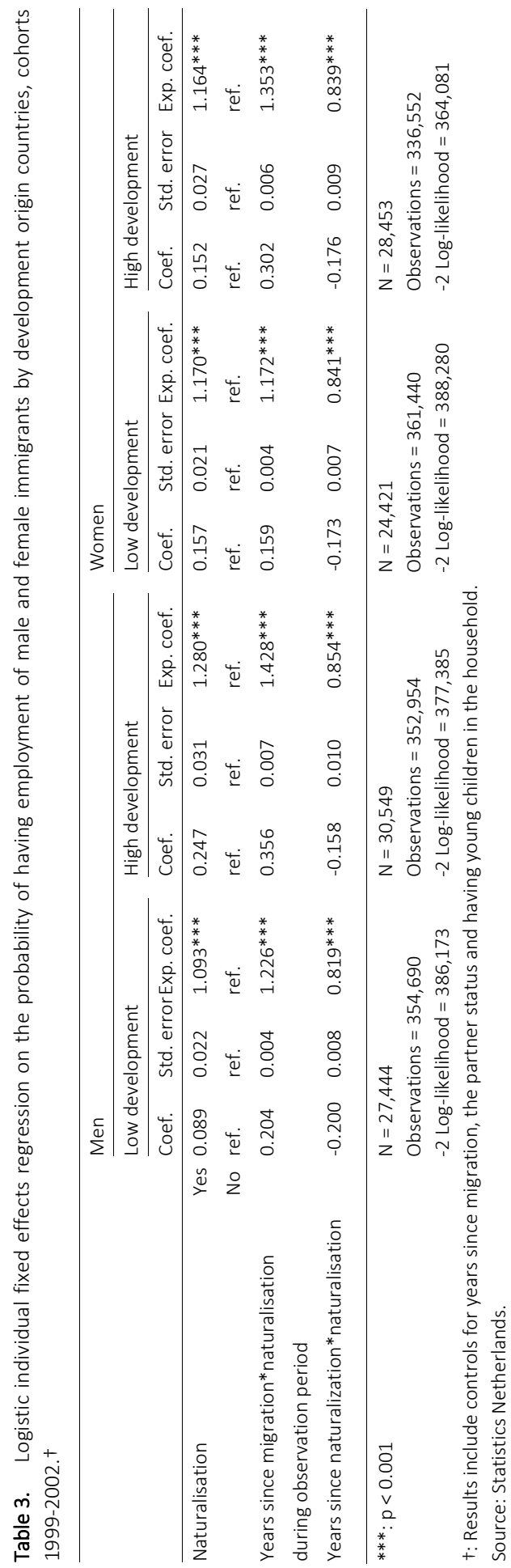


Chapter 4

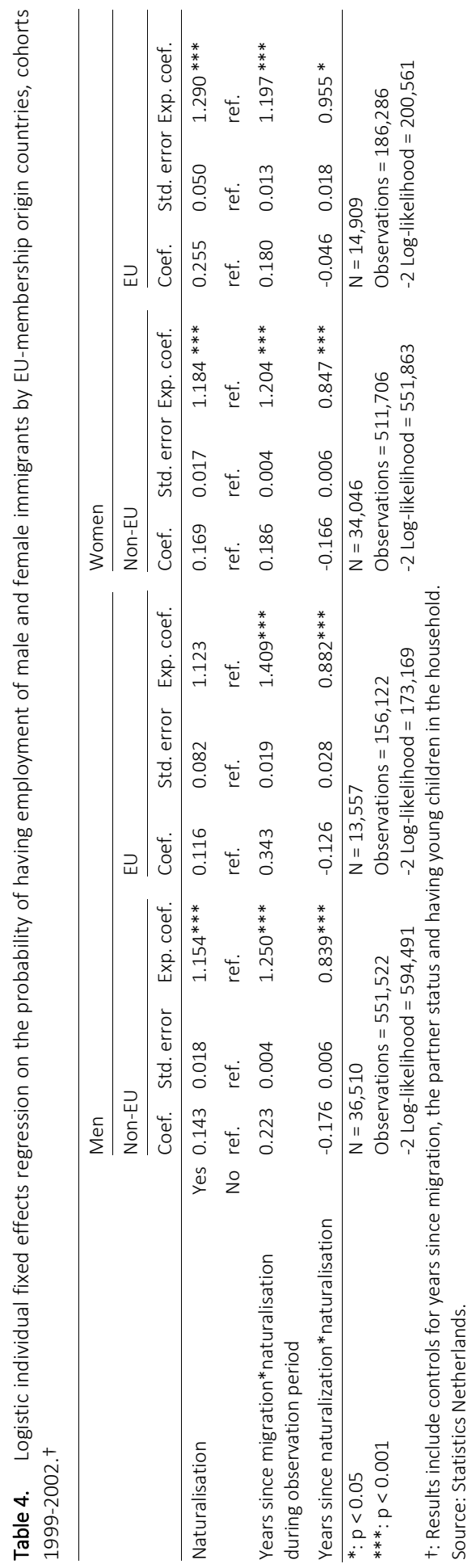


The results in Figure 5 show that - in line with our expectation - the labour market performance of immigrants improves leading up to naturalisation (detailed coefficients of the figures are reported in Tables A8-A10). More specifically, the probability of employment of migrants who naturalise is lower more than 3 years prior to naturalisation compared to all subsequent time points. Consistent with the notion of anticipation, the labour market performance peaks in the year prior to naturalisation. At that point, both male and female immigrants are more than twice as likely to have employment compared to more than 3 years prior to naturalisation. Note that the coefficients are relatively large due to the focus on naturalising immigrants. After naturalisation, the coefficients start to drop, particularly for male immigrants, meaning that the additive effect of naturalisation eventually decreases. This may explain why the slope after naturalisation is less steep for naturalised migrants compared to their nonnaturalised counterparts. Migrants who naturalise enjoy an accelerated integration trajectory rather than a systematic advantage (with the exception of the one-time effect after naturalisation, which is stable over time), allowing migrants who do not naturalise to eventually catch up.
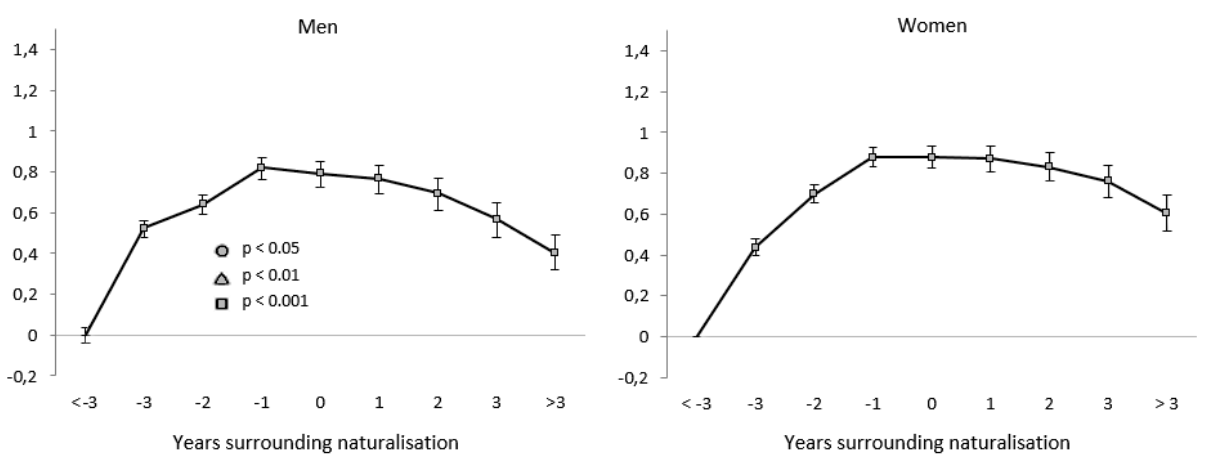

t: Controls for individual fixed-effects, years since migration, the partner status and having young children in the household.

Figure 5. Distributed logistic individual fixed-effects regression on the probability of having paid employment of male of female immigrants, cohorts 1999-2002. ${ }^{+}$

Source: Statistics Netherlands.

To what extent is the pattern from Figure 5 driven by migrants from a particular origin context? Figures 6 and 7 provide the results of separate analyses by the level of development and EU-membership of the origin country, respectively (see Table A9 and A10 in the annex for details). Again, the positive slope prior to naturalisation is apparent for immigrants from both more and less developed countries of origin. These findings thus show that the temporal pattern is similar between these origin groups. It is harder to derive conclusions from the separate analyses of migrants from EU and non-EU countries of origin, since the confidence intervals for EU migrants are substantial. The 
main reason for this is that migrants from the EU generally have a low propensity to naturalise and as such, the $\mathrm{N}$ of this group is smaller. In line with the findings from Figure 5, we observe an increase in the probability of employment leading up to the moment of naturalisation for both EU and non-EU migrants. We can conclude that the pattern from Figure 5 is not solely driven by migrants from a specific origin context.

Low development

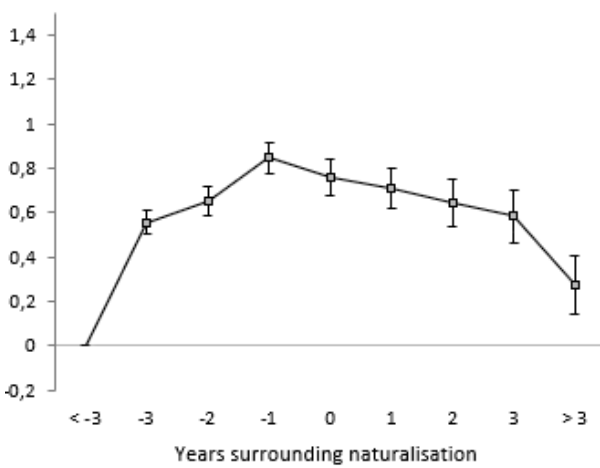

Low development

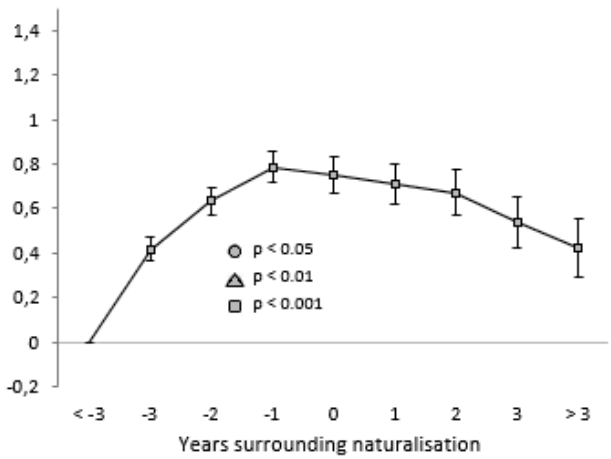

Men

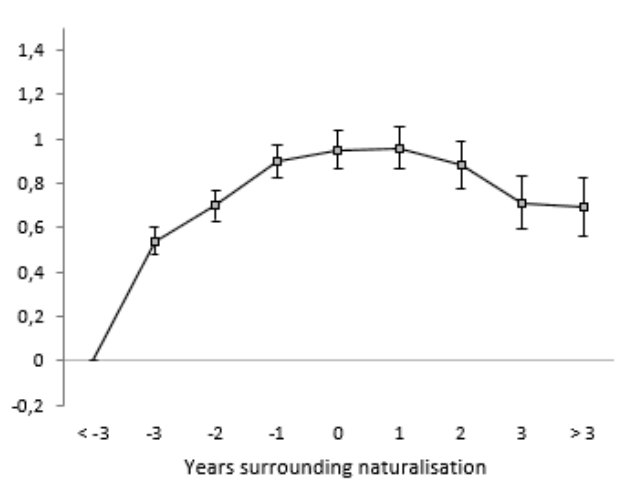

Women

High development

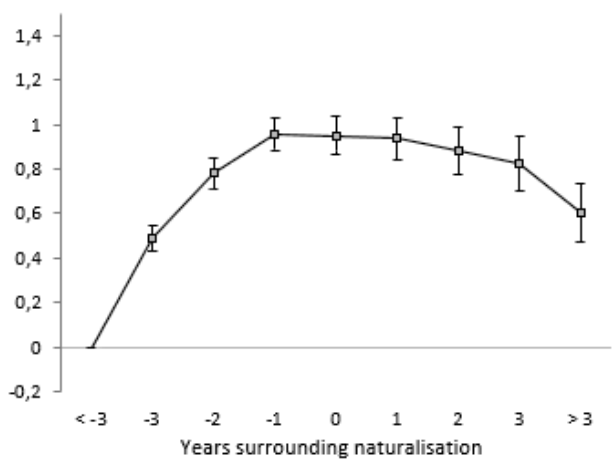

t: Controls for individual fixed-effects, years since migration, the partner status, and having young children in the household.

Figure 6. Distributed logistic individual fixed-effects regression on the probability of having employment of male and female immigrants from low/high developed countries who naturalise during the observation period, cohorts 1999-2002.†

Source: Statistics Netherlands. 
Non-EU

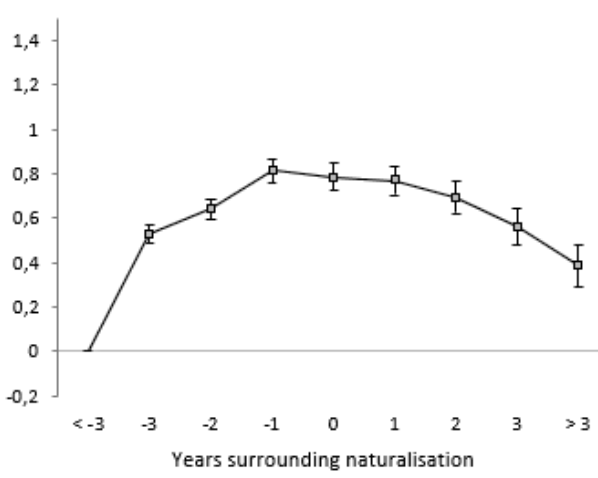

Non-EU

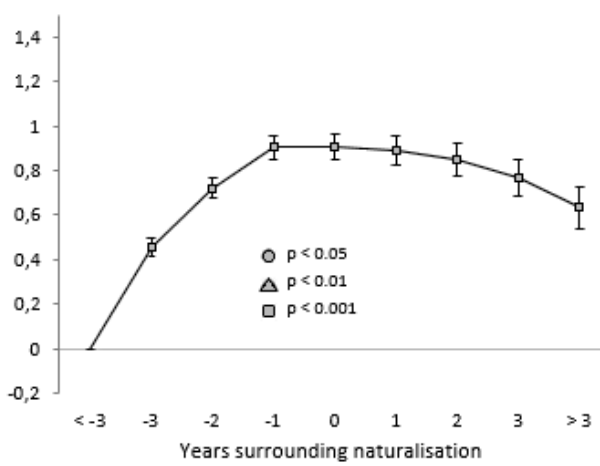

EU

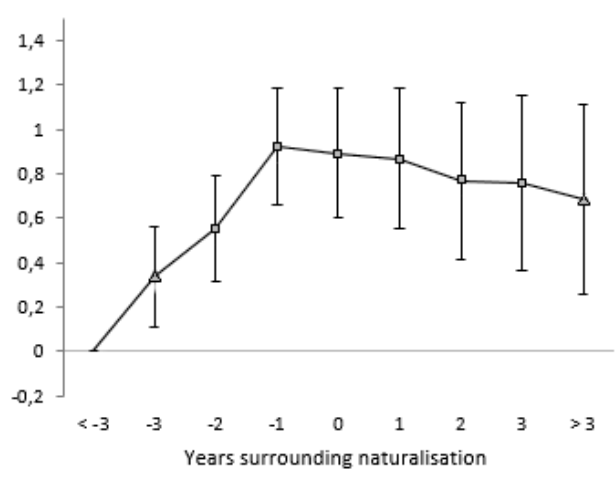

Women

EU

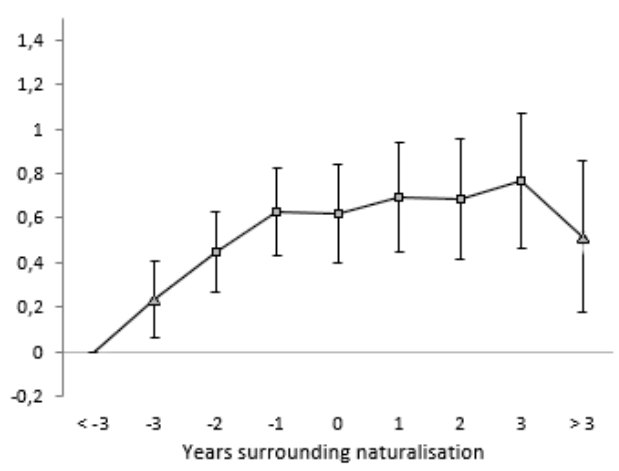

†: Controls for individual fixed-effects, years since migration, the partner status, and having young children in the household.

Figure 7. Distributed logistic individual fixed-effects regression on the probability of having employment of male and female immigrants from non-EU/EU countries who naturalise during the observation period, cohorts 1999-2002.†

Source: Statistics Netherlands.

\section{Speed of naturalisation: when does citizenship matter?}

We observe an increase in the probability of employment leading up to the moment of naturalisation, but that does not necessarily imply that anticipation is the underlying factor that drives these results. The mechanism behind the anticipation effect is assumed to be investment in relevant skills and knowledge in anticipation of acquiring citizenship. Since migrants also gradually accumulate host-country specific human capital over time, this would imply that accelerated investment in these skills becomes less relevant the longer migrants reside in the host country. Investing in for instance language capabilities is more likely to matter after 4 years of residence than after 10 
years. Therefore, if anticipation is one of the driving mechanisms behind the citizenship premium, then the effect of citizenship should be conditioned by the speed with which one naturalises. In other words, citizenship should particularly matter if migrants naturalise relatively quickly. In contrast, if the citizenship premium solely exists as positive signalling, then the speed with which one naturalises should not matter, since only the status of citizen is relevant, rather than the way in which it is acquired. The same is true if the citizenship premium is principally attributable to self-selection, since endogeneity exists irrespective of whether a migrant naturalises quickly or not. As mentioned, self-selection is related to the propensity to naturalise, but not the naturalisation process, whereas anticipation is.

To analyse this, we perform a distributed logistic regression in which the naturalisation variable is replaced by a time-invariant 'speed of naturalisation' variable (Table A11). To simulate the individual fixed-effects of the main analysis, we added a 1period lag of the dependent variable to the model, which captures the relevance of unmeasured characteristics that affect the labour market performance within individuals. Although migrants normally become eligible for naturalisation in the Netherlands after 5 years of residence, migrants can naturalise earlier if they have a Dutch partner for 3 consecutive years, and reside in the Netherlands.

We observe that the relevance of citizenship is comparatively higher as migrants naturalise earlier. In the sixth year of residence, when most migrants become eligible for naturalisation in the Netherlands, the probability of employment is $24 \%$ and $36 \%$ higher for male and female immigrants, respectively compared to their counterparts who do not naturalise during the observation period. For migrants who naturalise in the eighth year or later, this relative advantage has decreased to $10 \%$ for both men and women. Note that, as expected, immigrants who naturalise in the first 3 years of residence perform slightly worse than their counterparts who naturalise in the fourth year. We assume that for these migrants, not enough time has passed to fully invest in oneself, and enjoy an anticipation effect to the same degree as those who naturalise after 4 years. In general, these findings show that the speed of naturalisation matters, and that the relevance of citizenship varies in accordance to our expectations in the context of anticipation. This gives further credence to the notion of an anticipation effect, since the manner in which citizenship is acquired is assumed to be irrelevant in the traditional causal interpretation of the citizenship premium in the literature.

\section{The effect of employment on naturalisation}

An alternative explanation for the increased probability of employment in the period leading up to naturalisation is that being employed increases the likelihood of naturalisation. Employment may provide the means to meet the financial costs associated with naturalisation such as the fee, as well as costs of the language and integration course and exam. Moreover, having employment may improve skills and 
knowledge - notably language capabilities - required for citizenship acquisition. The employment effects prior to naturalisation could thus be the motivator of the decision to naturalise rather than its consequence. To analyse this alternative mechanism, we compare migrants who became eligible for citizenship acquisition before and after a restriction in citizenship policy in the Netherlands, namely the introduction of a naturalisation test in 2003. More specifically, we compare migrant cohorts 1996-1997 and 2001-2002. In light of the residence requirement of 5 years, migrants from the former cohort group became eligible for citizenship acquisition prior to the policy change, whereas the latter group had to perform the naturalisation test (see Chapters 3 and 5 for a similar approach). If the increasing coefficients prior to naturalisation are principally due to the fact that employment provides the ability to meet the financial requirements, than we would not expect the positive labour market outcomes prior to naturalisation to differ before and after the introduction of the naturalisation test. Indeed, these mechanisms should be stable over time. However, if the effect prior to naturalisation is principally due to improving (linguistic) skills, then we would expect a stronger effect under the institutional conditions where these skills are a requirement for naturalisation. Both anticipation and employment arguably have the potential to improve linguistic capabilities, but this strategy does allow us to disentangle specific employment mechanisms such as financial means. In other words, we expect a steeper slope prior to naturalisation for cohort 2001-2002 than cohort 1996-1997 if the development of language capabilities is an important underlying mechanism, and no difference if only financial means matter. Since we only have labour market information from 1999 onwards, we can only observe migrants from the early cohort group after their initial years of residence. However, the vast majority of these migrants will not yet be eligible for naturalisation in 1999 in light of the residence requirement. Results in Table A12 reveal a steeper slope prior to naturalisation than afterwards for all migrant cohorts, but the discrepancy between the slopes is more pronounced for the later cohorts (under the more restrictive institutional conditions) than for the earlier cohorts (under the more liberal conditions). These results are thus consistent with the notion that our previous findings prior to naturalisation are not solely due to employmentspecific effects.

\section{ROBUSTNESS ANALYSES}

In this paragraph, we perform a number of robustness analyses to assess the stability of our findings. First, as is common in this field of literature (e.g. Bratsberg \& Raaum, 2011; Engdahl, 2011, 2014), one of the consequences of performing a fixed-effects regression is that individuals with no variation on the dependent variable drop out of the analysis. These omitted individuals introduce the risk of selection bias, as migrants who remain in the analysis are not necessarily representative of the population. In that context, we 
compared migrants with and without variance on the dependent variable. Table A13 in the appendix shows the results of a logistic regression without fixed-effects for all immigrants (both with and without variance on the dependent variable), again with a 1period lag of the dependent variable to simulate the fixed-effects, and additional controls for time-invariant characteristics. In accordance with the main analyses, we observe a rising probability of employment leading up to naturalisation, consistent with anticipation. However, the coefficients of naturalisation are generally smaller compared to the main analysis. Detailed analyses reveal that this is due to the 1-period lag, which serves the same function as the individual fixed-effects (controlling for omitted variable bias), but does so in a different way. Indeed, this variable also captures changes over time in relevant unobserved characteristics. However, both the main analysis and these robustness analyses clearly show an increase in the probability of employment leading up to naturalisation. As such, we have no reason to assume that the anticipation effect is attributable to omitted individuals as a result of the fixed-effects.

Second, we follow immigrants from all cohorts for a maximum period of 10 years. When migrants emigrate before this point in time, they drop out of the data set from that point onwards. However, it could be argued that migrants who emigrate do so in many cases because of, for instance, negative experiences in the labour market. Since these unsuccessful migrants are unlikely to acquire citizenship and tend to perform worse in the labour market, the observed relevance of citizenship in our main analysis could be driven by these emigrating individuals. In light of this, we performed an analysis for men and women who remain in the Netherlands for the entire observation period. Table A14 shows that 1,792 male and 1,462 female individuals drop out of the data set due to right-truncation. However, the results of the analyses for migrants who remain in the Netherlands are highly similar to those in the main model, including the relevance of citizenship. As such, we conclude that our findings are not driven by unsuccessful migrants who emigrate during the observation period.

The differentiated analysis of migrants naturalising under liberal or restrictive institutional conditions shows that the positive labour market outcomes prior to naturalisation are not solely due to employment-specific effects such as increased financial means. But that still does not confirm that the accelerated integration trajectory prior to naturalisation is due to investment in anticipation of acquiring citizenship rather than employment increasing the propensity to naturalise. To analyse this in further detail, we employ an instrumental variable (IV) approach. More specifically, we include an alternative measurement for 'naturalisation during the observation period' that is strongly related to the propensity to naturalise, but not to the potential source of bias (in our case, employment). Doing so enables us to disentangle the effects of investment in anticipation of acquiring citizenship on the one hand, and effects resulting from having employment on the other hand. We follow the approach of Just and Anderson (2012, p. 499) by using the geographical distance between the host country and the origin country as an instrument for naturalisation. 
Literature suggests that migrants from more distant origin countries are more likely to naturalise due to increased costs associated with return migration (Yang, 1994, p. 473). Conversely, a shorter distance provides more opportunities to maintain ties with the origin country, and disincentives migrants to fully integrate into the host country through naturalisation. Our data confirm this expectation with a positive and statistically significant bivariate correlation between geographical distance and naturalisation. However, we expect no association between geographical distance between the origin and host country and employment (holding time-invariant country characteristics such as economic development constant through the individual fixedeffects). As such, we argue that this is a suitable instrument to isolate potential bias resulting from the association between naturalisation and employment. We dichotomise distance in kilometres by the median of men and women, respectively. Results in Table A15 show that the findings with the IV approach are similar to the main model. Note that the one-time effect after naturalisation is stronger, and the discrepancy in the slope between migrants who are naturalised and those who are not is smaller. However, the coefficient measuring anticipation is still positive and statistically significant. Assuming that geographical distance between the origin and host country is a valid instrument, this confirms that the positive labour market outcomes prior to naturalisation are not solely attributable to employment increasing the propensity to naturalise.

\section{CONCLUSION AND DISCUSSION}

Does citizenship acquisition matter for having employment or not? We observe a onetime boost in the probability of employment after naturalisation, consistent with the notion of positive signalling, and in line with some earlier findings in the Norwegian (Bratsberg \& Raaum, 2011, p. 196) and Swedish (Helgertz et al., 2014, p. 352) context. Second, we find confirmation for the prevalent empirical observation that migrants who naturalise are positively selected in terms of unobserved characteristics that affect both their propensity to naturalise and their labour market outcomes (e.g. Bratsberg et al., 2002, pp. 572-573). This again highlights that isolating these characteristics is essential to avoid an overestimation of the citizenship premium. However, our most important conclusion is that the probability of employment develops faster prior to naturalisation than afterwards, even when controlling for the endogeneity of naturalisation. This too is a recurring observation in the literature that is commonly considered inconsistent with the notion of a citizenship premium (Helgertz et al., 2014, p. 344). By contrast, we argue that this effect is an integral part of the process of naturalisation, reflecting the consequences of the decision to acquire citizenship in the future. Migrants actively plan their lives and anticipate potential rewards and opportunities of naturalisation by investing in their own human capital development. Moreover, these investments will 
often be necessary in light of the formal linguistic and civic requirements for naturalisation. Our results suggest that these investments result in an accelerated integration trajectory that already bears fruit in the labour market prior to naturalisation. Furthermore, citizenship matters most when acquired early in the settlement process, consistent with the notion that accelerated investment in hostcountry specific human capital loses its relevance after a longer period of residence in the host country. This provides further support for the mechanism of anticipation, since the manner in which citizenship is acquired is assumed to be irrelevant for the effects of both self-selection and positive signalling.

Further research is needed to assess the extent to which the anticipatory mechanisms apply for other forms of socio-economic integration. The focus on employment rather than wages in this chapter is an explicit decision, since the traditional mechanisms underlying the citizenship premium are predominantly relevant in the context of having employment or not. Moreover, an analysis of wages implies a fundamentally different research design (focusing on migrants with employment). Since the mechanisms explaining the relationship between citizenship and employment likely differ from those of other forms of socio-economic integration, our results cannot necessarily be translated to other economic indicators.

Our findings raise important questions regarding the restriction of access to Dutch citizenship in the Netherlands over the last decades (van Oers et al., 2013), as well as the recent debate in the Dutch parliament to increase the residence requirement for citizenship acquisition. Since positive effects on the probability of employment manifest not only as a result of citizenship itself, but also due to the active investment migrants themselves make in anticipation of acquiring citizenship, the citizenship premium depends on a balance between requirements to incentivize migrants to invest in themselves, and the feasibility of these requirements to encourage migrants to naturalise. Restricting access to citizenship too much is likely to delay the accelerated integration process to a point where it becomes redundant. Indeed, citizenship particularly matters if acquired early in the settlement process. This will be particularly important for marginalised migrant groups for whom restrictive citizenship policies represent significant and daunting obstacles, such as those from less developed and politically unstable countries of origin (Vink et al., 2013). These are also the very migrants who generally hold a weak position in the labour market, and thus need citizenship most. 


\section{Chapter}

\section{Naturalisation and Immigrant Earnings: Why and To Whom Citizenship Matters ${ }^{13}$}

${ }^{13}$ This chapter is submitted for publication and is currently under review (revise \& resubmit). 



\section{INTRODUCTION}

Foreign-born individuals hold a weaker position in the labour markets of western countries than natives (Heath \& Cheung, 2007; OECD, 2015). This disadvantaged position can be attributed to discrepancies in relevant human capital endowment (Friedberg, 2000), statistical discrimination (Arrow, 1972; Dustmann, 2000), and differing incentives to invest in one's labour market potential (Chiswick \& Miller, 2001; Dustmann, 2000). The (economic) incorporation of immigrants is high on the agenda of policy makers in OECD countries, and there is substantial political and academic interest in instruments or policy which may increase the probability of settlement success. One of the potentially promising vehicles to facilitate the process of immigrant integration is citizenship acquisition (OECD, 2011). This chapter analyses the relationship between naturalisation and labour market integration, specifically focusing on income from labour.

The relevance of citizenship acquisition for the labour market integration of immigrants - particularly in terms of earnings - has been a growing research subject over the last decades (see Helgertz et al. [2014, p. 343] for an overview). Although citizenship acquisition is traditionally assumed to positively affect immigrant earnings, empirical findings do not consistently support this notion (Bevelander \& Pendakur, 2012; Bevelander \& Veenman, 2008; Bratsberg \& Raaum, 2011; Bratsberg et al., 2002; Chiswick, 1978; Engdahl, 2011; Steinhardt, 2012). The relationship between citizenship and labour market integration is complex, and the mixed evidence for a citizenship premium is often attributed to the methodological challenge of establishing a causal link between naturalisation and positive labour market outcomes (Helgertz et al., 2014, p. 338). More specifically, individuals who naturalise may differ from those who do not in terms of characteristics such as motivation or ability, which are hard to measure and control for, thus introducing the risk of overestimating the relevance of citizenship (Bratsberg et al., 2002; Helgertz et al., 2014; Steinhardt, 2012). However, even when accounting for so-called self-selection bias using panel data, the contradictory findings persist. This suggests that there are differences in operationalisation, case selection and research design between studies which drive the heterogeneous results, or the contemporary theoretical framework is underdeveloped, and does not yet explain the conditioned relevance of citizenship. Hence, the question is not so much whether a citizenship premium exists or not, but particularly why and for whom this is the case.

The chapter contributes to this field of literature by addressing that question in two ways. First, we develop the existing theoretical framework further, and explicitly reflect on the determinants and mechanisms underlying the citizenship premium. Second, we build on the traditional methodological strategy of Bratsberg et al. (2002) by performing distributed fixed-effects analyses, which provides more detailed information on the temporal dynamic between citizenship acquisition and labour market outcomes. These two innovations shed new light on the question to whom and why naturalisation matters respectively. We make use of Dutch register data from Statistics Netherlands. 
This individual-level dataset is based on municipal population registers and complemented by information from the Dutch System of Social Statistical Datasets. These data enable us to track the citizenship status, labour market performance, and other relevant socio-economic and demographic characteristics of almost all registered first generation immigrants in the Netherlands over time $(N=102,499)$.

The chapter is structured as follows: first, we briefly outline the Dutch context in terms of the migrant population and citizenship policies. Subsequently, the state-of-theart on citizenship and labour market integration is discussed, and we reflect on the traditional mechanisms and theoretical assumptions in the literature. We then add to the existing theoretical framework, arguing that citizenship acquisition requires investment in relevant skills and knowledge leading up to naturalisation, and that this 'anticipation effect' should be apparent in the labour market performance prior to citizenship acquisition (Bratsberg et al., 2002, p. 590). Next, the methodological approach and research design are described, followed by an overview and discussion of our empirical findings. Finally, we summarize our main results and discuss their implications.

\section{CONTEXT: CITIZENSHIP POLICY AND LABOUR MARKET ACCESS IN THE NETHERLANDS}

In the Netherlands, the requirements for naturalisation are stipulated in the revised Dutch Nationality Act, introduced on April 1, 2003. Migrants are eligible for citizenship acquisition when at least 18 years of age, having a residence permit for an undefined period of time and residing legally in the Netherlands for an uninterrupted period of 5 years. If an individual is the registered partner of a Dutch national for three consecutive years, he or she is exempted from the normal residence requirement, in which case only a non-temporary residence permit and principal residence in the Netherlands is required. Furthermore, migrants should not constitute a danger to public order (i.e. have no criminal record). In principle, dual citizenship is not allowed in the Netherlands, although there are many exceptions to the renunciation requirement. Exceptions include being the registered partner of a Dutch national, or when renunciation of the original nationality is not legally possible or cannot be reasonably demanded. Finally, migrants who wish to naturalise should pass the language and integration requirement by successfully completing a formalized naturalisation test. Migrants are required to read, write and speak Dutch at level A2 of the Common European Framework of Reference for Languages, and should possess sufficient knowledge of the Dutch society. The Dutch nationality guarantees a secure legal status in the Netherlands, as well as full voting rights. Individuals without the Dutch nationality, but who originate from the European Economic Area (EEA), have unrestricted access to the labour market, with the exception of a small number of professions that are reserved for Dutch citizens, namely jobs in the army and high-ranking positions in law and the public sector. Naturalisation 
provides access to those jobs. Foreign individuals who originate from outside the EEA either need a work permit, or the employer needs to have permission to hire an employee from outside the EEA, who in that case only needs a residence permit. Facilitated work permit procedures exist for particular migrant groups, such as refugees, non-European students and athletes.

\section{THEORETICAL FRAMEWORK}

Literature on the determinants of economic integration of immigrants generally draws on the concept of human capital (Becker, 1964). In the framework of human capital theory, opportunities and success of individuals in the labour market depends on their resources and skills. Resources include social networks and relevant labour market information, while skills refer to for instance educational qualifications, training and work experience. First generation immigrants face structural disadvantages in the labour market compared to natives due to the diminished relevance or recognition of their original human capital in the host country (Algan et al., 2010; Friedberg, 2000). For instance, migrants often have a limited mastery of the host country language compared to natives (Chiswick \& Miller, 2001; van Tubergen \& Kalmijn, 2005). Furthermore, the social capital of immigrants is often less effective at facilitating upward mobility due to ethnic composition of the network (Lancee, 2010). Simultaneously, employers may favour a native job candidate in light of the perceived risk of short-term emigration (Dustmann, 2000), or in the context of statistical discrimination (Arrow, 1972).

Does citizenship acquisition have the potential to level the playing field? Traditionally, the literature points to three mechanisms that explain why naturalisation might mitigate some of the above disadvantages, and promote economic integration (Bratsberg et al., 2002, p. 569; OECD, 2011). First, naturalisation removes restrictions on occupations that are reserved for citizens, such as jobs in the public sector, law and military. Second, employers do not have to pay the administrative costs associated with the verification of work permits when hiring a naturalised migrant. Third, in the context of statistical discrimination, citizenship may function as a positive signalling device. Employers may assume that the naturalised status of a migrant is indicative of positive selection, reducing the risk of hiring said individual.

These mechanisms imply a positive effect of citizenship on the labour market performance of immigrants. However, an examination of empirical findings in the literature reveals substantial ambiguity. Whereas some studies identify the expected positive relationship (Bevelander \& Pendakur, 2012; Bevelander \& Veenman, 2008; Bratsberg et al., 2002; Steinhardt, 2012), others find no such relationship, or even a negative association (Bratsberg \& Raaum, 2011; Chiswick, 1978; Engdahl, 2011). Some of these studies are based on cross-sectional data, which is frequently criticized in this field of literature for its inability to analyse the causal nature of the relationship. 
Citizenship acquisition is an inherently selective process. As such, individuals who naturalise may be positively selected with regard to their labour market potential. Although empirical findings based on panel data consistently confirm this hypothesis (Bratsberg et al., 2002; Helgertz et al., 2014; Steinhardt, 2012), controlling for the endogeneity of naturalisation does not fully explain the contradictory findings in the literature. This enduring empirical ambiguity is often seen as a challenge to the existence of a citizenship premium in general. Alternatively, the ambiguity may invite us to theorise on its determinants, an approach which is remarkably absent in the literature. To address this gap, we first reflect on why the traditional mechanisms outlined above fail to explain empirical findings, and subsequently introduce complementary mechanisms which may facilitate a better understanding of why naturalisation matters for some migrants under certain conditions, and not for others.

\section{Why does citizenship acquisition matter?}

The literature on the citizenship premium predominantly analyses immigrant earnings, occasionally complemented by additional analyses on having employment or not. Regardless of the operationalisation of economic integration, the theoretical framework remains the same, focussing on the three established mechanisms: increased labour market access, reduced administrative costs and positive signalling. However, these mechanisms are not necessarily equally relevant in terms of having employment and earnings from labour. A focus on immigrant earnings implies a different research population than an analysis of employment. Indeed, migrants with earnings from labour per definition have employment. Arguably, having employment serves as a positive signalling device in its own right. These employed individuals therefore do not need citizenship as much as migrants who are unemployed. Hence, there seems to be a mismatch between the most common operationalisation of economic integration in the literature, namely earnings, and one of the most important mechanisms, namely positive signalling, which arguably is more relevant in the context of having employment. Our expectation is as follows:

$\mathrm{H} 1$ : The positive effect of citizenship acquisition on the income from labour of immigrants is stronger for migrants who are unemployed than for those with paid employment.

Traditionally, the relevance of citizenship acquisition in the labour market is almost exclusively attributed to the risk-calculation of employers. Individuals who naturalise are largely considered passive beneficiaries of the positive impact of citizenship. As such, the effect of naturalisation is generally understood as a dichotomous before-after phenomenon (e.g. Helgertz et al., 2014, p. 351). Indeed, the notion of positive signalling, reduced administrative costs and increased access to the labour market only applies for migrants who have successfully naturalised. But citizenship acquisition is not 
an abrupt legal status transition, but rather a process that requires careful planning and preparation leading up to naturalisation. Although there is significant cross-national variation in citizenship policies, most European countries have formalised the conditions for eligibility into not only a minimum period of (legal) residence, but also obligatory language and civic integration requirements. These conditions imply that migrants need to invest in relevant skills and knowledge, most notably linguistic capabilities, if they wish to naturalise in the future. This human capital development in anticipation of acquiring citizenship may increase labour market opportunities already prior to naturalisation. What fundamentally separates anticipation from self-selection is the time-invariant nature of the latter. Self-selection does not exclusively manifest surrounding the moment of naturalisation, but anticipation does. In other words, anticipation is an integral part of the process of naturalisation, whereas self-selection is merely related to the propensity to naturalise. Therefore, the former should be considered a citizenship premium, in contrast to the latter.

The notion of an anticipation effect has already been coined more than a decade ago by Bratsberg et al. (2002, p. 590) but surprisingly, has not received much attention in contemporary literature. However, findings from one of the most recent studies on the citizenship premium in Sweden and Denmark are consistent with this theory, as the labour market performance of migrants develops faster prior to naturalisation than afterwards, even when controlling for endogeneity (Helgertz et al., 2014, pp. 353-354). Our hypothesis is as follows: H2: The income from labour of immigrants who naturalise develops faster prior to the moment of naturalisation than afterwards.

\section{To whom does citizenship matter?}

In so far as citizenship acquisition matters, does it matter equally to all migrant groups? The literature seems to acknowledge that this is unlikely, since most studies perform separate analyses for migrants from various (parts of) continents (Bratsberg \& Raaum, 2011; Engdahl, 2011; Helgertz et al., 2014; Steinhardt, 2012). But there is little to no development of theory that explains why and how the effect of citizenship acquisition is conditioned by origin characteristics. As such, heterogeneity in the effect of naturalisation is observed, but not explained. Analyses focusing on specific characteristics of origin countries may facilitate a better understanding of how the origin context interacts with the mechanisms underlying the citizenship premium.

The signalling potential of citizenship is assumed to promote labour market integration by positively affecting the risk-calculation of employers. However, employers will associate the hiring of individuals from certain migrant groups with higher risk than others. Migrants who are assumed to be negatively selected by employers with regard to their productivity and general labour market performance arguably stand to benefit from naturalisation most, as citizenship acquisition has the potential to mitigate the negative consequences of statistical discrimination for these 
migrants. This raises the question which migrant groups hold a more negative reputation in the labour market. Some research suggests that the citizenship premium is stronger for migrants for whom the probability of having paid employment is lowest, such as those from economically less developed countries of origin (Bratsberg et al., 2002, p. 590; Fougère \& Safi, 2011, p. 138). Our expectation is as follows:

H3: The positive effect of citizenship acquisition on income from labour is stronger for immigrants from economically less developed countries of origin.

\section{DATA AND METHODOLOGY}

We make use of register data from Statistics Netherlands to analyse the potential relationship between citizenship acquisition and earnings from labour. The data are derived from the Dutch System of Social Statistical Datasets. This micro-level dataset allows us to track relevant characteristics of foreign-born individuals over time. More specifically, we observe individual characteristics every six months, and country characteristics with yearly precision, over the period of 1999 until 2011. Individuals are followed from the moment of arrival in the Netherlands onwards, until they reach the end of the observation period (January 2012), or leave the Netherlands. We focus on migrants who arrived in the Netherlands between 1999 and 2002. The reason for this cohort selection is that micro-data on labour market characteristics is only available from 1999 onwards. Moreover, excluding cohorts after 2002 allows us to observe all cohorts for more than 9 years. The observation period for all cohorts is fixed at a maximum of 10 years of residence.

The analysis focusses on first generation immigrants, defined as foreign-born individuals of whom both parents were born abroad. Furthermore, we exclude migrants who acquired Dutch citizenship prior to arriving in the Netherlands, such as those born in Suriname before 1975 or in the Netherlands Antilles, who are often Dutch citizens by birth. As is common in labour market research, we perform separate analyses for men and women. Also, we exclude migrants who are inactive in the labour market, namely students, retirees and individuals with health problems or disabilities that impede their participation in the labour market. To further focus the selection on individuals with an equal incentive to integrate into the labour market, we restrict the sample to migrants aged between 20 and 50 years at the moment of arrival in the Netherlands (Engdahl, 2014, p. 11; Helgertz et al., 2014, p. 347).

The dependent variable is income from labour. We measure earnings as the common logarithm of monthly wages. This includes income derived from employment and self-employment. Our analysis predominantly focusses on employed migrants. Note that these migrants per definition have the right to work in the Netherlands. However, in one of our analyses, we differentiate between two different models. The first model 
is restricted to observations of employed migrants, and the second model includes observations of migrants who are employed and unemployed. We argue that the comparison of results from both models facilitates a better understanding whether citizenship predominantly matters in terms of employment, earnings, or both. However, since we do not have information on whether individuals have a work permit, and unemployed migrants may not have the right to work, we perform a robustness check to analyse whether the relevance of naturalisation for unemployed migrants is attributable to a lack of labour market access prior to naturalisation.

Our independent variables include age at the moment of migration, years since migration, the partner status, having children in the household, the mean working hours per year, the labour market sector, and the level of economic development and EU membership of the country of origin. Due to the relatively small cohort selection, there is a strong relationship between years since migration and the years of observation. More detailed analyses confirm multicollinearity when the observation years are added to the models (VIF > 7) (O'brien, 2007). Controls for the observation years are therefore not included in the analyses. We track the registered partner of immigrants over time, differentiating between migrants with a foreign-born foreign partner, a foreign-born Dutch partner (a partner who has naturalised) and a native partner. We classify migrants of whom the youngest child in the household is younger than 18 as having children. In terms of origin characteristics, we focus on economic development, based on the Human Development Index (UNDP, 2014) and EU membership of origin countries.

To analyse the data, we make use of individual fixed-effects regression. This methodology is used to control for unmeasured, time-invariant heterogeneity between individuals. Basically, individual fixed-effects implies a control for each individual in the dataset. In other words, each individual has a unique baseline, and our findings are therefore based on changes within individuals over time rather than differences between individuals. In practice, this means that we control for all characteristics that do not vary within the observation period, such as the age at migration, migration motive and country of origin, but also endogenous characteristics such as commitment, motivation and ability. This strategy can be considered the state-of-the-art method to isolate endogeneity bias in this field of literature (Bratsberg \& Raaum, 2011; Bratsberg et al., 2002; Engdahl, 2014; Helgertz et al., 2014; Steinhardt, 2012). Additionally, we perform a distributed individual fixed-effects regression in which we distinguish between different timepoints surrounding the moment of naturalisation. This method provides a more detailed overview of how the citizenship premium develops over time, which is of interest in light of the hypothesised anticipation mechanism.

We follow the empirical strategy developed by Bratsberg et al. (2002), by measuring the relevance of naturalisation through three parameters. The first parameter $\left(\alpha_{0}\right)$ is a dummy measuring whether a migrant is naturalised or not $\left(N_{i t}\right)$, thus capturing a potential one-time shift in earnings from labour after naturalisation. The second 
parameter $\left(\alpha_{1}\right)$ is an interaction between a time-invariant dummy measuring whether a migrant naturalises during the observation period and years since migration $\left(D_{i} X_{i t}\right)$, which captures the differentiated effect of years since migration for migrants who naturalise, and those who do not. This parameter thus captures a potentially steeper slope for migrants who naturalise, including prior to naturalisation. The third parameter $\left(\alpha_{2}\right)$ measures a gradual change in earnings from labour after naturalisation. This is an interaction between years since naturalisation $\left(X_{i t}-X_{i N}\right)$ and a dummy measuring whether a migrant has naturalised or not at a given observation. Years since naturalisation is a continuous variable that is negative prior to naturalisation, positive after naturalisation, and 0 in the year of citizenship acquisition. A positive coefficient indicates a more positive development of income from labour after naturalisation, whereas a negative coefficient means that income develops faster among migrants who are not (yet) naturalised. All models include an additional vector of control variables $\left(Z_{i t}\right)$, as well as individual fixed-effects $\left(u_{i}\right)$. The main econometric equation is as follows:

$$
\ln \left(Y_{i t}\right)=\alpha_{0} N_{i t}+\alpha_{1} D_{i} X_{i t}+\alpha_{2} N_{i t}\left(X_{i t}-X_{i N}\right)+\gamma X_{i t}+\delta Z_{i t}+u_{i}+\varepsilon_{t}
$$

Table A16 in the annex contains descriptive statistics on the Log labour income of male and female immigrants with employment. Note that we distinguish between different timepoints surrounding the moment of naturalisation to illustrate the temporal development of immigrant earnings. As expected, male immigrants enjoy higher earnings than female immigrants. Furthermore, the income from labour of migrants who naturalise is lower more than three years prior to naturalisation compared to migrants who do not naturalise during the observation period. Over time, the income of naturalising migrants increases. The relevance of the additional personal and contextual characteristics corresponds to our expectations, and is in line with earlier studies on labour market integration of immigrants (Kanas, van Tubergen, \& van der Lippe, 2011; Kogan, 2011; Lancee, 2010; van Tubergen et al., 2004).

\section{ANALYSIS}

Table 5 provides the results of the three parameters on naturalisation, as well as a number of control variables which feature substantial changes over time, and are thus not captured by the individual fixed-effects. Model 1 contains only observations of individuals with employment, whereas Model 2 also includes observations of unemployed migrants, which is of interest in light of hypothesis 1. Results show that migrants do not enjoy a one-time boost in log labour income after naturalisation, as the coefficients for the parameter 'Naturalisation' of both men and women are statistically insignificant. The traditional theoretical framework would predict a positive upward shift in income as a result of for instance positive signalling. Our results are contrary to this hypothesis, but in line with findings from earlier studies in Norway (Bratsberg \& Raaum, 
2011, p. 197), Sweden and Denmark (Helgertz et al., 2014, p. 352), Germany (Steinhardt, 2012, p. 818) and the U.S. (Bratsberg et al., 2002, p. 582). Yet, these studies provide limited theoretical guidelines that explain why there is no positive relationship. Our interpretation is that the signalling potential of citizenship is particularly relevant for unemployed migrants, since having employment serves as a positive signalling device in its own right. The interaction between whether a migrant naturalises during the observation period and years since migration is positive and statistically significant. This confirms that migrants who naturalise perform better in the labour market, including prior to naturalisation. The coefficient of the third parameter is negative, indicating that the earnings profile develops faster for migrants who are not (yet) naturalised. In sum, income from labour particularly increases leading up to naturalisation. These findings are contrary to the traditional understanding of a citizenship premium, but consistent with the notion of anticipation. Migrants anticipate potential rewards and opportunities of naturalisation by investing in their own human capital development. In line with earlier theorisation in the literature (Bratsberg et al., 2002, pp. 582-583), we hypothesise that the steeper wage gains prior to naturalisation are the result of these investments.

Regarding our control variables, we observe a positive relationship between years since migration and earnings, all else constant. Furthermore, we find that having a partner is generally associated with increased earnings among men, whereas for women the effects are less positive (Kanas et al., 2011, p. 113). In line with our descriptive statistics, particularly having a naturalised partner has a negative effect on the earnings profile, especially for female immigrants. Having young children in the household has a positive effect on the Log labour earnings of men, whereas the effect is strongly negative for female immigrants. Clearly, these events have different implications in the life course of men and women respectively.

In line with our expectations, citizenship acquisition in general does not provide a onetime boost in earnings for employed migrants. However, if hypothesis 1 is correct, then the coefficient for the 'naturalisation' parameter should be more positive when migrants without employment are added to the model. Model 2 of Table 5 provides the results of the individual fixed-effects regression including observations of migrants without employment. In contrast to the findings of Model 1, we now observe an upward shift in income after naturalisation. This confirms hypothesis 1 , namely that the subsequent effect of naturalisation on immigrant earnings is stronger for migrants without employment. We theorise that this is the case because being employed has a positive signalling effect in its own right. Thus, these employed individuals do not need citizenship acquisition as much in the labour market. Moreover, for citizenship to have an effect for employed migrants implies the assumption that these migrants reorient themselves in the labour market after naturalisation. Our findings suggest that the traditional arguments for a citizenship premium are particularly relevant in the context of gaining access to the labour market (i.e. having employment) rather than occupational mobility (i.e. earnings), which is particularly important because most of the established literature focusses on earnings. 


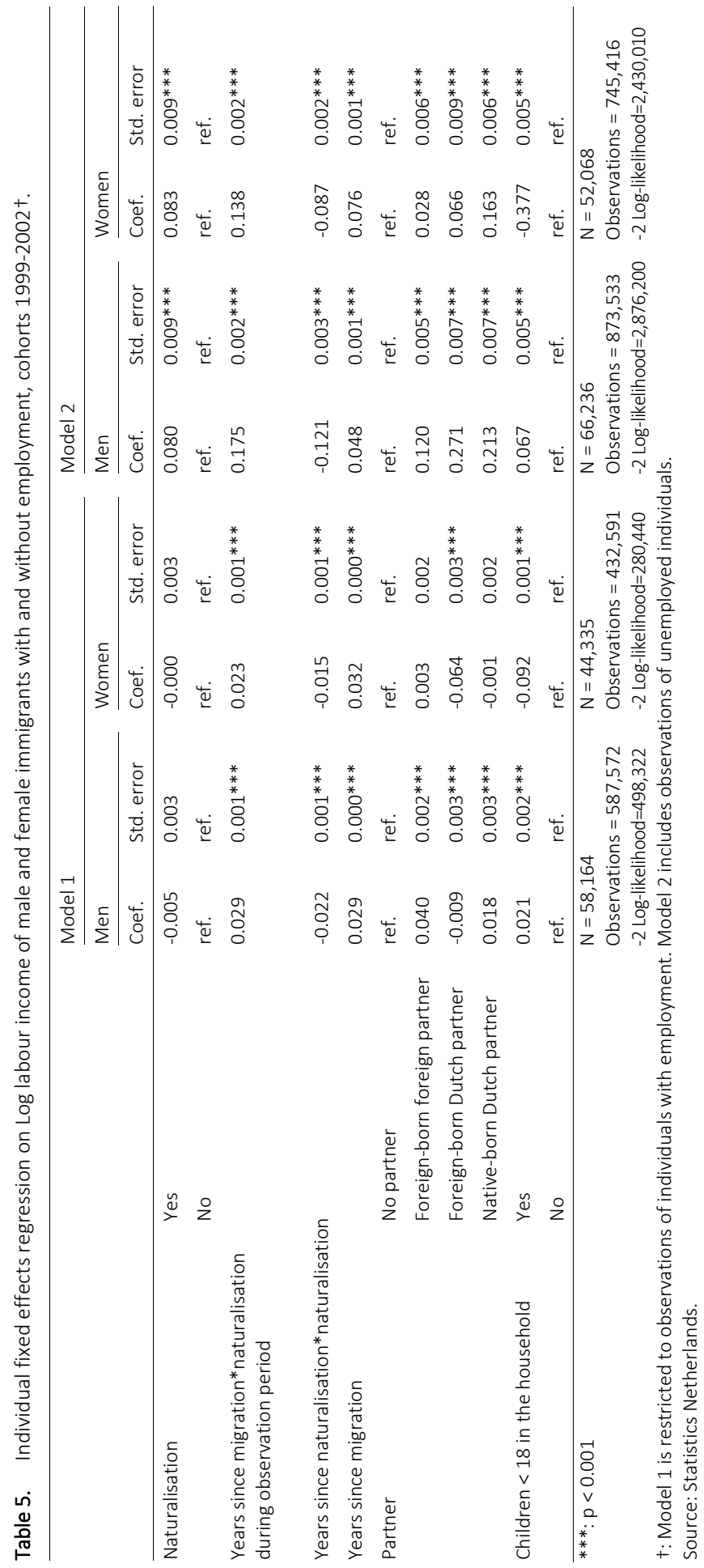


Although the positive labour market outcomes prior to citizenship acquisition suggest an anticipation effect, they do not provide any indication regarding the exact shape of the slope before and after naturalisation. If anticipation is the underlying mechanism, then we would expect earnings from labour to increase leading up citizenship acquisition. To analyse this in detail, we perform a distributed individual fixed-effects regression in which we distinguish between different timepoints surrounding naturalisation. We analyse immigrants who naturalise during the observation period, since the focus of these analyses is not so much on whether citizenship matters or not (which is the focus of Table 5), but rather how it matters. Table 6 shows that, as expected, immigrant earnings increase leading up to citizenship acquisition, and peak around the moment of naturalisation for both men and women. This confirms hypothesis 2 , and is in line with our theorisation that the explicit decision to naturalise in the future results in the corresponding decision to invest more heavily in host-country specific human capital already prior to naturalisation (Bratsberg et al., 2002, p. 582). We assume that the more positive labour market performance prior to naturalisation is a reflection of said investment. After naturalisation, the additive effect of naturalisation decreases, particularly for male immigrants.

Table 6. Distributed individual fixed effects regression on Log labour income of male and female immigrants with employment who naturalise during the observation period, cohorts 1999-2002.

\begin{tabular}{|c|c|c|c|c|c|c|c|c|}
\hline & \multicolumn{4}{|l|}{ Men } & \multicolumn{4}{|c|}{ Women } \\
\hline & Coef. & Std. error & \multicolumn{2}{|c|}{$\begin{array}{l}95 \% \text { conf. } \\
\text { intervals }\end{array}$} & Coef. & Std. error & \multicolumn{2}{|c|}{$\begin{array}{l}95 \% \text { conf. } \\
\text { intervals }\end{array}$} \\
\hline \multicolumn{8}{|l|}{ Naturalisation } & \\
\hline$>3$ years prior to naturalisation & ref. & ref. & ref. & ref. & ref. & ref. & ref. & ref. \\
\hline 3 years prior to naturalisation & 0.025 & $0.004 * * *$ & 0.017 & 0.033 & 0.022 & $0.004^{* * *}$ & 0.014 & 0.030 \\
\hline 2 years prior to naturalisation & 0.034 & $0.005 * * *$ & 0.024 & 0.042 & 0.043 & $0.005 * * *$ & 0.033 & 0.053 \\
\hline 1 year prior to naturalisation & 0.051 & $0.005 * * *$ & 0.041 & 0.061 & 0.052 & $0.005 * * *$ & 0.042 & 0.062 \\
\hline year of naturalisation & 0.048 & $0.006 * * *$ & 0.036 & 0.060 & 0.057 & $0.006 * * *$ & 0.045 & 0.069 \\
\hline 1 year after naturalisation & 0.049 & $0.007 * * *$ & 0.035 & 0.063 & 0.063 & $0.007 * * *$ & 0.049 & 0.077 \\
\hline 2 years after naturalisation & 0.048 & $0.008 * * *$ & 0.032 & 0.064 & 0.064 & $0.008 * * *$ & 0.048 & 0.080 \\
\hline 3 years after naturalisation & 0.032 & $0.009 * * *$ & 0.016 & 0.050 & 0.056 & $0.009 * * *$ & 0.038 & 0.074 \\
\hline$>3$ years after naturalisation & 0.007 & 0.010 & -0.010 & 0.027 & 0.044 & $0.010 * * *$ & 0.024 & 0.064 \\
\hline Years since migration & 0.044 & $0.001 * * *$ & 0.042 & 0.046 & 0.041 & $0.001 * * *$ & 0.039 & 0.043 \\
\hline \multicolumn{9}{|l|}{ Partner } \\
\hline No partner & ref. & ref. & ref. & ref. & ref. & ref. & ref. & ref. \\
\hline Foreign-born foreign partner & 0.018 & $0.004 * * *$ & 0.010 & 0.026 & -0.005 & 0.004 & -0.010 & 0.003 \\
\hline Foreign-born Dutch partner & 0.039 & $0.005^{* * *}$ & 0.029 & 0.049 & -0.020 & $0.005^{* * *}$ & -0.030 & -0.010 \\
\hline Native-born Dutch partner & 0.044 & $0.005 * * *$ & 0.034 & 0.054 & 0.020 & $0.004 * * *$ & 0.012 & 0.028 \\
\hline \multicolumn{9}{|l|}{ Children $<18$ in the household } \\
\hline Yes & -0.003 & 0.003 & -0.010 & 0.003 & -0.084 & $0.003 * * *$ & -0.090 & -0.078 \\
\hline No & ref. & ref. & ref. & ref. & ref. & ref. & ref. & ref. \\
\hline \multirow[t]{2}{*}{$* * *: p<0.001$} & \multicolumn{4}{|c|}{$N=14,299$} & \multicolumn{4}{|c|}{$N=13,834$} \\
\hline & \multicolumn{4}{|c|}{ Observations = 161,182 } & \multicolumn{4}{|c|}{ Observations = 135,695 } \\
\hline Source: Statistics Netherlands. & \multicolumn{4}{|c|}{-2 Log-likelihood = 166,370 } & \multicolumn{4}{|c|}{-2 Log-likelihood = 92,182 } \\
\hline
\end{tabular}


The next question is to whom citizenship matters. Analogous to the state-of-the-art literature (Bratsberg \& Raaum, 2011; Engdahl, 2014; Helgertz et al., 2014; Steinhardt, 2012), we start by performing separate analyses for large origin regions. Table 7a and Table $7 \mathrm{~b}$ provide results for men and women respectively. First, we observe that earnings of naturalising migrants from all origin groups develop faster over time, including prior to naturalisation. Furthermore, all migrant groups except women from the Middle-East perform better in the labour market when they have not (yet) naturalised. In line with the aggregate analyses, most migrant groups do not enjoy a one-time boost in Log labour income after naturalisation. However, we do observe a positive effect for male immigrants from Africa, and female immigrants from Asia and the Middle-East. More specifically, male African immigrants enjoy an increase of 7.7 percent in Log labour income $\left(10^{0.032}\right)$, and female immigrants from Asia and the Middle-East an increase of 9.7 and 5.7 percent respectively. In contrast, the coefficient is negative for women from the EU.

Due to substantial demographic and institutional variation between these large origin groups, it is hard to identify underlying mechanisms that explain these empirical differences. We hypothesise that these findings may partly reflect variation in economic development between origin countries. In so far as citizenship matters in terms of earnings from labour, we expect that it will be particularly relevant to migrants from less developed countries, who struggle in the labour market and stand to benefit from citizenship most. Table A17 provides results of separate analyses for migrants with employment from low and high developed countries. Individuals have been categorized along the median of men and women respectively. Results indicate that naturalising migrants from all origin groups perform better in the labour market, including prior to naturalisation. Moreover, the earnings profile develops faster among non-naturalised migrants. However, the one-time boost in earnings is positive and statistically significant for migrants from less developed countries of origin, whereas this is not the case for those from high developed countries. Among migrants from less developed countries, we observe an increase of 3 and 5.4 percent in Log labour income for male and female immigrants respectively. These findings provide support for hypothesis 3 , in which we argue that citizenship particularly matters for vulnerable migrant groups who struggle in the labour market, and need citizenship the most to mitigate this disadvantaged position (Bratsberg et al., 2002, p. 590; Fougère \& Safi, 2011, p. 138). 
Table 7a. Individual fixed effects regression on Log labour income of male immigrants with employment by origin regions, cohorts 1999-2002.†

\begin{tabular}{|c|c|c|c|c|c|c|c|c|}
\hline & & & EU & $\begin{array}{l}\text { Non-EU } \\
\text { Europe, } \\
\text { North- } \\
\text { America } \\
\text { and } \\
\text { Australia }\end{array}$ & $\begin{array}{l}\text { South- } \\
\text { America }\end{array}$ & Africa & Asia & $\begin{array}{l}\text { Middle- } \\
\text { East }\end{array}$ \\
\hline & & & Coef. & Coef. & Coef. & Coef. & Coef. & Coef. \\
\hline \multirow{3}{*}{\multicolumn{2}{|c|}{ Naturalisation }} & Yes & -0.019 & 0.012 & -0.014 & $0.032 * * *$ & -0.001 & 0.009 \\
\hline & & & $(0.010)$ & $(0.016)$ & $(0.014)$ & $(0.005)$ & $(0.012)$ & $(0.006)$ \\
\hline & & No & ref. & ref. & ref. & ref. & ref. & ref. \\
\hline \multirow{2}{*}{\multicolumn{2}{|c|}{$\begin{array}{l}\text { Years since migration*naturalisation } \\
\text { during observation period }\end{array}$}} & & $0.029 * * *$ & $0.014^{* * *}$ & $0.021^{* * *}$ & $0.017 * * *$ & $0.024^{* * *}$ & $0.025^{* * *}$ \\
\hline & & & $(0.001)$ & $(0.003)$ & $(0.003)$ & $(0.001)$ & $(0.002)$ & $(0.001)$ \\
\hline \multirow{2}{*}{\multicolumn{3}{|c|}{ Years since naturalisation*naturalisation }} & $-0.013^{* * *}$ & $-0.013^{*}$ & $-0.015^{* * *}$ & $-0.019 * * *$ & $-0.025 * * *$ & $-0.016 * * *$ \\
\hline & & & $(0.003)$ & $(0.005)$ & $(0.004)$ & $(0.001)$ & $(0.004)$ & $(0.002)$ \\
\hline$*: p<0.05$ & $\mathrm{~N}$ & & 21,593 & 5,880 & 1,544 & 11,068 & 4,640 & 14,827 \\
\hline \multirow[t]{2}{*}{$* * *: p<0.001$} & Observations & & 209,376 & 45,817 & 15,686 & 121,723 & 43,766 & 151,204 \\
\hline & -2 Log-likelihood & & 143,434 & 34,820 & 9,967 & 64,908 & 31,684 & 181,997 \\
\hline
\end{tabular}

Table 7b. Individual fixed effects regression on Log labour income of female immigrants with employment by origin regions, cohorts 1999-2002. +

\begin{tabular}{|c|c|c|c|c|c|c|c|c|}
\hline & & \multicolumn{2}{|r|}{ EU } & \multicolumn{2}{|l|}{$\begin{array}{l}\text { Non-EU } \\
\text { Europe, } \\
\text { North- } \\
\text { America } \\
\text { and } \\
\text { Australia }\end{array}$} & Africa & Asia & $\begin{array}{l}\text { Middle- } \\
\text { East }\end{array}$ \\
\hline & & & Coef. & Coef. & Coef. & Coef. & Coef. & Coef. \\
\hline \multirow{3}{*}{\multicolumn{2}{|c|}{ Naturalisation }} & Yes & $-0.030 * * *$ & 0.002 & 0.009 & 0.012 & $0.040 * * *$ & $0.024 * *$ \\
\hline & & & $(0.006)$ & $(0.010)$ & $(0.007)$ & $(0.006)$ & $(0.008)$ & $(0.008)$ \\
\hline & & No & ref. & ref. & ref. & ref. & ref. & ref. \\
\hline \multirow{2}{*}{\multicolumn{2}{|c|}{$\begin{array}{l}\text { Years since migration* naturalisation } \\
\text { during observation period }\end{array}$}} & & $0.030 * * *$ & $0.032 * * *$ & $0.006^{* *}$ & $0.017 * * *$ & $0.014 * * *$ & $0.016^{* * *}$ \\
\hline & & & $(0.002)$ & $(0.002)$ & $(0.002)$ & $(0.001)$ & $(0.002)$ & $(0.001)$ \\
\hline \multirow{2}{*}{\multicolumn{2}{|c|}{ Years since naturalisation*naturalisation }} & & $-0.019 * * *$ & $-0.039 * * *$ & -0.004 & $-0.011^{* * *}$ & $-0.021 * * *$ & -0.001 \\
\hline & & & $(0.002)$ & $(0.004)$ & $(0.002)$ & $(0.002)$ & $(0.003)$ & $(0.003)$ \\
\hline$* *: p<0.01$ & $\mathrm{~N}$ & & 19,715 & 6,222 & 3,149 & 5,695 & 6,318 & 5,745 \\
\hline \multirow[t]{2}{*}{$* * *: p<0.001$} & Observations & & 196,886 & 44,253 & 31,341 & 52,048 & 64,439 & 43,624 \\
\hline & -2 Log-likelihood & & 127,610 & 31,095 & 13,184 & 17,270 & 49,431 & 32,740 \\
\hline
\end{tabular}

t: Standard errors in parentheses. Results include controls for years since migration, the partner status and having young children in the household.

Source: Statistics Netherlands.

In sum, we observe an effect of citizenship on immigrant earnings even when controlling for endogeneity, but (1) it only applies to specific migrant groups, and (2) it does not solely 
manifest as a consequence of naturalisation itself but also from the decision to naturalise in the future. However, our findings do not provide an indication where these effects in Log labour income are coming from. On the one hand, naturalisation may facilitate access to better (i.e. higher paying) jobs, but on the other hand, the effect might also stem from contract extensions (i.e. more working hours). To analyse this in detail, we include a control for working hours to the main model. Data on working hours is only available for migrant cohorts 2001 onwards, so we perform the main analysis (without a control for working hours) for cohorts 2001-2002 to facilitate the comparison, and provide a clear indication as to the relevance of working hours to the model. Table 8 shows the findings for men and women respectively. Results from the model without a control for working hours are similar to those in the main analysis (Table 5), except that male immigrants now enjoy a minor upward shift in income of 2.3 percent after naturalisation. However, this 'Naturalisation' coefficient loses its significance when working hours are added to the model. For women, the coefficient even becomes negative. Furthermore, the Log labour income now develops equally fast for migrants who have naturalised and those who have not, all else constant. More generally, all the coefficients on naturalisation decrease when controlling for working hours. These findings thus suggest that in so far as there is an effect of naturalisation, it partly stems from an increase in working hours.

Table 8. Individual fixed effects regression on Log labour income and Log labour income when controlling for working hours of male and female immigrants with employment, cohorts 2001-2002.

\begin{tabular}{|c|c|c|c|c|c|c|c|c|c|}
\hline & & \multicolumn{4}{|l|}{ Men } & \multicolumn{4}{|c|}{ Women } \\
\hline & & \multicolumn{2}{|c|}{$\begin{array}{l}\text { No control working } \\
\text { hours }\end{array}$} & \multicolumn{2}{|c|}{$\begin{array}{l}\text { Control working } \\
\text { hours }\end{array}$} & \multicolumn{2}{|c|}{$\begin{array}{l}\text { No control working } \\
\text { hours }\end{array}$} & \multicolumn{2}{|c|}{$\begin{array}{l}\text { Control working } \\
\text { hours }\end{array}$} \\
\hline & & Coef. & Std. error & Coef. & Std. error & Coef. & Std. error & Coef. & Std. error \\
\hline \multirow[t]{2}{*}{ Naturalisation } & Yes & 0.010 & $0.005^{*}$ & 0.001 & 0.005 & 0.005 & 0.004 & -0.016 & $0.004 * * *$ \\
\hline & No & ref. & ref. & ref. & ref. & ref. & ref. & ref. & ref. \\
\hline $\begin{array}{l}\text { Years since migration* } \\
\text { naturalisation during } \\
\text { observation period }\end{array}$ & & 0.025 & $0.001 * * *$ & 0.014 & $0.000 * * *$ & 0.022 & $0.001 * * *$ & 0.009 & $0.001 * * *$ \\
\hline $\begin{array}{l}\text { Years since } \\
\text { naturalisation* } \\
\text { naturalisation }\end{array}$ & & -0.017 & $0.002 * * *$ & -0.006 & $0.002 * * *$ & -0.010 & $0.001 * * *$ & 0.001 & 0.001 \\
\hline $\begin{array}{l}*: p<0.05 \\
* * *: p<0.001\end{array}$ & & \multicolumn{2}{|c|}{$\begin{array}{l}\text { Observations }=301,740 \\
-2 \text { Log-likelihood }=256,955\end{array}$} & \multicolumn{2}{|c|}{$\begin{array}{l}\text { Observations = 183,106 } \\
-2 \text { Log-likelihood = 197,279 }\end{array}$} & \multicolumn{2}{|c|}{$\begin{array}{l}\text { Observations }=224,672 \\
-2 \text { Log-likelihood }=145,728\end{array}$} & \multicolumn{2}{|c|}{$\begin{array}{l}\text { Observations }=212,087 \\
-2 \text { Log-likelihood }=79,071\end{array}$} \\
\hline
\end{tabular}

Naturalisation has the potential to stimulate earnings from labour for some immigrant groups. But is this mobility limited to the labour market sector in which migrants are already employed, or does citizenship acquisition facilitate access to other, higher paying sectors? In other words, does naturalisation affect the job distribution of immigrants? Tables 9a and 9b provide estimates for employed men and women respectively when labour market sectors are added to the main model. Since information on labour market sectors is unknown for a number of individuals, we also repeat the main analysis (without controlling for labour 
market sectors) for the population where information on sectors is available. Our findings reveal some discrepancies in Log labour income between sectors (see also Tables A18 and A19 in the appendix). Detailed analyses indicate that heterogeneity in Log labour income between labour market sectors is largely explained by discrepancies in levels of education, which are mostly captured by the individual fixed-effects (the relevance of education is analysed in detail in the paragraph 'robustness analyses'). The substantial number of immigrants working in jobs in business services, such as call centres, packaging and office cleaning, enjoy relatively low earnings. In contrast, earnings are high in information and communication (e.g. system administrators, technical support of companies, radio and television) and the financial services (e.g. banks, investment companies, credit unions), although the number of migrants working in these sectors is comparatively small. Our data do not allow for a disentanglement of jobs in the public sector and the care sector. While a substantial proportion of immigrants are represented in this category (particularly female immigrants), earnings tend to be relatively low in the care sector, which may explain why the coefficients for this category are not higher. With regard to citizenship acquisition, when labour market sectors are added to the model, the coefficients of the various naturalisation parameters remain almost identical for both men and women. We conclude that the effect of citizenship does not result from mobility between sectors of the labour market.

Table 9a. Individual fixed-effects regression on Log labour income and Log labour income when controlling for labour market sectors of male immigrants with employment, cohorts 1999-2002. ${ }^{\dagger}$

\begin{tabular}{|c|c|c|c|c|}
\hline & \multicolumn{4}{|l|}{ Men } \\
\hline & Coef. & Std. error & Coef. & Std. error \\
\hline \multicolumn{5}{|l|}{ Naturalisation } \\
\hline Yes & 0.002 & 0.003 & 0.001 & 0.003 \\
\hline No & ref. & ref. & ref. & ref. \\
\hline $\begin{array}{l}\text { Years since migration*naturalisation during } \\
\text { observation period }\end{array}$ & 0.026 & $0.001 * * *$ & 0.025 & $0.001 * * *$ \\
\hline Years since naturalisation*naturalisation & -0.017 & $0.001 * * *$ & -0.016 & $0.001 * * *$ \\
\hline \multicolumn{5}{|l|}{ Sector } \\
\hline Agriculture, forestry and fishery & & & ref. & ref. \\
\hline Non-housing industry and energy & & & 0.089 & $0.005 * * *$ \\
\hline Housing industry & & & 0.100 & $0.006 * * *$ \\
\hline Transportation and catering & & & 0.021 & $0.005^{* * *}$ \\
\hline Information and communication & & & 0.063 & $0.006 * * *$ \\
\hline Financial services & & & 0.154 & $0.007 * * *$ \\
\hline Rent and management of property & & & 0.073 & $0.012 * * *$ \\
\hline Business services & & & 0.037 & $0.005 * * *$ \\
\hline Public sector and care sector & & & 0.063 & $0.006 * * *$ \\
\hline Culture, recreation and other & & & 0.073 & $0.007^{* * *}$ \\
\hline \multirow[t]{3}{*}{$* * *: p<0.001$} & \multicolumn{2}{|c|}{$N=51,217$} & \multicolumn{2}{|c|}{$N=51,217$} \\
\hline & \multicolumn{2}{|c|}{ Observations $=472,848$} & \multicolumn{2}{|c|}{ Observations $=472,848$} \\
\hline & \multicolumn{2}{|c|}{-2 Log-likelihood $=271,350$} & \multicolumn{2}{|c|}{-2 Log-likelihood $=269,768$} \\
\hline
\end{tabular}


Table 9b. Individual fixed-effects regression on Log labour income and Log labour income when controlling for labour market sectors of female immigrants with employment, cohorts 1999-2002. ${ }^{+}$

\begin{tabular}{|c|c|c|c|c|}
\hline & \multicolumn{4}{|l|}{ Women } \\
\hline & Coef. & Std. error & Coef. & Std. error \\
\hline \multicolumn{5}{|l|}{ Naturalisation } \\
\hline Yes & 0.005 & 0.003 & 0.003 & 0.003 \\
\hline No & ref. & ref. & ref. & ref. \\
\hline $\begin{array}{l}\text { Years since migration*naturalisation during } \\
\text { observation period }\end{array}$ & 0.020 & $0.001 * * *$ & 0.019 & $0.001 * * *$ \\
\hline Years since naturalisation*naturalisation & -0.015 & $0.001 * * *$ & -0.015 & $0.001 * * *$ \\
\hline \multicolumn{5}{|l|}{ Sector } \\
\hline Agriculture, forestry and fishery & & & ref. & ref. \\
\hline Non-housing industry and energy & & & 0.059 & $0.005 * * *$ \\
\hline Housing industry & & & 0.034 & $0.011^{* *}$ \\
\hline Transportation and catering & & & 0.001 & 0.005 \\
\hline Information and communication & & & 0.059 & $0.006 * * *$ \\
\hline Financial services & & & 0.095 & $0.007 * * *$ \\
\hline Rent and management of property & & & 0.022 & $0.011 *$ \\
\hline Business services & & & -0.022 & $0.005^{* * *}$ \\
\hline Public sector and care sector & & & 0.031 & $0.006^{* * *}$ \\
\hline Culture, recreation and other & & & 0.004 & 0.006 \\
\hline$*: p<0.05$ & \multicolumn{2}{|c|}{$N=38,994$} & \multicolumn{2}{|c|}{$N=38,994$} \\
\hline$* *: p<0.01$ & \multirow{2}{*}{\multicolumn{2}{|c|}{$\begin{array}{l}\text { Observations }=350,518 \\
-2 \text { Log-likelihood }=106,278\end{array}$}} & \multicolumn{2}{|c|}{ Observations $=350,518$} \\
\hline$* * *: p<0.001$ & & & -2 Log-1 & ood $=104,488$ \\
\hline
\end{tabular}

\section{ROBUSTNESS ANALYSES}

In our analyses, migrants are tracked over time for a maximum period of 10 years. However, if migrants emigrate before this point in time, they drop out of the analysis. These right-truncated migrants potentially introduce bias by driving our findings. More specifically, migrants who decide to leave the Netherlands after a relatively short period of residence may do so partly because of negative experiences in the labour market. These unsuccessful migrants are simultaneously unlikely to acquire citizenship. To analyse whether the observed citizenship premium is predominantly driven by these emigrating individuals, we perform a separate analysis for migrants who remain in the Netherlands for the entire observation period. Table A20 shows that 24,398 individuals drop out of the analysis due to right-truncation. However, the findings for migrants who remain in the Netherlands are highly similar to those in the main model. Most importantly, we have no reason to assume that we are overestimating the citizenship premium in the main model (Table 5, Model 1) due to right-truncation. We conclude that the observed relevance of citizenship in our analyses is not driven by emigrating individuals. 
In the Netherlands, information on education is mostly based on survey data, and therefore incomplete. For this reason, we refrained from including education in our models. Since the level of education is predominantly stable within individuals during the observation period, the relevance of education is mostly captured by the individual fixed-effects. However, given the importance of education for research on labour market outcomes, we performed a number of robustness checks with the available information on education. Table A21 provides coefficients of employed immigrants for whom the level of education is known, both with and without the inclusion of education to the model. The relevance of naturalisation is highly comparable to the population in the main model (Table 5, Model 1). In line with our expectations, education is positively associated with income from labour. More importantly, the coefficients of naturalisation remain very stable when education is included in the model. In Table A22, we conducted the same analysis, but included observations of immigrants without employment (in line with Table 5, Model 2). Again, the level of education is positively associated with income from labour, but does not explain the relevance of naturalisation. As such, we have no reason to assume that we are overestimating the relevance of citizenship due to education.

Almost all of our analyses focus on migrants with employment. In Table 5, Model 2, we include observations of the unemployed, and observe a stronger effect of naturalisation for these migrants. However, we do not have information in the Dutch register data on whether migrants have a work permit or not. The more positive effect of naturalisation for unemployed migrants may thus be explained by a lack of labour market access for these migrants prior to naturalisation. To analyse this in detail, we perform additional analyses for migrants from origin countries that became part of the $\mathrm{EU}$ in 2004. Although migrants from the EU have unrestricted labour market access in the Netherlands (excluding jobs reserved for citizens), work permit restrictions for this group of migrants were only lifted from May 1, 2007 onwards. In that context, we perform a separate analysis for these migrants, with the inclusion of a dummy that is set to unity in the period after May 2007. Results in Table A23 show that the relevance of citizenship for migrants from countries that joined the EU in 2004 is similar to the main model. The exception is the one-time effect after naturalisation, which is not statistically significant for both men and women. This is not surprising, since literature on naturalisation and employment shows that the one-time boost after naturalisation for migrants from the EU is comparatively small. However, we do observe a positive effect leading up to naturalisation, consistent with the notion of anticipation. And importantly, the relevance of citizenship remains highly stable when a dummy for the period before and after May 2007 is introduced to the model. In other words, the relevance of citizenship acquisition is not substantially affected by the lifting of work permit restrictions. These findings thus suggest that the results in Table 5, Model 2 are not driven by migrants without a work permit. 
We observe an increase in earnings leading up to naturalisation, and hypothesise that this is due to investments migrants make in anticipation of acquiring citizenship. However, an alternative explanation could be that higher earnings increase the propensity or ability to naturalise. For instance, financial means may provide the opportunity to pay for the costs associated with applying for citizenship and completing the exam. To analyse this reversed causal pathway, we compare migrants who became eligible for citizenship acquisition before and after a restriction in citizenship policy in the Netherlands, namely the introduction of a naturalisation test in 2003. More specifically, we compare migrant cohorts 1996-1997, who could naturalise prior to the policy change, and cohorts 2001-2002, who had to complete the naturalisation test (see Chapter 3 and Chapter 4 for a similar approach). If the effect prior to naturalisation is solely due to increased earnings facilitating naturalisation, then we should observe no differences between the cohorts. But if investment in (language) skills and knowledge of the Dutch society in anticipation of citizenship acquisition also matters, than we would expect a stronger effect under the institutional conditions where these skills are a formal requirement for naturalisation. We can only observe migrants from the early cohort group from 1999 onwards, but these migrants are normally only eligible for naturalisation after this point in time due to the residence requirement of 5 years. Results in Table A24 reveal that the relevance of naturalisation for migrant cohort 19961997 is similar to the main sample. However, the positive labour market outcomes we observe already prior to naturalisation (years since migration*naturalisation during the observation period) are stronger for the later cohort group under the more restrictive institutional conditions compared to the earlier cohort group who did not have to successfully complete the naturalisation test. These findings thus suggest that the labour market outcomes prior to naturalisation are not solely due to earnings-specific effects.

To further determine whether the effects prior to naturalisation are due to investment in anticipation of naturalisation, or rather higher earnings increasing the propensity to naturalise, we again estimate the main model with an instrumental variable. We follow the approach of Just and Anderson (2012, p. 499) by using the geographical distance between the host country and the origin country as an instrument for naturalisation. Literature suggests that a shorter distance between the origin and host country makes it easier to maintain ties with the origin country, and thus disincentives full integration through naturalisation. In the same vein, more geographical distance increases the costs associated with return migration, and thus increases the propensity to naturalise (Yang, 1994, p. 473). However, when timeinvariant country characteristics such as economic development are held constant through the individual fixed-effects, there is no clear association between geographical distance and earnings from labour. As such, geographical distance between the host and origin country is a suitable instrument to isolate the association between naturalisation and earnings. Results in Table A25 show that the coefficient measuring 
anticipation (years since migration*naturalisation during the observation period) remains positive and statistically significant with our instrumental variable. Assuming that this is a good instrument for naturalisation, these findings suggest that the positive labour market outcomes prior to naturalisation are not solely attributable to higher earnings facilitating naturalisation.

\section{CONCLUSION}

Over the last decades, naturalisation has emerged as a potentially promising vehicle to facilitate the settlement process of immigrants. However, empirical support for a socalled citizenship premium is inconclusive, as some studies reveal a positive effect of naturalisation in terms of income from labour, whereas others do not. In this chapter, we theorise on potential explanations for this empirical ambiguity, and test these assumptions using register data from Statistics Netherlands.

Our analyses reveal that in general, naturalisation does not confer a one-time boost in immigrant earnings after naturalisation. As such, we find no support for the traditional hypothesis that naturalisation promotes income from labour through positive signalling, increased labour market access and reduced administrative costs for employers. This is a common observation in the literature (Bratsberg \& Raaum, 2011, p. 197; Bratsberg et al., 2002, p. 582; Helgertz et al., 2014, p. 352; Steinhardt, 2012, p. 818), but so far there is no clear explanation for these findings. We argue that the signalling potential of citizenship is particularly relevant to unemployed migrants, since having paid employment potentially serves as a positive signalling device in its own right. Consistent with this argument, we do observe a subsequent positive effect of naturalisation when including unemployed migrants in the model. This suggests that citizenship acquisition particularly facilitates access to the labour market rather than occupational mobility. Given the predominant focus in the literature on immigrant earnings as opposed to employment, this may in part explain the limited empirical support for a citizenship premium in contemporary studies. Furthermore, our findings indicate that citizenship acquisition does provide an upward shift in earnings for employed migrants from economically less developed countries of origin. In other words, in so far as there is a subsequent effect of naturalisation, it matters exclusively to migrants from poorer countries of origin, which is consistent with earlier longitudinal research in the U.S. (Bratsberg et al., 2002, p. 590). We argue that these migrants face the most structural disadvantages in the labour market, and therefore stand to benefit from citizenship most. More detailed analyses show that the relevance of citizenship for employed immigrants in part results from an increase in working hours, but not from mobility between labour market sectors.

Consistent with earlier research in Sweden and Denmark (Helgertz et al., 2014, p. 352), the earnings profile of immigrants develops faster prior to naturalisation than 


\section{Chapter 5}

afterwards. Detailed analyses confirm that earnings from labour increase leading up to the moment of naturalisation, and peak shortly after citizenship acquisition. We follow the interpretation of Bratsberg et al. (2002, p. 590), who argue that immigrants anticipate naturalisation by investing in their own human capital development. As such, the labour market performance of these migrants already improves prior to naturalisation as a result of the explicit decision to naturalise in the future.

More generally, our findings underline that the identification of a citizenship premium is strongly dependent on the research design in terms of case selection and operationalisation. Most of the literature focusses on immigrant earnings, but the established theoretical framework is particularly relevant in the context of having employment. Indeed, we particularly observe positive effects in earnings from labour after naturalisation for unemployed migrants. In so far as there is an effect of citizenship for employed immigrants, it predominantly manifests leading up to naturalisation. Our findings thus suggest that citizenship matters in terms of income from labour, but that its impact is conditional, and only applies to particular migrant groups. 
Chapter

\section{Naturalisation and the Transition to Homeownership: An Analysis of Signalling and Legal Status Discrimination in the Dutch Housing Market ${ }^{14}$}

${ }^{14}$ This chapter is submitted for publication and is currently under review. 



\section{INTRODUCTION}

Over the last decade, a large number of foreign-born individuals acquired the citizenship of an OECD country (OECD, 2015, p. 204). Among long-term settlers who are resident for at least ten years, more than sixty percent possesses the host-country citizenship. In that context, a broad range of literature has analysed whether naturalisation improves the odds of settlement success (e.g. OECD, 2011). While the integration of immigrants starts at the moment of arrival in the host country, naturalisation may still be an important transition. Indeed, literature suggests that citizenship acquisition facilitates socio-economic integration for some migrant groups under certain conditions (Bratsberg, et al., 2002; Engdahl, 2014; Helgertz et al., 2014; Steinhardt, 2012).

However, research on integration outcomes of naturalisation - also known as the 'citizenship premium' - has so far predominantly focussed on labour market indicators, such as employment and earnings. Yet the settlement process comprises a much broader range of socio-economic factors, such as quality of housing, living conditions and neighbourhood characteristics. Although there is research on those indicators (Feijten, Hooimeijer, \& Mulder, 2008; McConnel, 2015; Rossi \& Weber, 1996; Uunk, 2017; Zorlu, Mulder, \& van Gaalen, 2014), the role of citizenship for these integration outcomes is often not specifically addressed. As such, the relevance of naturalisation remains an open question. This paper analyses whether citizenship acquisition matters for one of the understudied non-labour market indicators of socio-economic integration, namely housing market integration. More specifically, I analyse the relevance of Dutch citizenship for homeownership of first generation immigrants in the Netherlands. Homeownership is an important facet of the settlement process, providing long-term financial benefits compared to private and social rented housing. For instance, homeowners enjoy lower long-term payment for housing, favourable tax treatment and the gradual accumulation of property wealth (Charles \& Hurst, 2002). Furthermore, homeownership may stimulate social well-being through an increase in social status, greater psychological health (Rohe \& Stegman, 1994) and better neighbourhood conditions (Rossi \& Weber, 1996).

This paper contributes to the literature in two ways. First, a substantial amount of literature has already analysed the so-called ethnic gap in homeownership, revealing that immigrants are more likely to be tenants than homeowners compared to the native population (Boehm \& Slottmann, 2004; Dawkins, 2005; Uunk, 2017; Zorlu et al., 2014). These findings are robust to controls for various socio-economic and demographic characteristics. Some studies include citizenship in their models, revealing a positive association between naturalisation and homeownership (Constant, Roberts, \& Zimmermann, 2009; Enchautegui \& Giannarelli, 2015; Hutcheson \& Jeffers, 2013; Masnick, 1997). However, these studies either use cross-sectional data, or analyse longitudinal data in a descriptive way (often cross-nationally). Given the selective nature 
of the naturalisation process, this introduces the risk of so-called self-selection bias. More specifically, migrants who naturalise are positively selected in terms of motivation, ability, and other endogenous characteristics that are hard to measure and control for. These characteristics may simultaneously be positively associated with the propensity and ability to buy a house. Failing to account for endogeneity may result in an overestimation of the citizenship premium in the housing market. This study makes use of panel data to compare the moment before and after naturalisation, and disentangle selection effects from citizenship effects. Second, this chapter draws on the established theoretical framework on labour market outcomes of naturalisation to develop a model for housing market integration. Citizenship acquisition has the potential to provide a boost in employment and earnings for some migrant groups (Bratsberg et al., 2002; Steinhardt, 2012; Helgertz et al., 2014). One of the most important mechanisms that is traditionally associated with a citizenship premium in the labour market is positive signalling. This paper builds on that theoretical framework by analysing whether the signalling potential of citizenship also matters in the housing market, and if so, to whom and under which conditions citizenship matters.

I make use of register data from Statistics Netherlands based on information from the Dutch System of Social Statistical Datasets. These data include almost all registered first generation immigrants in the Netherlands $(N=106,187)$ over the period 20032011, whose characteristics can be tracked over time. The paper is structured as follows. First, I briefly detail the Dutch housing market and citizenship policy. I then outline the theoretical framework and hypotheses, as well as the data and empirical strategy. Subsequently, results from the analyses are presented, and finally, I discuss the conclusions and implications of the findings.

\section{CONTEXT}

Homeownership is comparatively attractive in the Netherlands. Down-payment requirements are typically limited, and houses can be financed through a mortgage with relatively little investment of personal wealth (Uuhl, 2016, p. 98). Moreover, the Dutch government encourages homeownership through tax deduction of interest payments. These advantages are reflected in the large number of mortgaged homeowners, as well as the relatively high mortgage debt per capita in the Netherlands (Norris \& Winston, 2012).

There are no legal restrictions for immigrants to buy property in the Netherlands. Yet migrants are less often homeowners compared to the native population. Figures from Statistics Netherlands show that on January 1, 2011, over 3.5 million native-born individuals were homeowners, constituting 60.4 percent of all households with a nativeborn principal wage-earner (CBS, 2017a). Among migrant households of western origin, the proportion of homeowners is 46.1 percent, and among migrant households of non- 
western descent, this is limited to 24.4 percent. ${ }^{15}$ In addition to structural factors (e.g. compositional differences between migrants and natives), a contextual explanation for this discrepancy is that individuals with a non-permanent residence status are not eligible for the so-called Dutch National Mortgage Guarantee (Nationale Hypotheek Garantie [NHG] in Dutch). When a mortgage is NHG-backed, periodic payment is guaranteed to the mortgage lender (in most cases a bank) by the governmental Homeownership Guarantee Fund (Waarborgfonds Eigen Woningen) when payment is not possible due to exceptional circumstances beyond the lenders control (such as the loss of employment or the death of the partner). Given the relatively secure, low-risk nature of such loans, banks are generally willing to offer a mortgage under more liberal conditions, which in practice means that these individuals are better able to afford a house. However, there are strict requirements for an NHG-backed mortgage, including a non-temporary residence permit. In the Netherlands, this may explain part of the ethnic gap in homeownership.

Eligibility for a mortgage is formally not linked to citizenship status. In fact, article 7, paragraph 1c of the Equal Treatment Act (Algemene Wet Gelijke Behandeling) prohibits unequal treatment in the provision of services and goods, as well as the closing, executing and terminating of agreements in the field of housing on the basis of nationality. In practice however, banks may consider mortgage applications of nonnaturalised migrants as risky due to observed or perceived higher failure rates compared to naturalised or native-born applicants. Indeed, there are signs that Dutch banks do not always abide by the Equal Treatment Act. ${ }^{16}$ In other words, while from a legal perspective, citizenship acquisition should not matter for homeownership in the Netherlands, it may in practice still matter through positive signalling to mortgage lenders.

The conditions under which migrants are eligible for citizenship acquisition in the Netherlands are stipulated in the Dutch Nationality Act. Since April 1, 2003, requirements for naturalisation include being at least 18 years of age, having a nontemporary residence permit, residing legally in the Netherlands for an uninterrupted

\footnotetext{
15 Statistics Netherlands distinguishes between migrants of western and non-western descent. Western migrants are individuals originating from a country in Europe (excluding Turkey), North-America, Oceania, Indonesia and Japan, whereas migrants from Africa, South-America, Asia (excluding Indonesia and Japan) and Turkey are classified as non-western. Statistics Netherlands considers migrants from Indonesia and Japan western due to their socio-economic and cultural position, and in light of the colonial history of the Netherlands.

${ }^{16}$ See for instance the case of a German migrant versus the Dutch Bank SNS in 2016, where the Netherlands Institute for Human Rights (College voor de Rechten van de Mens, 2016) ruled that discrimination on the basis of nationality occurred when said migrant applied for a mortgage. In this case, SNS conditioned eligibility of migrants for a mortgage to a minimum period of activity in the Dutch labour market. A recent report by the National Ombudsman revealed that migrants in the Netherlands indeed have trouble securing a mortgage due to their nationality (van Dorst et al., 2017, pp. 22-23). And in a recent response to the explanatory memorandum on the proposed law concerning the residence requirement for naturalisation, the Dutch government noted that not possessing the Dutch nationality likely decreases the odds of successfully securing credit in the housing market of the Netherlands (Eerste Kamer, 2017a, p. 3).
} 
period of 5 years, and the absence of a criminal record. Migrants with a Dutch partner are exempted from the residence requirement, and only need a permanent residence permit and principal residence in the Netherlands. Dual citizenship is not allowed in the Netherlands. However, there are many exceptions to the renunciation requirement, for instance for migrants who are the registered partner of a Dutch national, or for whom renunciation of the original nationality is not legally possible or cannot be reasonably demanded. Finally, migrants need to pass a formalised naturalisation test in which their Dutch language skills and civic knowledge of the Netherlands are tested. The language requirement is at level A2 of the Common European Framework of Reference for Languages. Labour market activity is not a requirement for naturalisation. In terms of formal benefits, the Dutch nationality provides a secure legal status on the territory of the Netherlands, full voting rights, and diplomatic protection and support. With regard to labour market access, naturalisation lifts restrictions on a small number of professions in the army, law and the public sector.

\section{THEORETICAL FRAMEWORK}

Literature has identified four main explanations for the ethnic gap in homeownership. First, migrants generally have a weaker socio-economic position in terms of wealth and labour market access compared to natives (Heath \& Cheung, 2007). Due to these financial constraints, migrants have limited opportunities in the credit market, and are less able to afford a house (Charles \& Hurst, 2002; Coulson \& Dalton, 2010). Second, it is often assumed that individuals prefer homeownership to renting due to long-term financial, social, physical and ecological benefits (Charles \& Hurst, 2002; Rohe \& Stegman, 1994; Rossi \& Weber, 1996; Uunk, 2017). This implies that individuals in social or private rented housing face particular constraints that deter them from becoming a homeowner. However, for migrants, the decision to buy a house is not just an economic cost-benefit consideration, but can also be seen as a commitment to the community, and a life course decision to permanently settle in the host country (Constant et al., 2009). In the initial years after migration, immigrants differ from the native population with regard to the stability of their life situation in the host country. More specifically, migrant households may be more mobile and less settled compared to natives (Charles \& Hurst, 2002). Homeownership is arguably less attractive while long-term prospects remain unclear. Migrants may therefore be less inclined to buy a house. Third, research shows that housing appreciation rates are positively associated with income (Case \& Mayer, 1996). Since migrants in general have more limited financial means, the appreciation rates of houses that are affordable to them will be lower. As such, expected returns on the investment will be smaller, and the valuation of homeownership more limited compared to natives. Fourth, migrants can face ethnic discrimination in the housing and credit market. Lenders may be less inclined to 
approve credit for immigrants in light of real or perceived higher risk associated with such a loan compared to natives. Although the migrant background is only one factor that lenders consider in their risk-calculation, studies have found evidence of so-called redlining by ethnicity when holding other personal and contextual characteristics constant (Aalbers, 2007; Ross \& Tootell, 2004).

\section{Citizenship and homeownership: the citizenship premium in the housing market}

How does citizenship factor into the dynamics underlying the ethnic homeownership gap? A systematic analysis of a potential citizenship premium in the housing market is surprisingly absent in the literature. In most studies, citizenship is not considered, as the foreign and naturalised population are pooled together (e.g. Borjas, 2002, p. 450). One study that does analyse the role of citizenship for living conditions of immigrants, including homeownership, reveals more positive outcomes among naturalised migrants compared to the foreign population (Hutcheson \& Jeffers, 2013). However, these aggregate, cross-national findings do not include any controls for socio-economic or demographic characteristics. Another study in the United States makes use of a quasiexperimental matching strategy to isolate omitted variable bias (Enchautegui \& Giannarelli, 2015). However, the cross-sectional nature of their data does not allow for controls on reverse causality. In other words, it is unclear to what extent the positive effect of naturalisation on homeownership is explained by homeownership increasing the odds of naturalisation. As such, the question remains to what extent citizenship acquisition facilitates homeownership of immigrants.

Most of the literature on the citizenship premium focusses on labour market outcomes rather than the housing market. Although this field of literature is more extensive, empirical findings are equally ambiguous (Helgertz et al., 2014, p. 343). Some studies identify a positive effect of naturalisation on the earnings of particular migrant groups (Bratsberg et al., 2002; Engdahl, 2014; Helgertz et al., 2014; Steinhardt, 2012), while other reveal no effect or even a negative association (e.g. Bratsberg \& Raaum, 2011; Engdahl, 2011; Scott, 2008). The literature points towards the signalling potential of citizenship as the main explanation for positive labour market outcomes. In light of unfamiliar or unrecognised educational qualifications, as well as possible short-term out-migration, employers may find it risky to hire foreign-born individuals. Possessing the citizenship of the host country may placate those uncertainties by signalling commitment and the intention to permanently settle in the host country. For similar reasons, citizenship may positively affect the opportunities of immigrants in the credit market. Lenders consider many characteristics when evaluating creditworthiness, such as an applicants' household wealth, household income and job prospects. Research confirms that financial means are an important determinant of homeownership, and constitute one of the main explanations for the ethnic gap in homeownership (Charles \& Hurst, 2002; Coulson \& Dalton, 2010). In that context, possessing the host country 
citizenship may prove instrumental for immigrants to secure credit. Naturalisation may signal motivation, commitment and the intention to invest in building a life in the host country, and lenders may thus assume that job prospects for these migrants are more positive. Indeed, naturalising migrants are positively selected with regard to their labour market potential, and citizenship acquisition facilitates access to the labour market (see Chapter 4 for details). In other words, citizenship acquisition may favourably influence the risk-calculation of lenders, improving the odds of successfully securing a mortgage.

Another determinant of the ethnic gap in homeownership is ethnic discrimination (Aalbers, 2007; Ross \& Tootell, 2004), which can manifest in different forms. First, lenders will have to work harder to get a mortgage approved for households who are in the margins of qualification, and thus face additional costs when doing so (Uunk, 2017, p. 98). In that context, mortgage officers may be warned of higher failure rates among immigrants, and not consider applicants with a migrant background. This process of 'redlining by ethnicity' is a statistical form of discrimination. Alternatively, lenders may hold ethnic prejudices and discriminate more directly. While ethnic discrimination is illegal in the Netherlands, some research suggests that discriminatory practices do occur in the Dutch housing market (Aalbers, 2007). Again, possession of the citizenship of the host country may positively factor into the risk-calculation of lenders, and mitigate discriminatory behaviour. The naturalised status may signal that these individuals are the cream of the immigrant population, and are therefore the exception to the rule that migrants constitute a future payment risk. As such, naturalised migrants may have more opportunities in the credit market due to legal status discrimination.

\section{Unpacking the citizenship premium: to whom does naturalisation matter?}

If naturalisation matters in the housing market, does it matter equally to all migrant groups? Research has identified that the ethnic gap in homeownership is bigger for lower income households (Uunk, 2017, p. 107) and for particular ethnic groups (Borjas, 2002, p. 468). Yet the literature provides no guidelines whether the relevance of citizenship acquisition is conditional. Although the signalling effect of citizenship may positively influence the risk-calculation of lenders, it cannot provide a foundation for creditworthiness on its own. Without a stable and sufficient financial basis to meet standard loan qualifications, the citizenship of an applicant may not even be considered. In other words, if migrants do not fulfil the minimum financial requirements to be eligible for credit, lenders will have no reason to discriminate on the basis of legal status. I argue that migrants without employment are relatively unlikely to meet basic loan qualifications, as they are almost completely dependent on the earnings of their spouse to meet the necessary criteria. I thus theorize that the host country citizenship is unlikely to matter for these migrants, as financial constraints likely weigh more heavily than migrants' legal status in the risk calculation of lenders. My hypothesis reads as follows 
H1: Citizenship acquisition has a positive effect on the probability of homeownership of employed immigrants after naturalisation.

One of the mechanisms underlying the hypothesised citizenship premium in the housing market is that the host country citizenship attenuates discriminatory practices among lenders. While lenders may associate the migrant background with credit problems due to real or perceived higher failure rates among immigrants, naturalised migrants may be considered the exception to the rule, and thus suffer less from ethnic redlining. However, mortgage applications are often filed together with the partner, and qualifications are thus evaluated at the family level. If the spouse does not have a migrant background, this may placate perceived risk associated with approving a loan to a migrant. Lenders may in those cases be less inclined to discriminate on the grounds of legal status. In other words, having a native-born partner may function as a positive signalling device in its own right, and the legal status of the migrant is less relevant in that context. Naturalisation is thus particularly relevant to migrants without a nativeborn partner, who need the citizenship of the host country to mitigate the negative consequences of their migrant background.

Furthermore, lenders will not associate all migrants with an equal amount of risk. Some migrant groups may be considered more of a potential credit problem than others. Moreover, lenders may not discriminate against migrants in general, but rather against particular migrant groups. I expect that migrants who are culturally more dissimilar to the native population are more likely to be the subject of ethnic discrimination. Possessing the citizenship of the host country may matter more for these migrants, as naturalisation has the potential to attenuate such discrimination. Conversely, migrants who are phenotypically hard to distinguish from natives, or who share similar cultural values and beliefs, may not suffer from ethnic discrimination as much, and thus may not benefit from naturalisation. My expectations are as follows:

$\mathrm{H} 2$ : The positive effect of citizenship acquisition on the probability of homeownership of employed immigrants after naturalisation is weaker for migrants with a native-born partner.

H3: The positive effect of citizenship acquisition on the probability of homeownership of employed immigrants after naturalisation is stronger for migrants from origin countries that are culturally more dissimilar to the host country.

Besides the applicants' characteristics at the individual and family level, contextual circumstances will also factor into the risk-calculation of lenders. Liberal behaviour in mortgage approvals, speculative investment of housing assets and evasion of regulatory capital requirements for lending were instrumental in triggering the global financial crisis in 2008 (Acharya \& Schnabl, 2009; Martin, 2011). Moreover, in the context of poorly performing economies and high national unemployment rates, the risk that 
individuals will lose their job and have trouble paying their mortgage will be higher. For both reasons, lenders may have become more critical when evaluating creditworthiness during and after the global financial crisis. In that context, additional criteria may be considered, including the legal status of immigrants. In other words, the potential of the naturalised status to mitigate the risk associated with the migrant background may be more relevant under conditions where lenders are more critical, for instance post-2008. My expectation is thus as follows:

H4: The positive effect of citizenship acquisition on the probability of homeownership of employed immigrants after naturalisation is stronger during and after the global financial crisis of 2008.

\section{DATA AND METHODOLOGY}

To analyse the relevance of citizenship acquisition in the housing market, I make use of register data from Statistics Netherlands. Information is derived from the Dutch System of Social Statistical Datasets. This integral data source, developed by Statistics Netherlands, includes centrally stored and standardized information from a wide range of registers (see Bakker et al. [2014] for details). Relevant socio-economic and demographic characteristics have been linked to municipal population registers using assigned linkage keys. The final dataset consists of annual observations of first generation immigrants in the Netherlands between 2003 and 2011 ( $N=$ 106,187). Migrants are tracked over this period of time until the end of the observation period or the potential moment of emigration (right-truncation). In light of the methodological strategy (which is discussed below), the observation period also ends if migrants become a homeowner. I analyse migrants who arrived in the Netherlands between 1999 and 2002. The argument for this cohort selection is twofold. First, in light of the residence requirement for naturalisation, almost all migrants in this cohort selection became eligible for citizenship acquisition under the same institutional conditions, namely after the revision of the Dutch Nationality Act in 2003. Second, these migrants can be tracked up to 10 years after migration. The observation period is fixed to a maximum of 10 years of residence to standardise the tracking period between the cohorts.

This paper analyses foreign-born individuals of whom both parents were born abroad. I focus on first generation immigrants because later generations can acquire citizenship through a facilitated procedure, and the determinants of naturalisation differ between generations (Bauböck et al., 2013). The small number of migrants who already acquired Dutch citizenship prior to migrating to the Netherlands were excluded. This includes migrants born in Suriname before 1975, and individuals born in the Netherlands Antilles, who are often Dutch citizens by birth. I further focus the selection 
on migrants aged between 20 and 50 at the moment of arrival in the Netherlands. Homeownership rates of migrants younger than 20 are very low, and migrants older than 50 may have a relatively low incentive for homeownership, as returns on the investment will be comparatively small. Finally, I exclude migrants who are already homeowners at the moment of migration.

The dependent variable in this study is homeownership, which is measured dichotomously as living in a house that is owned by one or more members of the household. In other words, if the partner is the legal owner of the house in which both spouses live, then the given individual is still considered a homeowner. I analyse the impact of measuring homeownership at the household level in the paragraph 'robustness analyses'. Independent variables include characteristics at the individual, household and contextual level. Individual characteristics are naturalisation, gender, age at the moment of migration, the partner status, the employment status and education. The relevance of naturalisation is captured by two variables. The first is a dummy that is set to unity when a migrant acquires Dutch citizenship. The second is a time-invariant dummy that is set to unity if a migrant naturalises during the observation period. The latter variable is included to capture positive selection into naturalisation, whereas the former measures a potential one-time boost in the probability of homeownership after citizenship acquisition. This study distinguishes between having a foreign-born foreign partner (a non-naturalised migrant), a foreign-born Dutch partner (a naturalised migrant) and a native partner. This is important in light of the legal status discrimination hypothesis, in which I theorize that having a native-born Dutch partner attenuates discriminatory behaviour by lenders. I track partners and their legal status over time. Employment is measured dichotomously as being employed or not. The household variables are standardized household income and having young children. I use household income as opposed to individual income, since the financial basis for mortgage eligibility is typically determined at the household level. When migrants have children below the age of 18 in the household, they are considered to have young children. Contextual variables include the level of economic development and EU membership of the country of origin, the level of cultural difference between the origin country and the Netherlands, and the global financial crisis. The level of economic development is based on the Human Development Index (UNDP, 2014), including indicators for gross domestic product, general levels of education and life expectancy. The index provides a yearly country score between 0 and 1 , where a higher score equals more development. Cultural differences between migrants' origin country and the Netherlands are based on the Dimensions of National Culture index, developed by Geert Hofstede (Hofstede, 2001). This model of national culture consists of six dimensions, each with a score ranging between 0 and 100 . The difference between the scores of the origin country and the Netherlands are calculated for each of these dimensions. The sum of these differences is an individuals' cultural distance to the Netherlands, where a higher score equals greater distance. I keep track of changes in 
EU membership of origin countries over time. Finally, information on education is predominantly based on survey data in the Netherlands, and therefore incomplete. For this reason, I do not include education in the main models. However, the relevance of education is analysed using the available data in the paragraph 'robustness analyses'.

Kaplan Meier analyses on cumulative homeownership rates show that migrants who are younger at the moment of migration are more often homeowners (Figure 8a and 8b). Moreover, homeownership rates are slightly higher for migrants who have not naturalised after ten years of residence (see Table A26 in the annex for descriptive statistics on the research population). Note that due to characteristics that are associated with both the propensity to naturalise and homeownership, these statistics do not provide an indication of the unique effect of naturalisation. To analyse these data in greater detail, I perform Cox Proportional Hazards Regression with timedependent covariates (Cox, 1972). Cox regression is a survival analysis that examines the relationship between the survival distribution and explanatory variables. In other words, it estimates the relevance of the independent variables for the probability that a specific event occurs (in this case, homeownership). Homeownership is theoretically not an event that occurs only once in an individuals' life course. However, since individuals are tracked for a period of 10 years, and homeownership constitutes a significant longterm investment, the vast majority of migrants either becomes a homeowner and remains a homeowner, or never becomes a homeowner during the observation period. This pattern is ideally suited to a survival analysis.

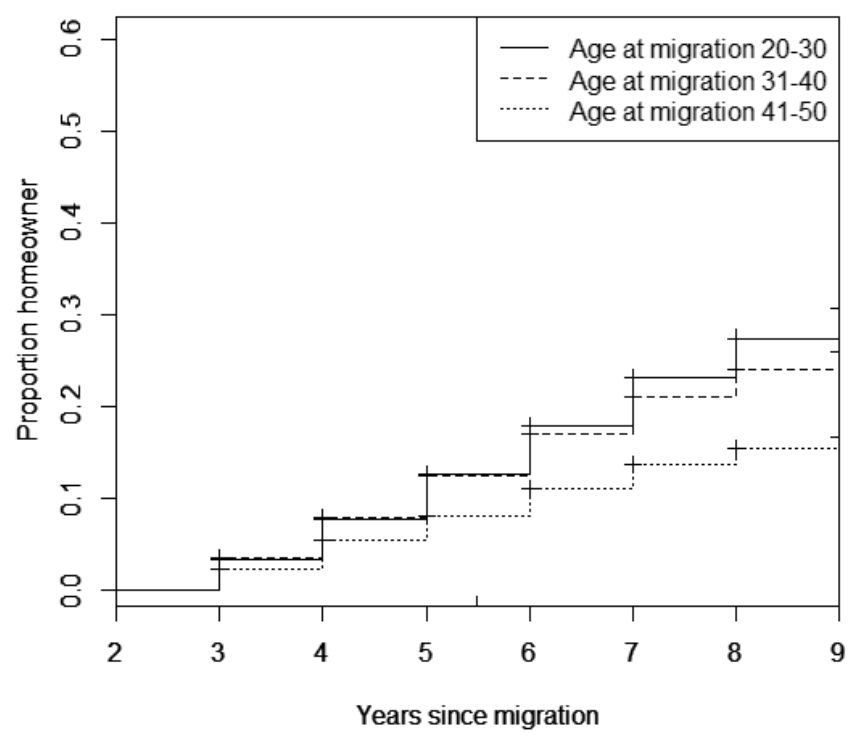

Figure 8a. Cumulative homeownership of immigrants who do not naturalise during the observation period by age at migration.

Source: Statistics Netherlands. 


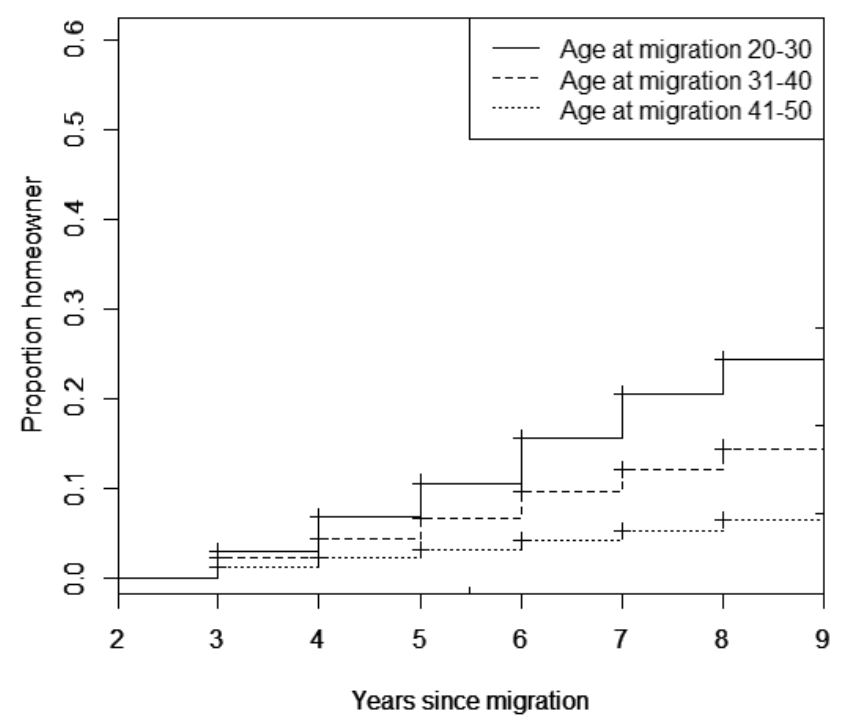

Figure 8b. Cumulative homeownership of immigrants who naturalise during the observation period by age at migration.

Source: Statistics Netherlands.

\section{ANALYSIS}

Table 10 contains the results of the Cox Proportional Hazards regression, providing coefficients on the risk of homeownership. As expected, employed migrants enjoy an increase in the odds of homeownership of 25 percent after naturalisation, whereas citizenship acquisition has no effect for unemployed migrants, all else constant. This confirms hypothesis 1, in which I argue that migrants' legal status only matters for those who meet the basic financial requirements for credit in the housing market. In other words, financial constraints weigh more heavily than migrants' legal status in the risk calculation of lenders. When migrants do not qualify for the minimum economic criteria, their citizenship will not make a difference. However, when applicants are eligible for a mortgage, the citizenship of the host country factors positively into the evaluation of creditworthiness. I theorize that the naturalised status signals commitment, motivation and better career prospects, and mitigates the negative consequences of statistical discrimination.

Moving to the control variables, I observe positive selection into naturalisation for employed migrants. More specifically, migrants who naturalise during the observation period are 18 percent more likely to become a homeowner. Note that this is already the case prior to citizenship acquisition. This can be rationalised by the selective nature of both the processes of naturalisation and of becoming a homeowner. Those who 
successfully acquire the host country citizenship are generally more motivated and skilled. Isolating such endogeneity bias is crucial to avoid overestimating the relevance of naturalisation for homeownership. In line with the descriptive statistics and previous literature (e.g. Boehm \& Schlottmann, 2004, p. 121; Coulson \& Dalton, 2010, p. 160), women are more likely to be a homeowner than men. A potential explanation is that women are more often family reunification migrants, who are more likely to permanently settle and buy a house, whereas male immigrants are more often economic migrants or seasonal workers, who are more prone to emigration or circular migration (and thus less likely to buy a house). The age at migration is positively associated with homeownership. However, the squared term is negative, which corresponds to the curvilinear pattern observed in the descriptive statistics. The partner also matters for the probability of homeownership, particularly if the partner is nativeborn. ${ }^{17}$ Having children decreases the odds of homeownership for migrants without employment. Given their weaker financial position, these migrants may find it difficult to meet the economic requirements to finance a house in addition to the costs associated with having children. Conversely, having young children in the household increases the probability of homeownership for employed immigrants by 15 percent. From a life course perspective, migrants with children are likely more settled and less mobile, and thus more likely to invest in property. As expected, employment and disposable household income increase the odds of homeownership. The same is true for economic development and EU membership of the origin country. Finally, the probability of homeownership is 12 to 13 percent lower after the onset of the global financial crisis in 2008.

\footnotetext{
${ }^{17}$ Note that the positive role of the native-born partner will in part be attributable to the measurement of homeownership at the household level. I perform a robustness analysis to analyse this in detail.
} 
Table 10. Cox proportional hazard regression on the risk of homeownership of immigrants, cohorts 19992002.

\begin{tabular}{|c|c|c|c|c|c|c|}
\hline & \multicolumn{3}{|c|}{ Not employed } & \multicolumn{3}{|c|}{ Employed } \\
\hline & Coef. & Std. error & Exp. coef. & Coef. & Std. error & Exp. coef. \\
\hline \multicolumn{7}{|l|}{ Naturalisation } \\
\hline Yes & 0.091 & 0.050 & 1.096 & 0.223 & 0.031 & $1.250 * * *$ \\
\hline No & ref. & ref. & ref. & ref. & ref. & ref. \\
\hline \multicolumn{7}{|c|}{ Naturalisation during observation period } \\
\hline Yes & -0.020 & 0.035 & 0.980 & 0.162 & 0.026 & $1.176^{* * *}$ \\
\hline No & ref. & ref. & ref. & ref. & ref. & ref. \\
\hline \multicolumn{7}{|l|}{ Gender } \\
\hline Male & ref. & ref. & ref. & ref. & ref. & ref. \\
\hline Female & 0.201 & 0.031 & $1.223^{* * *}$ & 0.181 & 0.017 & $1.198^{* * *}$ \\
\hline Age at migration & 0.052 & 0.016 & $1.054^{* *}$ & 0.061 & 0.011 & $1.063^{* * *}$ \\
\hline Age at migration ^ 2 & -0.002 & 0.000 & $0.998 * * *$ & -0.002 & 0.000 & $0.998 * * *$ \\
\hline \multicolumn{7}{|l|}{ Partner } \\
\hline No partner & ref. & ref. & ref. & ref. & ref. & ref. \\
\hline Foreign-born foreign partner & -0.146 & 0.039 & $0.865^{* * *}$ & 0.191 & 0.024 & $1.210^{* * *}$ \\
\hline Foreign-born Dutch partner & -0.088 & 0.043 & $0.916^{*}$ & 0.093 & 0.031 & $1.097^{* *}$ \\
\hline Native-born Dutch partner & 0.649 & 0.039 & $1.913^{* * *}$ & 0.492 & 0.024 & $1.635^{* * *}$ \\
\hline \multicolumn{7}{|l|}{ Children $<18$ in the household } \\
\hline Yes & -0.195 & 0.031 & $0.823 * * *$ & 0.143 & 0.020 & $1.153^{* * *}$ \\
\hline No & ref. & ref. & ref. & ref. & ref. & ref. \\
\hline Disposable household income & 2.364 & 0.047 & $10.629 * * *$ & 1.511 & 0.039 & $4.531^{* * *}$ \\
\hline Development country of origin & 2.413 & 0.118 & $11.165^{* * *}$ & 2.112 & 0.087 & $8.265^{* * *}$ \\
\hline \multicolumn{7}{|l|}{ EU country of origin } \\
\hline Yes & 0.160 & 0.039 & $1.173^{* * *}$ & 0.135 & 0.024 & $1.145^{* * *}$ \\
\hline No & ref. & ref. & ref. & ref. & ref. & ref. \\
\hline \multicolumn{7}{|l|}{ After 01-01-2008 } \\
\hline Yes & -0.124 & 0.050 & $0.884^{*}$ & -0.137 & 0.029 & $0.873^{* * *}$ \\
\hline No & ref. & ref. & ref. & ref. & ref. & ref. \\
\hline$*: p<0.05$ & \multicolumn{3}{|c|}{$N=76,444$} & \multicolumn{3}{|c|}{$N=67,593$} \\
\hline$* *: p<0.01$ & \multicolumn{3}{|c|}{ Observations = 286,149 } & \multicolumn{3}{|c|}{ Observations = 231,502 } \\
\hline \multirow[t]{2}{*}{$* * *: p<0.001$} & \multicolumn{3}{|c|}{ Events $=5,834$} & \multicolumn{3}{|c|}{ Events $=14,446$} \\
\hline & \multicolumn{3}{|c|}{-2 Log-likelihood = 116,439 } & \multicolumn{3}{|c|}{-2 Log-likelihood $=289,328$} \\
\hline
\end{tabular}

Source: Statistics Netherlands.

Citizenship acquisition matters for employed immigrants in the housing market, and I theorize that this effect is based on two mechanisms. First, the naturalised status may signal motivation, commitment and skills, which may positively factor into the evaluation of creditworthiness. Second, migrants who have acquired the host country citizenship may not suffer from ethnic discrimination to the same extent as their nonnaturalised counterparts. Naturalised migrants may be perceived as an exceptional group to whom prejudiced beliefs about migrants in general do not apply. However, if legal status discrimination is indeed one of the underlying mechanisms behind the 
citizenship premium in the housing market, then the effect of naturalisation should be weaker for migrants with a native-born Dutch partner. Having a native-born partner fulfils a similar function as the naturalised status by attenuating discriminatory behaviour, limiting the added benefit of the host country citizenship. To test these assumptions, I perform the main analysis with the inclusion of an interaction term between naturalisation and having a native-born Dutch partner. Since it has already been established that citizenship acquisition only matters for employed migrants, I exclude migrants without employment (results for migrants without employment are reported in Table A27 in the appendix). Findings in Table 11, Model 1 show that the interaction term is negative, meaning that the role of naturalisation is weaker for migrants with a native-born Dutch partner. This confirms hypothesis 2, and suggests that either citizenship or a native-born partner can overcome legal status discrimination.

To further analyse the legal status discrimination mechanism, I perform the main analysis with an interaction between cultural distance and naturalisation. If the host country citizenship attenuates ethnic discrimination, then the effect should be stronger for migrants from origin countries whose culture is more dissimilar compared to the Netherlands. I assume that these migrants are more likely to be subject to ethnic discrimination, and thus stand to benefit most from the mitigating effect of the host country citizenship. As expected, Table 11, Model 2 shows that cultural distance between the origin country and the Netherlands is negatively associated with the odds of homeownership. Immigrants from culturally more dissimilar countries either are less willing to buy property in the host country, or they face structural obstacles in the housing market. However, the results provide no evidence for the expectation that the relevance of naturalisation is conditioned by cultural distance. While citizenship has the potential to attenuate some of the concerns of lenders, it clearly does not remove all obstacles for migrants. Assuming that the negative coefficient from cultural distance stems from discrimination by lenders, citizenship does not have the power to attenuate this problem. As such, hypothesis 3 is rejected. ${ }^{18}$

Finally, I argue that the signalling potential of citizenship is more relevant when lenders are more critical in their evaluation of creditworthiness. When the overall risk of approving a mortgage is high, additional criteria may be considered such as the legal status of an applicant. Given the fact that lenient behaviour when approving credit was one of the mechanisms behind the collapse of the housing market in 2008 (Acharya \& Schnabel, 2009; Martin, 2011), I assume that lenders will be more critical during and after this point in time. In that context, I perform the main analysis with an interaction between a dummy that is set to unity from 2008 onwards and naturalisation (Table 11, Model 3). As expected, the probability of homeownership is more than 13 percent

18 Table A27 confirms that the addition of the interaction term does not change the relevance of naturalisation for unemployed migrants. 
lower after the onset of the financial crisis. Presumably lenders have become more critical during the crisis, to the detriment of the opportunities of immigrants in the housing market. However, the relevance of naturalisation is not conditioned by the financial crisis, as the interaction term is not statistically significant. As such, the host country citizenship is not able to remove the increased hesitations of lenders. Hypothesis 4 is therefore rejected. ${ }^{19}$

Table 11. Cox proportional hazard regression on the risk of homeownership of employed immigrants, cohorts 1999-2002. ${ }^{+}$

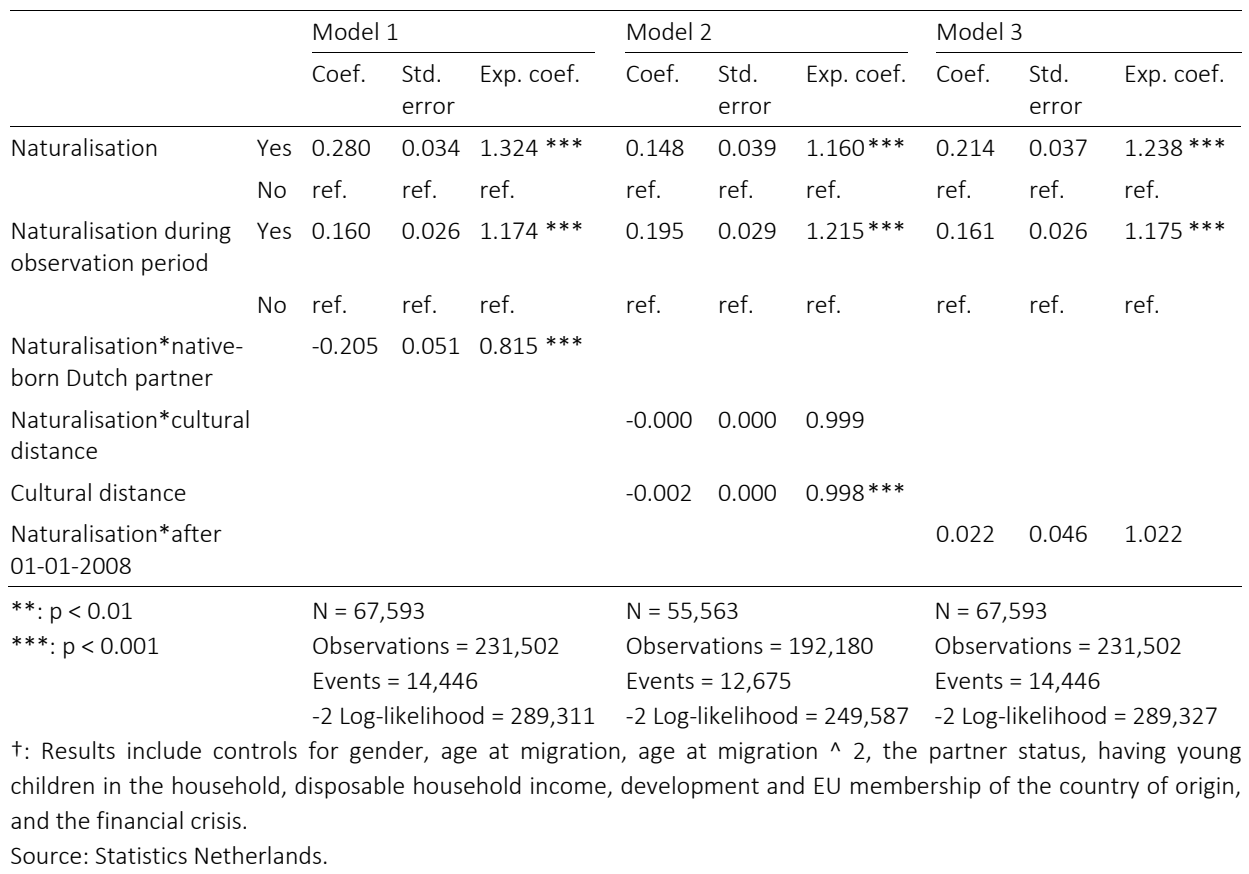

\section{ROBUSTNESS ANALYSES}

In this paragraph, I perform additional analyses to assess the robustness of the findings. First, homeownership is measured at the household level. As such, if a migrant becomes the registered partner of a homeowner, he or she becomes a homeowner as well. However, this study is interested in the relevance of naturalisation for the decision and ability to become a homeowner, not transitions into homeownership through partners. To disentangle the latter from the former, I include a variable that captures instances where the occurrence of the event (homeownership) may be attributable to a partner

\footnotetext{
${ }^{19}$ Findings in Table A27 confirm that the relevance of naturalisation for unemployed migrants remains statistically insignificant when the interaction term is added to the model.
} 
shift. More specifically, this is a dummy variable that is set to unity when a migrant has a partner and did not have a partner during the previous observation, or when a migrant has a different partner compared to the previous observation. This dummy thus captures any events that may be due to the fact that the new spouse was already a homeowner prior to the partnership. The results reported in Table A28 are very similar to the main model. As expected, the partner shift dummy is positive and statistically significant, presumably due to the fact that some new spouses were already a homeowner. Also note that by disentangling partner effects from household measurement effects, the relevance of the partner slightly decreases compared to the main model. Most importantly, the relevance of naturalisation remains almost identical with a control for partner shifts. In other words, there is no reason to assume that the positive effect of naturalisation is explained by the measurement of homeownership at the household level.

Second, data on the level of education are predominantly based on surveys in the Netherlands. As such, there is not information on education for all foreign-born residents of the Netherlands. However, given the importance of education for labour market outcomes and job prospects, as well as the propensity and ability to naturalise, the positive effect of citizenship acquisition may be explained by compositional differences in education. In that context, I perform the main analysis with migrants for whom the level of education is known, and include education to the model. Results in Table A29 are similar to the main model. As expected, education is positively associated with homeownership. Migrants with middle education are 29 percent more likely to become a homeowner compared to the low educated. This discrepancy increases to 62 percent for migrants with higher education. Also note that controls for education explain the positive coefficient for the time-invariant naturalisation dummy in the main analysis (which is no longer significant in Table A29). In other words, education seems to capture the residual self-selection into naturalisation. Most importantly, the relevance of citizenship acquisition is not explained by differences in education between those who have naturalised and those who have not. I thus conclude that our findings are robust to controls for education.

Finally, immigrants are tracked until they reach the end of the observation period, experience the event of homeownership or leave the Netherlands (right-truncation). However, emigration is not random, and the dataset may thus constitute a self-selected sample. More specifically, migrants who leave the Netherlands may do so because their settlement process is less successful, for instance due to negative experiences in the labour or housing market. These unsuccessful migrants will also be less likely to acquire the citizenship of the host country. To analyse this in detail, I perform the main analysis only for employed migrants that remain in the Netherlands during the observation period. Findings in Table A30 show strong similarities to the main model. Furthermore, the relevance of naturalisation remains positive and statistically significant. This 
confirms that the main findings are not attributable to selection resulting from emigration.

\section{CONCLUSION}

This paper explores a potential citizenship premium in the housing market. More specifically, I analyse whether citizenship acquisition matters for homeownership of foreign-born residents of the Netherlands. Research on the ethnic gap in homeownership shows that immigrants are more likely to be tenants than homeowners compared to the native population. Although literature has identified numerous explanations for this discrepancy, including compositional differences in socio-economic and demographic terms (Charles \& Hurst, 2002; Coulson \& Dalton, 2010), ethnic discrimination in the housing market (Aalbers, 2007; Ross \& Tootell, 2004) and lower preferences for homeownership (Constant et al., 2009), the relevance of citizenship acquisition has so far not received much attention. I draw on the traditional literature of the citizenship premium in the labour market, and theorize that the host country citizenship may favourably factor into the evaluation of creditworthiness through positive signalling towards lenders and legal status discrimination. However, I hypothesise that naturalisation will only make a difference if applicants fulfil the basic financial requirements for a mortgage, and are thus eligible for credit in the housing market.

To test these assumptions, this study analyses individual-level register data from Statistics Netherlands. I find empirical support for a citizenship premium in the housing market, but only for employed migrants. Citizenship acquisition increases the odds of homeownership for these immigrants by 25 percent, all else constant. This suggests that naturalisation signals creditworthiness to lenders and mitigates the negative consequences of discrimination. The host country citizenship has no added benefit for employed migrants with a native-born Dutch partner, providing support for the legal status discrimination mechanism. Furthermore, cultural distance between the origin and host country and the global financial crisis decrease the odds of homeownership of immigrants. However, the relevance of naturalisation is not conditioned by these factors. In other words, possession of the host country citizenship removes some concerns of lenders, but not all. Additional analyses confirm that the findings are robust to controls for education and right-truncation.

This chapter only constitutes the first step in developing a model of legal status transitions and homeownership, and presents several avenues for future inquiry. First, homeownership is only one aspect of immigrant living conditions. Future research could analyse the relevance of citizenship for a broader set of indicators, including physical quality of the accommodation, overcrowding, and characteristics of the neighbourhood and its resident population. Second, this paper builds on the traditional understanding 
of the citizenship premium as a causal before-after phenomenon, where naturalisation subsequently provides a boost in integration (Helgertz et al., 2014, p. 351). However, citizenship acquisition is not an isolated, abrupt legal status transition, but rather an important life course event that requires timing and preparation. Migrants will for instance have to invest in meeting the formal civic and linguistic requirements for naturalisation (Goodman, 2014). The decision to start preparing for the moment of naturalisation may also affect tenure choices of immigrants. Indeed, the future life course perspective of immigrants who have decided to naturalise is more clear and established compared to other migrants. As such, naturalisation may already increase the propensity for homeownership prior to citizenship acquisition, not because of the legal status transition, but rather due to the decision to permanently settle and naturalise in the future. Analysing housing market outcomes prior to citizenship acquisition would require an adjusted regression model. Third, given the fact that citizenship has the potential to increase labour market access and employment opportunities for some migrant groups (Bratsberg et al., 2002; Engdahl, 2014; Helgertz et al., 2014; Steinhardt, 2012), the citizenship premium in the labour market may subsequently affect opportunities in the housing market. Through a process of cumulative advantage (also known as the 'Matthew effect' [Merton, 1968]), naturalisation may trigger a process of successive increments of opportunity that build on each other. Citizenship acquisition improves employment opportunities, and the resulting consecutive period of activity in the labour market may subsequently improve opportunities in the credit market. Future research could attempt to identify the extent to which the role of naturalisation on homeownership is mediated by positive labour market outcomes. 
Chapter

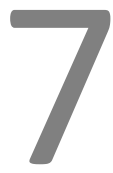

Conclusion 
Chapter 7 
Discussions on citizenship are often phrased in a universalistic language. Citizenship guarantees equal status and protection of the law by transcending particularity and difference. In that sense, all citizens are peers in the political public (Youngh, 1989). The promise of citizenship is thus substantial: a status where individuals have the same opportunities as their fellow citizens to build their lives and pursue private ends. The stark reality of inequality within citizenship challenges this ideal. Empirically, migrants suffer from taste-based and statistical discrimination by employers and lenders (Aalbers, 2007; Blommaert, Coenders, \& van Tubergen, 2014; Ross \& Tootell, 2004; Zschirnt \& Ruedin, 2016), yet naturalised migrants continue to perform worse in the labour and housing market (Enchautegui \& Giannarelli, 2015; OECD, 2011). Furthermore, individuals with a migrant background are more likely to be socially excluded (Hutcheson \& Jeffers, 2013), are underrepresented in legislatures that are supposed to speak for them (Bird, 2005; Ruedin, 2009), and are more likely to be convicted of crime (Light et al., 2014) than their native-born counterparts. Critics of the universalist notion of citizenship may thus argue that substantively, citizenship constitutes a hollow promise; a status that continues to harbour the inequalities it supposedly transcends. Others may point towards the transferal of rights and benefits from citizenship to legal residency, and the rise of supranational institutions, as evidence that nation-centric citizenship has lost much of its relevance in a globalised and privatised world (Bosniak, 2000; Schuck, 1989; Spiro, 2007). Both the empirical observation that citizenship in practice fails to rule out discriminatory practices and act as a mainstreaming device, and the gradual decoupling of rights and benefits traditionally associated with citizenship, provide serious arguments to be sceptical about the ability of citizenship to ensure justice, equality and security. However, while citizenship may not meet its universalistic ideal, it does not necessarily follow that access to and holding citizenship is thus irrelevant (Bloemraad, 2017, p. 546). While inequalities based on origin, religion, education and class are clearly not erased by naturalisation, citizenship may serve to attenuate such discrepancies, and promote opportunities for full participation and integration. Literature suggests that citizenship acquisition improves the labour market performance of immigrants (Bratsberg et al., 2002; Helgertz et al., 2014; Steinhardt, 2012), increases civic engagement and political efficacy (Hainmueller et al., 2015) and promotes social integration and selfidentification with the political community (Bloemraad \& Wright, 2014; Manning \& Roy, 2010; Maxwell \& Bleich, 2014). However, empirical findings in this field of literature are characterised by substantial ambiguity, and the key question of whether (and particularly why) citizenship matters for immigrant integration remains unresolved. In that context, this thesis aims to advance our understanding of the citizenship premium by modelling legal status transitions as life course events, which are embedded in the social context of migrants' origin and family situation on the one hand, and the institutional context of citizenship policies and membership regulations on the other hand. The key innovation is that the social and institutional context shapes the pathway 
into citizenship, which in turn matters for its associated outcomes. These assumptions are tested using Dutch administrative data from Statistics Netherlands, covering almost all registered first generation immigrants in the Netherlands. More specifically, I pose the following central research question: What are the determinants of citizenship acquisition, and what is the relevance of naturalisation for the socio-economic integration of first generation immigrants in the Netherlands?

\section{Theoretical contribution: a life course perspective to immigrant naturalisation} and socio-economic integration

A substantial field of literature is dedicated to the question whether a citizenship premium exists or not (Chiswick, 1978; Bevelander \& Veenman, 2008; Fougère \& Safi, 2009; Scott, 2008). In light of ambiguous findings, more recent studies have invested in the development of a more complex empirical model that accounts for omitted variable bias (Bratsberg \& Raaum, 2010; Bratsberg et al., 2002; Engdahl, 2014; Helgertz et al., 2014; Steinhardt, 2012). While these studies clearly illustrate that naturalised migrants indeed constitute a self-selected group that is already better integrated prior to naturalisation, controls for endogeneity do not explain why some migrants enjoy a citizenship premium, while others do not. In other words, the (justified) focus on disentangling the direction of the association between naturalisation and integration has left the theoretical framework underdeveloped. I therefore argue for more focus on the question to whom and under which conditions citizenship matters. To that end, this thesis pioneers in introducing life course concepts and principles (Elder, 1974) to this field of literature in Chapter 2, which provide a useful starting point to develop a framework that explains varying outcomes of naturalisation. A life course perspective to immigrant naturalisation and integration combines two strands of literature. One strand focusses on individual incentives for naturalisation based on personal and origin characteristics (e.g. Chiswick \& Miller, 2009; Helgertz \& Bevelander, 2016; Yang, 1994), while the other emphasizes institutional, historical and political properties of the destination context (e.g. Aleksyndra \& Algan, 2010; Janoski, 2010; Reichel, 2011). In isolation, neither approach is able to answer the core question on the conditioned relevance of citizenship. However, life course concepts and principles allow for a dynamic synthesis of both strands of literature, providing guidelines for the formulation of a theoretical framework that explains variation in citizenship acquisition rates and integration outcomes by emphasizing the social and institutional context in which immigrant lives are embedded.

The temporal dynamic inherent in such an approach requires longitudinal data. By observing individuals over time, the interrelated development of human biographies in transforming societal conditions can be analysed (Diewald \& Mayer, 2009). The use of such data aligns well with the emphasis in the literature on the methodological importance of longitudinal data to account for self-selection into naturalisation. In light 
of these considerations, I make use of register data from Statistics Netherlands, which allows for controls on omitted variable bias. Moreover, the administrative nature of the data circumvents problems that typically complicate the collection and analysis of survey data among immigrants, such as underrepresentation, non-response and social desirability. Furthermore, the Netherlands is an ideal context to apply this novel life course approach, given significant variation in citizenship policies and naturalisation rates over the last decades, and the extent to which immigrant integration has historically been the subject of contention in Dutch politics (Entzinger, 2003; van Oers, 2014; van Oers et al., 2013).

\section{Empirical contribution: answering the research question}

To answer the central research question, this thesis consists of four empirical chapters, based on published and submitted research articles. Chapter 3 focusses on determinants of citizenship acquisition. First, I analyse the relevance of personal and origin characteristics for the propensity to naturalise, with a specific focus on the social dynamic of naturalisation decisions. Results confirm that a cost-benefit framework is a good predictor of citizenship acquisition. Particularly migrants for whom the utility of citizenship is greatest, such as those from economically less developed, politically unstable and non-EU countries of origin, are likely to naturalise. The same is true when the costs associated with citizenship acquisition are relatively low, for instance when migrants are exempted from the renunciation requirement, and thus (may) retain their original citizenship upon naturalisation. Migrants who are younger at the moment of migration also have a higher propensity to naturalise, as the period of time in which they may enjoy the benefits associated with citizenship acquisition is longer. Conversely, the necessary investment may not be worth it for migrants in a later stage of the life course. The analysis also shows that having a native or naturalised partner is positively associated with immigrant naturalisation. The effect is particularly strong in the year in which the foreign-born partner acquires citizenship. These findings suggest that the decision to naturalise is at least partly made at the family level. This has important implications for the traditional theoretical framework, which is based on the notion of individual utility maximization. If important life course decisions, such as the choice to permanently settle and naturalise, are not solely motivated by personal gain, then a more developed theoretical framework is needed to capture the social complexity of immigrant lives. The results also highlights that measuring the family dynamic through marital status obscures important variation, since having a nonnaturalised partner is negatively associated with the propensity to naturalise.

However, the most important findings in this chapter concern the relevance of citizenship policy. We exploit a restriction in citizenship policy in the Netherlands on April 1, 2003, namely the introduction of a naturalisation test. Naturalisation rates dropped markedly after this point in time, but it remains unclear whether this was due 
to the policy change, and if so, which migrant groups were particularly affected. Results confirm that citizenship policies matter for the propensity to naturalise. Migrants are less likely to acquire Dutch citizenship after the introduction of the naturalisation test. Moreover, those who did naturalise under the more restrictive institutional conditions needed more time to do so. Furthermore, the relevance of citizenship policy is conditioned by origin country characteristics. More specifically, restrictive citizenship policies only matter to migrants from less developed and politically unstable countries of origin. These are the same migrants who stand to benefit from citizenship most, and are highly interested in naturalisation to reinforce their legal status and remove structural obstacles to integration.

Findings in Chapter 3 suggest that migrants for whom the host country citizenship may be a valuable asset to their integration are particularly dependent on the institutional conditions that make naturalisation a realistic proposition or not. To analyse in detail whether naturalisation indeed facilitates socio-economic integration of immigrants, Chapter 4 investigates a potential citizenship premium in terms of employment. Analyses confirm that migrants are more likely to be employed after naturalisation, all else constant. These findings are consistent with the prevalent notion in the literature that citizenship acquisition facilitates integration through increased labour market access, reduced administrative costs and positive signalling towards employers (Liebig \& von Haaren, 2011). I also find evidence of positive selection into naturalisation. Migrants who naturalise have endogenous characteristics that are positively associated with both the propensity to naturalise and labour market outcomes. They may for instance be more motivated, skilled or intelligent. These analyses again highlight that failing to account for self-selection into naturalisation results in an overestimation of the citizenship premium. However, the most important finding is that the labour market performance of immigrants already starts to improve prior to naturalisation, not only afterwards. While this is not an uncommon observation in the literature (e.g. Helgertz et al., 2014, p. 344), any positive labour market outcomes prior to citizenship acquisition are typically considered inconsistent with the notion of a citizenship premium. Indeed, how can the effect of a treatment condition (the host country citizenship) precede the treatment (naturalisation)? However, this dichotomous before-after approach to the citizenship premium ignores the relevance of the pathway to citizenship (i.e. the process through which citizenship is acquired). I argue that the positive effects prior to naturalisation reflect a human capital investment by migrants in anticipation of the formal civic and linguistic requirements of naturalisation, and the potential rewards and opportunities that citizenship will offer in the future. As such, migrants not only benefit from the legal status transition itself, but also enjoy an accelerated integration trajectory leading up to naturalisation. In line with this reasoning, citizenship matters most when it is acquired early in the settlement process, as investment in host-country specific human capital (most notably language capabilities) loses its relevance after a longer period of residence in the host country. 
In Chapter 5, I delve deeper into the employment outcomes of naturalisation by analysing earnings from labour. This is the most common operationalisation of labour market integration in the literature, yet empirical support for an income effect is inconsistent (Helgertz et al., 2014, p. 343). I explore three explanations for this empirical ambiguity. First, I argue that the signalling potential of citizenship is less relevant for employed migrants, whose employment status serves as a positive signalling device in its own right. Second, in so far as citizenship matters for the earnings of immigrants, I argue that it matters particularly to migrants who face structural obstacles in the labour market. Employers may assume that individuals from economically less developed countries of origin are negatively selected with regard to their productivity and general labour market performance. These migrants thus stand to benefit from citizenship most to mitigate their relatively weak reputation in the labour market. Third, analogous to Chapter 4, I argue that immigrant earnings already improve leading up to naturalisation, as migrants invest in their labour market potential in anticipation of citizenship acquisition. Since the literature typically dismisses all positive effects prior to naturalisation as self-selection bias, the state-of-the-art analytical models may underestimate the citizenship premium. Like many studies in the literature (Bratsberg \& Raaum, 2011, p. 197; Bratsberg et al., 2002, p. 582; Helgertz et al., 2014, p. 352; Steinhardt, 2012, p. 818), I find no support for a citizenship premium in terms of income from labour after naturalisation. Yet so far, the literature provides no clear explanation for these findings. In line with my expectations, I do observe a positive effect for migrants from economically less developed countries of origin and for unemployed migrants. Moreover, the income from labour of immigrants already improves prior to naturalisation, and peaks around the moment of citizenship acquisition, consistent with the notion of anticipation. These findings thus suggest that citizenship matters for immigrant earnings, but that not all migrants benefit equally (or at all), and that the effects particularly manifests as a result of the intention to permanently settle and naturalise, rather than the legal status transition itself.

Finally, Chapter 6 broadens the conceptual scope of immigrant integration by breaking with the state-of-the-art's exclusive focus on the labour market. More specifically, this chapter analyses whether citizenship acquisition matters for immigrant homeownership. While a substantial field of literature has investigated determinants of the so-called ethnic gap in homeownership (Aalbers, 2007; Charles \& Hurst, 2002; Constant et al., 2009; Coulson \& Dalton, 2010; Ross \& Tootell, 2004), citizenship has so far not received much systematic attention. I start by building on the traditional theoretical framework of the citizenship premium, and hypothesise that the host country citizenship sends a positive signal towards lenders, and attenuates potential ethnic discrimination. However, I argue that creditworthiness cannot be solely based on citizenship status. As such, naturalisation will only matter for migrants who fulfil the basic financial requirements for credit in the housing market. Empirical findings show that citizenship acquisition increases the probability of homeownership, but only for 
employed migrants. Moreover, the host country citizenship does not matter for migrants with a native-born Dutch partner. This suggests that legal status discrimination may be one of the underlying mechanisms behind the citizenship premium in the housing market, as migrants with a native partner are less likely to be discriminated against on ethnic grounds. Finally, both cultural distance between the origin and host country and the global financial crisis decrease the probability of homeownership of immigrants. However, possession of the host country citizenship is not able to attenuate those disadvantages. In other words, citizenship facilitates access to the housing market, but does not remove all structural obstacles to homeownership.

How do these findings relate to the central research question: what are the determinants of citizenship acquisition, and what is the relevance of naturalisation for the socio-economic integration of first generation immigrants in the Netherlands? Starting with the second part of the question, it can be concluded that citizenship matters. Naturalisation has the potential to contribute substantially to the socioeconomic integration of immigrants. Citizenship acquisition facilitates access to the labour market by increasing the odds of employment by about 13 percent. While the effects are more limited in terms of occupational mobility, male and female immigrants from economically less developed countries of origin still enjoy 3 and 5 percent higher earnings respectively. On top of that, the labour market performance of immigrants already starts to improve prior to naturalisation, as migrants invest in their human capital development to meet the formal civic and linguistic requirements, and to utilize the rewards and opportunities that citizenship will offer. Therefore, possession of the host country citizenship matters most if it is acquired relatively early in the settlement process, when accelerated investment in these skills can make a difference. For instance, while the probability of employment for migrants who naturalise after 5 years of legal residence (the current residence requirement in the Netherlands) is 34 and 38 percent higher for male and female immigrants respectively compared to their nonnaturalising counterparts, this is limited to only 10 percent for those who naturalise after 8-10 years of legal residence. Naturalisation also facilitates housing market integration of employed immigrants, as the probability of homeownership is 25 percent higher after naturalisation, all else constant. While these advantages do not level the playing field with natives, it would be wrong to conclude that citizenship is a hollow promise that has no substance in practice, or that it has been eclipsed by post-national processes of globalisation and privatisation. The legal status transition from non-citizen to citizen does not miraculously erase structural and socially generated inequalities, but it does have the potential to attenuate them, and provide opportunities for upward mobility. This is particularly true for vulnerable migrant groups, such as those from economically less developed countries of origin, who face structural obstacles in the labour market, and for whom the host country citizenship is a valuable asset to mitigate their disadvantaged position. However, the same migrants who stand to benefit from naturalisation most are also highly dependent on policies that stipulate the conditions 
for access to citizenship. This brings me to the first part of the research question. Migrants naturalise less quickly and less often under more restrictive institutional conditions. Yet the relevance of citizenship policies is not equal for all migrant groups. Particularly migrants for whom the utility of citizenship is greatest are deterred by more restrictive requirements. In contrast, institutional variation does not substantially affect naturalisation rates of migrants who do not need citizenship as much, and who are generally less interested in naturalisation. The potential for citizenship to function as a vehicle for immigrant integration thus constitutes a balancing act. If there are no requirements for naturalisation, citizenship is unlikely to play a role in the integration process, as any rights and entitlements linked to the status would be meaningless. Yet if institutional conditions are too restrictive, then the very migrants who need it most may find it difficult to meet these requirements. Moreover, since investment in anticipation of naturalisation is one of the driving mechanisms behind the citizenship premium, the criteria for access to citizenship play an important role in potential positive outcomes of the status. Certain requirements for naturalisation are more likely to facilitate integration than others. For instance, some mastery of the native language is a precondition for participation in many spheres of society. As such, basic linguistic requirements and a short period of residence to develop these skills may play a positive role. Yet high financial costs to apply for naturalisation only serve to make citizenship more selective, and a long residence requirement will erode the added benefit of accelerated investment in host-country specific human capital. Moreover, if linguistic requirements are too high, and no financial support is offered for study materials and language training, then it is unsurprising if particularly disadvantaged migrant groups are unable to naturalise, or do not consider naturalisation a reasonable proposition. In that case, the potential for citizenship to stimulate and incentivise their integration is wasted.

\section{Limitations}

The findings of this thesis should be considered in light of a number of limitations. First, analogous to some research in this field of literature (predominantly in Nordic countries), this thesis exploits individual-level register data. The advantages of such an approach can hardly be overstated. Administrative data is inherently inclusive, and ensures that even migrant groups who are difficult to reach (because of size, language barriers or other socio-cultural obstacles to participation in surveys) do not need to be added artificially through imputation or weighing strategies, or worse, are ignored altogether. Register data are also characterised by a high observation frequency and panel data structure. Depending on the register in question, characteristics of individuals can often be tracked and observed on a monthly basis, and in some cases per day. This allows for hitherto unfeasible levels of detail, and provides important methodological opportunities (including, but not limited to, the ability to control for 
self-selection bias without losing too many degrees of freedom, and a more detailed comparison of the period before and after naturalisation). In light of these advantages, it is easy to ignore the limitations of such an approach. First, the inclusive nature of administrative data is limited to the registered population, and thus per definition excludes undocumented immigrants. Notwithstanding that these migrants are also difficult to reach by more traditional means (e.g. in surveys), this inherent selectivity needs to be acknowledged. For starters, it is important to emphasize that the research population only constitutes 'legal' immigrants who are registered in a Dutch municipality. How large the blind spot is remains largely an open question. By their very nature, the size of the undocumented population is hard to ascertain. ${ }^{20}$ However, given the fact that access to citizenship is conditioned on a period of legal residence, any theorisation on the determinants of citizenship acquisition and associated outcomes does not apply to the illegal population. These migrants would therefore need to be excluded from the research population even if the data were available. As such, there is no reason to assume that the empirical findings in this thesis are biased, but it is important to recognise that they are only relevant for a specific group of migrants, namely those that reside in the host country legally.

The development of register-based forms of census taking and data collection is a relatively new phenomenon. The range of characteristics collected from various institutions, and available for statistical analysis, continues to increase. Yet the extent to which these characteristics can be traced back in the past varies widely. This issue will resolve itself over time, but until then, researchers are at times restricted in their methodological opportunities, and dependent on creative empirical strategies when information is only available for a limited window of time, or for specific migrant cohorts. An example in this thesis would be the analysis of homeownership, of which data is only available from 2003 onwards. While the research population (cohorts 19992002) could generally only naturalise after 2003 in light of the residence requirement for naturalisation in the Netherlands, there is no information on homeownership during the period leading up to naturalisation. A systematic analysis of a potential anticipation effect in the housing market is therefore not possible. Another example is the data on labour market integration (including employment and earnings), which is only available in its current form from 1999 onwards. This complicates a comparative analysis of migrants who could naturalise under more liberal and restrictive institutional conditions (before and after April 1, 2003 respectively). In Chapter 4 and 5, I compare migrant cohorts 1996-1997 to cohorts 2001-2002, but labour market information on the initial years of residence of the former cohort group is missing. As such, a comparative analysis of the period leading up to naturalisation for migrants under varying citizenship regimes is not possible. This would be particularly interesting because institutional

\footnotetext{
${ }^{20}$ Statistics Netherlands estimated that on January 1, 2001, between 46,000 and 116,000 individuals resided in the Netherlands illegally (Hoogteijling, 2002).
} 
conditions are an integral part of the mechanism underlying anticipation. In other words, the relevance of anticipation is likely conditioned by the formal requirements for naturalisation. Whether this is the case, and which requirements affect integration outcomes leading up to naturalisation positively or negatively, remains the subject of speculation.

Finally, the methodological design and empirical strategy of this thesis is exclusively quantitative in nature. This decision is motivated by two factors. First, an analysis of the determinants of legal-status transitions and associated socio-economic outcomes requires large- $\mathrm{N}$ data to test systematically. Whether and to what extent citizenship matters are quantifiable questions that can only be confirmed for a research population as sizable and diverse as all registered first-generation immigrants in the Netherlands through statistical analyses. In other words, the central research question of this thesis constitutes a puzzle that can only be solved quantitatively. Second, individual-level register data is restricted for privacy reasons. Access to such data sources is therefore highly conditional, and requires substantial planning and coordination with statistical offices to realize. Establishing the necessary infrastructure is therefore a significant investment, and once in place, is worthwhile to utilise in depth. However, that is not to say that the quantitative findings in this study would not benefit from a qualitative approach. Indeed, this thesis raises important follow-up questions that are specifically suited to a qualitative empirical design. Notable examples include the mechanisms underlying the established positive association between citizenship and socio-economic integration (or lack thereof), the question what exactly drives immigrants to invest in acquiring the host country citizenship or not, and why restrictive institutional conditions deter immigrants from naturalisation. While this thesis theorises on potential mechanisms, a solid grasp on the why questions requires complementary analyses of a qualitative nature.

\section{Moving forward: avenues of future research}

One of the key contributions of this thesis is the development of a theoretical framework that may help explain why some migrants naturalise and benefit from citizenship, while others do not. I predominantly seek answers to that question in characteristics of the immigrants who naturalise (to whom does citizenship matter?), the relevant membership regulations that condition access to the host country citizenship (under which conditions does citizenship matter?) and the nexus between them (to whom do citizenship policies matter most?). For instance, a fast track to naturalisation facilitates integration for vulnerable migrant groups (such as those from less developed countries of origin), yet these migrants are particularly dependent on the institutional context that conditions access to citizenship. Moreover, too short a pathway to citizenship and a lack of (linguistic) requirements for naturalisation may disincentivise integration. The identification of a citizenship premium thus depends on a 
complex interaction between the composition of the migrant population and citizenship policies of the host country, which may explain why we observe an effect of citizenship in some countries, but not in others. While this thesis takes a first step in that direction, a systematic analysis of these expectations requires a cross-national design, since institutional and compositional variation is limited by the focus on a single destination country. Such a comparative perspective is largely absent in the literature. This may be linked to difficulties in securing access to restricted administrative data sources in multiple countries at the same time. Moreover, variation in citizenship regimes complicates a simple comparison of empirical findings in different countries. For instance Helgertz et al. (2014) analyse a citizenship premium in the labour market by performing a bi-national comparison between Sweden and Denmark. Yet it is difficult to compare the migrant populations in both countries, who are selected on the basis of the residence requirement (which is at least 4 consecutive years in Sweden, compared to 6 [until 2002] and 8 years in Denmark). While this study finds no differences in naturalisation outcomes between both countries, it remains unclear whether institutional conditions indeed do not matter, or if compositional differences between the selected migrant populations of both countries plays a role. Our limited understanding of the relevance of citizenship policies for the socio-economic impact of naturalisation further complicates the interpretation of the findings. One could hypothesise that relatively liberal institutional conditions in Sweden disincentivise integration, while the long waiting period in Denmark erodes the added value of accelerated investment in host-country specific human capital. As such, we may not expect a citizenship premium in either country, yet it remains difficult to identify the underlying mechanisms. What is thus needed is a more controlled analysis of the impact of policy changes on legal status transitions and associated integration outcomes (Bloemraad, 2017; Vink, 2017). The development of such an integrated, comparative research agenda would require close collaboration between scholars to ensure that research populations, model specifications and operationalisations of key concepts are as closely aligned as possible with studies in other countries.

Furthermore, the analysis of the relevance of citizenship regimes for the integration outcomes of naturalisation not only requires more coordination between scholars to standardise research designs and measurements, but also needs to go beyond the traditional focus on formal requirements for naturalisation. While the legal framework of rules and regulations, as laid down in constitutions and citizenship legislation, stipulates the formal conditions for eligibility, access to citizenship also depends on a set of informal norms and practices (Vink, 2017, p. 223). States' normative stance towards immigrant integration and citizenship acquisition likely shapes the extent to which these processes are facilitated and encouraged (Bloemraad, 2002). Whether governments circulate information about the rewards and opportunities of the host country citizenship, for instance by coordinating with and supporting ethnic organisations and community leaders, may determine whether migrants are mobilised 
to invest in naturalisation. Moreover, the ways in which administrations implement citizenship laws, and how state officials interpret and execute them, may incentivise or discourage citizenship acquisition. Such informal properties of the institutional context are generally ignored, likely because these conditions are difficult to measure and quantify. However, theorising on the relevance of these 'soft' contextual factors may prove necessary to explain differences in naturalisation rates between and within countries. Moreover, since the pathway to citizenship matters for the socio-economic outcomes of naturalisation, it may also serve as an important determinant of the citizenship premium. For instance, if citizenship acquisition is encouraged by state officials in a given municipality, and migrants naturalise more quickly and more often as a result, then the socio-economic outcomes of naturalisation are likely more positive compared to a similar municipality where naturalisation is not facilitated and thus delayed.

Similar questions remain with regard to whom citizenship matters. Almost all of the literature, including this thesis, focusses on foreign-born immigrants. While there are good reasons for analysing first and later generation immigrants in isolation, as the latter group can often naturalise through a facilitated procedure, and determinants of citizenship acquisition differ between generations (Bauböck et al., 2013; Dronkers \& Vink, 2012), almost nothing is known about the relevance of naturalisation for foreignborn (1.5 generation) and native-born (2nd generation) descendants of immigrants. Whether or not they enjoy a citizenship premium, and if legal status transitions of the parents affect the life course of their children ${ }^{21}$, remain open questions.

Furthermore, the state-of-the-art literature is almost exclusively focussed on labour market outcomes of naturalisation. While this thesis has taken a first step towards broadening the conceptual scope of socio-economic integration by analysing homeownership, a life course approach to legal status transitions can be applied to a wide range of integration indicators. The area that has probably received the most attention so far is living conditions of immigrants (Borjas, 2002; Feijten et al., 2008; Hutcheson \& Jeffers, 2013). This includes the relevance of citizenship for the probability of homeownership, as explored in Chapter 6, but can be expanded to other indicators such as residential crowding, quality of the accommodation, and characteristics of the area of residence. Citizenship acquisition may matter directly through positive signalling towards lenders and landlords, or indirectly through positive labour market outcomes. Furthermore, contextual factors such as housing systems and welfare regimes, as well as social/public housing, likely matter for residential patterns of immigrants, and may condition the relevance of citizenship (Arbaci, 2007). For instance, spatial division of tenures and social/public housing contributes to ethnic segregation (Andersen, Andersson, Wessel, \& Vilkama, 2015). In those cases, citizenship may be negatively associated with living in a neighbourhood with a large migrant population by improving

\footnotetext{
${ }^{21}$ See Street (2014) for a qualitative study of intergenerational motives for naturalisation.
} 
the odds of securing credit to finance a house. Conversely, when rented and tenure housing is more equally distributed, the impact of citizenship for homeownership may not matter as much for the ethnic composition of the area of residence.

Another area that has received some attention is citizenship and civic engagement. Literature suggests a positive association, although empirical findings are largely based on cross-sectional data (Just \& Anderson, 2012; Leal, 2002; Vermeulen \& Berger, 2008; Wong, 2000). A recent study by Hainmueller et al. (2015) employs a natural experiment design in Switzerland to address the omitted variable bias that confounds these crosssectional studies. For several decades, naturalisation requests in Switzerland were granted or denied by popular vote of resident citizens by reviewing résumés of applicants. In this controlled setting, voters are thus unable to distinguish between migrants whose characteristics on their respective résumés are the same. Therefore, controlling for these observable characteristics isolates omitted variable bias. Results show that naturalisation increases political participation and efficacy, even when controlling for non-random selection into naturalisation. Moreover, citizenship acquisition matters most if it is acquired relatively quickly after the moment of migration. Street (2015) arrives at the same conclusion based on panel survey data in Germany, identifying a positive relationship between naturalisation and political participation. Moreover, the effect is particularly strong if the host country citizenship is acquired early in the life course. In other words, citizenship matters for the political integration of immigrants, but the outcomes of naturalisation cannot be understood in isolation of when and how the status is acquired. This suggests that the life course framework underlying the citizenship premium in the labour and housing market is also applicable to political outcomes of naturalisation, although the relevant mechanisms may differ.

Literature suggests that citizenship acquisition also matters for feelings of identity and belonging (Hainmueller, Hangartner, \& Pietrantou, 2016). Similar to socio-economic and political outcomes of naturalisation, the institutional context may condition the relevance of citizenship for the social integration of immigrants. Formal requirements for naturalisation increasingly include cultural components, such as civic knowledge, integration contracts and loyalty oaths (Orgad, 2015, 2017). The underlying assumption seems to be a positive association between such institutional conditions and identification with the national culture. This implies the hypothesis that the effect of citizenship on cultural assimilation is amplified in countries with restrictive cultural requirements, or absent where these conditions are relatively liberal. Yet whether this is the case is as of yet unknown.

Finally, the literature on the citizenship premium (including this thesis) focuses almost exclusively on legal status transitions at the national level, and has largely ignored membership at the local (residential) level (Bauböck, 2010, 2015). However, developing a theoretical framework that goes beyond its current monistic national focus may prove useful to explain varying outcomes of naturalisation. The reason for this is 
that the socio-economic impact of naturalisation is conditioned by the pathway to citizenship. For instance, migrants who acquire the host country citizenship relatively early in the settlement process enjoy a more positive effect in the labour market. This has important implications for the institutional context of destination countries, as particularly vulnerable migrant groups, who stand to benefit from citizenship most, are dependent on citizenship policies that determine whether a fast track to naturalisation is a realistic proposition or not. However, the propensity to naturalise is not only conditioned by the relative accessibility of the status, but also by the rights and duties associated with it. For instance, migrants from the EU are unlikely to naturalise in another EU country, because these migrants already enjoy the benefits associated with EU citizenship. While controls for EU countries of origin are therefore common in the literature on the citizenship premium, the same is not true for rights and entitlements associated with local membership (i.e. legal residence). Yet it is arguable that from a cost-benefit perspective, migrants will be less likely to naturalise in countries where fewer rights are exclusively associated with citizenship. Examples include countries where the franchise is extended to non-citizens, or where access to healthcare and social welfare is universal. When instrumental incentives for naturalisation are limited, the propensity to naturalise largely depends on years of residence (Vink et al., 2013). As such, rights and entitlements at the local level may condition the extent to which citizenship functions as an effective instrument for socio-economic integration, as the comparatively limited advantages associated with citizenship acquisition delay the moment of naturalisation to a point where it is no longer relevant as a stepping stone for integration.

In sum, a progressive research agenda of the citizenship premium could focus on a more systematic, comparative analysis of the relevance of citizenship policies - and associated pathways to citizenship - for the integration of immigrants. Moreover, the operationalisation of membership regimes should be expanded to include informal norms and practices, Examples include the extent to which governments circulate information about access to citizenship and the rewards and opportunities of naturalisation, the ways in which administrations implement citizenship law, and how state officials interpret and execute these regulations. Finally, literature suggests that the analytical models underlying the citizenship premium in the labour market are also relevant in other domains of life, such as political participation and socio-cultural integration. This should invite us to broaden the substantive scope of the state-of-theart by analysing the relevance of legal status transitions for alternative indicators of immigrant integration. 



\section{References}

Aalbers, M. B. (2007). What Types of Neighbourhoods are Redlined?. Journal of Housing and the Built Environment, 22(2), 177-198.

Abascal, M. (2017). Tu Casa, Mi Casa: Naturalisation and Belonging among Latino Immigrants. International Migration Review, 51(2), 291-322.

Abbott, A. (1997). On the Concept of Turning Point. Comparative Social Research, 16, 85-106.

Acharya, V. V., \& Schnabl, P. (2009). How Banks Played the Leverage Game. In V. V. Acharya \& M. Richardson (Eds.), Restoring Financial Stability (83-100). Hoboken: John Wiley \& Sons.

Aleksynska, M., \& Algan, Y. (2010). Assimilation and Integration of Immigrants in Europe. IZA Discussion Paper no. 5185.

Algan, Y., Dustmann, C., Glitz, A., \& Manning, A. (2010). The Economic Situation of First and SecondGeneration Immigrants in France, Germany and the United Kingdom. The Economic Journal, 120(542), 430.

Andersen, H. S., Andersson, R., Wessel, T., \& Vilkama, K. (2015). The Impact of Housing Policies and Housing Markets on Ethnic Spatial Segregation: Comparing the Capital Cities of Four Nordic Welfare States. International Journal of Housing Policy, 16(1), 1-30.

Andriessen, I., Nievers, E., \& Dagevos, J. (2012). Op achterstand: discriminatie van niet-westerse migranten op de arbeidsmarkt. Den Haag: SCP.

Aptekar, S. (2015). The road to citizenship: what naturalisation means for immigrants and the United States. New Brunswick: Rutgers University Press.

Arbaci, S. (2007). Ethnic Segregation, Housing Systems and Welfare Regimes in Europe. International Journal of Housing Policy, 7(4), 401-433.

Arrow, K. J. (1972). Some Mathematical Models of Race Discrimination in the Labor Market. In A. H. Pascal (Eds.), Economic life (187-204). Lexington: D. C. Heath.

Bakker, B. (2011). Micro integration. Den Haag/Heerlen: CBS.

Bakker, B. (2012). Estimating the Validity of Administrative variables. Statistica Neerlandica, 66, 8-17.

Bakker, L., Dagevos, J., \& Engbersen, G. (2016). Explaining the Refugee Gap: A Longitudinal Study of Labour Market Participation of Refugees in the Netherlands. Journal of Ethnic and Migration Studies, 43(11), 117.

Bakker, B., van Rooijen, J., \& van Toor, L. (2014). The System of Social Statistical Datasets of Statistics Netherlands: An Integral Approach to the Production of Register-Based Social Statistics. Statistical Journal of IAOS, 30, 411-424.

Barkan, E. R., \& Khokhlov, N. (1980). Socioeconomic Data as Indexes of Naturalization Patterns in the UnitedStates: A Theory Revisited. Ethnicity, 7(2), 159-190.

Bauböck, R. (2010). Studying Citizenship Constellations. Journal of Ethnic and Migration Studies, 36(5), 847859.

Bauböck, R. (2015). The Three Levels of Citizenship in the European Union. Phenomenology and Mind, 8, 6676.

Bauböck, R. (2017). Political Membership and Democratic Boundaries. In A. Shachar., R. Bauböck., I. Bloemraad., \& M. Vink (Eds.), The Oxford handbook of citizenship (60-82). Oxford: Oxford University Press.

Bauböck, R., Honohan, I., Huddleston, T., Hutcheson, D., Shaw, J., \& Vink, M. (2013). Access to citizenship and its impact on immigrant integration. Robert Schuman Centre for Advanced Studies: EUDO Citizenship Observatory.

Becker, G. S. (1962). Investment in Human Capital: A Theoretical Analysis. The Journal of Political Economy, $70(5), 9-49$.

Becker, G. S. (1964). Human capital. New York: National Bureau of Economic Research. 
Beijbohm, U. (1971). Swedes in Chicago: a demographic and social study of the 1846-1880 immigration. Chicago: Chicago Historical Society.

Bernard, W. S. (1936). Cultural Determinants of Naturalization. American Sociological Review, 1(6), 943-953.

Bevelander, P., \& Pendakur, R. (2012). Citizenship, Co-Ethnic Populations, and Employment Probabilities of Immigrants in Sweden. Journal of International Migration and Integration, 13(2), 203-222.

Bevelander, P., \& Veenman, J. (2008). Naturalization and Socio-Economic Integration: The Case of the Netherlands. In P. Bevelander \& D. J. DeVoretz (Eds.), The economics of citizenship (63-88). Malmö: Malmö University Press.

Biemer, P. P., de Leeuw, E., Eckman, S., Edwards, B., Kreuter, F., Lyberg, L. E., Tucker, N. C., \& West, B. T. (2017). Total survey error in practice. Hoboken: John Wiley \& Sons.

Bird, K. (2005). The Political Representation of Visible Minorities in Electoral Democracies: A Comparison of France, Denmark, and Canada. Nationalism and Ethnic Politics, 11, 425-465.

Blitz, B. K., \& Lynch, M. (2011). Statelessness and citizenship. Northampton: Edward Elgar Publishing.

Bloemraad, I. (2002). The North American Naturalization Gap: An Institutional Approach to Citizenship Acquisition in the United States and Canada. International Migration Review, 36(1), 193-228.

Bloemraad, I. (2004). Who Claims Dual Citizenship? The Limits of Postnationalism, the Possibilities of Transnationalism, and the Persistence of Traditional Citizenship. International Migration Review, 38(2), 389-426.

Bloemraad, I. (2006). Becoming a Citizen in the United States and Canada: Structured Mobilization and Immigrant Incorporation. Social Forces, 85(2), 667-695.

Bloemraad, I. (2017). Does Citizenship Matter?. In A. Shachar., R. Bauböck., I. Bloemraad., \& M. Vink (Eds.), The Oxford handbook of citizenship (525-550). Oxford: Oxford University Press.

Bloemraad, I., \& Wright, M. (2014). "Utter Failure” or Unity Out of Diversity? Debating and Evaluating Policies of Multiculturalism. Integration Migration Review, 48(1), 292-334.

Blommaert, L., Coenders, M., \& van Tubergen, F. (2014). Discrimination of Arabic-Named Applicants in the Netherlands: An Internet-Based Field Experiment Examining Different Phases in Online Recruitment Procedures. Social Forces, 92(3), 957-982.

Bodvarsson, Ö. B., \& van den Berg, H. (2009). Economic Growth and Immigration. In Ö. B. Bodvarsson \& H. van den Berg (Eds.), The economics of immigration: theory and policy (221-258). Heidelberg: Springer.

Boehm, T. P., \& Schlottmann, A. M. (2004). The Dynamics of Race, Income, and Homeownership. Journal of Urban Economics, 55(1), 113-130.

Borjas, G. J. (2002). Homeownership in the Immigrant Population. Journal of Urban Economics, 52(3), 448476.

Bosniak, L. (2000). Citizenship Denationalized. Indiana Journal of Global Legal Studies, 7(2), 447-509.

Bosniak, L. (2017). Status Non-Citizens. In A. Shachar., R. Bauböck., I. Bloemraad., \& M. Vink (Eds.), The Oxford handbook of citizenship (314-336). Oxford: Oxford University Press.

Bove, V., \& Elia, L. (2017). Migration, Diversity, and Economic Growth. World Development, 89, 227-239.

Bratsberg, B., \& Raaum, O. (2011). The Labour Market Outcomes of Naturalised Citizens in Norway. In Naturalisation: a passport for the better integration of immigrants? (184-205). Paris: OECD Publishing.

Bratsberg, B., Ragan, J. F., Jr., \& Nasir, Z. M. (2002). The Effect of Naturalisation on Wage Growth: A Panel Study of Young Male Immigrants. Journal of Labor Economics, 20(3), 568-597.

Bueker, C. S. (2003). The Personal is Political: The Relationship Between Marital Status and Immigrant Political Incorporation. Paper presented at the 2003 annual meeting of the American Political Science Association.

Bueker, C. S. (2005). Political Incorporation Among Immigrants from Ten Areas of Origin: The Persistence of Source Country Effects. International Migration Review, 39(1), 103-140.

Case, K., \& Mayer, C. (1996). Housing Price Dynamics within a Metropolitan Area. Regional Science and Urban Economics, 26(3-4), 387-407.

CBS. (2016). Jaarrapport integratie 2016. Den Haag/Heerlen: CBS.

CBS. (2017a). Vermogen van huishoudens, 2007-2015: samenstelling vermogen particuliere huishoudens naar kenmerken. Den Haag/Heerlen: CBS. 
CBS. (2017b). Nationaliteitswijzigingen; ges/acht, nationaliteit en regeling. Den Haag/Heerlen: CBS.

Charles, K. K., \& Hurst, E. (2002). The Transition to Home Ownership and the Black-White Wealth Gap. The Review of Economics and Statistics, 84(2), 281-297.

Chiswick, B. R. (1978). The Effect of Americanization on the Earnings of Foreign-Born Men. The Journal of Political Economy, 86(5), 897-921.

Chiswick, B. R., \& Miller, P. W. (2001). A Model of Destination-Language Acquisition: Application to Male Immigrants in Canada. Demography, 38(3), 391-409.

Chiswick, B. R., \& Miller, P. W. (2009). Citizenship in the United States: The Roles of Immigrant Characteristics and Country of Origin. Research in Labor Economics, 29, 91-130.

Cohen, E. F. (2009). Semi-citizenship in democratic politics. New York: Cambridge University Press.

College voor de Rechten van de Mens. (2016). Oordeel in de Zaak van Verzoeker tegen SNS Bank N.V. Judgement no. 2016-138.

Constant, A. F., Roberts, R., \& Zimmermann, K. F. (2009). Ethnic Identity and Immigrant Homeownership. Urban Studies, 46(9), 1879-1898.

Coulson, N. E., \& Dalton, M. (2010). Temporal and Ethnic Decomposition of Homeownership Rates: Synthetic Cohorts Across Five Censuses. Journal of Housing Economics, 19(3), 155-166.

Couper, M. P. (2017). New Developments in Survey Data Collection. Annual Review of Sociology, 43, 121-145.

Cox, D. R. (1972). Regression Models and Life Tables. Journal of the Royal Statistical Society, Series B (Methodological), 34(2), 187-220.

Czaika, M., \& de Haas, H. (2014). The Globalization of Migration: Has the World Become More Migratory?. International Migration Review, 48(2), 283-323.

Dauvergne, C. (2007). Citizenship with a Vengeance. Theoretical Inquiries in Law, 8, 489-508.

Dawkins, C. (2005). Racial Gaps in the Transition to First-Time Homeownership: The Role of Residential Location. Journal of Urban Economics, 58(3), 537-554.

Devoretz, D. J., \& Pivnenko, S. (2008). The Economic Determinants and Consequences of Canadian Citizenship Ascension. In P. Bevelander \& D. J. DeVoretz (Eds.), The economic consequences of citizenship ascension. a cross country comparison (21-62). Malmö: Malmö University Press.

Diewald, M., \& Mayer, K. U. (2009). The Sociology of the Life Course and Life Span Psychology: Integrated Paradigm or Complementing Pathways?, Advances in Life Course Research, 14(1), 5-14.

van Dorst, P., Hoogendijk, S., Vreeburg, E., \& Verheul, R. (2017). Geen Huis zonder Nederlands Paspoort. De Nationale Ombudsman Report no. 2017/077.

Drever, A. I., \& Hoffmeister, O. (2008). Immigrants and Social Networks in a Job-Scarce Environment: The Case of Germany. International Migration Review, 42(2), 425-448.

Dronkers, J., \& Vink, M. (2012). Explaining Access to Citizenship in Europe: How Citizenship Policies Affect Naturalization Rates. European Union Politics, 13(3), 390-412.

Dustmann, C. (2002). Temporary Migration and Economic Assimilation. IZA Discussion Paper no. 186.

Dustmann, C., \& Frattini, T. (2014). The Fiscal Effects of Immigration to the UK. The Economic Journal, $124(580), 593-643$.

Dustmann, C., Glitz, A., \& Frattini, T. (2008). The Labour Market Impact of Immigration. Oxford Review of Economic Policy, 24(3), 477-494.

Edin, P. A., Fredriksson, P., \& Åslund, O. (2003). Ethnic Enclaves and the Economic Success of Immigrants: Evidence from a Natural Experiment. The Quarterly Journal of Economics, 118(1), 329-357.

Eerste Kamer. (2016). Wijziging van de Rijkswet op het Nederlanderschap ter Verlenging van de Termijnen voor Verlenen van het Nederlanderschap en Enige Andere Wijzigingen: Voorlopig Verslag van de Vaste Commissie voor Immigratie en Asiel. JBZ-Raad, 33 852, (R2023).

Eerste Kamer. (2017a). Nader Voorlopig Verslag van de Vaste Commissie voor Immigratie en Asiel. JBZ-Raad, 33 382, (R2023).

Eerste Kamer. (2017b). Wijziging van de Rijkswet op het Nederlanderschap ter Verlenging van de Termijnen voor Verlenen van het Nederlanderschap en Enige Andere Wijzigingen: Voorlopig Verslag van de Vaste Commissie voor Immigratie en Asiel. JBZ-Raad, 33 852, (R2023). 
Eerste Kamer. (2017c). Termijnen Verlening Nederlanderschap: Verslag van de Vergadering van 26 September 2017 (2017/2018 nr. 1).

Elder, G. H., Jr. (1974). Children of the great depression: social change in life experience. Chicago: University of Chicago Press.

Elder, G. H., Jr. (1985). Perspectives on the Life Course. In G. H. Elder Jr. (Eds.), Life course dynamics: transitions and trajectories (23-49). Ithaca: Cornell University Press.

Elder, G. H., Jr. (1994). Time, Human Agency, and Social Change: Perspectives on the Life Course. Social Psychology Quarterly, 57(1), 4-15.

Enchautegui, M. E., \& Giannarelli, L. (2015). The economic impact of naturalization on immigrants and cities. New York: Urban Institute.

Engdahl, M. (2011). The Impact of Naturalisation on Labour Market Outcomes in Sweden. In Naturalisation: a passport for the better integration of immigrants? (99-130). Paris: OECD Publishing.

Engdahl, M. (2014). Naturalisation and the Economic and Social Integration of Immigrants. IFAU Working paper no. 2014.11.

Entzinger, H. (2003). The Rise and Fall of Multiculturalism. In C. Joppke \& E. Morawska (Eds.), Towards assimilation and citizenship: immigrants in liberal nation-states (59-86). Londen: Palgrave Macmillan.

Eurostat. (2017a). Employment and activity by sex and age - annual data. Luxembourg: Eurostat.

Eurostat. (2017b). Employment rates by sex, age and citizenship (\%). Luxembourg: Eurostat.

Feijten, P., Hooimeijer, P., \& Mulder, C. H. (2008). Residential Experience and Residential Environment Choice over the Life Course. Urban Studies, 45(1), 141-162.

Fleischmann, F., \& Dronkers, J. (2010). Unemployment Among Immigrants in European Labour Markets: An Analysis of Origin and Destination Effects. Work, Employment \& Society, 24(2), 337-354.

Font, J., \& Mendez, M. (2014). Surveying ethnic minorities and immigrant populations. Amsterdam: Amsterdam University Press.

Fortin, N. M. (2005). Gender Role Attitudes and the Labour-Market Outcomes of Women Across OECD countries. Oxford Review of Economic Policy, 21(3), 416-438.

Fougère, D., \& Safi. M. (2009). Naturalisation and Employment of Immigrants in France (1968-1999). International Journal of Manpower, 30(1/2), 83-96.

Franzen, A., \& Hangartner, D. (2006). Social Networks and Labour Market Outcomes: The Non-Monetary Benefits of Social Capital. European Sociological Review, 22(4), 353-368.

Friedberg, R. M. (2000). You Can't Take it With You? Immigrant Assimilation and the Portability of Human Capital. Journal of Labor Economics, 18(2), 221-251.

Gagnon, J. (2014). Demographic Change and the Future of the Labour Force in the EU27, other OECD Countries and Selected Emerging Economies. In Matching Economic Migration with Labour Market Needs (111-149). Paris: OECD Publishing.

Gonzalez-Ferrer, A., \& Cortina-Trilla, C. (2011). Naturalisation Decisions in Spain: The Importance of Legal Asymmetries. Paper presented at the 2011 annual meeting of the Population Association of America.

Goodman, S. W. (2014). Immigration and membership politics in Western Europe. Cambridge: Cambridge University Press.

de Graaf, N. D., \& Flap, H. D. (1988). With a Little Help From my Friends: Social Resources as an Explanation of Occupational Status and Income in West Germany, the Netherlands, and the United States. Social Forces 67(2), 452-472.

Groenendijk, K., \& Heijs, E. (2001). Immigration, Immigrants and Nationality Law in the Netherlands, 19451998. In R. Hansen \& P. Weil (Eds.), Towards a European nationality: citizenship, immigration and nationality law (143-172). New York: Palgrave.

Hainmueller, J., Hangartner, D., \& Pietrantuono, G. (2015). Naturalization Fosters the Long-Term Political Integration of Immigrants. Proceedings of the National Academy of Sciences, 112(41), 12651-12656.

Hainmueller, J., Hangartner, D., \& Pietrantuono, G. (2016). Catalyst or Crown: Does Naturalization Promote the Long-Term Social Integration of Immigrants?. American Political Science Review, 111(2), 256-276.

de Hart, B. (2004). Debates on Dual Nationality in the Netherlands. IMIS Beiträge, 24, 149-162.

von Hayek, F. A. (1943). Scientism and the Study of Society. Economica, 10(37), 34-63. 
Hayfron, J. E. (2001). Language Training, Language Proficiency and Earnings of Immigrants in Norway. Applied Economics, 33(15), 1971-1979.

Heath, A. F., \& Cheung, S. Y. (2007). Unequal chances: ethnic minorities in Western labour markets. Oxford: Oxford University Press.

Heijs, E. (1995). Van vreemdeling tot Nederlander: de verlening van het Nederlanderschap aan vreemdelingen 1813-1992. Amsterdam: het Spinhuis.

Heinz, W. R. (1996). Status Passages as Micro-Macro Linkages in Life Course Research. In A. Weymann, W. R. Heinz, \& P. Alheit (Eds.), Society and biography: interrelationships between social structure, institutions and the life course (51-66). Weinheim: Deutscher Studien Verlag.

Helgertz, J., \& Bevelander, P. (2016). The Influence of Partner Choice and Country of Origin Characteristics on the Naturalization of Immigrants in Sweden: A Longitudinal Analysis. International Migration Review, 51(3), 667-700.

Helgertz, J., Bevelander, P., \& Tegunimataka, A. (2014). Naturalisation and Earnings: A Denmark-Sweden Comparison. European Journal of Population, 30(3), 337-359.

Hofstede, G. (2001). Culture's consequences: comparing values, behaviors, institutions, and organizations across nations. Thousand Oaks: Sage Publications.

Hoogteijling, E. M. J. (2002). Illegal People in the Netherlands. Monthly Bulletin of Population Statistics, 3, 21.

Huijnk, W., \& Andriessen, I. (2016). Integratie in zicht? De integratie van migranten in Nederland op acht terreinen nader bekeken. Den Haag: SCP.

Hutcheson, D., \& Jeffers, K. (2013). Citizenship Status and the Integration of Immigrants: CITINT Indicators. Robert Schuman Centre for Advanced Studies: EUDO Citizenship Observatory.

Jacobsen, D. (1996). Rights across borders: immigration and the decline of citizenship. Baltimore: John Hopkins University Press.

Janoski, T. (2010). The ironies of citizenship: naturalization and integration in industrialized countries. New York: Cambridge University Press.

Jasso, G., \& Rosenzweig, M. R. (1986). Family Reunification and the Immigration Multiplier: US Immigration Law, Origin-Country Conditions, and the Reproduction of Immigrants. Demography, 23(3), 291-311.

Jennissen, R. (2011). Internationale Migratie Naar en Vanuit Nederland: Algemene Trends. In R. Jenissen (Eds.), De Nederlandse migratiekaart (33-72). Den Haag: WODC.

Jones-Correa, M. (2001). Under Two Flags: Dual Nationality in Latin America and its Consequences for Naturalization in the United States. International Migration Review, 35(4), 997-1029.

Joppke, C. (2003). Citizenship Between De- and Re-Ethnicization. European Journal of Sociology, 44(3), 429458.

Just, A., \& Anderson, C. J. (2012). Immigrants, Citizenship and Political Action in Europe. British Journal of Political Science, 42(3), 481-509.

Kanas, A., van Tubergen, F., \& van der Lippe, T. (2011). The Role of Social Contacts in the Employment Status of Immigrants: A Panel Study of Immigrants in Germany. International Sociology, 26(1), 95-122.

Kappelhof, J. (2014). The Effect of Different Survey Designs on Nonresponse in Surveys Among Non-Western Minorities in the Netherlands. Survey Research, 8(2), 81-98.

Kappelhof, J. (2017). Survey Research and the Quality of Survey Data Among Ethnic Minorities. In P. P. Biemer, E. de Leeuw, S. Eckman, B. Edwards, F. Kreuter, L. E. Lyberg, N. C. Tucker, \& B. T. West (Eds.), Total Survey Error in Practice (235-252). Hoboken: John Wiley \& Sons.

Kaufmann, D., Kraay, A., \& Mastruzzi, M. (2011). The Worldwide Governance Indicators: A Summary of Methodology, Data and Analytical Issues. Hague Journal of the Rule of Law, 3(2), 220-246.

Kee, P., \& von Ophem, H. (1996). Immigrant Wages in the Netherlands: The Role of Dutch Language Proficiency. In S. Gazioglu (Eds.), Migrants in the European Labor Market (62-84). Aberdeen: J-Net.

Kogan, I. (2011). New Immigrants - Old Disadvantage Patterns? Labour Market Integration of Recent Immigrants in Germany. International Migration, 49(1), 91-117.

Krahn, H., Derwing, T., Mulder, M., \& Wilkinson, L. (2000). Educated and Underemployed: Refugee Integration into the Canadian Labour Market. Journal of International Migration and Integration, 1(1), 59-84. 
Lancee, B. (2010). The Economic Returns of Immigrants' Bonding and Bridging Social Capital: The Case of the Netherlands. International Migration Review, 44(1), 202-226.

Lancee, B. (2012). Immigrant Performance in the Labour Market: Bonding and Bridging Social Capital. Amsterdam: Amsterdam University Press.

Lancee, B., \& Hartung, A. (2012). Turkish Migrants and Native Germans Compared: The Effects of Inter-Ethnic and Intra-Ethnic Friendships on the Transition from Unemployment to Work. International Migration, 50(1), 39-54.

Leal, D. L. (2002). Political Participation by Latino Non-Citizens in the United States. British Journal of Political Science, 32(2), 353-370.

de Leeuw, E., \& de Heer, W. (2002) Trends in Household Survey Nonresponse: A Longitudinal and International Comparison. In R. M. Groves, D. A. Dillman, J. L. Eltinge, \& R. J. A. Little (Eds.), Survey Nonresponse (41-54). New York: Wiley.

Liang, Z. (1994). Social Contact, Social Capital, and the Naturalization Process: Evidence from Six Immigrant Groups. Social Science Research, 23(4), 407-437.

Liebig, T., \& von Haaren, F. (2011). Citizenship and the Socioeconomic Integration of Immigrants and Their Children. In Naturalisation: a passport for the better integration of immigrants? (24-60). Paris: OECD Publishing.

Light, M. T., Massoglia, M., \& King, R. D. (2014). Citizenship and Punishment: The Salience of National Membership in U.S. Criminal Courts. American Sociological Review, 79(5), 825-847.

Logan, J. R., Oh, S., \& Darrah, J. (2012). The Political and Community Context of Immigrant Naturalisation in the United States. Journal of Ethnic and Migration Studies, 38(4), 535-554.

Manning, A., \& Roy, S. (2010). Culture Clash or Culture Club? National Identity in Britain. The Economic Journal, 120(542), 72-100.

Martin, R. (2011). The Local Geographies of the Financial Crisis: From the Housing Bubble to Economic Recession and Beyond. Journal of Economic Geography, 11(4), 587-618.

Masnick, G. (1997). Citizenship and Homeownership among Foreign Born Residents in the U.S. Joint Center for Housing Studies, Research Note no. 97-1.

Maxwell, R., \& Bleich, E. (2014). What Makes Muslims Feel French?. Social Forces, 93(1), 155-179.

Mayer, K. U. (2004). Whose Lives? How History, Societies, and Institutions Define and Shape Life Courses. Research in Human Development, 1(3), 161-187.

Mayer, K. U. (2009). New Directions in Life Course Research. Annual Review of Sociology, 35, 413-433.

Mazzolari, F. (2009). Dual Citizenship Rights: Do They Make More and Richer Citizens?. Demography, 46(1), 169-191.

McConnel, E. D. (2015). Restricted Movement: Nativity, Citizenship, Legal Status, and the Residential Crowding of Latinos in Los Angeles. Social Problems, 62(1), 141-162.

Merton, R. K. (1968). The Matthew Effect in Social Science: The Reward and Communication System of Science. Science, 159(3810), 56-63.

Nee, V., \& Sanders, J. (2001). Trust in Ethnic Ties: Social Capital and Immigrants. In K. S. Cook (Eds.), Trust in Society (374-392). New York: Russell Sage Foundation.

Norris, M., \& Winston, N. (2012). Home-Ownership, Housing Regimes and Income Inequalities in Western Europe. International Journal of Social Welfare, 21(2), 127-138.

Oberski, D. L., Kirchner, A., Eckman, S., \& Kreuter, F. (2017). Evaluating the Quality of Survey and Administrative Data with Generalized Multitrait-Multimethod Models. Journal of the American Statistical Association, forthcoming.

O’brien, R. M. (2007). A Caution Regarding Rules of Thumb for Variance Inflation Factors. Quality \& Quantity, 41(5), 673-690.

OECD. (2008). Jobs for immigrants: labour market integration in Belgium, France, the Netherlands and Portugal. Paris: OECD Publishing.

OECD. (2011). Naturalisation: a passport for the better integration of immigrants?. Paris: OECD Publishing.

OECD. (2015). Indicators of immigrant integration 2015: settling in. Paris: OECD Publishing.

van Oers, R. (2014). Deserving citizenship. Leiden: Martinus Nijhoff Publishers. 
van Oers, R., de Hart, B., \& Groenendijk, K. (2013). Country Report: The Netherlands. Robert Schuman Centre for Advanced Studies: EUDO Citizenship Observatory.

Orgad, L. (2015). The cultural defence of nations: a liberal theory of majority rights. Oxford: Oxford University Press.

Orgad, L. (2017). Naturalization. In A. Shachar., R. Bauböck., I. Bloemraad., \& M. Vink (Eds.), The Oxford handbook of citizenship (337-357). Oxford: Oxford University Press.

Peters, F., Schmeets, H., \& Vink, M. (2017). Perspectief op het Nederlanderschap: Het Effect van de Snelheid van Naturalisatie. Bevolkingstrends, 1, 1-14.

Portes, A., \& Curtis, J. W. (1987). Changing Flags: Naturalization and its Determinants Among Mexican Immigrants. International Migration Review, 21(2), 352-371.

Reichel, D. (2011). Do Legal Regulations Hinder Naturalisation?: Citizenship Policies and Naturalisation Rates in Europe. Robert Shuman Centre for Advanced Studies: EUDO Citizenship Observatory.

Reichel, D., \& Perchinig, B. (2015). Reflections on the Value of Citizenship: Explaining Naturalisation Practices. Australian Journal of Political Science, 44(1), 32-45.

Rijksoverheid. (2017). Vertrouwen in de toekomst: regeerakkoord 2017-2021. Den Haag: Ministerie van Algemene Zaken.

Rohe, W. M., \& Stegman, M. A. (1994). The Effects of Homeownership: On the Self-Esteem, Perceived Control and Life Satisfaction of Low-Income People. Journal of the American Planning Association, 60(2), 173184.

Ross, S. L., \& Tootell, G. M. B. (2004). Redlining, the Community Reinvestment Act, and Private Mortgage Insurance. Journal of Urban Economics, 55(2), 278-297.

Rossi, P. H., \& Weber, E. (1996). The Social Benefits of Homeownership: Empirical Evidence from National Surveys. Housing Policy Debate, 7(1), 1-35.

Ruedin, D. (2009). Ethnic Group Representation in a Cross-National Comparison. The Journal of Legislative Studies, 15(4), 335-354.

Sassen, S. (1996). Losing control: sovereignty in an age of globalization. New York: Colombia University Press.

Saurer, J., \& Felfe, C. (2014). Granting Birthright Citizenship: A Door Opener for Immigrant Children's Educational Participation and Success?. CESifo Working Paper no. 4959.

Schmeets, H., \& te Riele, S. (2010). Integratie van Allochtonen. In H. Schmeets (Eds.), Sociale samenhang: participatie, vertrouwen en integratie (153-164). Den Haag/Heerlen: CBS.

Schmidt, C. M. (1997). Immigrant Performance in Germany: Labor Earnings of Ethnic German Migrants and Foreign Guest-Workers. The Quarterly Review of Economics and Finance, 37(1), 379-397.

Schuck, P. H. (1989). Membership in the Liberal Polity: The Devaluation of American Citizenship. Georgetown Immigration Law Journal, 3(3), 1-18.

Schulte Nordholt, E., Hartgers, M., \& Gircour, R. (2004). The Dutch virtual census of 2001: analysis and methodology. Den Haag/Heerlen: CBS.

Schultz, T. W. (1961). Investment in Human Capital. The American Economic Review, 51(1), 1-17.

Scott, K. (2008). The Economics of Citizenship: Is There a Naturalization Effect?. In P. Bevelander \& D. J. DeVoretz (Eds.), The economic consequences of citizenship ascension. a cross country comparison (105126). Malmö: Malmö University Press.

Shanahan, M. J., \& Macmillan, R. (2008). Biography and the sociological imagination: contexts and contingencies. New York: Norton.

Smith, R. M. (2017). Citizenship and Membership Duties Towards Quasi-Citizens. In A. Shachar., R. Bauböck., I. Bloemraad., \& M. Vink (Eds.), The Oxford handbook of citizenship (817-838). Oxford: Oxford University Press.

Soysal, Y. N. (1994). Limits of citizenship: migrants and postnational membership in Europe. Chicago: University of Chicago Press.

Spiro, P. J. (2007). Beyond citizenship: American identity after globalization. Oxford: Oxford University Press.

Steinhardt, M. F. (2012). Does Citizenship Matter?: The Economic Impact of Naturalisations in Germany. Labour Economics, 19(6), 813-823. 
Street, A. (2014). My Child will be a Citizen: Intergenerational Motives for Naturalization. World Politics, 66(2), 264-292.

Street, A. (2015). The Political Effects of Immigrant Naturalisation. International Migration Review, 51(2), 323343.

Tan, K. (2017). Cosmopolitan Citizenship. In A. Shachar., R. Bauböck., I. Bloemraad., \& M. Vink (Eds.), The Oxford handbook of citizenship (694-713). Oxford: Oxford University Press.

van Tubergen, F. (2006). Immigrant integration: a cross-national study. New York: LFB Scholarly Publishing.

van Tubergen, F., \& Kalmijn, M. (2005). Destination-Language Proficiency in Cross-National Perspective: A Study of Immigrant Groups in Nine Western Countries. American Journal of Sociology, 110(5), 14121457.

van Tubergen, F., Maas, I., \& Flap, H. (2004). The Economic Incorporation of Immigrants in 18 Western Societies: Origin, Destination, and Community Effects. American Sociological Review, 69(5), 704-727.

Tweede Kamer (2000). Wijziging van de Rijkswet op het Nederlanderschap met betrekking tot de Verkrijging, de Verlening en het Verlies. Kamerstuk 25891-(R1609).

UNDP. (2014). Human Development Index Trends, 1980-2013. New York: UNDP.

Uunk, W. (2017). Does the Ethnic Gap in Homeownership Vary by Income? An Analysis on Dutch Survey Data. Housing Studies, 32(1), 95-114.

Vella, F. (1994). Gender Roles and Human Capital Investment: The Relationship Between Traditional Attitudes and Female Labour Market Performance. Economica, 61(242), 191-211.

Vermeulen, F., \& Berger, M. (2008). Civic Networks and Political Behavior: Turks in Amsterdam and Berlin. In S. K. Ramakrishnan \& I. Bloemraad (Eds.), Civic hopes and political realities: immigrants, community organizations, and political engagement (160-192). New York: Russel Sage Foundation.

Vink, M., \& de Groot, G. R. (2010). Citizenship Attribution in Western Europe: International Framework and Domestic Trends. Journal of Ethnic and Migration Studies, 36(5), 713-734.

Vink, M., de Groot, G. R., \& Luk, N. C. (2015). MACIMIDE Global Expatriate Dual Citizenship Datasets. Available from doi:10.7910/DVN/TTMZO8.

Vink, M., Peters, F., \& Schmeets, H. (2016). Snelle Naturalisatie Bevordert Kans op Baan. Economisch Statistische Berichten, 101(4740), 578-579.

Vink, M., Prokic-Breuer, T., \& Dronkers, J. (2013). Immigrant Naturalization in the Context of Institutional Diversity: Policy Matters, but to Whom?. International Migration, 51(5), 1-20.

Wingens, M., Valk, H., Windzio, M., \& Aybek, C. (2011). A life-course perspective on migration and integration. Dordrecht: Springer.

Wong, J. (2000). The Effects of Age and Political Exposure on the Development of Party Identification among Asian American and Latino Immigrants in the United States. Political Behavior, 22(4), 341-371.

Wooden, M. (1991). The Experience of Refugees in the Australian Labor Market. International Migration Review, 25(3), 514-535.

Yang, P. Q. (1994). Explaining Immigrant Naturalization. International Migration Review, 28(3), 449-477.

Youngh, I. M. (1989). Polity and Group Difference: A Critique of the Ideal of Universal Citizenship. Ethics, 99(2), 250-274.

Zschirnt, E., \& Ruedin, D. (2016). Ethnic Discrimination in Hiring Decisions: A Meta-Analysis of Correspondence Tests 1990-2015. Journal of Ethnic and Migration Studies, 42(7), 1115-1134.

Zorlu, A., Mulder, C. H., \& van Gaalen, R. (2014). Ethnic Disparities in the Transition to Home Ownership. IZA Discussion Paper no. 8039. 
Appendix A: Additional Tables 
Table A1. Naturalisation by personal- and contextual characteristics, cohorts 1995-2002.

\begin{tabular}{|c|c|c|c|c|c|}
\hline & & \multicolumn{2}{|c|}{ Naturalised } & \multicolumn{2}{|c|}{ Not naturalised } \\
\hline & & $\mathrm{N}$ & $\%$ & $\mathrm{~N}$ & $\%$ \\
\hline \multirow[t]{2}{*}{ Gender } & Male & 31,014 & 29.0 & 75,829 & 71.0 \\
\hline & Female & 41,084 & 33.1 & 83,195 & 66.9 \\
\hline \multirow[t]{8}{*}{ Age at migration } & $15-17$ year & 8,372 & 48.4 & 8,910 & 51.6 \\
\hline & 18-24 year & 19,917 & 31.0 & 44,249 & 69.0 \\
\hline & 25-34 year & 29,716 & 31.9 & 63,357 & 68.1 \\
\hline & $35-44$ year & 10,120 & 26.7 & 27,830 & 73.3 \\
\hline & 45-54 year & 2,706 & 21.6 & 9,804 & 78.4 \\
\hline & 55-64 year & 849 & 21.3 & 3,141 & 78.7 \\
\hline & $65-74$ year & 357 & 21.8 & 1,277 & 78.2 \\
\hline & $>74$ year & 61 & 11.8 & 456 & 88.2 \\
\hline \multirow[t]{8}{*}{ Partner } & No partner & 19,051 & 23.5 & 62,096 & 76.5 \\
\hline & Native Dutch partner & 18,867 & 39.6 & 28,819 & 60.4 \\
\hline & Foreign born foreign partner & 11,702 & 19.6 & 47,877 & 80.4 \\
\hline & Year naturalisation partner & 6,823 & 91.3 & 652 & 8.7 \\
\hline & 1 year after naturalisation partner & 1,180 & 63.5 & 677 & 36.5 \\
\hline & 2 years after naturalisation partner & 875 & 56.2 & 682 & 43.8 \\
\hline & 3 years after naturalisation partner & 855 & 52.9 & 761 & 47.1 \\
\hline & $>3$ years after naturalisation partner & 12,745 & 42.2 & 17,460 & 57.8 \\
\hline \multirow[t]{2}{*}{ Children $<18$ in household } & Yes & 40,520 & 36.4 & 70,759 & 63.6 \\
\hline & No & 31,578 & 26.3 & 88,265 & 73.7 \\
\hline \multirow[t]{2}{*}{ Dual nationality } & No automatic loss & 49,507 & 31.9 & 105,547 & 68.1 \\
\hline & Automatic loss & 22,591 & 29.7 & 53,477 & 70.3 \\
\hline \multirow[t]{4}{*}{ Development country of origin } & First quartile & 30,620 & 51.0 & 29,367 & 49.0 \\
\hline & Second quartile & 23,109 & 41.5 & 32,618 & 58.5 \\
\hline & Thrid quartile & 16,107 & 27.8 & 41,823 & 72.2 \\
\hline & Fourth quartile & 2,262 & 3.9 & 55,216 & 96.1 \\
\hline \multirow[t]{4}{*}{ Stability country of origin } & First quartile & 27,763 & 47.6 & 30,516 & 52.4 \\
\hline & Second quartile & 19,555 & 34.0 & 37,915 & 66.0 \\
\hline & Third quartile & 20,280 & 35.1 & 37,571 & 64.9 \\
\hline & Fourth quartile & 4,500 & 7.8 & 53,022 & 92.2 \\
\hline \multirow[t]{2}{*}{ EU } & Yes & 2,779 & 4.9 & 54,476 & 95.1 \\
\hline & No & 69,319 & 39.9 & 104,548 & 60.1 \\
\hline \multirow[t]{8}{*}{ Migrant cohort } & Cohort 1995 & 6,798 & 34.1 & 13,115 & 65.9 \\
\hline & Cohort 1996 & 8,422 & 33.8 & 16,502 & 66.2 \\
\hline & Cohort 1997 & 9,297 & 33.7 & 18,307 & 66.3 \\
\hline & Cohort 1998 & 9,287 & 30.4 & 21,224 & 69.6 \\
\hline & Cohort 1999 & 8,307 & 31.2 & 18,341 & 68.8 \\
\hline & Cohort 2000 & 10,512 & 30.5 & 23,959 & 69.5 \\
\hline & Cohort 2001 & 10,627 & 30.3 & 24,440 & 69.7 \\
\hline & Cohort 2002 & 8,848 & 27.7 & 23,136 & 72.3 \\
\hline Total & & 72,098 & 31.2 & 159,024 & 68.8 \\
\hline
\end{tabular}

Source: Statistics Netherlands. 
Table A2. Cox proportional hazards regression on the risk of naturalisation of migrants, from low developed countries, cohorts 1995-2002.

\begin{tabular}{|c|c|c|c|c|}
\hline & & Coef. & Exp. coef. & Std. error \\
\hline \multirow[t]{2}{*}{ Gender } & Male & 0.178 & $1.195^{* * *}$ & 0.009 \\
\hline & Female & ref. & ref. & ref. \\
\hline \multicolumn{2}{|l|}{ Age at migration } & -0.012 & $0.988^{* * *}$ & 0.001 \\
\hline \multirow[t]{8}{*}{ Partner } & No partner & ref. & ref. & ref. \\
\hline & Native Dutch partner & 0.278 & $1.320^{* * *}$ & 0.016 \\
\hline & Foreign born foreign partner & -0.356 & $0.701^{* * *}$ & 0.014 \\
\hline & Year naturalization partner & 2.156 & $8.634 * * *$ & 0.017 \\
\hline & 1 year after naturalisation partner & 0.789 & $2.200 * * *$ & 0.034 \\
\hline & 2 years after naturalisation partner & 0.535 & $1.708^{* * *}$ & 0.038 \\
\hline & 3 years after naturalisation partner & 0.235 & $1.265^{* * *}$ & 0.038 \\
\hline & $>3$ years after naturalisation partner & -0.304 & $0.738 * * *$ & 0.016 \\
\hline \multirow[t]{2}{*}{ Children $<18$ in household } & Yes & ref. & ref. & ref. \\
\hline & No & -0.002 & 0.998 & 0.011 \\
\hline \multirow[t]{2}{*}{ Dual nationality } & No automatic loss & ref. & ref. & ref. \\
\hline & Automatic loss & -0.058 & $0.943 * * *$ & 0.011 \\
\hline \multirow[t]{8}{*}{ Migrant cohort } & Cohort 1995 & ref. & ref. & ref. \\
\hline & Cohort 1996 & 0.020 & 1.020 & 0.019 \\
\hline & Cohort 1997 & -0.005 & 0.995 & 0.018 \\
\hline & Cohort 1998 & -0.225 & $0.798 * * *$ & 0.018 \\
\hline & Cohort 1999 & -0.209 & $0.811^{* * *}$ & 0.019 \\
\hline & Cohort 2000 & -0.352 & $0.703 * * *$ & 0.018 \\
\hline & Cohort 2001 & -0.454 & $0.635 * * *$ & 0.018 \\
\hline & Cohort 2002 & -0.464 & $0.629 * * *$ & 0.020 \\
\hline \multirow[t]{3}{*}{$* * *: p<0.001$} & & \multicolumn{3}{|c|}{$N=113,837$} \\
\hline & & \multicolumn{3}{|c|}{ Events $=53,252$} \\
\hline & & \multicolumn{3}{|c|}{ Observations = 596,597 } \\
\hline \multicolumn{2}{|l|}{ Source: Statistics Netherlands. } & \multicolumn{3}{|c|}{ Logrank $=41,924(p<0.00001)$} \\
\hline
\end{tabular}


Table A4. Descriptive statistics total sample (cohorts 1995-2002) and education sample, cohorts 2000-2002.

\begin{tabular}{|c|c|c|c|c|c|}
\hline & & \multicolumn{2}{|c|}{ Total sample } & \multicolumn{2}{|c|}{ Education sample } \\
\hline & & $\%$ & Mean & $\%$ & Mean \\
\hline \multirow[t]{2}{*}{ Gender } & Male & 46.2 & & 45.0 & \\
\hline & Female & 53.8 & & 55.0 & \\
\hline Age at migration & & & 29.43 & & 26.83 \\
\hline \multirow[t]{8}{*}{ Partner } & No partner & 35.1 & & 39.1 & \\
\hline & Native Dutch partner & 20.6 & & 16.1 & \\
\hline & Foreign born foreign partner & 25.8 & & 23.9 & \\
\hline & Year naturalisation partner & 3.2 & & 3.1 & \\
\hline & 1 year after naturalisation partner & 0.8 & & 1.1 & \\
\hline & 2 years after naturalisation partner & 0.7 & & 0.8 & \\
\hline & 3 years after naturalisation partner & 0.7 & & 0.8 & \\
\hline & $>3$ years after naturalisation partner & 13.1 & & 15.1 & \\
\hline \multirow[t]{2}{*}{ Children $<18$ in household } & Yes & 48.1 & & 48.6 & \\
\hline & No & 51.9 & & 51.4 & \\
\hline \multirow[t]{2}{*}{ Dual nationality } & No automatic loss & 67.1 & & 68.2 & \\
\hline & Automatic loss & 32.9 & & 31.8 & \\
\hline Development country of origin & & & 0.694 & & 0.661 \\
\hline Stability country of origin & & & -0.456 & & -0.722 \\
\hline \multirow[t]{2}{*}{ EU } & Yes & 24.8 & & 14.2 & \\
\hline & No & 75.2 & & 85.8 & \\
\hline \multirow[t]{3}{*}{ Education } & Low & & & 48.1 & \\
\hline & Middle & & & 29.3 & \\
\hline & High & & & 22.6 & \\
\hline Source: Statistics Netherlands. & & $N=2$ & & $N=4$ & 942 \\
\hline
\end{tabular}


Table A5. Cox proportional hazards regression on the risk of naturalisation including education cohorts 20002002.

\begin{tabular}{|c|c|c|c|c|}
\hline & & Coef. & Exp. coef. & Std. error \\
\hline \multirow[t]{2}{*}{ Gender } & Male & -0.165 & $0.848 * * *$ & 0.017 \\
\hline & Female & ref. & ref. & ref. \\
\hline Age at migration & & -0.013 & $0.987^{* * *}$ & 0.001 \\
\hline \multirow[t]{8}{*}{ Partner } & No partner & ref. & ref. & ref. \\
\hline & Native Dutch partner & 0.251 & $1.286 * * *$ & 0.027 \\
\hline & Foreign born foreign partner & -0.340 & $0.712 * * *$ & 0.025 \\
\hline & Year naturalisation partner & 1.706 & $5.505 * * *$ & 0.034 \\
\hline & 1 year after naturalisation partner & 0.834 & $2.302 * * *$ & 0.057 \\
\hline & 2 years after naturalisation partner & 0.423 & $1.527^{* * *}$ & 0.073 \\
\hline & 3 years after naturalisation partner & 0.244 & $1.276^{* *}$ & 0.081 \\
\hline & $>3$ years after naturalisation partner & -0.107 & $0.898 * * *$ & 0.027 \\
\hline \multirow[t]{2}{*}{ Children $<18$ in household } & Yes & ref. & ref. & ref. \\
\hline & No & -0.035 & 0.966 & 0.018 \\
\hline \multirow[t]{2}{*}{ Dual nationality } & No automatic loss & ref. & ref. & ref. \\
\hline & Automatic loss & -0.148 & $0.862 * * *$ & 0.018 \\
\hline Development country of origin & & -1.266 & $0.282 * * *$ & 0.064 \\
\hline Stability country of origin & & -0.216 & $0.805^{* * *}$ & 0.010 \\
\hline \multirow[t]{2}{*}{ EU } & Yes & -1.376 & $0.253 * * *$ & 0.048 \\
\hline & No & ref. & ref. & ref. \\
\hline \multirow[t]{3}{*}{ Education } & Low education & ref. & ref. & ref. \\
\hline & Middle education & 0.561 & $1.753^{* * *}$ & 0.018 \\
\hline & High education & 0.379 & $1.461^{* * *}$ & 0.023 \\
\hline
\end{tabular}

$* *: p<0.01$

$* * *: p<0.001$

Source: Statistics Netherlands.
$\mathrm{N}=43,942$

Events $=16,470$

Observations $=191,581$

Logrank $=11,792(p<0.00001)$ 
Table A6. Cox proportional hazards regression on the risk of naturalisation including rush into naturalisation dummy, cohorts 1995-2002.

\begin{tabular}{|c|c|c|c|c|}
\hline & & Coef. & Exp. coef. & Std. error \\
\hline \multirow[t]{2}{*}{ Gender } & Male & 0.014 & 1.014 & 0.008 \\
\hline & Female & ref. & ref. & ref. \\
\hline \multicolumn{2}{|l|}{ Age at migration } & -0.016 & $0.984^{* * *}$ & 0.001 \\
\hline \multirow[t]{8}{*}{ Partner } & No partner & ref. & ref. & ref. \\
\hline & Native Dutch partner & 0.511 & $1.667 * * *$ & 0.013 \\
\hline & Foreign born foreign partner & -0.284 & $0.753 * * *$ & 0.013 \\
\hline & Year naturalisation partner & 2.201 & $9.038 * * *$ & 0.015 \\
\hline & 1 year after naturalisation partner & 0.869 & $2.385 * * *$ & 0.030 \\
\hline & 2 years after naturalisation partner & 0.597 & $1.817 * * *$ & 0.035 \\
\hline & 3 years after naturalisation partner & 0.254 & $1.289 * * *$ & 0.036 \\
\hline & $>3$ years after naturalisation partner & -0.122 & $0.885 * * *$ & 0.014 \\
\hline \multirow[t]{2}{*}{ Children $<18$ in household } & Yes & ref. & ref. & ref. \\
\hline & No & 0.008 & 1.008 & 0.009 \\
\hline \multirow[t]{2}{*}{ Dual nationality } & No automatic loss & ref. & ref. & ref. \\
\hline & Automatic loss & -0.033 & $0.968 * * *$ & 0.009 \\
\hline \multicolumn{2}{|l|}{ Development country of origin } & -1.402 & $0.246 * * *$ & 0.032 \\
\hline \multicolumn{2}{|l|}{ Stability country of origin } & -0.240 & $0.786 * * *$ & 0.005 \\
\hline \multirow[t]{2}{*}{ EU } & Yes & -1.630 & $0.196 * * *$ & 0.021 \\
\hline & No & ref. & ref. & ref. \\
\hline \multirow[t]{8}{*}{ Migrant cohort } & Cohort 1995 & ref. & ref. & ref. \\
\hline & Cohort 1996 & -0.018 & 0.982 & 0.016 \\
\hline & Cohort 1997 & -0.092 & $0.913 * * *$ & 0.016 \\
\hline & Cohort 1998 & -0.300 & $0.741 * * *$ & 0.016 \\
\hline & Cohort 1999 & -0.273 & $0.761 * * *$ & 0.016 \\
\hline & Cohort 2000 & -0.352 & $0.703^{* * *}$ & 0.016 \\
\hline & Cohort 2001 & -0.398 & $0.672 * * *$ & 0.016 \\
\hline & Cohort 2002 & -0.371 & $0.690 * * *$ & 0.016 \\
\hline \multirow[t]{2}{*}{ Period 01-04-2002 - 01-04-2003 } & Yes & 0.314 & $1.369 * * *$ & 0.013 \\
\hline & No & ref. & ref. & ref. \\
\hline \multirow[t]{3}{*}{$* * *: p<0.001$} & & \multicolumn{3}{|c|}{$N=231,122$} \\
\hline & & \multicolumn{3}{|c|}{ Events $=72,098$} \\
\hline & & \multicolumn{3}{|c|}{ Observations $=1,247,745$} \\
\hline \multicolumn{2}{|l|}{ Source: Statistics Netherlands. } & \multicolumn{3}{|c|}{ Logrank $=104,121(p<0.00001)$} \\
\hline
\end{tabular}


Table A7. Descriptive statistics on employment of male and female immigrants in percentages, cohorts 19992002.

\begin{tabular}{|c|c|c|c|}
\hline & & Men* & Women** \\
\hline \multirow[t]{10}{*}{ Naturalisation } & No naturalisation & 58.0 & 52.9 \\
\hline & $>3$ years prior to naturalisation & 39.2 & 33.0 \\
\hline & 3 years prior to naturalisation & 54.7 & 44.3 \\
\hline & 2 years prior to naturalisation & 60.4 & 51.8 \\
\hline & 1 year prior to naturalisation & 66.5 & 57.9 \\
\hline & year of naturalisation & 69.9 & 60.9 \\
\hline & 1 year after naturalisation & 72.3 & 63.3 \\
\hline & 2 years after naturalisation & 74.3 & 65.6 \\
\hline & 3 years after naturalisation & 75.5 & 67.2 \\
\hline & $>3$ years after naturalisation & 76.3 & 68.0 \\
\hline \multirow[t]{6}{*}{ Age at migration } & 20-24 year & 60.0 & 50.7 \\
\hline & 25-29 year & 61.3 & 54.5 \\
\hline & 30-34 year & 57.2 & 52.0 \\
\hline & 35-39 year & 54.5 & 50.9 \\
\hline & 40-44 year & 52.6 & 51.8 \\
\hline & $45-50$ year & 51.5 & 50.6 \\
\hline \multirow[t]{5}{*}{ Years since migration } & $0-1$ years & 47.6 & 38.6 \\
\hline & $2-3$ years & 53.3 & 50.1 \\
\hline & $4-5$ years & 58.8 & 53.5 \\
\hline & $6-7$ years & 67.0 & 59.7 \\
\hline & $8-9$ years & 71.0 & 63.9 \\
\hline \multirow[t]{4}{*}{ Partner } & No partner & 48.5 & 47.7 \\
\hline & Foreign-born foreign partner & 59.2 & 49.0 \\
\hline & Foreign-born Dutch partner & 70.6 & 45.3 \\
\hline & Native-born Dutch partner & 71.9 & 61.7 \\
\hline \multirow[t]{2}{*}{ Children $<18$ in household } & Yes & 63.4 & 46.8 \\
\hline & No & 54.9 & 58.0 \\
\hline \multirow[t]{4}{*}{ Development country of origin } & Lowest quartile & 50.9 & 42.9 \\
\hline & Second quartile & 55.4 & 48.8 \\
\hline & Third quartile & 61.5 & 54.7 \\
\hline & Highest quartile & 64.9 & 62.0 \\
\hline \multirow[t]{2}{*}{ EU country of origin } & Yes & 64.9 & 63.3 \\
\hline & No & 56.3 & 48.1 \\
\hline Total & & 58.2 & 52.2 \\
\hline
\end{tabular}

$*: \mathrm{N}=48,969$

$*$ : Observations $=707,644$

**: $N=45,351$

**: Observations $=697,992$

Source: Statistics Netherlands. 


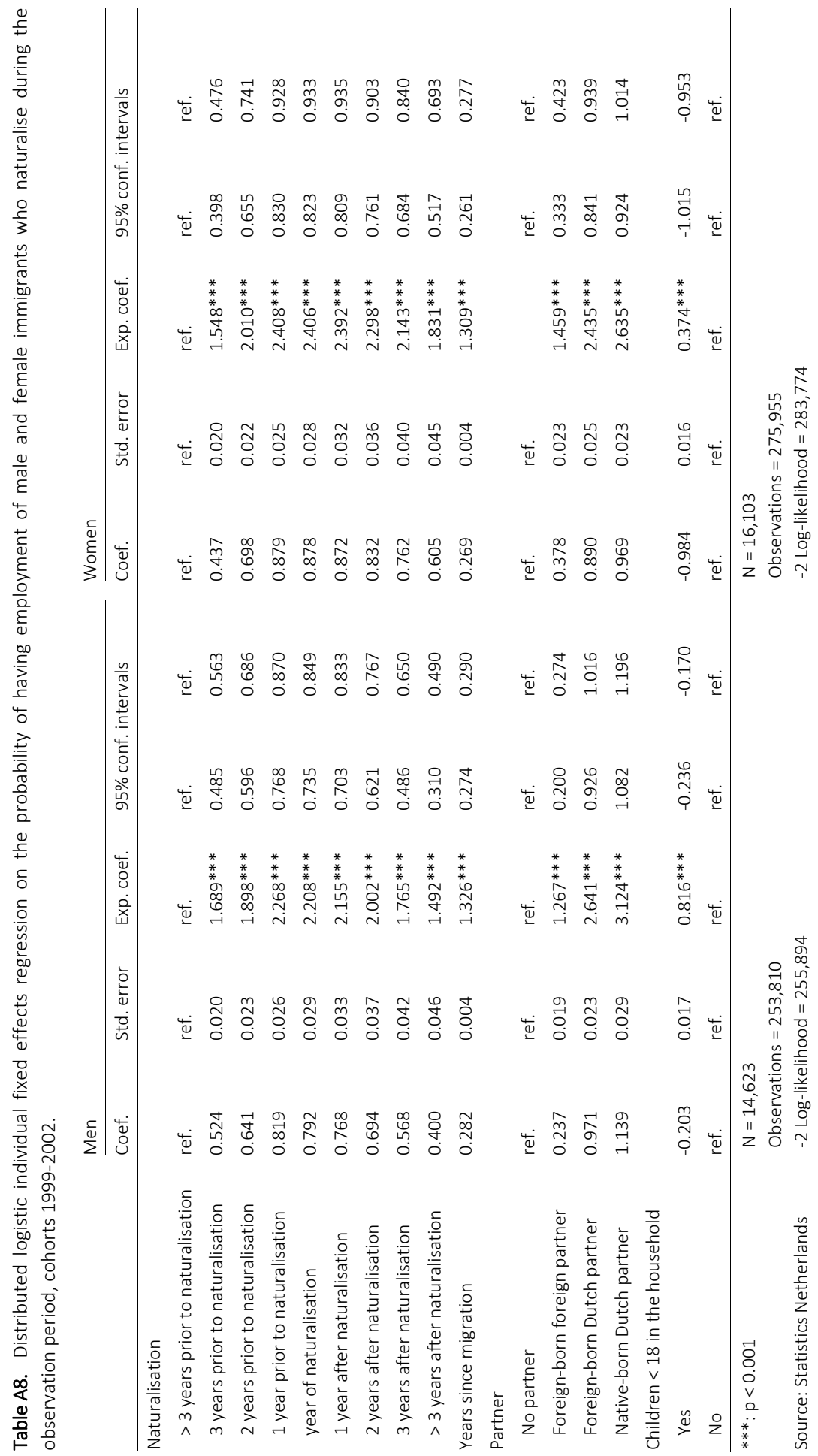


Table A9a. Distributed logistic individual fixed effects regression on the probability of having employment, male immigrants who naturalise during the observation period from low/high developed countries, cohorts 1999-2002†.

\begin{tabular}{|c|c|c|c|c|c|c|}
\hline & \multicolumn{6}{|l|}{ Men } \\
\hline & \multicolumn{3}{|c|}{ Low development } & \multicolumn{3}{|c|}{ High development } \\
\hline & \multirow[t]{2}{*}{ Exp. coef. } & \multicolumn{2}{|c|}{$95 \%$ conf. intervals } & \multirow[t]{2}{*}{ Exp. coef. } & \multicolumn{2}{|c|}{$95 \%$ conf. intervals } \\
\hline \multicolumn{5}{|l|}{ Naturalisation } & & \\
\hline$>3$ years prior to naturalisation & ref. & ref. & ref. & ref. & ref. & ref. \\
\hline 3 years prior to naturalisation & $1.744^{* * *}$ & 0.501 & 0.611 & $1.716^{* * *}$ & 0.479 & 0.601 \\
\hline 2 years prior to naturalisation & $1.919 * * *$ & 0.589 & 0.715 & $2.010 * * *$ & 0.631 & 0.765 \\
\hline 1 year prior to naturalisation & $2.330 * * *$ & 0.775 & 0.917 & $2.455^{* * *}$ & 0.824 & 0.972 \\
\hline year of naturalisation & $2.140 * * *$ & 0.679 & 0.843 & $2.583^{* * *}$ & 0.865 & 1.033 \\
\hline 1 year after naturalisation & $2.034 * * *$ & 0.618 & 0.802 & $2.604^{* * *}$ & 0.863 & 1.051 \\
\hline 2 years after naturalisation & $1.904^{* * *}$ & 0.538 & 0.750 & $2.411^{* * *}$ & 0.774 & 0.986 \\
\hline 3 years after naturalisation & $1.795^{* * *}$ & 0.465 & 0.705 & $2.040 * * *$ & 0.593 & 0.833 \\
\hline$>3$ years after naturalisation & $1.317 * * *$ & 0.146 & 0.404 & $2.006 * * *$ & 0.565 & 0.827 \\
\hline$* * *: p<0.001$ & \multicolumn{3}{|c|}{$N=8,736$} & \multicolumn{3}{|c|}{$N=8,900$} \\
\hline & \multicolumn{3}{|c|}{ Observations $=131,217$} & \multicolumn{3}{|c|}{ Observations $=122,593$} \\
\hline & \multicolumn{3}{|c|}{-2 Log-likelihood = 132,876 } & \multicolumn{3}{|c|}{-2 Log-likelihood = 121,020 } \\
\hline
\end{tabular}

Table A9b. Distributed logistic individual fixed effects regression on the probability of having employment, female immigrants who naturalise during the observation period from low/high developed countries, cohorts 1999-2002†.

\begin{tabular}{|c|c|c|c|c|c|c|}
\hline & \multicolumn{6}{|l|}{ Women } \\
\hline & \multicolumn{3}{|c|}{ Low development } & \multicolumn{3}{|c|}{ High development } \\
\hline & \multirow[t]{2}{*}{ Exp. coef. } & \multicolumn{2}{|c|}{$95 \%$ conf. intervals } & \multirow[t]{2}{*}{ Exp. coef. } & \multicolumn{2}{|c|}{$95 \%$ conf. intervals } \\
\hline \multicolumn{5}{|l|}{ Naturalisation } & & \\
\hline$>3$ years prior to naturalisation & ref. & ref. & ref. & ref. & ref. & ref. \\
\hline 3 years prior to naturalisation & $1.517 * * *$ & 0.362 & 0.472 & $1.627 * * *$ & 0.428 & 0.546 \\
\hline 2 years prior to naturalisation & $1.887 * * *$ & 0.574 & 0.696 & $2.181^{* * *}$ & 0.713 & 0.847 \\
\hline 1 year prior to naturalisation & $2.195^{* * *}$ & 0.715 & 0.857 & $2.609 * * *$ & 0.885 & 1.033 \\
\hline year of naturalisation & $2.115^{* * *}$ & 0.669 & 0.829 & $2.586 * * *$ & 0.866 & 1.034 \\
\hline 1 year after naturalisation & $2.034^{* * *}$ & 0.618 & 0.802 & $2.552 * * *$ & 0.841 & 1.033 \\
\hline 2 years after naturalisation & $1.956 * * *$ & 0.567 & 0.775 & $2.413^{* * *}$ & 0.773 & 0.989 \\
\hline 3 years after naturalisation & $1.713^{* * *}$ & 0.422 & 0.654 & $2.280 * * *$ & 0.704 & 0.944 \\
\hline$>3$ years after naturalisation & $1.523 * * *$ & 0.292 & 0.550 & $1.828 * * *$ & 0.470 & 0.736 \\
\hline \multirow[t]{3}{*}{$* * *: p<0.001$} & \multicolumn{3}{|l|}{$N=10,021$} & \multicolumn{3}{|l|}{$N=9,862$} \\
\hline & \multicolumn{3}{|c|}{ Observations $=138,628$} & \multicolumn{3}{|c|}{ Observations $=137,327$} \\
\hline & \multicolumn{3}{|c|}{-2 Log-likelihood $=141,434$} & \multicolumn{3}{|c|}{-2 Log-likelihood = 137,932 } \\
\hline
\end{tabular}


Table A10a. Distributed logistic individual fixed effects regression on the probability of having employment, male immigrants who naturalise during the observation period from EU/non-EU countries, cohorts 1999$2002+$

\begin{tabular}{|c|c|c|c|c|c|c|}
\hline & \multicolumn{6}{|l|}{ Men } \\
\hline & \multicolumn{3}{|l|}{ Non-EU } & \multicolumn{3}{|l|}{ EU } \\
\hline & Exp. coef. & \multicolumn{2}{|c|}{$95 \%$ conf. intervals } & Exp. coef. & \multicolumn{2}{|c|}{$95 \%$ conf. intervals } \\
\hline$>3$ years prior to naturalisation & ref. & ref. & ref. & ref. & ref. & ref. \\
\hline 3 years prior to naturalisation & $1.696^{* * *}$ & 0.487 & 0.569 & $1.401^{* *}$ & 0.110 & 0.564 \\
\hline 2 years prior to naturalisation & $1.900 * * *$ & 0.597 & 0.687 & $1.735^{* * *}$ & 0.312 & 0.790 \\
\hline 1 year prior to naturalisation & $2.252 * * *$ & 0.761 & 0.863 & $2.519 * * *$ & 0.661 & 1.187 \\
\hline year of naturalisation & $2.197 * * *$ & 0.728 & 0.846 & $2.442 * * *$ & 0.601 & 1.185 \\
\hline 1 year after naturalisation & $2.147^{* * *}$ & 0.697 & 0.831 & $2.382 * * *$ & 0.550 & 1.186 \\
\hline 2 years after naturalisation & $2.000 * * *$ & 0.619 & 0.767 & $2.155^{* * *}$ & 0.417 & 1.119 \\
\hline 3 years after naturalisation & $1.751^{* * *}$ & 0.476 & 0.644 & $2.138 * * *$ & 0.368 & 1.152 \\
\hline$>3$ years after naturalisation & $1.473^{* * *}$ & 0.295 & 0.479 & $1.978^{* *}$ & 0.255 & 1.109 \\
\hline$* *: p<0.01$ & \multicolumn{3}{|c|}{$N=13,924$} & \multicolumn{3}{|c|}{$N=821$} \\
\hline$* * *: p<0.001$ & \multicolumn{3}{|c|}{ Observations $=244,522$} & \multicolumn{3}{|c|}{ Observations $=9,288$} \\
\hline & \multicolumn{3}{|c|}{-2 Log-likelihood $=246,168$} & \multicolumn{3}{|c|}{-2 Log-likelihood = 9,580 } \\
\hline
\end{tabular}

Table A10b. Distributed logistic individual fixed effects regression on the probability of having employment, female immigrants who naturalise during the observation period from EU/non-EU countries, cohorts 19992002†.

\begin{tabular}{|c|c|c|c|c|c|c|}
\hline & \multicolumn{6}{|l|}{ Women } \\
\hline & \multicolumn{3}{|l|}{ Non-EU } & \multicolumn{3}{|l|}{ EU } \\
\hline & Exp. coef. & \multicolumn{2}{|c|}{$95 \%$ conf. intervals } & Exp. coef. & \multicolumn{2}{|c|}{$95 \%$ conf. intervals } \\
\hline \multicolumn{7}{|l|}{ Naturalisation } \\
\hline$>3$ years prior to naturalisation & ref. & ref. & ref. & ref. & ref. & ref. \\
\hline 3 years prior to naturalisation & $1.576 * * *$ & 0.414 & 0.496 & $1.264^{* *}$ & 0.060 & 0.408 \\
\hline 2 years prior to naturalisation & $2.050 * * *$ & 0.673 & 0.763 & $1.567 * * *$ & 0.267 & 0.631 \\
\hline 1 year prior to naturalisation & $2.467 * * *$ & 0.852 & 0.954 & $1.878 * * *$ & 0.432 & 0.828 \\
\hline year of naturalisation & $2.474^{* * *}$ & 0.847 & 0.965 & $1.852 * * *$ & 0.395 & 0.837 \\
\hline 1 year after naturalisation & $2.433 * * *$ & 0.822 & 0.956 & $1.998 * * *$ & 0.447 & 0.937 \\
\hline 2 years after naturalisation & $2.335^{* * *}$ & 0.774 & 0.922 & $1.984 * * *$ & 0.413 & 0.957 \\
\hline 3 years after naturalisation & $2.149 * * *$ & 0.683 & 0.847 & $2.155^{* * *}$ & 0.464 & 1.072 \\
\hline$>3$ years after naturalisation & $1.881 * * *$ & 0.540 & 0.724 & $1.674^{* *}$ & 0.176 & 0.854 \\
\hline$* *: p<0.01$ & \multicolumn{3}{|c|}{$N=15,276$} & \multicolumn{3}{|c|}{$N=2,195$} \\
\hline$* * *: p<0.001$ & \multicolumn{3}{|c|}{ Observations $=251,258$} & \multicolumn{3}{|c|}{ Observations $=24,697$} \\
\hline
\end{tabular}




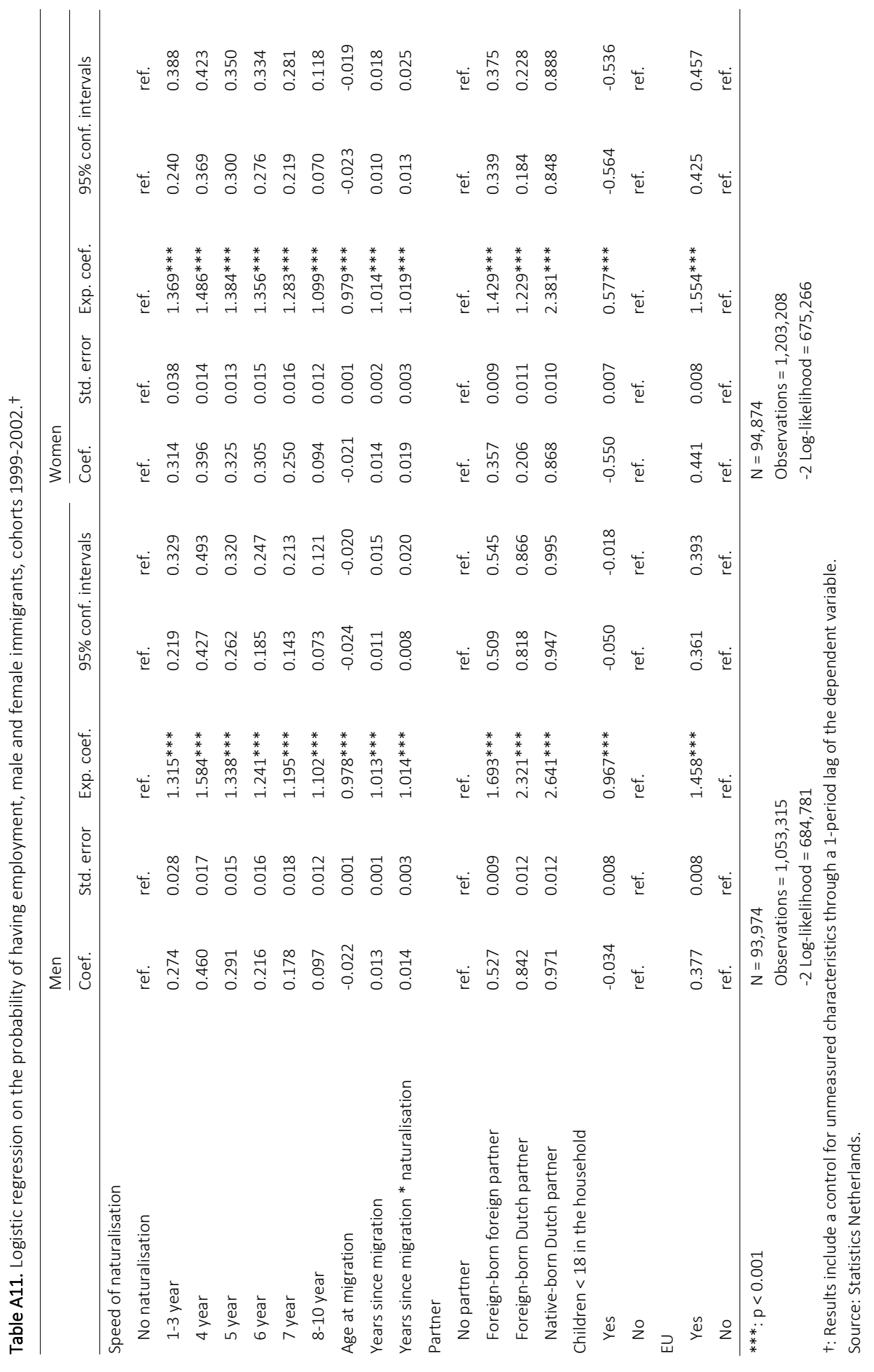


Additional Tables

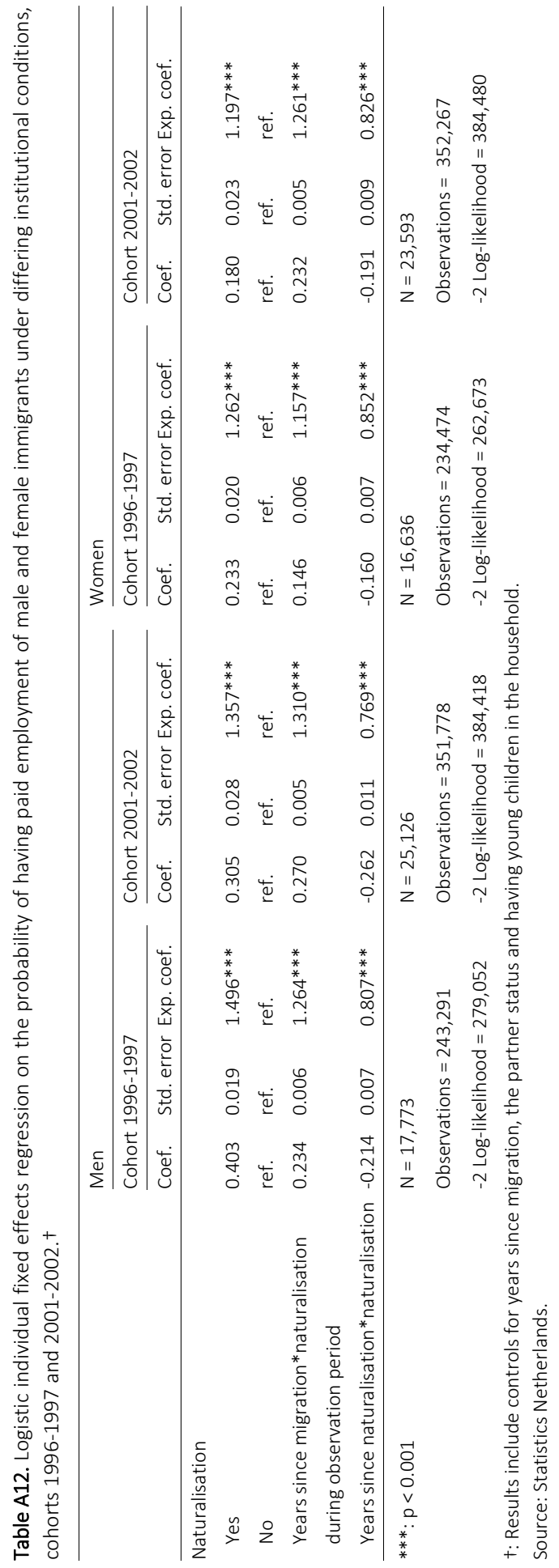


Appendix A

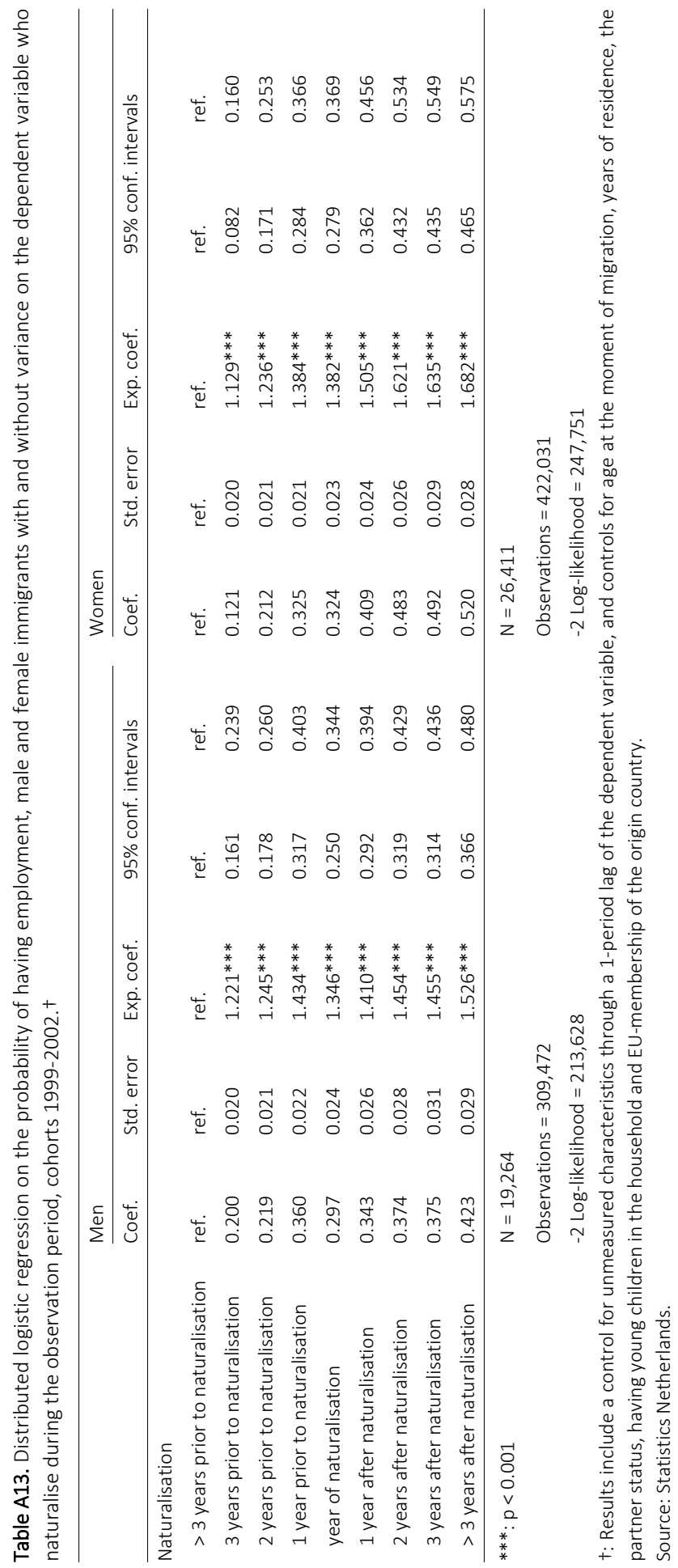




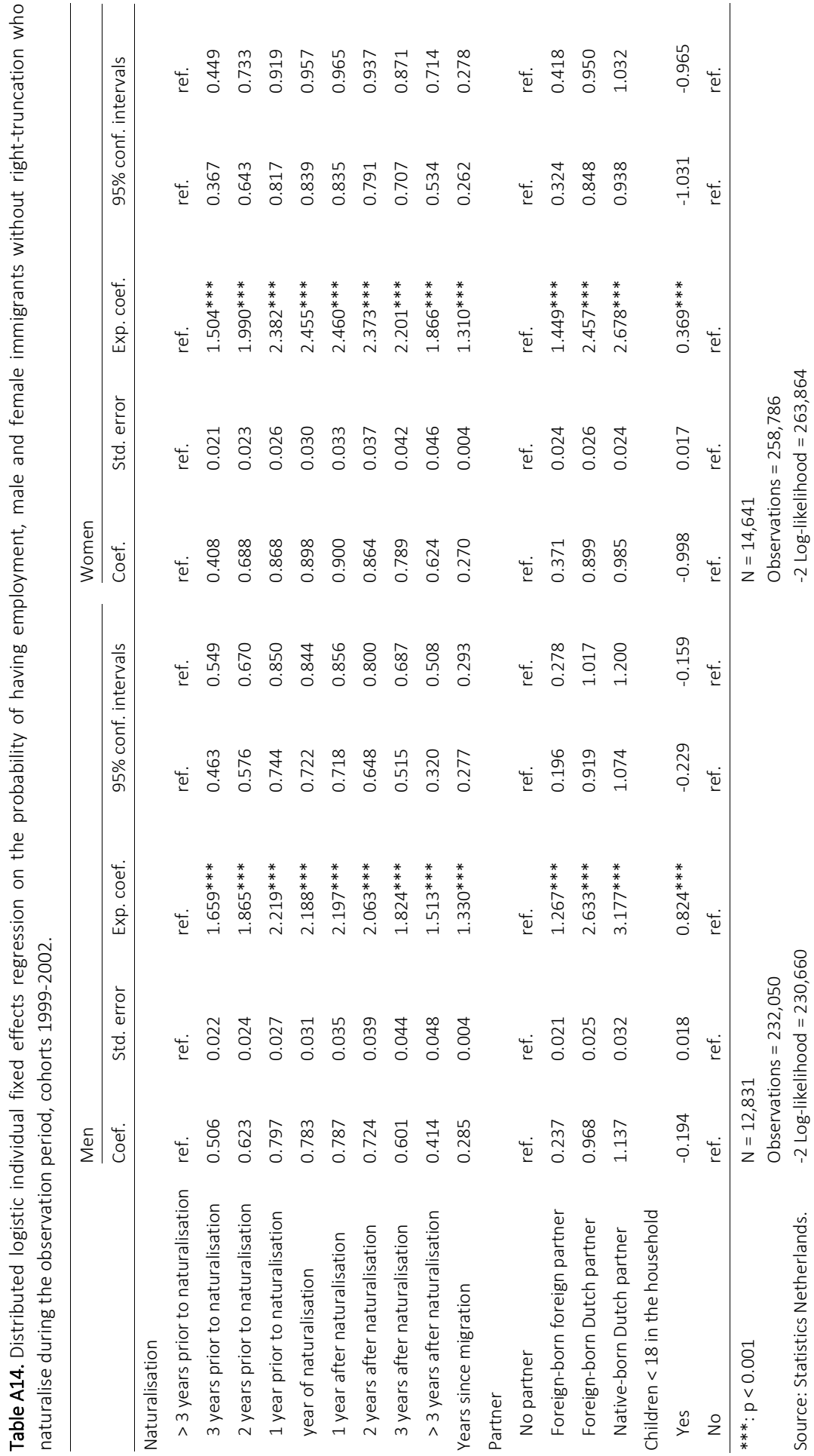


Table A15. Logistic individual fixed effects regression on the probability of having employment of male and female immigrants, cohorts 1999-2002. +

\begin{tabular}{|c|c|c|c|c|c|c|}
\hline & \multicolumn{3}{|l|}{ Men } & \multicolumn{3}{|c|}{ Women } \\
\hline & Coef. & Std. error & Exp. coef. & Coef. & Std. error & Exp. coef. \\
\hline \multicolumn{7}{|l|}{ Naturalisation } \\
\hline Yes & 0.644 & 0.015 & $1.904^{* * *}$ & 0.596 & 0.014 & $1.815^{* * *}$ \\
\hline No & ref. & ref. & ref. & ref. & ref. & ref. \\
\hline $\begin{array}{l}\text { Years since migration*distance between } \\
\text { origin and host country }\end{array}$ & 0.154 & 0.002 & $1.166 * * *$ & 0.052 & 0.002 & $1.053 * * *$ \\
\hline Years since naturalisation*naturalisation & -0.011 & 0.005 & $0.989 *$ & -0.021 & 0.005 & $0.979 * * *$ \\
\hline$*: p<0.05$ & \multicolumn{3}{|c|}{$N=48,969$} & \multicolumn{3}{|c|}{$N=45,351$} \\
\hline$* * *: p<0.001$ & \multicolumn{3}{|c|}{$\begin{array}{l}\text { Observations }=707,644 \\
-2 \text { Log-likelihood }=775,729\end{array}$} & \multicolumn{3}{|c|}{$\begin{array}{l}\text { Observations }=697,992 \\
-2 \text { Log-likelihood }=763,054\end{array}$} \\
\hline
\end{tabular}


Table A16. Descriptive statistics on mean Log labour income of male and female immigrants with employment in percentages, cohorts 1999-2002.

\begin{tabular}{|c|c|c|c|}
\hline & & Men* & Women** \\
\hline \multirow[t]{10}{*}{ Naturalization } & No naturalization & 3.386 & 3.215 \\
\hline & $>3$ years prior to naturalization & 3.134 & 2.997 \\
\hline & 3 years prior to naturalization & 3.184 & 3.041 \\
\hline & 2 years prior to naturalization & 3.225 & 3.085 \\
\hline & 1 year prior to naturalization & 3.269 & 3.117 \\
\hline & Year of naturalization & 3.287 & 3.144 \\
\hline & 1 year after naturalization & 3.313 & 3.175 \\
\hline & 2 years after naturalization & 3.341 & 3.200 \\
\hline & 3 years after naturalization & 3.349 & 3.207 \\
\hline & $>3$ years after naturalization & 3.359 & 3.217 \\
\hline \multirow[t]{6}{*}{ Age at migration } & 20-24 year & 3.268 & 3.132 \\
\hline & 25-29 year & 3.322 & 3.220 \\
\hline & 30-34 year & 3.357 & 3.219 \\
\hline & 35-39 year & 3.412 & 3.179 \\
\hline & 40-44 year & 3.461 & 3.154 \\
\hline & 45-50 year & 3.505 & 3.149 \\
\hline \multirow[t]{5}{*}{ Years since migration } & $0-1$ years & 3.285 & 3.111 \\
\hline & $2-3$ years & 3.328 & 3.151 \\
\hline & $4-5$ years & 3.349 & 3.178 \\
\hline & $6-7$ years & 3.382 & 3.219 \\
\hline & $8-9$ years & 3.406 & 3.243 \\
\hline \multirow[t]{4}{*}{ Partner } & No partner & 3.230 & 3.254 \\
\hline & Foreign-born foreign partner & 3.432 & 3.189 \\
\hline & Foreign-born Dutch partner & 3.264 & 3.001 \\
\hline & Native-born Dutch partner & 3.365 & 3.192 \\
\hline \multirow[t]{2}{*}{ Children $<18$ in household } & Yes & 3.391 & 3.111 \\
\hline & No & 3.320 & 3.238 \\
\hline \multirow[t]{4}{*}{ Development country of origin } & Lowest quartile & 3.209 & 3.038 \\
\hline & Second quartile & 3.274 & 3.116 \\
\hline & Third quartile & 3.382 & 3.227 \\
\hline & Highest quartile & 3.547 & 3.360 \\
\hline \multirow[t]{2}{*}{ EU country of origin } & Yes & 3.464 & 3.299 \\
\hline & No & 3.293 & 3.114 \\
\hline Total & & 3.349 & 3.185 \\
\hline
\end{tabular}

$*: \mathrm{N}=58,164$

$*:$ Observations $=587,572$

$* *: \mathrm{N}=44,335$

**: Observations $=432,591$

Source: Statistics Netherlands. 
Appendix A

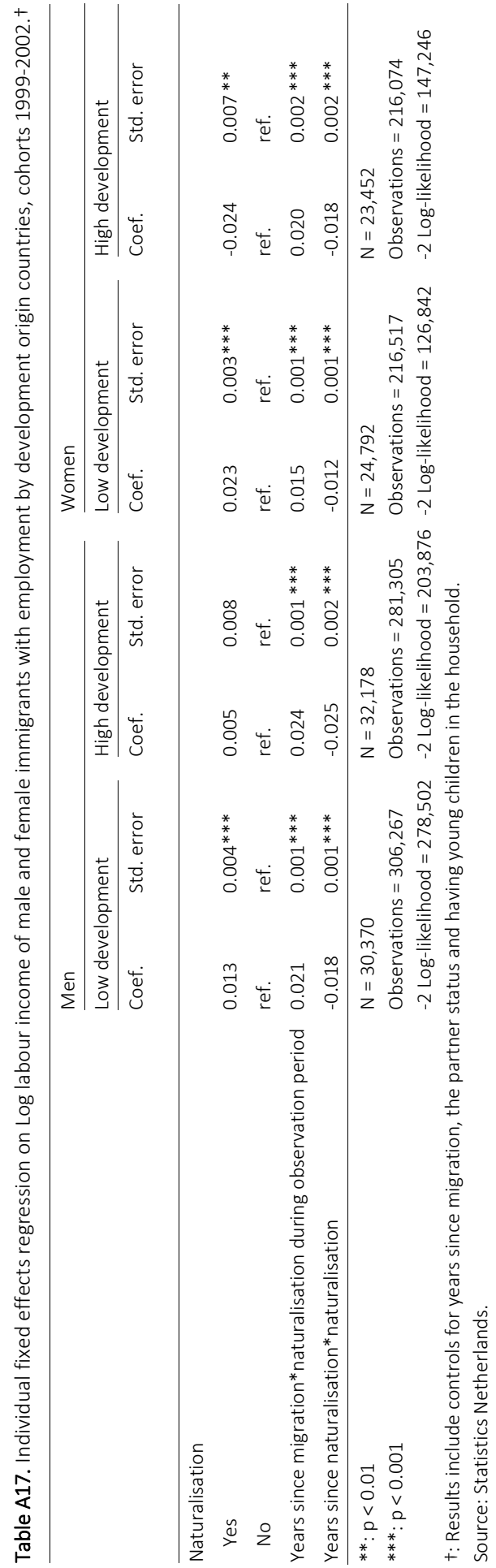


Table A18. Percentages labour market sector by naturalisation of male and female immigrants with employment, cohorts 1999-2002.

\begin{tabular}{|c|c|c|c|c|}
\hline & \multicolumn{2}{|l|}{ Men } & \multicolumn{2}{|l|}{ Women } \\
\hline & Not naturalised & Naturalised & Not naturalised & Naturalised \\
\hline \multicolumn{5}{|l|}{ Sector } \\
\hline Agriculture, forestry and fishery & 2.0 & 1.6 & 1.9 & 1.1 \\
\hline Non-housing industry and energy & 14.6 & 17.2 & 7.6 & 6.2 \\
\hline Housing industry & 2.9 & 3.3 & 0.4 & 0.7 \\
\hline Transportation and catering & 26.4 & 30.9 & 23.6 & 22.8 \\
\hline Information and communication & 5.7 & 2.6 & 4.1 & 2.7 \\
\hline Financial services & 2.4 & 1.4 & 2.7 & 3.4 \\
\hline Rent and management of property & 0.3 & 0.4 & 0.4 & 0.3 \\
\hline Business services & 35.7 & 30.0 & 36.9 & 30.9 \\
\hline Public sector and care sector & 7.6 & 10.2 & 18.6 & 28.5 \\
\hline Culture, recreation and other & 2.4 & 2.4 & 3.7 & 3.4 \\
\hline \multirow[t]{2}{*}{ Total } & 100 & 100 & 100 & 100 \\
\hline & \multicolumn{2}{|c|}{$N=51,217$} & \multicolumn{2}{|c|}{$N=51,217$} \\
\hline Source: Statistics Netherlands. & \multicolumn{2}{|c|}{ Observations $=472,848$} & \multicolumn{2}{|c|}{ Observations $=472,848$} \\
\hline
\end{tabular}

Table A19. Percentages labour market sector by naturalisation of male and female immigrants with employment, cohorts 1999-2002.

\begin{tabular}{lll}
\hline & Men & Women \\
\hline Sector & & \\
Agriculture, forestry and fishery & 3.222 & 3.080 \\
Non-housing industry and energy & 3.423 & 3.328 \\
Housing industry & 3.410 & 3.196 \\
Transportation and catering & 3.324 & 3.203 \\
Information and communication & 3.543 & 3.448 \\
Financial services & 3.719 & 3.510 \\
Rent and management of property & 3.384 & 3.218 \\
Business services & 3.343 & 3.124 \\
Public sector and care sector & 3.411 & 3.258 \\
Culture, recreation and other & 3.417 & 3.212 \\
Total & 3.376 & 3.211 \\
\hline & $\mathrm{N}=51,217$ & $\mathrm{~N}=38,994$ \\
Source: Statistics Netherlands. & Observations = 472,848 & Observations = 350,518
\end{tabular}


Table A20. Distributed individual fixed effects regression on Log labour income of male and female immigrants with employment. No right truncation. Cohorts 1999-2002.

\begin{tabular}{|c|c|c|c|c|}
\hline & \multicolumn{2}{|l|}{ Men } & \multicolumn{2}{|c|}{ Women } \\
\hline & Coef. & Std. error & Coef. & Std. error \\
\hline \multicolumn{5}{|l|}{ Naturalisation } \\
\hline Yes & 0.005 & 0.003 & 0.007 & $0.003 *$ \\
\hline No & ref. & ref. & ref. & ref. \\
\hline $\begin{array}{l}\text { Years since migration*naturalisation during } \\
\text { observation period }\end{array}$ & 0.026 & $0.001 * * *$ & 0.021 & $0.001 * * *$ \\
\hline Years since naturalisation*naturalisation & -0.020 & $0.001 * * *$ & -0.014 & $0.001 * * *$ \\
\hline$*: p<0.05$ & \multicolumn{2}{|c|}{$N=43,113$} & \multicolumn{2}{|c|}{$N=34,988$} \\
\hline$* * *: p<0.001$ & \multicolumn{2}{|c|}{ Observations $=477,255$} & \multicolumn{2}{|c|}{ Observations $=366,696$} \\
\hline
\end{tabular}

Table A21. Individual fixed-effects regression on Log labour income of male and female immigrants with employment, cohorts 1999-2002. ${ }^{\dagger}$

\begin{tabular}{|c|c|c|c|c|c|c|c|c|}
\hline & \multicolumn{2}{|l|}{ Men } & \multicolumn{2}{|c|}{ Women } & \multicolumn{2}{|l|}{ Men } & \multicolumn{2}{|c|}{ Women } \\
\hline & Coef. & Std. error & Coef. & Std. error & Coef. & Std. error & Coef. & Std. error \\
\hline \multicolumn{9}{|l|}{ Naturalisation } \\
\hline Yes & -0.000 & 0.005 & 0.007 & 0.004 & -0.007 & 0.005 & -0.002 & 0.004 \\
\hline No & ref. & ref. & ref. & ref. & ref. & ref. & ref. & ref. \\
\hline $\begin{array}{l}\text { Years since migration* } \\
\text { naturalisation during } \\
\text { observation period }\end{array}$ & 0.023 & $0.002 * * *$ & 0.021 & $0.002 * * *$ & 0.021 & $0.002 * * *$ & 0.019 & $0.002 * * *$ \\
\hline $\begin{array}{l}\text { Years since naturalisation* } \\
\text { naturalisation }\end{array}$ & -0.012 & $0.002 * * *$ & -0.012 & $0.002 * * *$ & -0.011 & $0.002 * * *$ & -0.010 & $0.002 * * *$ \\
\hline \multicolumn{9}{|l|}{ Education } \\
\hline Low education & & & & & ref. & ref. & ref. & ref. \\
\hline Middle education & & & & & 0.041 & $0.005 * * *$ & 0.069 & $0.005^{* * *}$ \\
\hline High education & & & & & 0.165 & $0.006^{* * *}$ & 0.227 & $0.005^{* * *}$ \\
\hline$* * *: p<0.001$ & \multicolumn{2}{|c|}{$\begin{array}{l}N=16,120 \\
\text { Observations = } \\
119,192 \\
-2 \text { Log-likelihood = } \\
123,220\end{array}$} & \multicolumn{2}{|c|}{$\begin{array}{l}\mathrm{N}=14,870 \\
\text { Observations = } \\
107,853 \\
-2 \text { Log-likelihood = } \\
75,525\end{array}$} & \multicolumn{2}{|c|}{$\begin{array}{l}\mathrm{N}=16,120 \\
\text { Observations = } \\
119,192 \\
-2 \text { Log-likelihood = } \\
122,439\end{array}$} & \multicolumn{2}{|c|}{$\begin{array}{l}N=14,870 \\
\text { Observations = } \\
107,853 \\
-2 \text { Log-likelihood = } \\
73,726\end{array}$} \\
\hline
\end{tabular}

t: Model includes controls for years since migration, the partner status and having youngh children in the household. Source: Statistics Netherlands. 
Table A22. Individual fixed-effects regression on Log labour income of male and female immigrants, cohorts 1999-2002.†

\begin{tabular}{|c|c|c|c|c|c|c|c|c|}
\hline & \multicolumn{2}{|l|}{ Men } & \multicolumn{2}{|c|}{ Women } & \multicolumn{2}{|l|}{ Men } & \multicolumn{2}{|c|}{ Women } \\
\hline & Coef. & Std. error & Coef. & Std. error & Coef. & Std. error & Coef. & Std. error \\
\hline \multicolumn{9}{|l|}{ Naturalisation } \\
\hline Yes & 0.078 & $0.013 * * *$ & 0.072 & $0.013 * * *$ & 0.066 & $0.013^{* * *}$ & 0.053 & $0.013^{* * *}$ \\
\hline No & ref. & ref. & ref. & ref. & ref. & ref. & ref. & ref. \\
\hline $\begin{array}{l}\text { Years since migration* } \\
\text { naturalisation during } \\
\text { observation period }\end{array}$ & 0.116 & $0.004 * * *$ & 0.133 & $0.004^{* * *}$ & 0.112 & $0.004 * * *$ & 0.0127 & $0.004^{* * *}$ \\
\hline $\begin{array}{l}\text { Years since naturalisation* } \\
\text { naturalisation }\end{array}$ & -0.073 & $0.005^{* * *}$ & -0.088 & $0.005 * * *$ & -0.072 & $0.005 * * *$ & -0.085 & $0.005 * * *$ \\
\hline \multicolumn{9}{|l|}{ Education } \\
\hline Low education & & & & & ref. & ref. & ref. & ref. \\
\hline Middle education & & & & & 0.127 & $0.013 * * *$ & 0.180 & $0.013 * * *$ \\
\hline High education & & & & & 0.280 & $0.016^{* * *}$ & 0.451 & $0.015 * * *$ \\
\hline$* * *: p<0.001$ & \multicolumn{2}{|c|}{$\begin{array}{l}N=18,087 \\
\text { Observations = } \\
159,508 \\
-2 \text { Log-likelihood = } \\
521,153\end{array}$} & \multicolumn{2}{|c|}{$\begin{array}{l}N=17,386 \\
\text { Observations = } \\
158,654 \\
-2 \text { Log-likelihood = } \\
514,392\end{array}$} & \multicolumn{2}{|c|}{$\begin{array}{l}N=18,087 \\
\text { Observations = } \\
159,508 \\
-2 \text { Log-likelihood = } \\
520,850\end{array}$} & \multicolumn{2}{|c|}{$\begin{array}{l}N=17,386 \\
\text { Observations = } \\
158,654 \\
-2 \text { Log-likelihood = } \\
513,541\end{array}$} \\
\hline
\end{tabular}

t: Sample includes observations of migrants with and without employment. Model includes controls for years since migration, the partner status and having youngh children in the household.

Source: Statistics Netherlands.

Table A23. Individual fixed-effects regression on Log labour income of male and female immigrants from countries that joined the EU in 2004, cohorts 1999-2002. ${ }^{\dagger}$

\begin{tabular}{|c|c|c|c|c|c|c|c|c|}
\hline & \multicolumn{2}{|l|}{ Men } & \multicolumn{2}{|c|}{ Women } & \multicolumn{2}{|l|}{ Men } & \multicolumn{2}{|c|}{ Women } \\
\hline & Coef. & Std. error & Coef. & Std. error & Coef. & Std. error & Coef. & Std. error \\
\hline \multicolumn{9}{|l|}{ Naturalisation } \\
\hline Yes & -0.011 & 0.148 & -0.027 & 0.044 & -0.007 & 0.148 & -0.031 & 0.044 \\
\hline No & ref. & ref. & ref. & ref. & ref. & ref. & ref. & ref. \\
\hline $\begin{array}{l}\text { Years since } \\
\text { migration*naturalisation } \\
\text { during observation period }\end{array}$ & 0.147 & $0.025 * * *$ & 0.135 & $0.008 * * *$ & 0.150 & $0.025 * * *$ & 0.131 & $0.008 * * *$ \\
\hline $\begin{array}{l}\text { Years since } \\
\text { naturalisation*naturalisation }\end{array}$ & -0.125 & $0.044 * *$ & -0.102 & $0.014^{* * *}$ & -0.131 & $0.044 * *$ & -0.094 & $0.014 * * *$ \\
\hline \multicolumn{9}{|l|}{ Period after May 2007} \\
\hline Yes & & & & & 0.080 & $0.029 * *$ & -0.087 & $0.022 * * *$ \\
\hline No & & & & & ref. & ref. & ref. & ref. \\
\hline$* *: p<0.01$ & \multirow{2}{*}{\multicolumn{2}{|c|}{$\begin{array}{l}N=1,340 \\
\text { Observations }= \\
15,925 \\
-2 \text { Log-likelihood }= \\
45,823\end{array}$}} & \multirow{2}{*}{\multicolumn{2}{|c|}{$\begin{array}{l}N=2,253 \\
\text { Observations = } \\
34,611 \\
-2 \text { Log-likelihood = } \\
110,299\end{array}$}} & \multirow{2}{*}{\multicolumn{2}{|c|}{$\begin{array}{l}N=1,340 \\
\text { Observations = } \\
15,925 \\
-2 \text { Log-likelihood = } \\
45,821\end{array}$}} & \multirow{2}{*}{\multicolumn{2}{|c|}{$\begin{array}{l}N=2,253 \\
\text { Observations = } \\
34,611 \\
-2 \text { Log-likelihood }= \\
110,289\end{array}$}} \\
\hline$* * *: p<0.001$ & & & & & & & & \\
\hline
\end{tabular}

†: Model includes controls for years since migration, the partner status and having young children in the household. Source: Statistics Netherlands. 
Appendix A

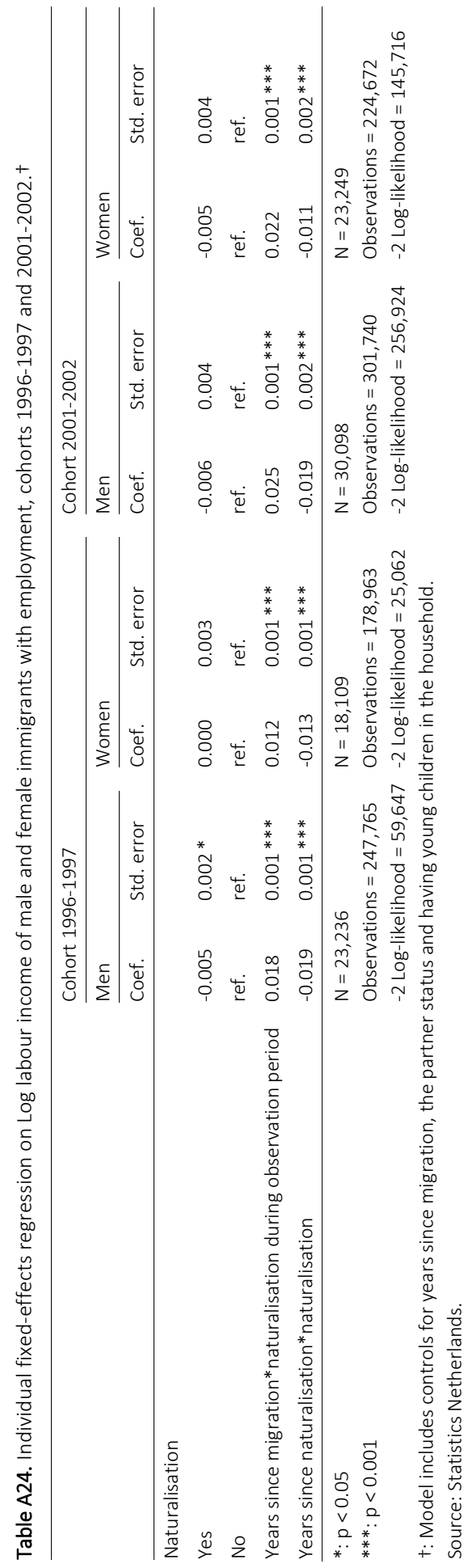


Table A25. Individual fixed-effects regression on Log labour income of male and female immigrants with employment, cohorts 1996-1997 and 2001-2002. ${ }^{\dagger}$

\begin{tabular}{|c|c|c|c|c|}
\hline & \multicolumn{2}{|l|}{ Men } & \multicolumn{2}{|c|}{ Women } \\
\hline & Coef. & Std. error & Coef. & Std. error \\
\hline \multicolumn{5}{|l|}{ Naturalisation } \\
\hline Yes & 0.032 & $0.002 * * *$ & 0.027 & $0.002 * * *$ \\
\hline No & ref. & ref. & ref. & ref. \\
\hline $\begin{array}{l}\text { Years since migration* distance origin } \\
\text { country and host country }\end{array}$ & 0.006 & $0.001 * * *$ & 0.006 & $0.000 * * *$ \\
\hline Years since naturalisation*naturalisation & -0.004 & $0.001 * * *$ & -0.001 & 0.001 \\
\hline \multirow[t]{3}{*}{$* * *: p<0.001$} & \multicolumn{2}{|c|}{$N=58,164$} & \multicolumn{2}{|c|}{$N=44,335$} \\
\hline & \multicolumn{2}{|c|}{ Observations $=587,572$} & \multicolumn{2}{|c|}{ Observations $=432,591$} \\
\hline & \multicolumn{2}{|c|}{-2 Log-likelihood $=500,169$} & \multicolumn{2}{|c|}{-2 Log-likelihood $=281,436$} \\
\hline
\end{tabular}


Table A26. Descriptive statistics on homeownership of immigrants in percentages, last observation, cohorts 1999-2002.

\begin{tabular}{|c|c|c|}
\hline & & Event (homeownership) \\
\hline \multirow[t]{2}{*}{ Naturalisation } & Yes & 14,1 \\
\hline & No & 20,5 \\
\hline \multirow[t]{2}{*}{ Naturalisation during observation period } & Yes & 21,6 \\
\hline & No & 18,0 \\
\hline \multirow[t]{2}{*}{ Gender } & Male & 17.5 \\
\hline & Female & 20.7 \\
\hline \multirow[t]{6}{*}{ Age at migration } & 20-24 year & 21.6 \\
\hline & 25-29 year & 23.4 \\
\hline & 30-34 year & 18.5 \\
\hline & 35-39 year & 15.1 \\
\hline & 40-44 year & 10.7 \\
\hline & $45-50$ year & 8.3 \\
\hline \multirow[t]{4}{*}{ Partner } & No partner & 13.4 \\
\hline & Foreign-born foreign partner & 19.1 \\
\hline & Foreign-born Dutch partner & 15.5 \\
\hline & Native-born Dutch partner & 42.8 \\
\hline \multirow[t]{2}{*}{ Children $<18$ in household } & Yes & 18.8 \\
\hline & No & 19.4 \\
\hline \multirow[t]{2}{*}{ Employment } & Yes & 26.9 \\
\hline & No & 11.1 \\
\hline \multirow[t]{4}{*}{ Disposable household income } & Lowest quartile & 7.4 \\
\hline & Second quartile & 10.8 \\
\hline & Third quartile & 23.8 \\
\hline & Highest quartile & 34.4 \\
\hline \multirow[t]{4}{*}{ Development country of origin } & Lowest quartile & 11.3 \\
\hline & Second quartile & 24.3 \\
\hline & Third quartile & 17.5 \\
\hline & Highest quartile & 24.1 \\
\hline \multirow[t]{2}{*}{ EU country of origin } & Yes & 27.2 \\
\hline & No & 16.7 \\
\hline \multirow[t]{2}{*}{ After 01-01-2008 } & Yes & 8.6 \\
\hline & No & 33.8 \\
\hline Total & & 19.1 \\
\hline
\end{tabular}

$\mathrm{N}=106,187$

Source: Statistics Netherlands. 
Table A27. Cox proportional hazard regression on the risk of homeownership of unemployed immigrants, cohorts 1999-2002.†

\begin{tabular}{|c|c|c|c|c|c|c|c|c|c|}
\hline & \multicolumn{3}{|c|}{ Model 1} & \multicolumn{3}{|c|}{ Model 2} & \multicolumn{3}{|c|}{ Model 3} \\
\hline & Coef. & $\begin{array}{l}\text { Std. } \\
\text { error }\end{array}$ & Exp. coef. & Coef. & $\begin{array}{l}\text { Std. } \\
\text { error }\end{array}$ & Exp. coef. & Coef. & $\begin{array}{l}\text { Std. } \\
\text { error }\end{array}$ & Exp. coef. \\
\hline \multicolumn{10}{|l|}{ Naturalisation } \\
\hline Yes & 0.033 & 0.056 & 1.033 & 0.098 & 0.059 & 1.103 & 0.089 & 0.058 & 1.093 \\
\hline No & ref. & ref. & ref. & ref. & ref. & ref. & ref. & ref. & ref. \\
\hline \multicolumn{10}{|l|}{$\begin{array}{l}\text { Naturalisation during } \\
\text { observation period }\end{array}$} \\
\hline Yes & -0.020 & 0.035 & 0.980 & -0.020 & 0.035 & 0.981 & 0.049 & 0.040 & 1.051 \\
\hline No & ref. & ref. & ref. & ref. & ref. & ref. & ref. & ref. & ref. \\
\hline $\begin{array}{l}\text { Naturalisation * native-born } \\
\text { Dutch partner }\end{array}$ & 0.219 & 0.089 & $1.245^{*}$ & & & & & & \\
\hline $\begin{array}{l}\text { Naturalisation } * \text { cultural } \\
\text { distance }\end{array}$ & & & & -0.001 & 0.001 & 0.999 & & & \\
\hline Cultural distance & & & & -0.004 & 0.000 & $0.996 * * *$ & & & \\
\hline $\begin{array}{l}\text { Naturalisation * after 01-01- } \\
2008\end{array}$ & & & & & & & -0.019 & 0.085 & 0.982 \\
\hline$*: p<0.05$ & \multicolumn{3}{|c|}{$N=76,444$} & \multicolumn{3}{|c|}{$N=58,035$} & \multicolumn{3}{|c|}{$N=76,444$} \\
\hline$* * *: p<0.001$ & \multicolumn{3}{|c|}{$\begin{array}{l}\text { Observations }=286,149 \\
\text { Events }=5,834\end{array}$} & \multicolumn{3}{|c|}{$\begin{array}{l}\text { Events }=4,909 \\
-2 \text { Log-likelihood }=95,633\end{array}$} & $\begin{array}{l}\text { Observ } \\
\text { Events } \\
-2 \text { Log-1 }\end{array}$ & $\begin{array}{l}\text { lations }= \\
=5,834 \\
\text { likelihoc }\end{array}$ & $\begin{array}{l}=286,149 \\
\mathrm{od}=116,439\end{array}$ \\
\hline \multicolumn{10}{|c|}{$\begin{array}{l}\text { t: Model includes controls for gender, age at migration, age at migration } \wedge 2 \text {, the partner status, having young } \\
\text { children in the household, disposable household income, development country of origin, EU membership country of } \\
\text { origin, of and the financial crisis. }\end{array}$} \\
\hline
\end{tabular}


Table A28. Cox proportional hazard regression on the risk of homeownership of employed immigrants, cohorts 1999-2002.

\begin{tabular}{|c|c|c|c|}
\hline & Coef. & Std. error & Exp. coef \\
\hline \multicolumn{4}{|l|}{ Naturalisation } \\
\hline Yes & 0.222 & 0.031 & $1.248^{* * *}$ \\
\hline No & ref. & ref. & ref. \\
\hline \multicolumn{4}{|c|}{ Naturalisation during observation period } \\
\hline Yes & 0.167 & 0.026 & $1.182^{* * *}$ \\
\hline No & ref. & ref. & ref. \\
\hline \multicolumn{4}{|l|}{ Gender } \\
\hline Male & ref. & ref. & ref. \\
\hline Female & 0.186 & 0.017 & $1.205^{* * *}$ \\
\hline Age at migration & 0.062 & 0.011 & $1.064^{* * *}$ \\
\hline Age at migration ${ }^{\wedge} 2$ & -0.002 & 0.000 & $0.998^{* * *}$ \\
\hline \multicolumn{4}{|l|}{ Partner } \\
\hline No partner & ref. & ref. & ref. \\
\hline Foreign-born foreign partner & 0.152 & 0.024 & $1.164 * * *$ \\
\hline Foreign-born Dutch partner & 0.072 & 0.031 & $1.075^{*}$ \\
\hline Native-born Dutch partner & 0.465 & 0.024 & $1.592^{* * *}$ \\
\hline \multicolumn{4}{|l|}{ Partner shift } \\
\hline Yes & 0.251 & 0.031 & $1.285^{* * *}$ \\
\hline No & ref. & ref. & ref. \\
\hline \multicolumn{4}{|l|}{ Children $<18$ in the household } \\
\hline Yes & 0.168 & 0.020 & $1.183^{* * *}$ \\
\hline No & ref. & ref. & ref. \\
\hline Disposable household income & 1.520 & 0.039 & $4.572 * * *$ \\
\hline Development country of origin & 2.130 & 0.087 & $8.413^{* * *}$ \\
\hline \multicolumn{4}{|l|}{ EU country of origin } \\
\hline Yes & 0.130 & 0.024 & $1.139 * * *$ \\
\hline No & ref. & ref. & ref. \\
\hline \multicolumn{4}{|l|}{ After 01-01-2008 } \\
\hline Yes & -0.138 & 0.029 & $0.872^{* * *}$ \\
\hline No & ref. & ref. & ref. \\
\hline$*: p<0.05$ & $N=67$, & & \\
\hline \multirow[t]{2}{*}{$* * *: p<0.001$} & \multicolumn{3}{|c|}{ Observations $=231,502$} \\
\hline & \multicolumn{3}{|c|}{ Events $=14,446$} \\
\hline Source: Statistics Netherlands. & \multicolumn{3}{|c|}{-2 Log-likelihood = 289,266 } \\
\hline
\end{tabular}


Table A29. Cox proportional hazard regression on the risk of homeownership of employed immigrants, cohorts 1999-2002.

\begin{tabular}{|c|c|c|c|}
\hline & Coef. & Std. error & Exp. coef. \\
\hline \multicolumn{4}{|l|}{ Naturalisation } \\
\hline Yes & 0.336 & 0.049 & $1.399 * * *$ \\
\hline No & ref. & ref. & ref. \\
\hline \multicolumn{4}{|c|}{ Naturalisation during observation period } \\
\hline Yes & 0.021 & 0.047 & 1.022 \\
\hline No & ref. & ref. & ref. \\
\hline \multicolumn{4}{|l|}{ Gender } \\
\hline Male & ref. & ref. & ref. \\
\hline Female & 0.117 & 0.032 & $1.124 * * *$ \\
\hline Age at migration & 0.022 & 0.022 & 1.022 \\
\hline Age at migration ^ 2 & -0.001 & 0.000 & $0.999 * *$ \\
\hline \multicolumn{4}{|l|}{ Partner } \\
\hline No partner & ref. & ref. & ref. \\
\hline Foreign-born foreign partner & 0.215 & 0.044 & $1.240 * * *$ \\
\hline Foreign-born Dutch partner & 0.168 & 0.052 & $1.183^{* *}$ \\
\hline Native-born Dutch partner & 0.496 & 0.045 & $1.643 * * *$ \\
\hline \multicolumn{4}{|l|}{ Children $<18$ in the household } \\
\hline Yes & 0.195 & 0.036 & $1.216^{* * *}$ \\
\hline No & ref. & ref. & ref. \\
\hline Disposable household income & 2.112 & 0.087 & $8.261^{* * *}$ \\
\hline Development country of origin & 1.920 & 0.148 & $6.822 * * *$ \\
\hline \multicolumn{4}{|l|}{ EU country of origin } \\
\hline Yes & -0.081 & 0.046 & 0.922 \\
\hline No & ref. & ref. & ref. \\
\hline \multicolumn{4}{|l|}{ After 01-01-2008 } \\
\hline Yes & -0.120 & 0.044 & $0.887^{* *}$ \\
\hline No & ref. & ref. & ref. \\
\hline \multicolumn{4}{|l|}{ Education } \\
\hline Low & ref. & ref. & ref. \\
\hline Middle & 0.256 & 0.041 & $1.292 * * *$ \\
\hline High & 0.483 & 0.041 & $1.621 * * *$ \\
\hline$* *: p<0.01$ & $N=23$, & & \\
\hline \multirow[t]{2}{*}{$* * *: p<0.001$} & \multicolumn{3}{|c|}{ Observations $=66,244$} \\
\hline & \multicolumn{3}{|c|}{ Events $=4,348$} \\
\hline Source: Statistics Netherlands. & \multicolumn{3}{|c|}{-2 Log-likelihood = 77,511 } \\
\hline
\end{tabular}


Table A30. Cox proportional hazard regression on the risk of homeownership of employed immigrants without right-truncation, cohorts 1999-2002.

\begin{tabular}{|c|c|c|c|c|}
\hline & & Coef. & Std. error & Exp. coef. \\
\hline \multirow[t]{2}{*}{ Naturalisation } & Yes & 0.275 & 0.032 & $1.316^{* * *}$ \\
\hline & No & ref. & ref. & ref. \\
\hline \multirow[t]{2}{*}{ Naturalisation during observation period } & Yes & 0.118 & 0.027 & $1.126 * * *$ \\
\hline & No & ref. & ref. & ref. \\
\hline \multirow[t]{2}{*}{ Gender } & Male & ref. & ref. & ref. \\
\hline & Female & 0.136 & 0.018 & $1.146 * * *$ \\
\hline Age at migration & & 0.047 & 0.012 & $1.048^{* * *}$ \\
\hline Age at migration ^ 2 & & -0.001 & 0.000 & $0.999 * * *$ \\
\hline \multirow[t]{4}{*}{ Partner } & No partner & ref. & ref. & ref. \\
\hline & Foreign-born foreign partner & 0.231 & 0.025 & $1.259 * * *$ \\
\hline & Foreign-born Dutch partner & 0.070 & 0.032 & $1.073^{*}$ \\
\hline & Native-born Dutch partner & 0.426 & 0.026 & $1.531^{* * *}$ \\
\hline \multirow[t]{2}{*}{ Children $<18$ in the household } & Yes & 0.151 & 0.021 & $1.163^{* * *}$ \\
\hline & No & ref. & ref. & ref. \\
\hline Disposable household income & & 1.763 & 0.043 & $5.828^{* * *}$ \\
\hline Development country of origin & & 2.439 & 0.093 & $11.465^{* * *}$ \\
\hline \multirow[t]{2}{*}{ EU country of origin } & Yes & 0.120 & 0.026 & $1.128 * * *$ \\
\hline & No & ref. & ref. & ref. \\
\hline \multirow[t]{2}{*}{ After 01-01-2008 } & Yes & -0.155 & 0.030 & $0.857^{* * *}$ \\
\hline & No & ref. & ref. & ref. \\
\hline$*: p<0.05$ & & $N=53$, & & \\
\hline \multirow[t]{2}{*}{$* * *: p<0.001$} & & \multicolumn{3}{|c|}{ Observations $=196,395$} \\
\hline & & \multicolumn{3}{|c|}{ Events $=12,987$} \\
\hline \multicolumn{2}{|l|}{ Source: Statistics Netherlands. } & \multicolumn{3}{|c|}{-2 Log-likelihood = 255,611 } \\
\hline
\end{tabular}


Appendix B: Additional Figures 


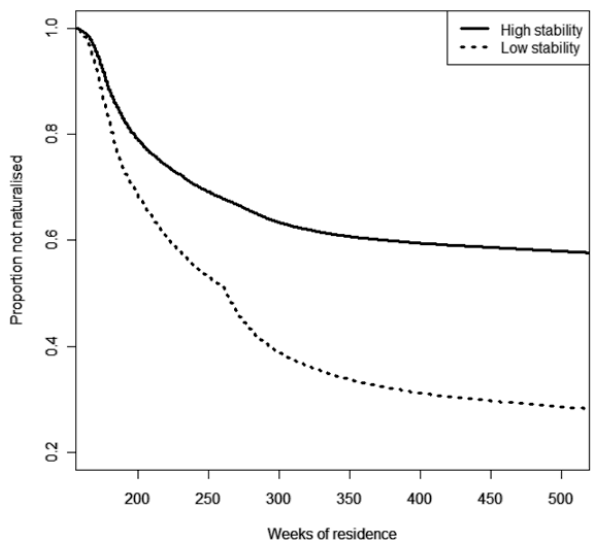

Figure A1a. Cumulative naturalisation migrant cohorts 1995-1997 by level of stability origin country.

Source: Statistics Netherlands.

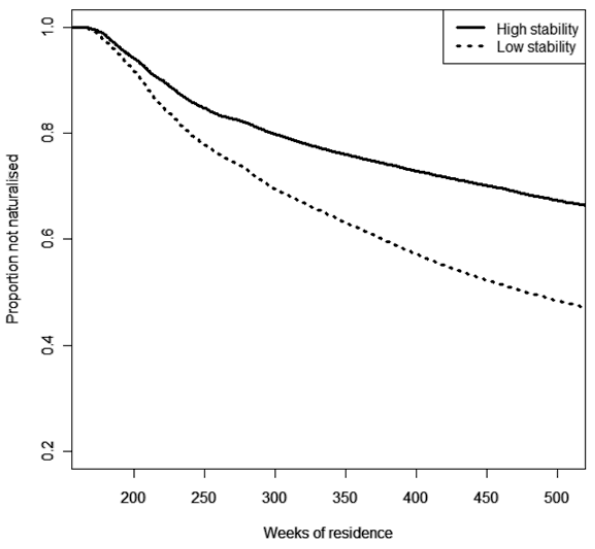

Figure A1b. Cumulative naturalisation migrant cohorts 2000-2002 by level of stability origin country.

Source: Statistics Netherlands. 
Nederlandse Samenvatting 

In dit proefschrift onderzoek ik de relatie tussen naturalisatie en sociaal-economische ${ }^{22}$ integratie van eerste generatie ${ }^{23}$ migranten in Nederland. De integratie van nieuwkomers staat al geruime tijd hoog op de beleidsagenda. Ook in het regeerakkoord van het kabinet Rutte III neemt integratie een prominente positie in (Rijksoverheid, 2017, pp. 54-55). Onderzoek toont consistent aan dat migranten een relatief zwakke positie bekleden op onder andere de arbeidsmarkt (Heath \& Cheung, 2007; Lancee, 2012) en de huizenmarkt (Boehm \& Slottmann, 2004; Dawkins, 2005; Zorlu et al., 2014). Nederland is daarin geen uitzondering; migranten hebben minder vaak betaald werk, genieten een lager inkomen uit werk, en zijn minder vaak huiseigenaar dan personen zonder migratieachtergrond (CBS, 2016, pp. 54-59, 68-73; Uunk, 2017). Deze discrepantie is deels te wijten aan structurele obstakels die migranten ondervinden op de arbeidsmarkt en huizenmarkt. Zo zijn bestaande hulpbronnen van migranten zoals diploma's, werkervaring en sociale contacten slechts beperkt relevant in het bestemmingsland, of worden niet als zodanig erkend (Friedberg, 2000). Bovendien hebben migranten dikwijls een achterstand op het gebied van taalbeheersing (van Tubergen \& Kalmijn, 2005), en kan er sprake zijn van discriminatie door werkgevers of geldverstrekkers (Aalbers, 2007; Andriessen, Nievers, \& Dagevos, 2012; Arrow, 1972). Vanuit dit oogpunt wordt naturalisatie door beleidsmakers gezien als een veelbelovend instrument om de integratie van migranten te bevorderen. Internationaal onderzoek laat zien dat genaturaliseerde migranten beter presteren op onder andere de arbeidsmarkt (OECD, 2011) en de huizenmarkt (Enchautegui \& Giannarelli, 2015; Hutcheson \& Jeffers, 2013) dan hun niet-genaturaliseerde tegenhangers. Dit positieve effect van naturalisatie wordt ook wel de naturalisatiepremie genoemd (OECD, 2011). Echter, er is nog veel onduidelijkheid in de literatuur over de vraag voor wie en waarom het staatsburgerschap van het bestemmingsland er toe doet. Niet alle migranten kiezen ervoor om te naturaliseren, en hoewel sommige migranten gebaat zijn bij naturalisatie in het integratieproces, is dat niet voor alle migranten het geval. Vanuit deze achtergrond wordt in dit proefschrift de volgende vraag onderzocht: wat zijn de verklarende factoren voor naturalisatie, en wat is de rol van naturalisatie voor de sociaal-economische integratie van eerste generatie migranten in Nederland?

Migratie naar Nederland is de afgelopen decennia toegenomen, niet alleen in volume, maar vooral ook in diversiteit. Dit sluit aan bij een mondiale trend, waarbij migranten uit een groeiend aantal herkomstlanden zich richt op een slinkende groep bestemmingslanden (Czaika \& de Haas, 2014). Als gevolg van deze ontwikkeling is de vestiging van nieuwkomers een prominent onderwerp in de Nederlandse politiek. Dit manifesteert zich onder andere in een verschuiving van de rol van naturalisatie in het integratiedebat (van

\footnotetext{
${ }^{22}$ Sociaal-economische integratie omvat in dit proefschrift betaald werk, inkomen uit arbeid en woningbezit.

${ }^{23}$ In dit proefschrift worden eerste generatie migranten gedefinieerd als personen van wie beide ouders in het buitenland geboren zijn, omdat tweede en verdere generaties kunnen naturaliseren via gefaciliteerde procedures, waaronder medenaturalisatie (de situatie waarbij minderjarige kinderen delen in de naturalisatie van hun ouder[s]).
} 
Oers, 2014; van Oers et al., 2013). In de jaren tachtig werd het Nederlanderschap vooral gezien als een instrument ter bevordering van de integratie van migranten. Deze notie van naturalisatie als springplank voor verdere integratie ging gepaard met een relatief liberaal naturalisatiebeleid, bedoeld om migranten aan te sporen Nederlander te worden (Heijs, 1995, p. 180). Echter, in de jaren negentig vond een verschuiving plaats van een 'minderhedenbeleid', gericht op het faciliteren van integratie, naar een 'integratiebeleid', waarbij individuele verantwoordelijkheid voor het integratieproces centraal stond (Entzinger, 2003). Daarmee veranderde ook de rol van naturalisatie. Het Nederlanderschap werd niet langer gezien als onderdeel van het integratieproces, maar als het eindpunt; de bekroning op voltooide integratie. De formele eisen voor naturalisatie werden vanuit dat oogpunt aangescherpt, met verscheidene beleidswijzigingen in de afgelopen twintig jaar. Cijfers van het CBS laten zien dat deze beleidswijzigingen gepaard gingen met fluctuaties in het aantal naturalisaties per jaar (CBS, 2017b). Het is echter onduidelijk in hoeverre beleid ook daadwerkelijk ten grondslag ligt aan het aantal migranten dat Nederlander wordt, en voor welke migranten strenge institutionele kaders belangrijke obstakels vormen voor het Nederlanderschap. Bovendien is er weinig bekend over het effect van naturalisatiebeleid voor de integratie van migranten. Zowel het prominente debat omtrent de vestiging van nieuwkomers, als de verscheidene wijzigingen in naturalisatiewetgeving in de afgelopen decennia, maakt dat de Nederlandse casus unieke mogelijkheden biedt om de rol van de institutionele context voor de naturalisatiepremie te onderzoeken.

In dit proefschrift analyseer ik registerdata uit het Stelsel van Sociaal Statistische Bestanden (Bakker et al., 2014) van het CBS. Het gebruik van administratieve databronnen voor onderzoek in de sociale wetenschappen is een relatief nieuw fenomeen dat belangrijke voordelen met zich meebrengt. Op de eerste plaats bevat registerdata de volledige geregistreerde populatie. Dit is met name waardevol wanneer de onderzoekspopulatie ondervertegenwoordigd is in meer traditionele databronnen, zoals vragenlijsten. Om diverse redenen, waaronder taalbeheersing, is dit dikwijls het geval voor eerste generatie migranten (Font \& Mendez, 2014, p. 16; Kappelhof, 2014, 2017). Bovendien biedt het administratieve karakter van de data deels een oplossing voor mogelijke sociale wenselijkheid. Verder wordt registerdata gekenmerkt door frequente observatiemomenten en een panel-structuur. Hoewel er ook beperkingen kleven aan het gebruik van registerdata, waaronder een beperkte conceptuele reikwijdte en mogelijke administratieve vertraging (Bakker, 2011), zijn deze data uitermate geschikt - en vooralsnog niet benut - om de relatie tussen naturalisatie en sociaal-economische integratie van migranten statistisch te onderzoeken. 
Theoretische bijdrage: naturalisatie en sociaal-economische integratie in de context van de levensloop

Er bestaat veel onderzoek naar de vraag of naturalisatie de integratie van migranten op de arbeidsmarkt bevordert (Chiswick, 1978; Bevelander \& Veenman, 2008; Fougère \& Safi, 2009; Scott, 2008). Resultaten uit dit onderzoeksveld schetsen echter geen eenduidig beeld; sommige studies bevestigen een positieve relatie, maar anderen niet. Om deze tegenstrijdige bevindingen te duiden is er de afgelopen jaren veel aandacht in de literatuur voor de analysemethode waarmee de naturalisatiepremie traditioneel onderzocht wordt. Meer specifiek is de gedachte dat het verband tussen naturalisatie en integratie verklaard wordt doordat beter geïntegreerde migranten vaker naturaliseren. Met andere woorden, integratie leidt tot naturalisatie in plaats van andersom. Om de naturalisatiepremie te onderzoeken moet dus de periode voor en na naturalisatie vergeleken worden in plaats van genaturaliseerde en niet-genaturaliseerde migranten. Internationaal onderzoek bevestigt dat sommige migranten beter presteren op de arbeidsmarkt nadat zij genaturaliseerd zijn in vergelijking met de periode voor naturalisatie (Bratsberg \& Raaum, 2011, p. 196; Engdahl, 2014, p. 18; Helgertz et al., 2014, p. 352). Deze studies bieden echter geen verklaring voor het feit dat sommige migranten profijt hebben van naturalisatie op de arbeidsmarkt, terwijl dat voor anderen niet het geval is. Met andere woorden, de focus in de literatuur op de verdere ontwikkeling van het analytisch model is belangrijk, maar geeft weinig inzicht in de vraag waarom en voor wie er sprake is van een naturalisatiepremie. Recente analytische ontwikkelingen in de literatuur moeten dus gepaard gaan met vergelijkbare theoretische vooruitgang zodat empirische resultaten beter gecontextualiseerd kunnen worden. Vanuit dat oogpunt verrijk ik in deze dissertatie het traditionele theoretische kader met concepten uit de sociologische levensloopbenadering (Elder, 1974). Deze benadering combineert twee gevestigde stromingen in de literatuur. Een stroming analyseert individuele drijfveren voor naturalisatie en herkomstkenmerken (Chiswick \& Miller, 2009; Helgertz \& Bevelander, 2016; Yang, 1994), terwijl de ander zich richt op de rol van institutionele, politieke en historische kenmerken van bestemmingslanden (Aleksyndra \& Algan, 2010; Janoski, 2010; Reichel, 2011). Afzonderlijk zijn beide stromingen niet in staat een antwoord te geven op de vraag waarom sommige migranten een naturalisatiepremie genieten, en anderen niet. De dynamische levensloopbenadering biedt hierin uitkomst door te benadrukken dat individuen genesteld zijn in een bredere sociale en institutionele context. Motieven voor naturalisatie en de rol van staatsburgerschap in het leven van migranten hangen niet alleen af van de relatieve waarde van de nationaliteit van het bestemmingsland, maar worden ook geconditioneerd door timing in de levensloop (bijvoorbeeld leeftijd, de partner of kinderen), en de juridische en sociaal-economische kaders van het bestemmingsland (waaronder naturalisatiebeleid, maar ook bijvoorbeeld conjunctuur of toegang tot sociale voorzieningen). In Hoofdstuk 2 wordt toegelicht hoe een dergelijke 
conceptualisering van naturalisatie in de context van de levensloop aanknopingspunten biedt om het effect van naturalisatie te duiden, en tegenstrijdige resultaten in de literatuur te verklaren. Deze benadering wordt vervolgens toegepast in vier empirische hoofdstukken.

\section{Empirische bijdrage: de naturalisatiepremie in Nederland}

Om uitspraken te doen over het effect van naturalisatie is het belangrijk eerst te begrijpen welke migranten naturaliseren en waarom. In Hoofdstuk 3 worden motieven voor naturalisatie geanalyseerd, met speciale aandacht voor de sociale en institutionele context waarin de afweging om het Nederlanderschap te verkrijgen gemaakt wordt. In 2016 werden ruim 15.600 personen Nederlander door zelfstandige naturalisatie (CBS, 2017b). Het Nederlanderschap biedt belangrijke privileges, waaronder ongelimiteerde toegang tot de arbeidsmarkt, stemrecht voor de Tweede Kamer- en Provinciale Statenverkiezingen en een gegarandeerde verblijfsstatus. Maar er zijn ook formele eisen waaraan voldaan moet worden alvorens men kan naturaliseren. Zo moeten migranten normaliter minimaal 5 jaar legaal in Nederland verblijven, en zal men op het moment van naturalisatie afstand moeten doen van de originele nationaliteit (hoewel Nederland veel uitzonderingen op de afstandseis kent). In hoeverre de voordelen van naturalisatie opwegen tegen de kosten is afhankelijk van de individuele situatie van migranten. Zo zijn vluchtelingen zeer gebaat bij de zekere verblijfsstatus die naturalisatie biedt, terwijl de afstandseis voor migranten uit welvarende landen een belangrijk obstakel vormt. Analyses bevestigen dat een kosten-baten model ook in Nederland een goede voorspeller van naturalisatie is. Migranten voor wie de voordelen van het Nederlanderschap een belangrijke rol in hun leven spelen, zoals migranten uit economisch laagontwikkelde, politiek instabiele of niet-EU landen, hebben een hoge kans om te naturaliseren. Omgekeerd zijn migranten die hun originele nationaliteit automatisch verliezen wanneer zij Nederlander worden minder geneigd te naturaliseren. Verder laten de resultaten zien dat de beslissing om te naturaliseren een sociale component bevat. De kans om te naturaliseren is hoger wanneer migranten een partner van Nederlandse herkomst of een genaturaliseerde partner hebben. Het positieve effect is met name sterk in het jaar dat de partner Nederlander wordt. Dit impliceert dat de keuze om te naturaliseren in ieder geval deels in gezinsverband gemaakt wordt. Deze conclusie heeft belangrijke implicaties voor het traditionele theoretische model. Immers, wanneer motieven voor naturalisatie niet louter gebaseerd zijn op persoonlijk gewin schiet een model dat individuen als geïsoleerde eenheden beschouwd tekort. Met andere woorden, diepgaand inzicht in de vraag waarom migranten naturaliseren vraagt om een model dat recht doet aan de sociale complexiteit van het leven van mensen.

De belangrijkste conclusie uit dit hoofdstuk heeft echter betrekking op de rol van naturalisatiebeleid. Hoewel er veel onderzoek is naar de relevantie van persoons- en 
herkomstkenmerken voor de neiging van migranten om te naturaliseren, is er maar weinig bekend over de rol van de institutionele context van het bestemmingsland. Echter, naturalisatiebeleid bepaald onder welke voorwaarden migranten in aanmerking komen voor het staatsburgerschap van het bestemmingsland, en speelt dus een cruciale rol in het naturalisatieproces. Vanuit dit oogpunt is de invoering van de naturalisatietoets in Nederland op 1 april 2003 geanalyseerd. De voorwaarden voor naturalisatie werden na deze beleidswijziging strenger (van Oers, 2014), maar het is onduidelijk of dit ook een effect heeft gehad op het naturalisatiegedrag van migranten, en zo ja, welke migranten vooral de gevolgen van restrictief beleid ondervinden. Om dat nader te onderzoeken zijn migranten vergeleken die in aanmerking kwamen voor het Nederlanderschap voor en na de invoering van de naturalisatietoets. Analyses bevestigen dat migranten minder snel en minder vaak naturaliseren onder de strengere institutionele condities na 2003. Echter, het effect van streng beleid wordt geconditioneerd door herkomstkenmerken. Meer specifiek doet restrictief beleid er alleen toe voor migranten uit economisch laagontwikkelde en politiek instabiele herkomstlanden. Dit zijn dezelfde migranten die zeer geïnteresseerd zijn in naturalisatie, en het Nederlanderschap goed kunnen gebruiken om hun relatief zwakke positie op bijvoorbeeld de arbeidsmarkt of huizenmarkt te verbeteren.

Resultaten in Hoofdstuk 3 laten zien dat migranten voor wie het staatsburgerschap van het bestemmingsland een waardevolle bijdrage kan leveren aan hun integratietraject sterk afhankelijk zijn van de beleidscontext die toegang tot naturalisatie conditioneert. Om nader te onderzoeken of, en onder welke voorwaarden, naturalisatie een rol speelt voor de integratie van migranten is in Hoofdstuk 4 het effect van het Nederlanderschap voor de kans op betaald werk geanalyseerd. Resultaten bevestigen dat naturalisatie de kans op werk bevordert met 12 en 13 procent (Odds ratio 1,12 en $1,13)$ voor respectievelijk mannen en vrouwen. Dit sluit aan bij de gevestigde theorie in de literatuur dat naturalisatie de kansen op de arbeidsmarkt vergroot door ongelimiteerde toegang tot de arbeidsmarkt te verschaffen en administratieve kosten voor werknemers te beperken. Bovendien kan de nationaliteit van het bestemmingsland een positief signaal afgeven richting werkgevers met betrekking tot de vaardigheden en arbeidsethos van de migrant in kwestie (Liebig \& von Haaren, 2011). Met andere woorden, werkgevers kunnen de genaturaliseerde status van een migrant zien als een indicatie voor wenselijke kenmerken, waardoor het in dienst nemen van deze migrant als minder risicovol beschouwd wordt. De analyses laten verder zien dat migranten die naturaliseren sowieso beter presteren op de arbeidsmarkt ongeacht hun nationaliteit, in de literatuur ook wel positieve selectie genoemd (Helgertz et al., 2014, p. 342; Steinhardt, 2012, p. 814). Het is dus belangrijk hiervoor te corrigeren zodat het effect van naturalisatie niet overschat wordt. De belangrijkste bevinding is echter dat de arbeidsmarktprestaties van migranten al verbeteren voordat zij daadwerkelijk naturaliseren, ook wanneer gecontroleerd wordt voor positieve selectie. Hoewel dit in internationaal onderzoek al eerder geconstateerd is (Helgertz et al., 2014, p. 344), 
ontbreekt vooralsnog een duidelijke verklaring hiervoor. Ik theoretiseer dat migranten anticiperen op de mogelijkheden en privileges die naturalisatie zal bieden bijvoorbeeld op de arbeidsmarkt - door al in aanloop naar het moment van naturalisatie in hun arbeidsmarktpotentie te investeren. Zo zullen migranten bijvoorbeeld de ontwikkeling van hun taalkennis versnellen om gebruik te kunnen maken van de ongelimiteerde toegang tot de arbeidsmarkt. Bovendien moeten migranten hun kennis van de Nederlandse taal en samenleving ontwikkelen om te voldoen aan de formele eisen voor naturalisatie. De resultaten suggereren dat deze investeringen al vruchten afwerpen voordat migranten daadwerkelijk Nederlander worden. Conform deze gedachte is het effect van naturalisatie het grootst wanneer migranten relatief snel naturaliseren. Immers, extra investering in bijvoorbeeld taalkennis is vooral van meerwaarde in de beginfase van het vestigingstraject, aangezien migranten ook geleidelijk taalkennis opdoen door simpelweg in het bestemmingsland te verblijven. Ter vergelijking: de kans op werk van migranten die na 5 jaar verblijf in Nederland naturaliseren - wanneer het gros van de migranten in aanmerking komt voor naturalisatie - is 34 procent hoger voor mannen (Odds ratio 1,34), en 38 procent hoger voor vrouwen (Odds ratio 1,38), dan hun nietnaturaliserende tegenhangers. Echter, onder migranten die na 8 tot 10 jaar naturaliseren is dit positieve effect geslonken tot 10 procent. Naturalisatie stimuleert dus de kans op werk, maar het maakt wel uit wanneer het Nederlanderschap verkregen wordt. De dichotome voor-na benadering die in de traditionele literatuur van de naturalisatiepremie gehanteerd wordt verhuld dus het belang van het traject dat aan naturalisatie vooraf gaat.

In Hoofdstuk 5 wordt het effect van naturalisatie in meer detail onderzocht door inkomen uit werk te analyseren. Dit is de meest gangbare operationalisatie van arbeidsmarktintegratie in de literatuur, maar er is geen consistent bewijs voor een positief effect van naturalisatie voor het inkomen van migranten (Helgertz et al., 2014, p. 343). Ik verken drie verklaringen voor deze empirische ambiguïteit. Op de eerste plaats stel ik dat het signaal-effect van naturalisatie minder relevant is voor migranten met betaald werk, aangezien de arbeidsmarktparticipatie van deze migranten al een positief signaal afgeeft richting werkgevers. Omdat het gros van de literatuur het effect van naturalisatie op inkomen analyseert - en zich dus per definitie op migranten met betaald werk richt - wordt de naturalisatiepremie mogelijk onderschat. Ten tweede zal naturalisatie vooral van belang zijn voor migranten die de meest structurele obstakels ondervinden op de arbeidsmarkt. Werkgevers associëren mogelijk meer risico bij het in dienst nemen van migranten uit economisch laag ontwikkelde landen. De nationaliteit van het bestemmingsland kan dergelijke vermeende risico's beperken, en is dus vooral waardevol voor deze kwetsbare migranten met een zwakkere reputatie op de arbeidsmarkt. Ten derde suggereren de resultaten in Hoofdstuk 4 dat migranten het verkrijgen van het staatsburgerschap van het bestemmingsland anticiperen, en reeds in hun arbeidsmarktpotentie investeren in aanloop naar het moment van naturalisatie. 
Echter, de meeste studies in de literatuur modelleren de naturalisatiepremie als een dichotoom voor-na fenomeen. Een mogelijk anticipatie-effect wordt daardoor verhuld, en het effect van naturalisatie onderschat. Conform veel internationaal onderzoek (Bratsberg \& Raaum, 2011, p. 197; Bratsberg et al., 2002, p. 582; Helgertz et al., 2014, p. 352; Steinhardt, 2012, p. 818) vind ik geen empirische ondersteuning voor een positief effect op het gebied van inkomen uit werk na naturalisatie. In lijn met mijn verwachting is er wel sprake van een positief effect voor migranten uit economisch laagontwikkelde herkomstlanden. Het inkomen uit werk van mannen en vrouwen uit deze landen stijgt met respectievelijk 3 en 5 procent na naturalisatie. Bovendien groeit het inkomen al in aanloop naar het moment van naturalisatie, en piekt rond het moment dat men Nederlander wordt. Dit sluit aan bij de gedachte dat migranten het verkrijgen van het Nederlanderschap anticiperen, en al op voorhand hun kennis en vaardigheden ontwikkelen om ten volste gebruik te maken van de mogelijkheden die naturalisatie in de toekomst zal bieden. Meer algemeen laten de analyses zien dat naturalisatie er toe doet voor het inkomen uit werk van de meest kwetsbare migrantengroepen, maar dat het effect vooral voortkomt uit de intentie om in Nederland te blijven en hier een bestaan op te bouwen (en dus in bijvoorbeeld kennis van de taal en maatschappij te investeren), en minder uit bezit van de Nederlandse nationaliteit an sich.

In Hoofdstuk 6 wordt de conceptuele reikwijdte van het begrip integratie breder getrokken dan in de traditionele literatuur door een naturalisatiepremie op de huizenmarkt te onderzoeken. Meer specifiek wordt het effect van het Nederlanderschap voor de kans op huizenbezit geanalyseerd, met speciale aandacht voor het signaal-effect van naturalisatie. Cijfers van het CBS laten zien dat personen met een migratieachtergrond beduidend minder vaak een eigen woning bezitten dan personen van Nederlandse herkomst. Op 1 januari 2015 was 60,9 procent van de huishoudens met een hoofdkostwinnaar van Nederlandse herkomst de eigenaar van een koophuis, terwijl dit onder migranten met een westerse en niet-westerse migratieachtergrond respectievelijk 44,9 en 25,1 procent bedroeg (CBS, 2017a). Hoewel er veel onderzoek is naar deze zogenoemde etnische kloof op de huizenmarkt (Aalbers, 2007; Charles \& Hurst, 2002; Constant et al., 2009; Coulson \& Dalton, 2010; Ross \& Tootell, 2004), is er maar weinig bekend over de rol die naturalisatie speelt voor de kansen van migranten op een koophuis.

Huizenbezit is financieel aantrekkelijk, en wordt in Nederland gestimuleerd door onder andere fiscale afterekbaarheid van hypotheekrente en collectieve bescherming van hypotheekschuld. Als gevolg van deze gunstige institutionele kaders is het aandeel huizenbezitters, evenals de hypotheekschuld per hoofd van de bevolking, in Nederland hoog (Norris \& Winston, 2012). Toch bestaan er forse verschillen in huizenbezit tussen personen met en zonder migratieachtergrond. Een belangrijke verklaring voor deze etnische kloof op de huizenmarkt zijn de structurele moeilijkheden die migranten ondervinden op de arbeidsmarkt (Huijnk \& Andriessen, 2016; Uunk, 2017). Dit verklaart 
echter maar een deel van de puzzel. Een additionele verklaring is dat de migratieachtergrond zelf de kans op een hypotheek beperkt. De nationaliteit van het bestemmingsland zou mogelijk voor deze achterstandspositie van migranten kunnen compenseren. Echter, in artikel 7, lid 1c van de Algemene Wet Gelijke Behandeling is vastgelegd dat onderscheid in Nederland naar onder andere nationaliteit door instellingen die werkzaam zijn op het gebied van volkshuisvesting verboden is. Formeel gezien zou de nationaliteit van migranten dus geen verklaring moeten bieden voor verschillen in huizenbezit tussen personen met en zonder migratieachtergrond. Echter, in de praktijk lijken geldverstrekkers toch de nationaliteit van migranten mee te nemen in hun risicoafweging (College voor de Rechten van de Mens, 2016; van Dorst, Hoogendijk, Vreeburg \& Verheul, 2017, pp. 22-23; Eerste Kamer, 2017, p. 3). Bezit van de Nederlandse nationaliteit kan gezien worden als een indicatie dat de migrant in kwestie gemotiveerd is, en gecommitteerd aan diens verblijf in Nederland. Met andere woorden, het Nederlanderschap geeft een positief signaal af richting geldverstrekkers, en kan mogelijke twijfels wegnemen met betrekking tot de migratieachtergrond van de aanvrager van een lening.

De resultaten van mijn analyses bevestigen deze gedachtegang. Migranten met betaald werk die het Nederlanderschap verkrijgen hebben vervolgens 25 procent meer kans (Odds ratio 1,25) om huiseigenaar te worden dan hun niet-genaturaliseerde tegenhangers. Vermoedelijk zien geldverstrekkers het Nederlanderschap in hun risicoafweging als een indicatie voor kredietwaardigheid, en hebben daardoor minder twijfels bij de migratieachtergrond van de aanvrager. Echter, het effect van naturalisatie is zwakker voor migranten met een partner van Nederlandse herkomst. Deze migranten ondervinden mogelijk minder moeilijkheden op de huizenmarkt, en hebben het Nederlanderschap dus ook minder nodig bij het krijgen van een hypotheek. Verder doet naturalisatie er alleen toe voor migranten met betaald werk. Dit sluit aan bij de gedachte dat de nationaliteit van migranten niet kan dienen als een op zichzelf staande kwalificatie voor kredietwaardigheid. Als de vereiste financiële basis voor een lening ontbreekt, zal de nationaliteit van de kandidaat waarschijnlijk helemaal niet in acht worden genomen. Er lijkt met andere woorden sprake te zijn van discriminatie op grond van nationaliteit. Niet-Nederlandse migranten die in principe in aanmerking komen voor een lening hebben ongelijke kansen in vergelijking met hun Nederlandse tegenhangers met vergelijkbare achtergrondkenmerken. Verder ondervinden migranten meer moeilijkheden op de huizenmarkt tijdens en na de economische crisis. Datzelfde geldt voor migranten afkomstig uit landen die cultureel meer afwijken van Nederland. Echter, deze obstakels zijn niet afhankelijk van de nationaliteit van migranten. Kortom, naturalisatie lijkt migranten te helpen op de huizenmarkt, maar het lost niet alle problemen op.

Hoe verhouden deze resultaten zich tot de centrale onderzoeksvraag: wat zijn de verklarende factoren voor naturalisatie, en wat is de rol van naturalisatie voor de sociaal-economische integratie van eerste generatie migranten in Nederland? Om te 
beginnen bij het tweede gedeelte van de onderzoeksvraag; er kan geconcludeerd worden dat naturalisatie er toe doet voor de integratie van migranten. Het Nederlanderschap verhoogt de kans op werk, en heeft voor migranten uit economisch laagontwikkelde landen een positief effect in termen van inkomen uit arbeid. Bovendien stijgen de kansen op de arbeidsmarkt al in aanloop naar het moment van naturalisatie. Migranten investeren in hun arbeidsmarktpotentie anticiperende op de mogelijkheden die het Nederlanderschap zal bieden, en in het kader van de formele eisen voor naturalisatie. Om die reden doet naturalisatie er vooral toe wanneer het staatsburgerschap van het bestemmingsland relatief snel verkregen wordt. Naturalisatie faciliteert ook toegang tot de huizenmarkt door de kans op huizenbezit te vergroten. Hoewel naturalisatie daarmee niet alle obstakels van migranten op de arbeidsmarkt en huizenmarkt wegneemt, kan wel geconcludeerd worden dat het staatsburgerschap van het bestemmingsland een belangrijke bijdrage kan leveren aan het oplossen van een aantal structurele obstakels die migranten ondervinden in het integratieproces. Naturalisatie kan met andere woorden functioneren als een springplank voor integratie, en deuren openen voor verdere opwaartse mobiliteit. Dit geldt in het bijzonder voor migranten uit economisch laagontwikkelde herkomstlanden, die de meeste moeilijkheden hebben op de arbeidsmarkt, en een steuntje in de rug goed kunnen gebruiken. Echter, deze kwetsbare migranten zijn erg afhankelijk van de toegankelijkheid van naturalisatiebeleid om te kunnen naturaliseren.

Dit brengt mij bij het eerste gedeelte van de onderzoeksvraag. Migranten naturaliseren minder snel en minder vaak onder restrictief naturalisatiebeleid. Het effect van streng beleid is echter niet gelijk voor alle migrantengroepen. Strenge eisen zijn vooral een obstakel om te naturaliseren voor migranten uit economisch laagontwikkelde en politiek instabiele herkomstlanden. Daarentegen doet naturalisatiebeleid er nauwelijks toe voor migranten uit hoogontwikkelde en politiek stabiele herkomstlanden. Deze migranten zijn weinig geïnteresseerd in naturalisatie, en hebben het staatsburgerschap van het bestemmingsland bovendien minder nodig. De positieve rol die naturalisatie kan spelen voor de integratie van migranten is dus afhankelijk van een balans tussen enerzijds eisen voor naturalisatie, om migranten te stimuleren om in hun integratie te investeren, en anderzijds de toegankelijkheid van deze eisen om migranten een realistisch perspectief op naturalisatie te bieden. Zo bezien zijn bepaalde eisen voor naturalisatie waardevoller voor de integratie van migranten dan anderen. Basale taalbeheersing is een belangrijke voorwaarde voor participatie in de samenleving. Een zekere mate van vereiste taalkennis kan migranten stimuleren om hier al in een vroeg stadium in te investeren. Wanneer taaleisen echter te hoog zijn, of (financiële) ondersteuning om deze kennis te ontwikkelen ontbreekt, zullen met name de migranten die het staatsburgerschap van het bestemmingsland het meest nodig hebben niet langer in staat zijn te naturaliseren, of wordt het moment van naturalisatie zodanig vertraagd dat het niet langer relevant is. Verder zal een lange verblijfstermijn of hoge kosten voor naturalisatie het staatsburgerschap van het bestemmingsland alleen exclusiever maken. 
De positieve rol die naturalisatie kan spelen in het integratieproces van migranten wordt daardoor alleen maar beperkt. Kortom, naturalisatie kan een kickstart geven aan het integratieproces van migranten, maar het effect is wel afhankelijk van de juiste timing en functionele beleidscondities. 
Valorisation Addendum 

In light of the growing salience of international migration, policy-makers of destination countries have a strong incentive to ensure a quick and successful settlement process of newcomers. The Netherlands - being a country of net-immigration - is no exception. The integration of immigrants constitutes a prominent subject in the coalition agreement of the Dutch Rutte III government, recently sworn into office in October 2017. According to this document (Rijksoverheid, 2017, p. 54), successful integration is characterized among other things by mastery of the native language and active participation in Dutch society, including (but not limited to) the labour market. Research consistently shows that particularly first generation immigrants perform worse than natives on these indicators of integration (CBS, 2016; Eurostat, 2017a, 2017b; Heath \& Cheung, 2007). This is unsurprising, given that these migrants enjoyed their formative years abroad, and have resided in the host country for a comparatively short period of time. Yet it is in the interest of both immigrants themselves and host societies to develop ways to facilitate the integration process. Immigration has the potential to stimulate real (inflation adjusted) GDP per capita (Bove \& Elia, 2017), decrease natives' financial burden for public expenditures (Dustmann \& Frattini, 2014) and reduce dependency ratios (the share of the population that is not in the labour force) in host countries (Gagnon, 2014). ${ }^{24}$ However, the positive fiscal and demographic outcomes of immigration depend on the formal and informal opportunities of immigrants to actively participate in society. In other words, immigrants can only provide an economic contribution to host countries if they are allowed to do so. In that context, citizenship may play an important role, for instance by providing unrestricted access to the labour market. Indeed, international research suggests a positive association between citizenship acquisition and income from labour (Bratsberg et al., 2002; Helgertz et al., 2014; Steinhardt, 2012). Such positive outcomes associated with naturalisation are also known as the citizenship premium (OECD, 2011).

Although there is a large field of literature that has analysed the effects of citizenship in the labour market (Helgertz et al., 2014, p. 343), these studies focus almost exclusively on the question whether a citizenship premium exists or not. Such research is of limited use for policy makers, because there is substantial heterogeneity in citizenship regimes and pathways to citizenship. For example, migrants may acquire citizenship early or late in the settlement process, through facilitated procedures, or at different stages of their life course. Citizenship policies differ between countries and over time, and may not be equally relevant to all migrant groups. This dissertation therefore sheds light on the question to whom and under which conditions naturalisation facilitates socio-economic integration. By putting emphasis on the question why (rather than whether or not) naturalisation matters, the focus shifts to a more context-specific understanding of the citizenship premium. This may aid the

\footnotetext{
${ }^{24}$ See also Bodvarsson \& van der Berg (2009) for a theoretical discussion. Note that aggregate economic outcomes of immigration depend on labour market characteristics of destination countries, as well as the skill structure of the native workforce vis-à-vis the migrant inflow (Dustmann, Glitz, \& Frattini, 2008).
} 
formulation of targeted policy, tailored to get the most out of migrants' legal status transition from non-citizen to citizen.

This dissertation focusses on the case of the Netherlands, where citizenship has historically played an important role in the integration debate. In the eighties, citizenship was predominantly seen as an instrument for integration. Requirements for naturalisation were thus relatively liberal to encourage migrants to naturalise (Heijs, 1995, p.180). This changed in the nineties, when particularly the Christian Democratic CDA and Conservative Liberal VVD called for more restrictive requirements for naturalisation. Rather than a stepping stone, naturalisation was seen as the end-state of the integration process; the 'crowning of the integration', as the Christian Democratic parliamentarian Verhagen argued (Tweede Kamer, 2000, p. 51). In line with the notion of citizenship as the reward for successful integration, citizenship policies became more demanding, for instance with the (re-)instalment of the renunciation requirement (prohibiting dual citizenship), and the introduction of a naturalisation test. However, these policies were implemented with very little knowledge of the effect of institutional conditions on (1) immigrants' propensity and ability to naturalise and (2) integration outcomes associated with naturalisation. This dissertation specifically addresses those questions.

\section{The relevance of citizenship in the labour market: work and income}

One of the main conclusions from this dissertation is that citizenship has the potential to stimulate the integration of immigrants in the labour market. Citizenship acquisition subsequently increases the probability of employment by about 13 percent (Odds ratio 1.12 for men and 1.13 for women). Furthermore, male and female immigrants from economically less developed countries of origin enjoy 3 and 5 percent higher earnings respectively if citizenship is acquired. On top of that, the labour market performance already starts to improve substantially prior to naturalisation. For instance, the employment probability of immigrants who naturalise is already more than twice as high at the moment of naturalisation compared to more than three years prior to naturalisation. While these findings clearly show that citizenship matters, any effective policy making on this issue will also require insight into the underlying mechanisms. Indeed, while many migrants enjoy a citizenship premium in the labour market, others do not, and part of the positive effect already manifests prior to citizenship acquisition. In other words, the relevance of citizenship seems to originate not only from the legal status transition itself. Simply handing out citizenship will thus not have the desired effect in terms of immigrant integration. So how can policy-makers maximise the positive labour market outcomes of naturalisation?

Findings in this dissertation provide two answers. First, the observed positive effects prior to naturalisation stem from the intention to naturalise in the future. Migrants start to invest in their human capital development (for instance language capabilities) to 
meet the formal civic and linguistic requirements for naturalisation, and to utilize the rewards and opportunities that citizenship will offer, such as unrestricted access to the labour market. These investments already start to bear fruit in the labour market before migrants become citizens of the host country. The citizenship premium is thus in part an anticipation effect. Consequently, possession of the host country citizenship matters most if it is acquired relatively early in the settlement process, when accelerated investment in host-country specific skills and knowledge can really make a difference. For instance, while the probability of employment for migrants who naturalise after 5 years of residence (the current residence requirement in the Netherlands) is 34 and 38 percent higher for male and female immigrants respectively (Odds ratio 1.34 and 1.38) compared to their non-naturalising counterparts, this is limited to only 10 percent for those who naturalise after 8-10 years of residence. In other words, the timing of naturalisation matters. The host country citizenship offers an incentive for migrants to invest in their integration process, rather than providing a systematic advantage that remains constant over time.

This has important implications for the residence requirement for naturalisation. If the required period of legal residence is too long, the moment of naturalisation is delayed to such an extent that it erodes the added benefit of accelerated investment in host-country specific human capital. My analyses suggest that acquiring the host country citizenship after four to five years of residence maximises associated positive labour market outcomes. While five years is the most common residence requirement in the EU $28^{25}$, many countries have more restrictive requirements up to 10 years of legal residence. Furthermore, citizenship policies differ not only between countries, but also change within countries over time in parallel with the political landscape. Conservative governments traditionally argue for restrictive conditions for naturalisation, including a long residence requirement. A good example is the Dutch government, which in January 2014 introduced a bill to increase the residence requirement for naturalisation from five to seven years. However, empirical findings in this dissertation show that a longer residence requirement would hamper the extent to which citizenship facilitates the integration of immigrants. While the proposal was accepted in the Second Chamber in June 2016 by the coalition of the Social Democrats (PvdA) and Conservative Liberals (VVD), senators of the PvdA took a more critical stance towards the proposal in the First Chamber. In the plenary debates, senators from the PvdA, as well as the Greens (Groenlinks), Liberal Democrats (D66) and Socialist Party (SP) referred to publications based on analyses in this dissertation ${ }^{26}$ to criticize the proposal (Eerste Kamer, 2016, p. 3, 5; Eerste Kamer, 2017b, p. 3; Eerste Kamer, 2017c). In October 2017, the proposal was rejected in the Senate. While it is difficult to ascertain the impact of this dissertation on

\footnotetext{
${ }^{25}$ Residence requirements in the EU range between 5 and 10 years of uninterrupted legal residence. See the Citizenship Law Indicators of the Global Citizenship Observatory (GLOBALCIT) for a more detailed comparative overview (http://globalcit.eu/).

${ }^{26}$ See Peters, Schmeets and Vink [2017] and Vink, Peters and Schmeets [2016].
} 
the final vote, the Dutch policy journal Economisch Statistische Berichten (ESB) highlighted its contribution in their annual overview. ${ }^{27}$ In sum, this dissertation emphasises that integration outcomes associated with naturalisation are conditioned by the way in which the status is acquired. Since the naturalisation process is in part determined by citizenship policies, policy-makers can have a direct impact on the pathways to citizenship that are open to immigrants.

Second, the relevance of citizenship depends on the individual background and life situation of immigrants. While some migrants may naturalise because of the legal rights and privileges it offers, the same status may for others predominantly constitute a reflection of social identification with the host society. Indeed, becoming a Dutch citizen has different implications for a migrant from Germany or the U.S. compared to an Eritrean or Afghan migrant. These differences condition the extent to which naturalisation matters for the integration of immigrants. My findings show that particularly migrants from economically less developed countries of origin benefit from citizenship acquisition in the labour market. However, these migrants are also highly dependent on citizenship policies that condition access to status. Migrants naturalise less quickly and less often under more restrictive institutional conditions. Yet the relevance of citizenship policies is not equal for all migrant groups. Particularly migrants for whom the utility of citizenship is greatest are deterred by more restrictive requirements. In contrast, institutional variation does not substantially affect naturalisation rates of migrants who do not need citizenship as much, and who are generally less interested in naturalisation.

The potential for citizenship to function as a vehicle for immigrant integration thus presents policy-makers with the challenge of an institutional balancing act. If there are no requirements for naturalisation, citizenship is unlikely to play a role in the integration process, as any rights and entitlements linked to the status would be meaningless. Yet if institutional conditions are too restrictive, then the very migrants who need it most may find it difficult to meet these criteria. Moreover, certain requirements for naturalisation are more likely to facilitate integration than others. For instance, some mastery of the native language is a precondition for participation in for instance the labour market or the political decision-making process. As such, basic linguistic requirements may play a positive role. Yet high financial costs to apply for naturalisation only serve to make citizenship more selective, and a long residence requirement will erode the added benefit of accelerated investment in host-country specific human capital. In other words, requirements for naturalisation that do not serve an integration objective can easily turn into mechanisms of exclusion. In that case, the potential for citizenship to stimulate and incentivise immigrant integration is wasted. The requirements for

\footnotetext{
${ }^{27}$ More specifically, the following was stated by the chief editor of the journal: "Contributions to ESB had a societal impact. They really mattered. For instance, the analyses of Hans Schmeets, Floris Peters and Maarten Vink on the relationship between citizenship acquisition and employment contributed to the fact that the proposal to increase the residence requirement for naturalisation was rejected in the Senate, (...)".
} 
naturalisation should be determined in such a manner that migrants have reasonable opportunities to acquire the status, and that the eligibility criteria serve a clear integration purpose.

The relevance of citizenship in the housing market: homeownership

Although there is an extensive body of literature on the relevance of citizenship for the integration of immigrants, these studies focus almost exclusively on labour market outcomes of naturalisation. Yet the settlement process comprises a much broader range of socio-economic factors, including quality of housing, living conditions and neighbourhood characteristics. However, in existing research on those indicators (Feijten et al., 2008; McConnel, 2015; Rossi \& Weber, 1996; Uunk, 2017; Zorlu et al., 2014) the role of citizenship for these integration outcomes is often not specifically addressed. In this dissertation, I break with the state-of-the-art's exclusive focus on the labour market, and analyse whether citizenship matters for homeownership of immigrants. Buying property can be thought of as a long-term commitment to the host society, and a reflection of the intent to stay and build a life in the destination country. Homeownership can also provide important financial benefits compared to private or social rented housing, including favourable tax treatment, the gradual accumulation of property wealth and lower long-term payment for housing. Furthermore, homeownership may stimulate social well-being through an increase in social status, greater psychological health (Rohe \& Stegman, 1994) and better neighbourhood conditions (Rossi \& Weber, 1996). For migrants who have successfully integrated into the labour market, homeownership may thus be the next step towards a self-sustained, stable life for themselves and their children in the host country.

Migrants are however less often homeowners compared to the native population. Figures from Statistics Netherlands show that on January 1, 2015, 60.9 percent of all households with a native-born principal wage-earner were homeowners, compared to 44.9 and 25.1 percent among migrant households of western and non-western origin (CBS, 2017a). Although this so-called 'ethnic gap' in the housing market is in part explained by compositional differences between migrants and natives in terms of income and wealth, this only explains part of the puzzle. An alternative explanation would be the legal status of immigrants. While unequal treatment in the field of housing on the basis of (among other things) nationality is prohibited in many countries including the Netherlands - there are indications that lenders still consider the citizenship status of migrants when evaluating their creditworthiness (College voor de Rechten van de Mens, 2016; van Dorst et al., 2017, p. 22-23). Naturalisation may placate feelings of risk associated with approving a loan for individuals with a migrant background. In that context, I analyse whether citizenship acquisition matters for the probability of homeownership of immigrants. 
Empirical findings show that citizenship acquisition increases the probability of homeownership of employed immigrants by 25 percent, holding all other characteristics constant. This suggests a mechanism of legal status discrimination in the housing market, as migrants who are in principle eligible for a mortgage are less likely to secure a loan if they do not have the Dutch citizenship. Moreover, naturalisation matters less for migrants with a native-born Dutch partner. This provides further credence to the notion of legal status discrimination, as migrants with a native partner are less likely to be discriminated against on ethnic grounds, and thus do not need the host country citizenship as much to mitigate their disadvantaged position. Migrants are less likely to own property after the onset of the financial crisis, or when originating from countries that are culturally more dissimilar from the host society. However, citizenship acquisition is unable to remove those obstacles in the housing market.

Policy-makers can respond to these findings in two ways. First, since unequal treatment in the field of housing on the basis of nationality is prohibited in the Netherlands, the government has a legal obligation to address discriminatory behaviour by lenders. Until then, policy-makers should recognise the current reality that citizenship matters in the housing market. Facilitating access to citizenship acquisition is thus an effective way to improve opportunities of immigrants to secure a mortgage. The former Dutch government argued as much in a recent explanatory memorandum on the residence requirement for naturalisation, stating that “(...) the opportunities of naturalised migrants in the labour market will generally be better compared to a nonnaturalised migrant, even with a permanent residence status. The same is likely true when migrants attempt to secure a loan to finance a house or set up a business" (Eerste Kamer, 2017a, p. 3). While citizenship may thus remove some of the structural obstacles migrants face in the housing market, it should be emphasized that from a legal perspective, this is not an acceptable situation. If lenders would act in accordance to existing anti-discrimination law, migrants would not need the host country citizenship to improve their chances to secure a mortgage. In the long-term, this issue should be prioritized.

In conclusion, findings in this dissertation support the notion of citizenship as a stepping stone for the integration of immigrants. Conceptualising citizenship as the reward for successful integration does not do justice to the fact that integration is a process, not a definitive state of being. If requirements for naturalisation are reasonably attainable, the prospect of full membership of the host society can stimulate migrants to invest in their integration. However, positive outcomes of naturalisation depend on the right timing and functional institutional conditions. The insights from this dissertation regarding the question to whom and under which conditions citizenship matters are thus crucial for policy-makers to get the most out of legal status transitions of immigrants. 


\section{About the author}

Floris Peters (1990) obtained a BA degree in General Social Sciences, and a MA degree (cum laude) in Multiculturalism in Comparative Perspective, both from the University of Utrecht, where he graduated in 2012. In 2012-2013, he worked as a statistical researcher at Statistics Netherlands, doing research on economic independence of young adolescents in the Netherlands. In 2013, he was a research assistant at the Netherlands Institute for Social Research, investigating the background and welfare of marriage immigrants, as well as perceived discrimination among immigrants in the Netherlands.

In January 2014, Floris started working as a PhD Candidate at the Faculty of Arts and Social Sciences at Maastricht University. His research focused on determinants of citizenship acquisition, and the relevance of citizenship for the socio-economic integration of first-generation immigrants in the Netherlands. As part of the project, he was part-time employed at Statistics Netherlands, and made use of individual-level register data from the System of Social Statistical Datasets. His research has been published both in international and Dutch journals, including the Journal of Ethnic and Migration Studies, Economisch Statistische Berichten and Bevolkingstrends. Floris has taught several courses both at the graduate and undergraduate level, and acquired his University Teaching Qualification in 2017. From January 2018 onwards, he has been working as a post-doctoral researcher at Maastricht University in the MiLifeStatus project, led by Prof. Maarten Vink. 


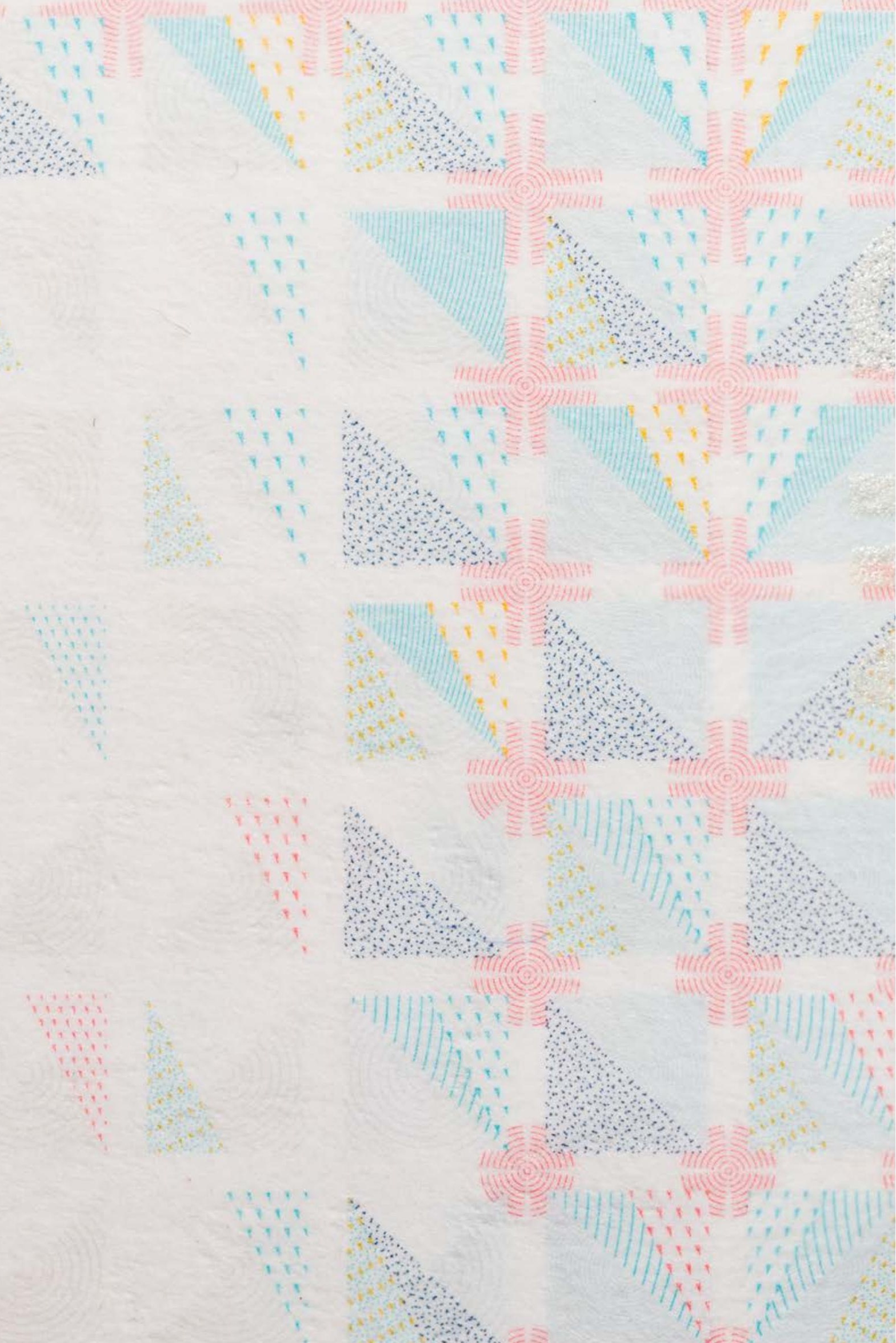

